\title{
Technology Assessments in Transportation: Survey of Recent Literature
}

\author{
S. J. LaBelle
}

\section{MASTER}

\section{ARGONNE NATIONAL LABORATORY}




\section{DISCLAIMER}

This report was prepared as an account of work sponsored by an agency of the United States Government. Neither the United States Government nor any agency Thereof, nor any of their employees, makes any warranty, express or implied, or assumes any legal liability or responsibility for the accuracy, completeness, or usefulness of any information, apparatus, product, or process disclosed, or represents that its use would not infringe privately owned rights. Reference herein to any specific commercial product, process, or service by trade name, trademark, manufacturer, or otherwise does not necessarily constitute or imply its endorsement, recommendation, or favoring by the United States Government or any agency thereof. The views and opinions of authors expressed herein do not necessarily state or reflect those of the United States Government or any agency thereof. 


\section{DISCLAIMER}

Portions of this document may be illegible in electronic image products. Images are produced from the best available original document. 
The facilities of Argonne National Laboratory are owned by the United States Government. Under the terms of a contract (W-31-109-Eng-38) among the U.S. Department of Energy, Argonne Universities Association and The University of Chicago, the University employs the staff and operates the Laboratory in accordance with policies and programs formulated, approved and reviewed by the Association.

\section{MEMBERS OF ARGONNE UNIVERSITIES ASSOCIATION}

The University of Arizona

Carnegie-Mellon University

Case Western Reserve University

The University of Chicago

University of Cincinnati

Illinois Institute of Technology

University of Illinois

Indiana University

The University of lowa

lowa State University
The University of Kansas

Kansas State University

Loyola University of Chicago

Marquette University

The University of Michigan

Michigan State University

University of Minnesota

University of Missouri

Northwestern University

University of Notre Dame
The Ohio State University

Ohio University

The Pennsylvania State University

Purdue University

Saint Louis University

Southern Illinois University

The University of Texas at Austin

Washington University

Wayne State University

The University of Wisconsin-Madison

\section{NOTICE}

This report was prepared as an account of work sponsored by an agency of the United States Government. Neither the United States Government or any agency thereof, nor any of their employees, makke any warranty, express or implied, or assume any legal liability or responsibility for the accuracy, completeness, or usefulness of any information, apparatus, product, or process disclosed, or represent that its use would not infringe privately owned rights. Reference herein to any specific commercial product, process, or service by trade name, mark, manufacturer, or otherwise, does not necessarily constitute or imply its endorsement, recommendation, or favoring by the United States Government or any agency thereof. The views and opinions of authors expressed herein do not necessarily state or reflect those of the United States Government or any agency thereof.

This informal report presents preliminary results of ongoing work or work that is more limited in scope and depth than that described in formal reports issued by the Energy and Environmental Systems Division.

Printed in the United States of America. Available from National Technical Information Service, U. S. Department of Commerce, 5285 Port Royal Road, Springfield, Virginia 22161 
ARGONNE NATIONAL LABORATORY

9700 . South Cass Avenue

Argonne, Illinois 60439

ANL/CNSV-TM-44

TECHNOLOGY ASSESSMENTS IN TRANSPORTATION:

SURVEY OF RECENT LITERATURE

Sarah J. LaBelle

Energy and Environmental Systems Division

Transportation Energy Systems Section

March 1980

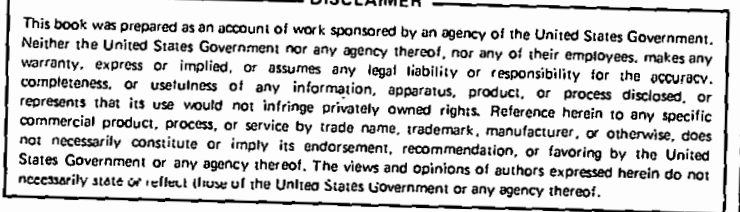

Work sponsored by

U.S. DEPARTMENT OF ENERGY

Assistant Secretary for Environment

Office of Technology Impacts

Technology Assessments Division 
THIS PAGE

\section{WAS INTENTIONALLY LEFT BLANK}




\section{CONTENTS}

ACKNOWLEDGMENTS : • • • • • • • • • • • • • • • • • • • • • • • • . • • • iv

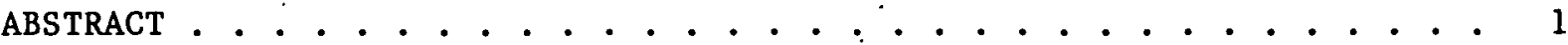

1 PURPOSE AND METHOD OF SURVEY AND SCREENING . • . . . . . . . . . . . 1

Purpose .. . . . . . . . . . . . . . . . . . . . . . . . . 1

Criteria for Review of Specific Reports . . . . . . . . . . . . . . . 2

Results of the Screening Process. . . . . . . . . . . . . . . . . . 4

Three Areas for Research in Transportation Energy Conservation. . . . 19

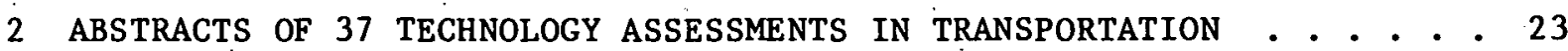

Multimode : . . . . . . . . . . . . . . . . . . . . . 25

Highway . . . . . . . . . . . . . . . . . . . . . . . . . 74

Mass Transit . . . . . . . . . . . . . . . . . . . . . . 148

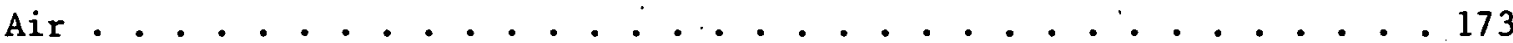

Marine . . . . . . . . . . . . . . . . . . . . . . . . 189

Pipeline . . . . . . . . . . . . . . . . . . . . . . . . . . 203

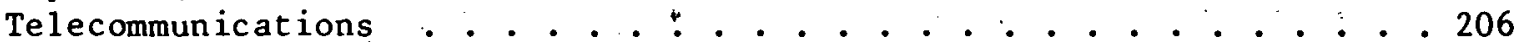

Fuels. . . . . . . . . . . . . . . . . . . . . . . . . 212

3 BRIEF ABSTRACTS OF SELECTED, RELATED REPORTS AND DATA SOURCES • • • 219 
The work reported in this document is the. result of a team effort, over the summer of 1979, to respond to a U.S: Department of Energy (DOE) request for candidate workscopes in transportation energy conservation based on a thorough review of the literature and current research. Larry $R$. Johnson and Martin J. Bernard of Argonne National Laboratory contributed significantly to the abstracts, the analysis, and the organization of the review process.

Staff from two groups completed many of the abstracts and aided in other parts of the review process: Barton-Aschman Associates (particularly Darwin Stuart,. Sandra Boehmer, Ray Giese, and Cynthia Ray) completed abstracts, enriched the base for the literature search, and aided in the analysis of the information on transportation demand in all markets. The Institute for Public Administration chartered by the New York. State Board of Regents (particularly Joseph Revis, Sumner Meyers, and Iames Powela) also prepared abstracts and contributed significantly to the design of the process used to organize the information contained in the literature.

Vary Coates, then on leave from George Washington University, provided the initial list of technology assessments for our bibliography and suggested several analytical structures for the review. David 0 . Moses of the DOE Office of Environment, Technology Assessments Division, served as project officer and provided significant technical assistance at all stages. The final presentation of these results within DOE to determine the scope of work to be funded was in fact his.

I wish to thank all of the technical contributors for their significant input. The fine quality of the text and format is due to the effort of the technical editor, Kathryn S. Macal, and the word processing staff (Jacqueline Dzinge1, Dawn Odrowski, and Anita Jandula). Responsibility for errors or omissions, however, rests with me. 


\section{TECHNOLOGY ASSESSMENTS IN TRANSPORTATION. SURVEY OF RECENT LITERATURE}

by

Sarah J. LaBelle

ABSTRACT

A survey and an evaluation of recent studies of transpor-. tation systems done in a technology assessment framework were undertaken as the basis for a detailed statement of work for a U.S. Department of Energy technology assessment of transportation energy conservation strategies. Several bibliographies were searched and numerous professionals in the field of technology assessment were contacted regarding current work. Detailed abstracts were prepared for studies judged to be sufficiently broad in coverage of impacts assessed, yet detailed in coverage of all or part of the nation's transportation systems. Some studies were rich in data but not comprehensive in their analytical approach; brief abstracts were prepared for these. An explanation of the criteria used to screen the studies, as well as abstracts of 37 reports, are provided in this compendium of transportation technology assessment literature.

1 PURPOSE AND METHOD OF SURVEY AND SCREENING

\section{PURPOSE}

The results of a literature survey of transportation technology assessments are presented in this report. The survey provided the information to focus a study of environmental impacts associated with transportation energy conservation strategies that may be implemented before the year 2000. Both the survey and the environmental impact study are funded by the U.S. Department of Energy (DOE).

As transportation is almost completely dependent upon petroleum, and directly accounts for one-fourth of the nation's total energy consumption, it is the target of many policies and technologies that will reduce petroleum use and perhaps total energy consumption. Transportation is also considered as a major cause of urban air quality problems and socioeconomic concerns in both urban and rural areas. The literature survey covered studies purporting to address environmental impact, energy consumption, and transportation demand for one or more transportation modes since 1973. The cutoff year was chosen because most economic and transportation trends and analyses have changed sharply since the Arab oil embargo of that year. 
The DOE Office of Environment, Technology Assessments Division - the group funding the literature survey and the resulting study -- is charged with meeting the objectives of the National Environmental Policy Act (NEPA) within DOE. The Technology Assessments Division is specifically concerned with identifying and scheduling environmental research needed to support technology programs sponsored by other DOE divisions. Major transportation technology programs are conducted under the Assistant Secretary for Conservation and Solar Energy, Office of Transportation Programs. This office funds hardware and operating strategy programs designed to reduce national petroleum dependence and total energy consumption. Other offices in DOE also have programs affecting transportation, including energy materials transport projects in the Resource Applications office and synfuels production efforts in the office of Fossil Energy. The responsibility of the Technology Assessments Division in the field of transportation is very broad; its focus is on identifying potential environmental impacts and incorporating that knowledge into DOE programs as early as possible. This survey is intended to assist the Division in that task. The technology assessment approach is one that requires a very broad and thorough coverage of impacts of proposed federal programs, providing decision makers with clearly organized forecasts of impacts.

The point of departure for the literature survey was a list of major transportation studies, prepared by the Technology Assessments Division. To supplement that 1 ist and be assured of thorough coverage of the field, several bibliographies and libraries were searched. The bibliographies reviewed were (1) the U.S. Government Announcements and Index, (2) 1ist of Congressional Office of Technology Assessment (OTA) publications, (3) A Handbook of Technology Assessment, published by DOE in March 1978, specifically Appendix 2, 43 Technology Asssessments in Six Years of Research (by NSF) at $\$ 10,018,700,(4)$ U.S. DOE, Office of Technology Impacts, Inventory of Reports - Subject Area: Technology Assessments, October 1978, and (5) NTIS Highlights in Transportation and in Administration. Further, recent acquisitions of the Transportation Center Library of Northwestern University were examined. This large library has access to shared catalogs of other major transportation libraries. Ongoing. or recently completed studies in the U.S. Department of Transportation, National Science Foundation, and DOE were identified through telephone survey of particular researchers in technology assessment and in offices of those agencies. The final report and staff working papers of the Congressionally mandated National Transportation Policy Study Commission were also reviewed.

\section{CRITERIA FOR REVIEW OF SPECIFIC REPORTS}

The literature curvcy was focused on two types of studies: (1) those defining the current state of knowledge of impacts of federal programs on transportation systems and (2) those providing a rich data base on the nature of travel demand or environmental impacts for one or more transportation modes. Detailed abstracts were prepared for all assessment studies of the first type, while only brief abstracts were written on the data sources. As the detailed abstracts took some time to prepare, initial screening was used to shorten the list of studies subject to such detailed review. The resulting list of 37 assessments provided the basis for identifying gaps in the literature, to be matched aganst DOE's role in transportation strategies and impact 
assessment in order to sharply define the two-year study now underway (see page 19).

Table 1 lists all the reports acquired and initially reviewed. They were classified by mode as the titles suggested (some were later reclassified on the basis of the detailed review). The reviews were conducted by staff from three groups, all versed in transportation, one also specializing in the technique of technology assessment. All three groups reviewed the reports in parallel; the bulk of the abstracting took place in July and August of 1979. The Energy and Environmental Systems Division of Argonne National Laboratory led the effort, assisted by Barton-Aschman Associates and the Institute for Public Administration.

The first criterion for screening the reports was timeliness. Forecasts made before the oil embargo were invariably too high in their estimates of travel demand by any sector. This was expected; as the embargo heralded a major change in two previously steady quantitites -- the price and availability of petroleum. The next criterion for inclusion as an assessment was the comprehensiveness of the evaluation. Failing this criterion were technology/ engineering design studies of a vehicle or guideway, cost studies, and regulatory studies. Studies rejected on this criterion were still considered for review as data sources on one transportatior mode or evaluation method. Detailed abstracts were prepared for 37 of the studies from Table 1; these studies are listed in Table 2. The abstracts themselves form section 2 of this report.

The 37 studies were subjected to a more-detailed examination of modal coverage, market coverage, evaluation methods employed, and overall effectiveness. The screen developed at this stage was the primary method of defining the state of the art of transportation technology assessment and provided the conceptual basis for the recommended studies (see page 19). It was a tool for communicating among members of the team assembled to advise DOE as well as a way to identify the features of the studies salient to DOE's function and the role of the office of Environment. The screen is displayed in Fig. 1.

The items included in the screen are significant to the objectives of the sponsor and mesh with the state-of-the-art approaches in the transportation and evaluation fields. The first category, modes, is a straightforward list of the modes, including both vehicles and guideways, that constitute the transportation system, requiring a yes/no indication of inclusion in a study. Telecommunications and fuels are two nonconventional entries there. Fuels are essentially a subsystem of each mode, but often are the focus of a study on transportation energy use. Telecommunication systems are often thought of as substitutes for certain types of passenger travel and constitute specific technologies, and as such can be considered along with the modes.

The concept of markets, the second major heading in Fig. 1, is taken from transportation demand theory, particularly as used in the National Transportation Policy Study Commission reports. This also required only a yes/no indication of inclusion. Travel occurs through modes, but trave1 happens because of a need to do something in a distant location -- work, shopping, recreation. The underlying reasons for travel define markets for travel, markets that can be satisfied by any of several modes. Auto travel, for example, does not encompass all travel in any of the three submarkets for 
passenger travel, though it is a crucial mode in all three. Using the market concept allows consideration of the concept of mode shift. The demand is for travel, rather than for modes. The concept of the market approach versus that of the mode and right-of-way approach is displayed in Fig. 2, which illustrates how various aspects of travel are accommodated in each view.

Returning to Fig. 1, the studies were evaluated as covering or not covering each of the modes and markets indicated. Under Analysis Methods, however, there was an effort to look at the quality of the application, where a rating of 1 was poor, 2 - average, and 3 - excellent. These were subjective ratings made by the reviewing group. Most of the methods are self-explanatory; three warrant some explanation. Intermodal referred to studies of the use of more than one mode' to accomplish a trip, as in truck/rail "piggyback" or trailer-on-flat-car (TOFC). Scenario analysis indicated the use of more than one forecast of basic or causal variables (macro-economic and population forecasts) as "reference futures" against which the propnsed policies or technologies were tested. This approach is founded in the idea that any point forecast will not occur, but that a reasonable probability exists that the future will lie between a range of high and low estimates of the causal. variables based on trend analyses. The environmental analysis method refers to a broad-based assessment of environmental impacts, not just of air quality or noise impacts, as is'typical of many transportation studies. A study could include any combination of these ten methods, with the quality ranking referring to each one specifically.

The last item, Overall Effectiveness, called for a subjective judgment by the reviewing group. Requisite to making the judgment, however, was direct knowledge of how the study was used or interviews with persons having such knowledge. Where that information was unavailable in the time available, no judgment was made. Although there are many studies not judged, the excrcioc had much value. First, it allowed the reviewers to give greater weight in evaluating the state of the art to studies judged effective, and, second, it provided the basis for discussion of elements to he includer in the $\mathrm{DOE}$ technology assessment to increase its potential for effective use by the decioiun makel's.

\section{RESULTS OF THE SCREENING PROCESS}

Tables 3 and 4 present the results of the screening process. In Table 3 , all 37 studies deemed comprehensive in evaluation and sufficiently recent are presented. (The table headings correspond to those in Fig. 2:) Using a stricter criterion on the evaluation method, Table 4 lists those studies meeting the description of a technology assessment as given in Strategies for Cunducting Technology Assessuents by Stanford University (abstracted in Section 3). Examination of these results provides the basis for the studies proposed by Argonne to DOE for consideration. The studies themselves are briefly described in the next subsection of this report. 
Table 1. Initial List of Research Reports for

Transportation Teçhnology Assessments

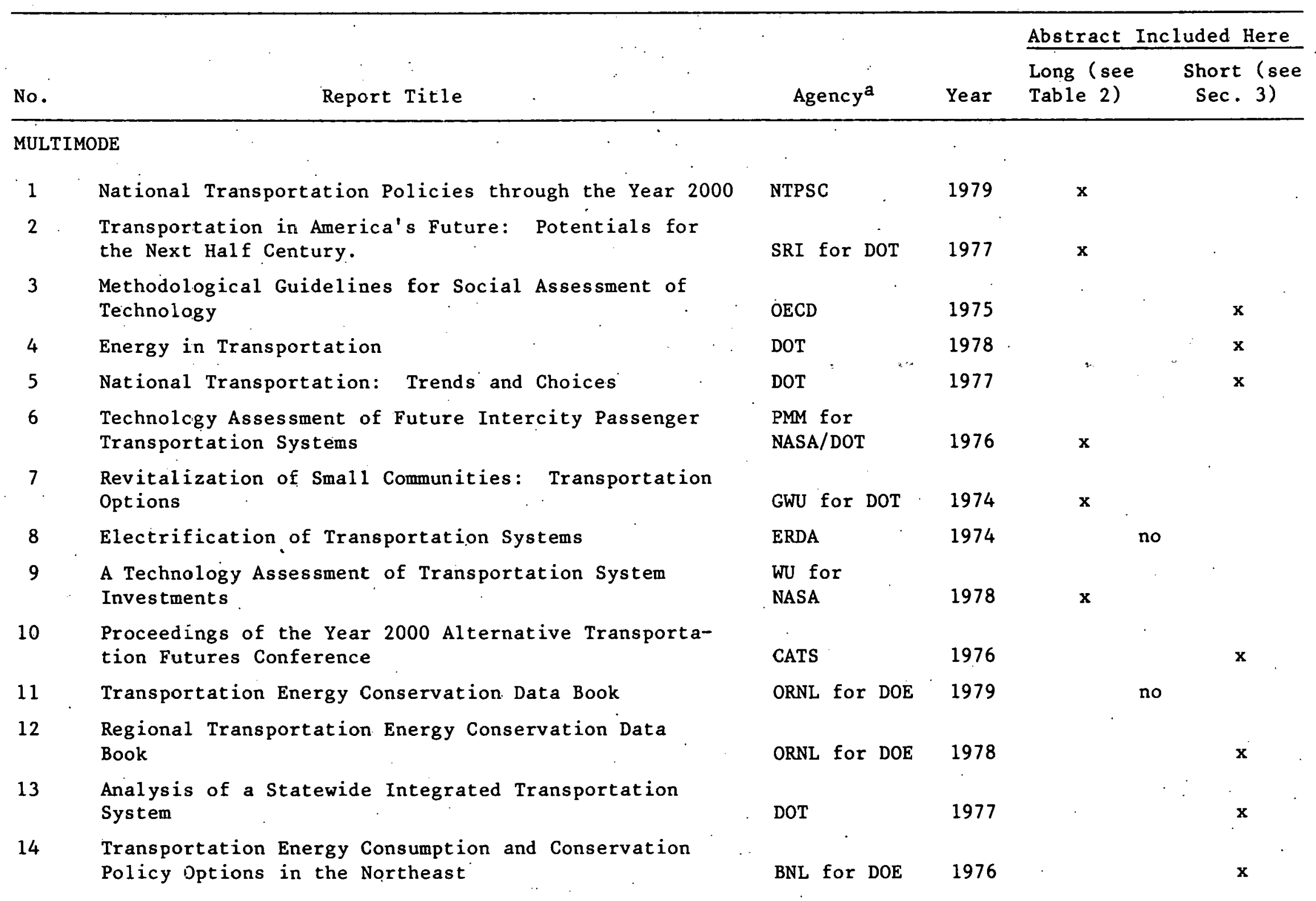


Tab_e i. (Cont'd.)

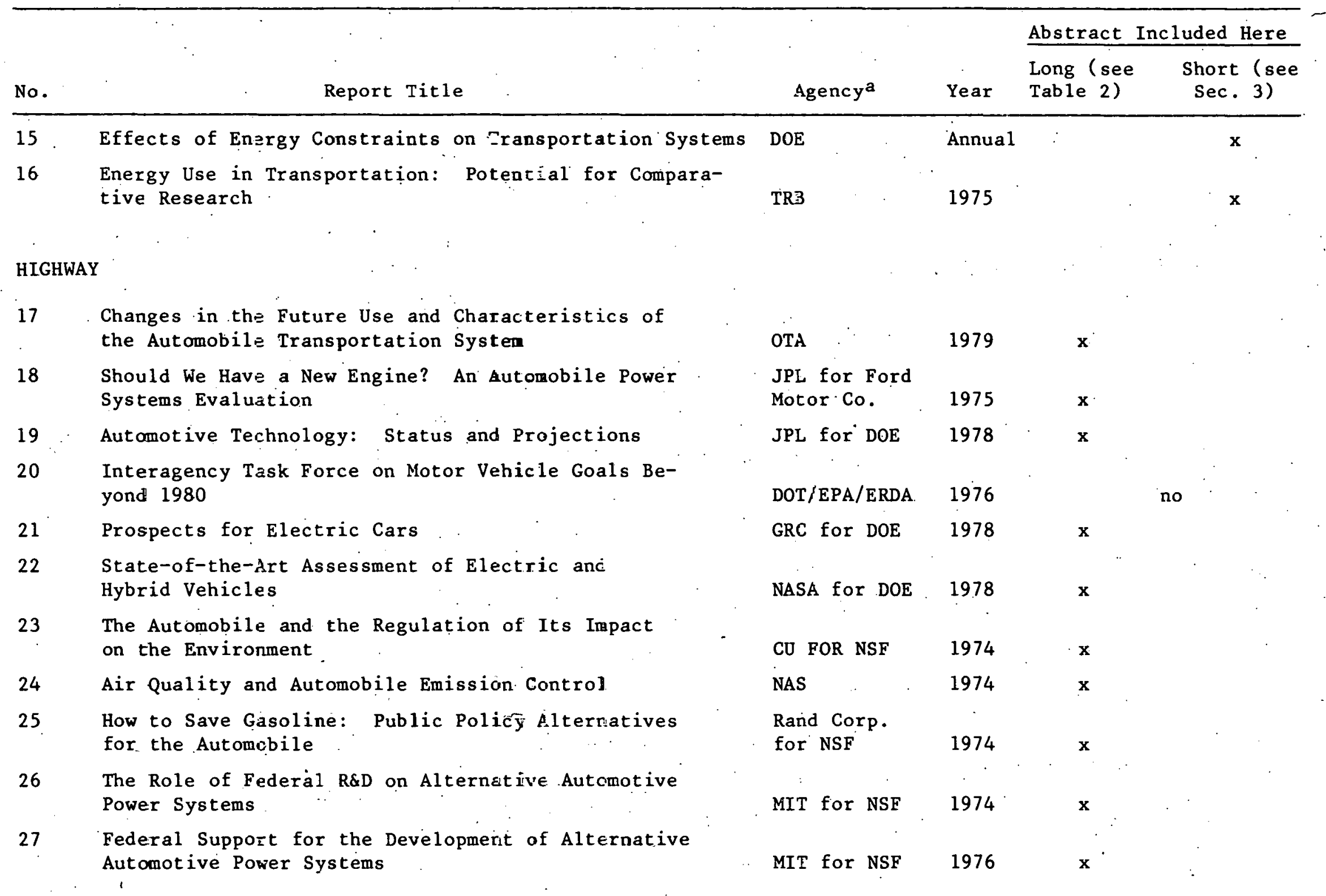


Table 1. (Cont'd.)

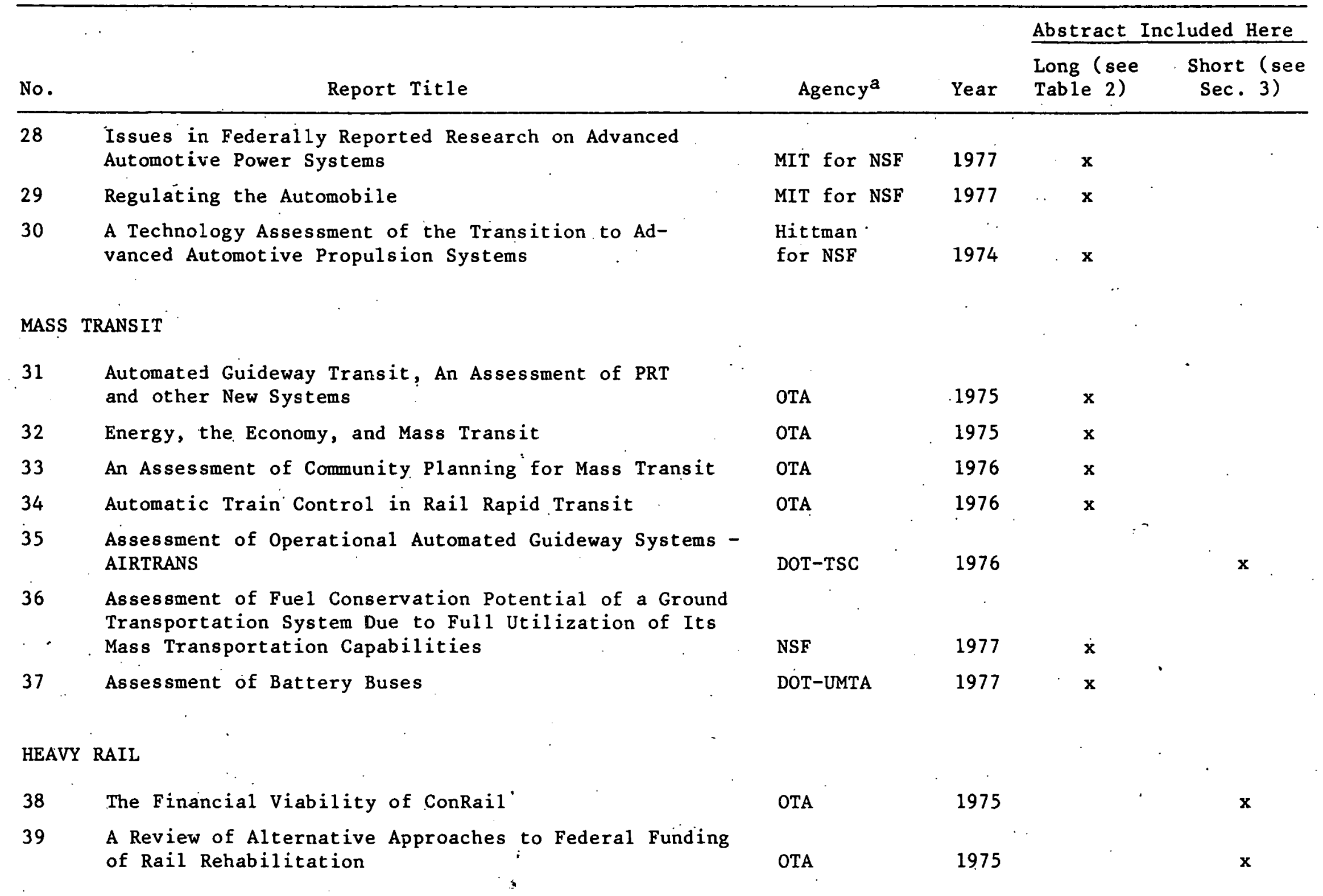


Zable.i. (Cont'd.)

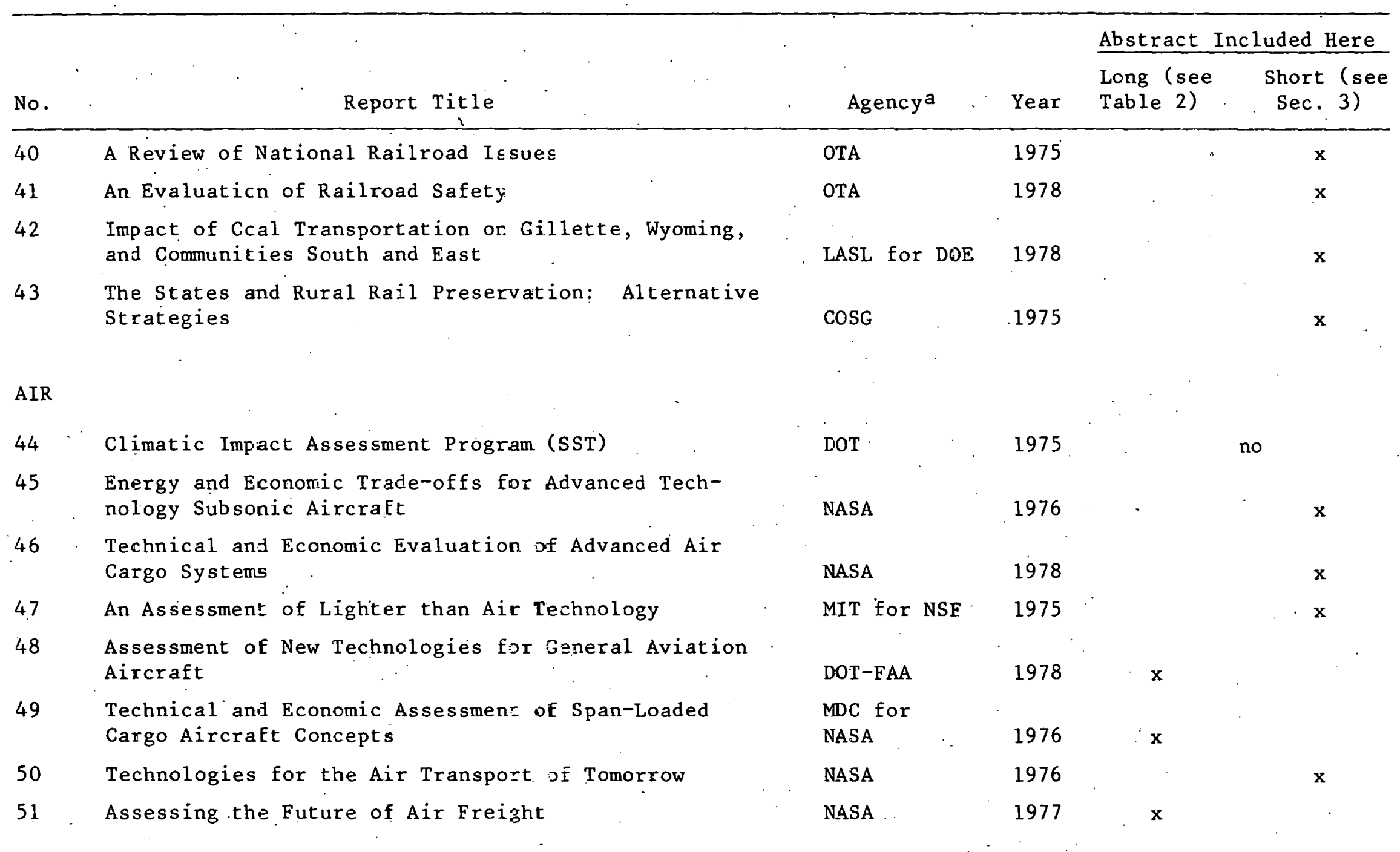


Tab1e 1. (Cont'd.)

\begin{tabular}{|c|c|c|c|c|}
\hline & & & & Abstract Included Here \\
\hline No.: & Report Title & Agency ${ }^{a}$ & Year & $\begin{array}{l}\text { Long (see } \\
\text { Table 2) }\end{array}$ \\
\hline
\end{tabular}

WATER

52 Oil Transportation by Tankers: An Analysis of Marine Pollution and Safety Measures

$\begin{array}{lll}\text { OTA } & 1975 & \mathbf{x} \\ \text { UAC for } & & \\ \text { DOC-MARAD } & 1974 & \mathbf{x} \\ \text { OTA } & 1977 & \mathbf{x}\end{array}$

PIPELINE

55 A Technology Assessment of Coal Slurry Pipelines

OTA

1978

$\mathbf{x}$

\section{OTHER FREIGHT}

56 Energy from the West: Policy Analysis Report (Section 11: Transportation)

57 The Need for a National System of Transportation and Utility Corridors

$\begin{array}{lll}\text { UO for EPA } & 1979 & \mathbf{x} \\ \text { DOI } & 1975 & \mathbf{x} \\ \text { TRB } & 1977 \\ \text { DOT/DOE } & 1980 \\ \text { DOT for NETS } & 1979\end{array}$

$\mathbf{x}$

58 Potential Fuel Conservation Measures by Motor Carriers in the Intercity Freight Market

59 National Energy Transportation Study

60 Impacts of Energy Materials Transporțation

DOT for NETS 1979

$\mathbf{x}$

$\mathbf{x}$

$\mathbf{x}$ 
Table 1. (Cont'd:)

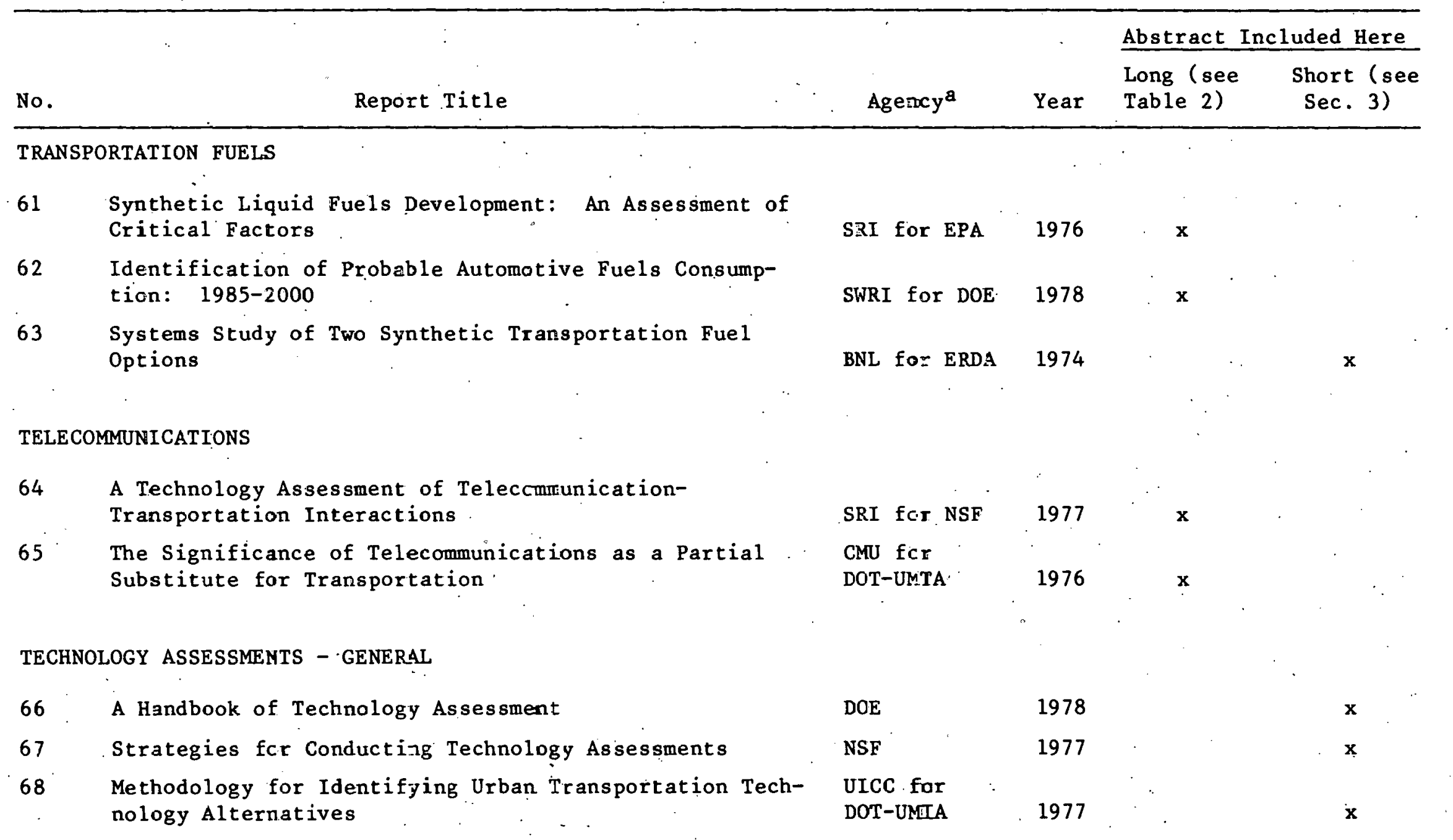


Table 1. (Cont'd.)

\begin{tabular}{|c|c|c|c|c|c|}
\hline . & & & & Abstract & Included Here \\
\hline No. & Report Title & Agencya & Year & $\begin{array}{l}\text { Long (see } \\
\text { Table 2) }\end{array}$ & $\begin{array}{c}\text { Short (see } \\
\text { Sec. 3) }\end{array}$ \\
\hline
\end{tabular}

ADDITIONAL

69 Contributions to the Foundations of Supply for Energy and Transportation: Concepts, Economics, and

Technologies

RFF

DOE

1978

DOT

1974

\section{$a_{\text {List }}$ of acronyms}

BNL Brookhaven National Laboratory

CATS Chicago.Area-Transportation Study in

Illinois Department of Transportation

Council of State Governments

Carnegie-Mellon University

CR I Center for Research, Inc.

CU Columbia University

DOC U.S. Department of Commerce

DOE U.S. Department of Energy

DOI U.S. Department of Interior

DOT U.S. Department of Transportation

EPA U.S. Environmental Protection Agency

ERDA U.S. Energy Research \& Development Administration

FAA Federal Aviation Administration in U.S. DOT

GRC General Research Corp.

GWU George Washington University

JPL Jet Propulsion Laboratory

LASL Los Alamos Scientific Laboratory

LASL LOs Alamos Scientific Laboratory

MDC McDonnell Douglas Corp.

MIT Massachuset:s Institute of Technology

NAS National Academy of Sciences

NASA National Aeronautics and Space Administration
NETS National Energy Transportation Study for U.S. Congress

NSF National Science Foundation

NTPSC . National Transportation Policy Study$$
\text { Commission }
$$

NU Northwestern University

OECD Organization of Economic Cooperation Organization of

ORNL Oak Ridge National Laboratory

OTA Office of Technology Assessment of U.S. Congress

PMM Peat, Marwick, Mitchell and Co.

RFF Resources for the Future, Inc.

SRI SRI International

SWR I Southwest. Research Institute

TRB. Transportation Research Board of Nas

TSC Transportation Systems Center in U.S. DOT

UAC United Aircraft Corp.

UICC University of Illinois at Chicago Circle

UMTA Urban Mass Transportation Administration in U.S. DOT

vo University of Oklahoma

WU Washington University 
Table 2. Recent Transportation Studies Presenting Comprehensive Evaluations of Federal Program Impacts

No. on

Table 1
Title, Agency, a Year
Page on Which Abstract Begins

MULTIMODE

1 National Transportation Policies through the Year 2000 (NTPSC, 1979)

2 Transportation in America's Future: Potentials for the Next Half Century (SRI for DOT, 1977)

6 Technology Assessment of Future Tntercity Paeconger Transportaliun Systems (PMM for NASA/DOT, 1976).

7 Revitalization of Small Communities: Transportation Options (GWII for DnT, 1974)

9 A Technology Assessment of Transportation System Investments (WU for NASA, 1978)

32 Energy, the Economy, and Mass Transit (OTA, 197.5)

56 Energy from the West: Policy Analysis Report (Section 11: Transportation) (UO for EPA, 1979)

57 The Need for a National System of Transportation and Utility Corridors (DOI, 1975)

64 A Technology Assessment of TelecommunicationTransportation Interactions (SRI for NSF, 1977)

17 Changes in the Future Use and Characteristics of the Automobile Transportation System (OTA, 1979)

18 Should We Have a New Engine? An Automobile Power Syeteme Evaluation (JPL for Ford Motor Co., 1975)

19 Automotive Technology: Status and Projections (JPL for DOE, 1978)

21 Prospects for Electric Cars (GRC for DOE, 1978)

22 state-of-the-Art Assessment of Electric and Hybrid Vehicles (NASA for DOE, 1978)

23. The Automobile and the Regulation of Its. Impact on the Environment (CU for NSF, 1974)

24 Air Quality and Automobile Emission Control (NAS, 1974)

25 How to Save Gasoline: Public Policy Alternatives for the Automobile (Rand Corp. for NSF, 1974)

26 The Role of Federal R\&D on Alternative Automotive Power Systems (MIT for NSF,. 1974) 
Table 2. (Cont'd.)

\begin{tabular}{clc}
$\begin{array}{l}\text { No. on } \\
\text { Table } 1\end{array}$ & \multicolumn{1}{c}{ Title, Agency, a Year } & $\begin{array}{c}\text { Page on Which } \\
\text { Abstract Begins }\end{array}$ \\
\hline 27 & $\begin{array}{l}\text { Federal Support for the Development of Alternative } \\
\text { Automotive Power Systems (MIT for NSF, 1976) }\end{array}$ & 121 \\
28 & $\begin{array}{l}\text { Issues in Federally Reported Research on Advanced } \\
\text { Automotive Power Systems (MIT for NSF, 1977) }\end{array}$ & 124 \\
29 & $\begin{array}{l}\text { Regulating the Automobile (MIT for NSF, 1977) } \\
30\end{array}$ & $\begin{array}{l}\text { A Technology Assessment of the Transition to } \\
\text { Advanced Automotive Propulsion Systems (Hittman } \\
\text { for NSF, 1974) }\end{array}$ \\
62 & $\begin{array}{l}\text { Identification of Probable Automotive Fuels } \\
\text { Consumption: 1985-2000 (SWRI for DOE, 1978) }\end{array}$
\end{tabular}

\section{MASS TRANSIT}

31. Automated Guideway Transit, An Assessment of PRT and Other New Systems (OTA, 1975)

33 An Assessment of Community Planning for Mass Transit (OTA, 1976)

34 Automatic Train Control in Rail Rapid Transit (OTA, 1976)

36 Assessment of Fuel Conservation Potential of a Ground Transportation System Due to Full Utilization of Its Mass Transportation Capabilities (CRI for NSF, 1977)

37 Assessment of Battery Buses (DOT-UMTA, 1977)

AIR

48 Assessment of New Technologies for General Aviation Aircraft (DOT-FAA, 1978)

49 Technical and Economic Assessment of Span-Loaded Cargo Aircraft Concepts (MDC for NASA, 1976)

51 Assessing the Future of Air Freight (NASA, 1977)

MARINE

52 Oil Transportation by Tankers: An Analysis of

Marine Pollution and Safety Measures (OTA, 1975)

53 U.S. Ocean Shipping Technology Forecast and Assessment (UAC for DOC-MARAD, 1974) . 192

54 Transportation of Liquid Natural Gas (OTA, 1977) . 200 
Table 2. (Cont'd.)

No. on

Table 1

Title, Agency, a Year

Page on Which

Abstract Begins

PIPELINE

56 A Technology Assessment of Coal Slurry Pipelines

(OTA, 1978)

203

TELECOMMUNICATIONS

66 The Significance of Telecommunications as a Partial

Substitute for Transportation (CMU for DNT-IMTA, 19.76)

FUELS

62 Synthetic Liquid Fuels Development: Assessment of Critical Factors (SRI for EPA, 1976)

a List of acronyms

CMU Carnegie-Mellon University

CRI Center for Research, Inc.

CU Columbia University

DOC U.S. Department of Commerce

DOE U.S. Department of Energy

DOI U.3. Lepartüént of Interior

DOT U.S. Department of Transportation

EPA U.S. Environmental Protection Agency

ERDA U.S. Energy Research \& Development Administration

FAA Federal Aviation Administration in U.S. DOT Generul Regearch Lorp.

George Washington University

Jet Propulsion Laboratory

JPL Jet Propulaion Laboracory

MARAD Maritime Administr

MDC McDonnell Douglas Corp.

MIT , Massachusetts Institute of Technology
NAS National Academy of Sciences
NASA. National Aeronatics and Space Administration
NSF
NTPSC National Science Foundation
Commission
OTA Office of Technology Assessment of U.S.
Congress
PMM Peat, Marwick, Mitcheli and Co.
SRI SRI Interational
SWRI Southwest Research Inetitute
UAC United Aircraft Corp.
UMTA Urban Mass Transportation Administration
in U.S. DOT
UO University of Oklahoma
WU Washington University




$$
\begin{aligned}
& 1=\text { POOR } \\
& 2=\text { AVERAGE } \\
& 3=\text { EXCELLENT }
\end{aligned}
$$

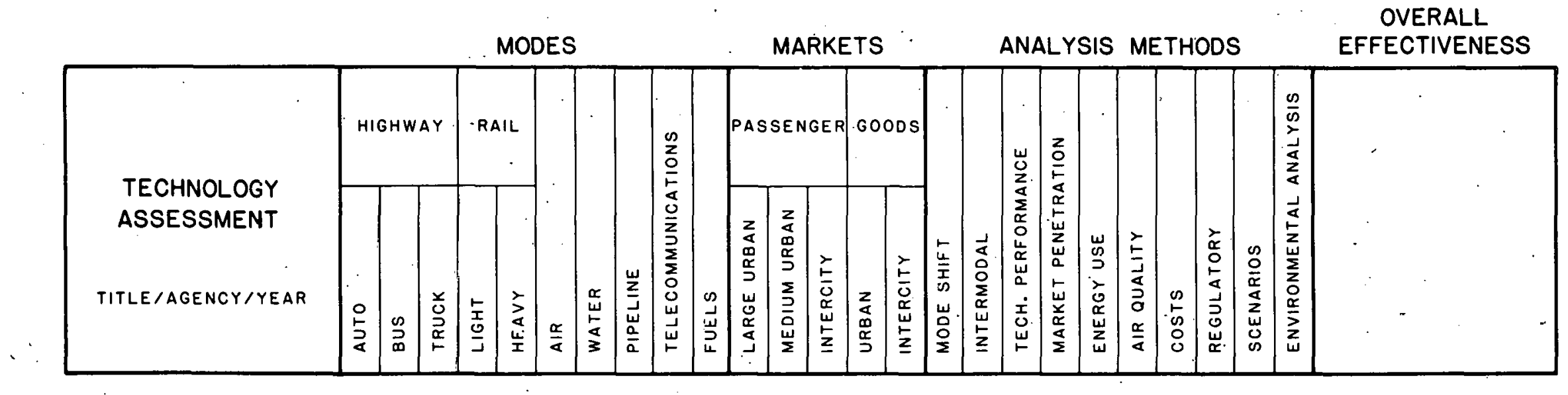

Fig. 1. Screen for Evaluating Transportation Technology Assessments 


\section{MARKET DEFINITION}
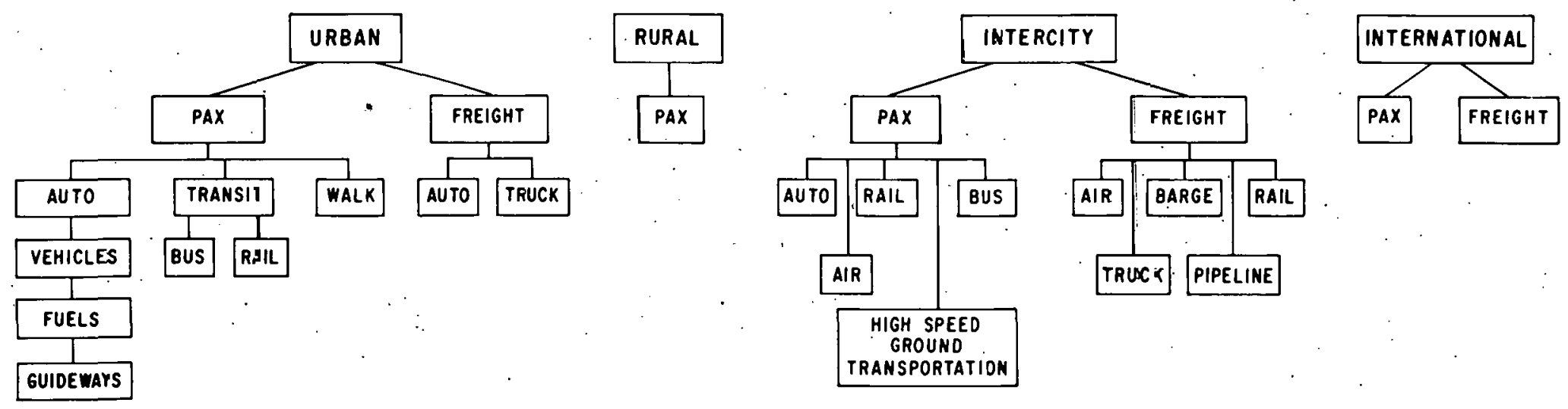

MODE / R.O.W.
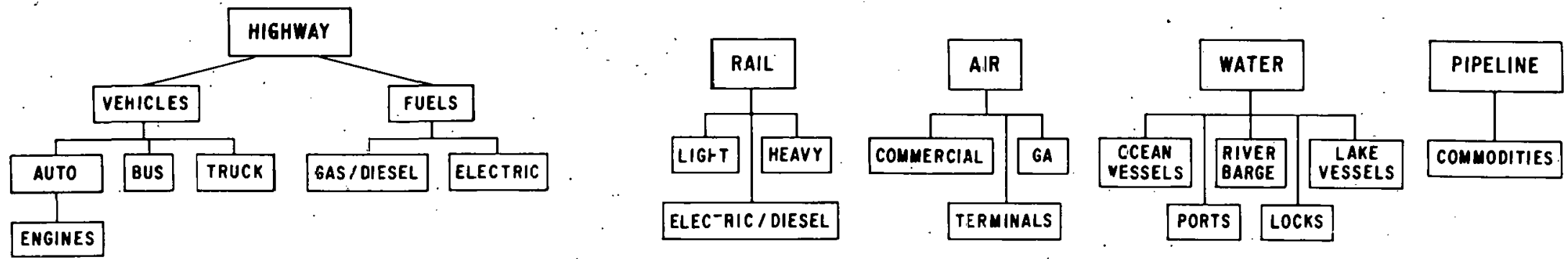

Fig. 2. Market and rode Appraaches to Planning and Assessment of the Transportation System 
Table 3. Technology Assessuents in Transportation by Modea

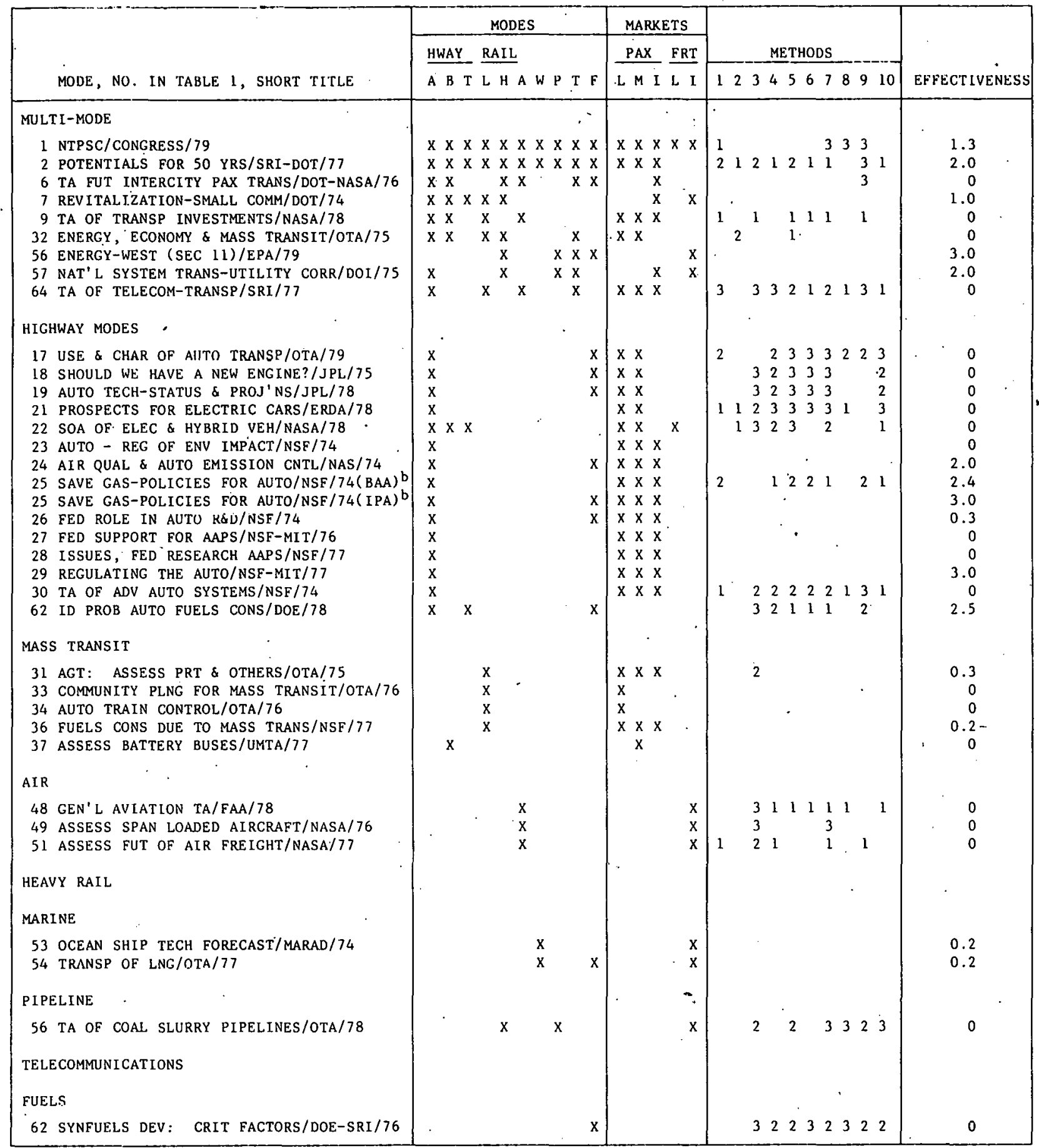

asee Figure 1 for definitions of table headiuys. See Table 2 for definitinns nf agency abbreviations.

bevaluations of this study by Barton Aschman Associates (BAA) and the Institute for Public Administration (IPA) were significantly different. The IPA abstract was subsequently selected for publication in this study. 
Table 4. Technology Assessments in Transportation by Mode -- Stanford University Definition ${ }^{a}$

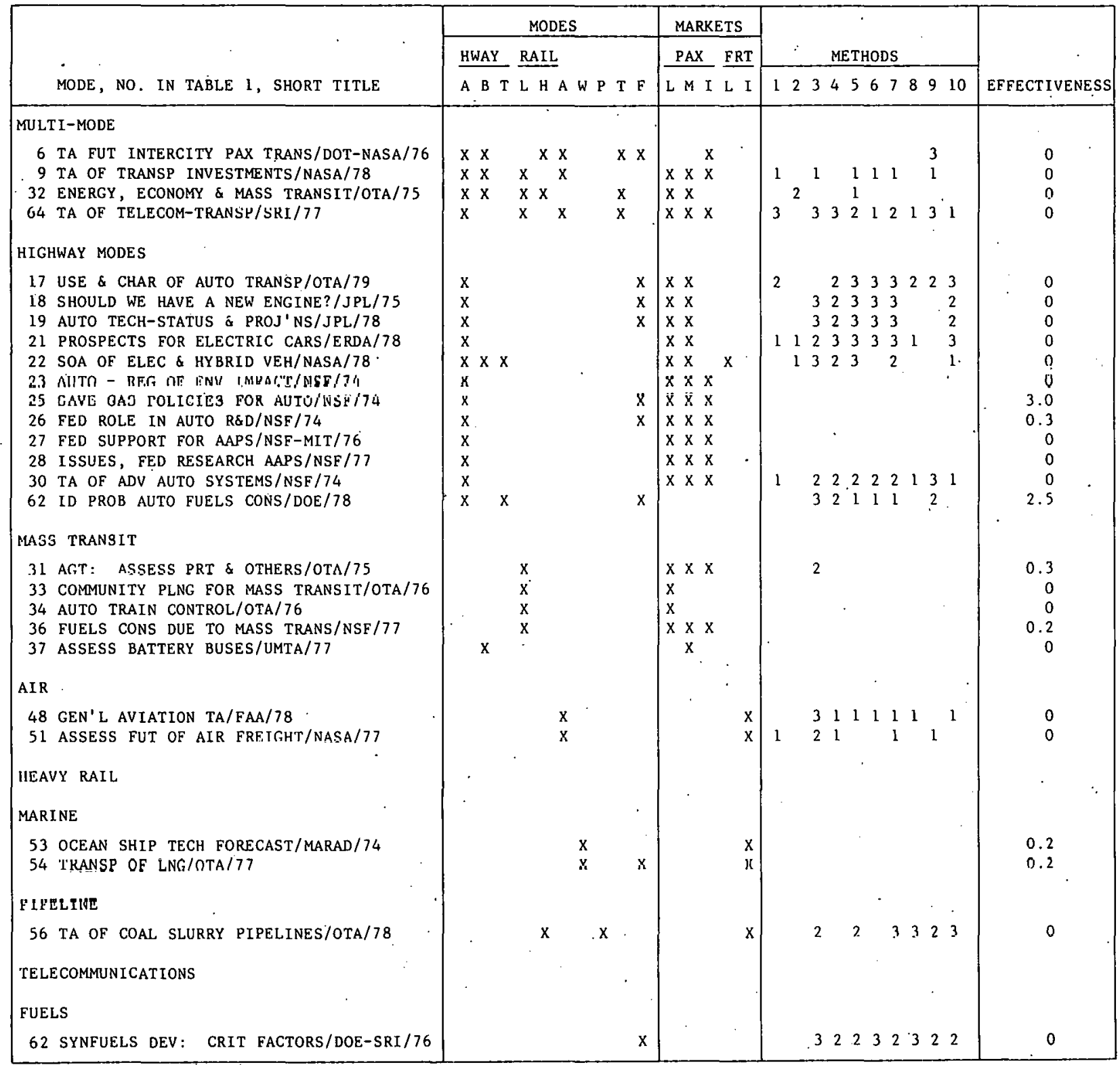

asee Figure 1 for definitions of table headings. See Tahle 2 for definitions of agency abbroviations. 
Several points emerge from Table 3. Few studies are multimodal, and fewer treat all the modes serving the narket. Only three studies were judged excellent in environmental impact analysis, of the dozen attempting it. Two of the three considered only the highway/passenger mode, and the third covered pipeline and heavy rail transport only. No multimodal study was rated excellent in analysis of energy use. Of the studies considered to have done sufficiently detailed analysis of energy use, all were passenger automobile studies, the majority for urban travel only. Only the few multimodal studies attempt to address more than one mode serving a market. Seventeen studies included intercity passenger travel, for example, but only three covered all relevant modes (auto, bus, rail, air) and 11 covered only one mode. Intercity freight studies, of which there were 11 , also focused on one mode in six cases; only one examined all modes. Some studies were commodity-specific, such as the 1979 EPA coal study (Energy-West), and others had focused on economic development (Revitalization of Small Communities), explaining the basis for their manpower coverage.

Further restricting the relevant field of review by the strict criterion of technology assessment method only (in Table 4), the single mode orientation of the studies is even more prominent. No multimodal studies that treat the intercity freight market, remain on Table 4.

\section{THREE AREAS FOR RESEARCH IN TRANSPORTATION ENERGY CONSERVATION}

This review of the relevant literature was then coupled with additional information on transportation energy use forecasts to formulate project statements to be recommended to DOE. Projections of Direct Energy Consumption by Mode: 1975-2000, by R.E. Knorr and M. Millar, Argonne National Laboratory Report ANL/CNSV-4, Aug. 1979, was the source of energy forecasts, with direct reference to certain of the original sources included in the Argonne publication (particularly the Congressional office of Technology Assessment study. of automobiles -- $\#_{21} 1$ in Table 1). The private automobile is now the largest consumer of petroleum among transportation modes, and most forecasters expect it to remain so until 2000. The now-in-place corporate average fuel economy (CAFE) standards will not be able to offset expected growth in vehicular travel beyond 1990 in most projections. Consumption is then predicted to rise to or beyond present - levels by 2000 in all forecasts -- a most unlikely situation in the face of decreasing domestic petroleum production and stated national policy to reduce dependence on imported oil. This conflict between trend-line projections of demand incorporating CAFE and diminishing fuel supply (in absolute, not relative, terms) suggests that travel markets dependent on gasoline are a prine area for study.

As the environmental impact of the federal strategies is a focus of the proposed studies, the effect of gasoline-powered vehicles on the environment is alco relevant. Urban auto travel is a major air pollution and noise source in cities. Any change in vehicle characteristics, mode choice, or fuel used to accommodate the shrinking supply will have a correspondingly significant impact on these environmental parameters. Proposed technological alternatives, including synthetic fuels to replace petroleum, alternative heat engines such as the Stirling or turbine, and new vehicle propulsion systems like electric vehicles all face as-yet-unresolved design problems having the potential for significant environmental impacts (documented in Environ- 
mental Development Plan for Transportation Programs, DOE, 1979). Synthetic fuels are intended to burn as cleanly as gasoline, but do not now; removal of sulfur from the emissions is an example of one problem. The alternative heat engines must operate at very high temperatures to meet future engine emission standards, requiring development of high-temperature ceramics or reliance on high-alloy steels to solve the design problem. High-alloy steels could have serious materials use and water quality impacts. Electric vehicle batteries may also present materials impacts. It is not now possible to say whether any or all of these problems will be resolved by research and development before the year 2000; the presence of the problems flags these alternatives as warranting environmental impact analysis.

Goods movement is forecast to be the most rapidly growing transportation user of energy. Trucks, the dominant carrier in revenue, and rail, the largest mode measured in ton-miles (due to long hauls of low-value, highbulk commodities), both rely primarily on petroleum fuels. Vcry little freight mnves on electrificd rail. This furecast increase in fuel use means increasing competition for decreasing petroleum supplies against the automobile, the largest fuel user even in 2000 .

Intercity passenger travel relies primarily on suto and aix wodes, the more energy-intensive of the intercity modes. Bus and rail consume $20-30 \%$ as much energy for intercity travel. This sector accounts for one-fifth the energy consumed in travel.

In developing the candidate workscopes, consideration was also given to the major issues in transportation as perceived by several groups or individuals knowledgeable in the field of transportation. The Transportation Research Board (TRB) of the National Academy of Sciences prepared a list of ten critical issues in 1978 relying on ite committec members' judguents. Full specification of the issues is found in the board's Research News (Nov.-Dec. 1978). The TRB identified the following critical areas: (1) the need for specific, measurable and attainable transportation goals at the national level, (2) determining appropriate intergovernmental responsibilities for. transportation systems, (3) financing transportation and equitably allocating resources, (4) the effects of economic and safety regulations for transportation, (5) the need for performance criteria and design standards for evaluating alternative transportation options, (6) improving use of existing facilities, (7) maintaining the present transportation systen to prevent delerioration, ( 8 ) maintaining the viability of U.S. railroads, (9) coordinating energy, land use, and transportation activities, and (10) conserving energy and developing alternate resources for transportation. The last two issues indicate the overriding importance of energy, use in the transportation sector. The TRB's list incorporates environmental impact concerns under the issue of intergovernmental responsibility, taking the view that the mechanisms are in place to address the environmental concerns but the mechanisms need attention. Environmental concerns are also specifically addressed under the issue of measurable national goals for the transportation system. The list of concerns generated by the TRB was supplemented by lists of concerns from four. individuals and the General Accounting office. The composite set of issues is presented in Table 5. The inclusion of these issues in the process for defining the 'workscopes insured that the studies' focus would mesh with the views of experts in transportation. The energy/environment focus is, however, dominant in each workscope. 
Table 5. Critical Issues for Transportation Identified by Six Sources

\begin{tabular}{|c|c|c|c|c|c|c|}
\hline 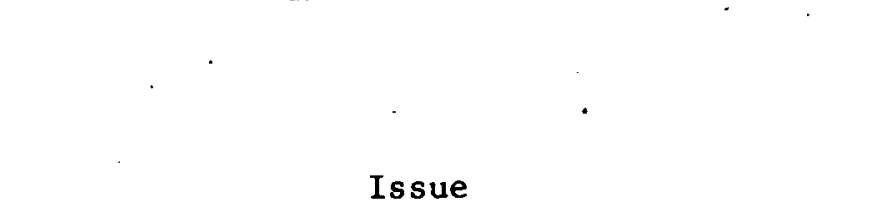 & 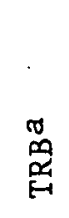 & 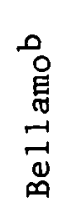 & 号 & $\begin{array}{l}0 \\
0 \\
0 \\
0 \\
0 \\
0\end{array}$ & 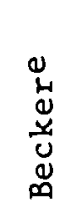 & 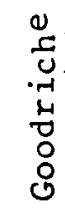 \\
\hline Conservation vs. (synfuel) supply & $\mathrm{x}$ & $\mathrm{X}$ & $\mathrm{X}$ & & . & \\
\hline Energy/land use/transportation & $\mathbf{X}$ & $\mathrm{X}$ & & $\mathrm{X}$ & & $\mathrm{x}$ \\
\hline Rail viability & $\mathrm{x}$ & $\mathrm{X}$ & $\mathrm{x}$ & & & \\
\hline Transportation systems management & $\mathrm{X}$ & & & : & & \\
\hline Utilization of existing facilities & $\mathrm{x}$ & & & & & \\
\hline Performance vs. design standards & $\mathrm{x}$ & $\mathrm{X}$ & $\mathbf{x}$ & $\mathrm{x}$ & & \\
\hline Regulation & $\mathrm{x}$ & & $\mathrm{x}$ & & & \\
\hline Equitable financing & $\mathrm{X}$ & & & $\mathrm{x}$ & & \\
\hline Intergovernmental relations & $\mathrm{X}$ & $\mathrm{X}$ & & $\mathrm{X}$ & & \\
\hline National goals (multimodal) & $\mathrm{X}$ & $\mathrm{X}$ & $\mathrm{x}$ & $\mathrm{x}$ & & \\
\hline Highway revenue shortfall & & $\mathrm{X}$ & & & & \\
\hline Corridor improvements & & $\mathrm{X}$ & & & & \\
\hline $\begin{array}{l}\text { Transit funding } \\
\text { Airport development }\end{array}$ & & $\begin{array}{l}\mathrm{X} \\
\mathrm{X}\end{array}$ & $\mathrm{x}$ & & & . \\
\hline Highway safety & & & $\mathrm{X}$ & $\mathrm{x}$ & & $\mathrm{x}$ \\
\hline Rail passenger services & & & $\mathrm{x}$ & & & \\
\hline Air transport reliability & & & $\mathrm{X}$ & & & \\
\hline Environmental quality & & & $\mathrm{X}$ & $\mathrm{x}$ & $\mathrm{x}$ & $\mathrm{X}$ \\
\hline Barge/ship subsidies & & & $\mathrm{X}$ & & & \\
\hline Pipeline pollution and water requirements & & & $\mathrm{X}$ & & & \\
\hline Liability (see highway safety) & & & & $\mathrm{x}$. & & \\
\hline Labor and U.S. economy & & & & $\mathrm{x}$ & $\mathrm{X}$ & $\mathrm{x}$ \\
\hline Oil competition among sectors & & & & $\mathrm{x}$ & & \\
\hline Indirect energy consumption & & & & $\mathrm{x}$ & & \\
\hline Load factors & & & . & $\mathbf{x}$ & & \\
\hline Energy transport & & & & $\begin{array}{l}x \\
x\end{array}$ & & \\
\hline Resource demands & & & & $\mathbf{X}$ & & \\
\hline Low-quality communications & & & & $\mathrm{X}$ & & \\
\hline High speed and weight & & & & $\mathbf{x}$ & & \\
\hline Inefficient vehicles/operation & & & & $\mathrm{x}$ & & \\
\hline Balance of trade. & & & & & $\mathrm{x}$ & \\
\hline Lifestyle & & & & & $\mathrm{x}$ & \\
\hline
\end{tabular}

aTransportation Research Board (see text discussion).

bSalvador Bellamo, Alan M. Voorhees Associates, Issues and New. Directions in Statewide Transportation Planning, presented at 56 th Annual Meeting of Transportation Research Board (Jan. 1976)

${ }^{c}$ Government Accounting Office, October 1978.

dAndrew Loeb1, Oak Ridge National Laboratory.

e Hal Becker and Don Goodrich, The Futures Group, August 1979. 
Based on the literature review contained herein and the data regarding present fuel consumption by mode and market and trend-line forecasts to the year 2000, three study areas were defined. After sketching out the major issues to be treated in each study, Argonne ranked them in the order most appropriate to the national interest in conservation of petroleum. The three areas for study are (1) productive conservation in the urban transportation market, (2) intercity freight transportation, and (3) intercity passenger transportation. All three have a year -2000 horizon. The first study has been further specified (Technology Assessment of Productive Conservation in Urban Transportation, U.S. DOE, DOE/EV-0070, Dec. 1979) and is underway. 
2 ABSTRACTS OF 37 TECHNOLOGY ASSESSMENTS IN TRANSPORTATION

*In order of listing in Table 2 . 


\section{THIS PAGE}

\section{WAS INTENTIONALLY LEFT BLANK}


NATIONAL TRANSPORTATION POLICIES THROUGH THE YEAR

Mode: MULTIMODE 2000 (1979)

National Transportation Policy Study Commission

PURPOSE

The commission was given a Congressional charter (Public Law 94-280) to study and determine national and regional transportation needs through 2000, determine the current transportation system's ability to meet them, and recommend policies to develop balanced national systems to meet projected needs. Funding was $\$ 5$ miliion for a 3-year study; a research team was specially assembled for the study. Recommendations were presented to Congress and 40 reports were published. The final report is organized by market segment rather than by mode and gives broad coverage of impacts.

\section{ASSUMPTIONS}

- Importance of pricing mechanisms in competitive markets.

- Six major policy themes developed midway through study.

National transportation policy should be uniform.

Overall federal involvement should be reduced.

Use economic analysis of intended federal actions.

When using transportation sector to pursue social goals, do so in a cost-effective manner.

Federal involvement, including funding, is required

for transportation safety and research.

Users and those who benefit from federal actions should

pay.

Many specific assumptions were made in defining three scenarios. A low-growth scenario supposes low population and gross-national-product growth, high unemployment, "restrained lifestyles," much income redistribution, and a low U.S. profile internationally. The medium-growth scenario includes a slightly larger population, U.S. as a stabilizing international force, healthy economy, major governmental role in growth planning, and strong migration to South and West. The high-growth scenario is based on low population growth, high degree of technology-fix, heavy migration to South and West, strong free enterprise, U.S. dominant as world power, full employment and strong cities.

INFORUM, the input/output model from the University of Maryland, which is used by EPA and DOE, was the basic modeling tool, generating sector activities in each scenario, using the socioeconomic variables as inputs. NTPSC staff used special teams to devise policy approaches to solve problems or fill gaps identified as a result of the scenario-definition/detailed-forecast procedures. Policy suggestions were organized according to the six themes noted above. 
METHODOLOGY

This is an exhaustive study of past transportation policy in the U.S. and abroad, with careful documentation of current activity. The three economic growth scenarios (high; medium, low) are supplemented by models and fully defined by 18 socioeconomic variables (abstracter's note: unable as yet to find definitive list of the 18 variables; likely further specification of the following list of 12). A11 three are status quo scenarios regarding transportation policies, varying from each other according to the socioeconomic variables:

- Population growth, migration, urban development.

- Economic growth, capital formation, unemployment:

- Reșource exploration, new technology.

- Government influence on growth policies, income rcdistributiun, sucial wel fare programs.

- International posture.

The commission defined the three scenarios to be internally conciotent, then used many models to determine the levels of transportation activity, impacts, and costs implicit in these scenarios. The models are organized by market:

- Size of auto fleet, vehicle miles traveled, gasoline consumption (DOE's TEC Model by Jack Faucett Assoc. and DOT TRANS Model).

- TRANS, transportation submodel of INFORUM for railroad, maritime, domestic waterborne, for-hire trucking, air carriers, pipeline, local transit, intercity bus, warehousing, private truck, private auto, private ship, general aviation, private bus.

- U.S. Department of Commerce Bureau of Economic Analyais (BEA) regions art basis for disaggregation of national resulta.

- Seventeen-commodity BEA regional flows with time and cost per person-mile or ton-mile.

- Urban passenger travel demand model with six city-type classes.

- Inlernational air travel modeling process.

- International maritime modeling process to forecast port and commodity activity.

- Rural passenger travel model, relying on urban per capita vehicle-mileștiaveled et imates.

- Urban and rural motor freight movement modeled as function of gross national product.

\section{CONCLUSIONS}

The commision produced a series of recommendations for national transportation policies and sets of policies. Major policies concerned 
promotion of deregulation and increased reliance on competitive market forces in all sectors of transportation; maintenance of separate modal trust funds; need for future environmental regulations to propose mechanisms for moreequitable, market-oriented distribution of the clean-up costs in dollars; and greater freedom for state and local governments in allocating federal transportation dollars, including a consistent, rational approach to setting the percentage for matching funds:

The final recommended policies are in response to several key gaps and issue areas that resulted from this study: (1) existing programs following status quo policies cannot provide transportation service equal to forecast demand; (2) costs of extending current levels of service into the future are high environmentally and in dollars; (3) there is no consistent U.S. transportation policy now, implying that resolution of conflicts among interest groups and stakeholders is required to determine and implement future transportation policies and programs.

\section{COMMENTS}

This was a massive study. The 40 or more detailed reports will be sources of data and methods. The impact of this study must be monitored. Many of the forecasts warrant further examination. Energy transportation is still not well studied, particularly if the as-yet-unpublished final report from the National Energy Transportation Study is inadequate. Urban transportation alternatives and the impacts of the various passenger modes also deserve further examination. 
TRANSPORTATION IN AMERICA'S FUTURE: POTENTIALS FOR THE NEXT HALF-CENTURY' (1977)

Mode: MULTIMODE

SRI International for U.S. Department of Transportation

PURPOSE

This is the final report for a study of future transportation developments, initiated by the U.S. Department of Transportation in March 1976. The objective was to define and explore the evolving national transportation system over the next 50 years and the process by which the present system will be transformed into future systems. The study also reviewed U.S. transportation developments and forecast needs under four future American scenarios: success, disciplined society, foul weather, and transformation.

ASSUMPTIONS

Success Scenario

International

1. Stability among world political systems, with a 20-year consolidation of socialist governments into regional forces.

2. Technological advances in food and energy production. Population shifts tn production arcas. Intense muvement coward industrialization and regional self-sufficiency. Rapid decline in world population growth.

3. Late 20 th century western multinational corporations survive and join in partnership with regional governments to ensure development.

Regional

1. Canada, Mexico, and U.S. join to develop energy, transportation, communications, and data processing networks.

2. National borders diminish in importance due to joint developments.

National

i. Mass population and industrial movements to southeastern U.S. and to the plains and Mountain states to take advantage of climate and energy reserves. U.S. population 280 million by 2020 .

2. U.S. gross national product $\$ 8$ trillion in 2025 with heavy input by the metals recycling industry.

3. Growing regional economic and political self-sufficiency. Decline of Northeast and Midwest in relative economic and population terms. Decline of several large cities. 
4. Fewer large commercial and industrial businesses. Greater emphasis on energy, transportation, and communications. More smaller, regionally based businesses.

5. Advanced high-speed communications and data processing accessible to all citizens, planners, and decision makers.

6. Increased leisure time. Little distinction between work and play.

7. Economic and population growth stabilizes. Population contains $8 \%$ voluntary simplicity component. Full integration of population along sex, race, and age lines.

8. Successful development of solar energy, synthetic fuels, fusion power, and magnetohydrodynamic technologies.

Foul Weather Scenario

1. Northern Hemisphere weather conditions revert to "mini ice age." Mean temperatures drop $1.5 \mathrm{C}^{\circ}$. More erratic conditions persist with extreme cases of drought, floods, and unseasonable temperature changes.

2. U.S. experiences relocation of high productivity centers and concentrations of specific crop types. New plant varieties adapt 1 ittle to freezes, droughts, etc. Accuracy of weather prediction by 2025 allows for seasonal management of agriculture. Agriculture impacted most significantly during this time.

3. U.S. population shifts from North to South and to the coastal areas in the West and Southwest.

4. World "food wars" threaten, but do not occur.

5. Extensive soil erosion plagues the Northwest, West, Southwest and parts of California, prompting national-level involvement.

Disciplined Society Scenario

1. Smooth nonrevolutionary development of authoritarian technocracy with sophisticated. psychotechnology and social engineering capability. A diffuse, "faceless" national leadership. Reassertion of materialistic values.

2. Increased urban population density.

3. Continued developments in data processing and telecommunications. Continued shortage of energy and materials, but achievement of U.S. energy independence through technology and conservation.

4. Breakdown of internalional relations.

$\underline{\text { Transformation Scenario }}$

1. Traditional industrial practices abandoned due to energy and materials shortages, pollution, and other high-growth ills. 
2. Voluntary simplicity emerges. Voluntary simplicity subpopulation and achievement-sector subpopulation coexist for several generations.

3. Nations cooperate on a global basis within 35 years, in part because of terrorist acts.

Energy Assumptions

\section{General}

1. There are major supply uncertainties. Domestic reserves decline rapidly. by end of century. Foreign reserves expected to be exhausted by middle of 21 st century.

2. Availability and price of oil dominated by foreign interests rather than eronomics.

3. Natural gas supplies to be short within the next 20 years, placing extra demands on petroleum.

\section{Success}

1. Total energy consumption 200 quads/year by 2025 . Two-percent growth rate in energy use from 1975 to 2025.

2. Use of domestic and imported oil and natural gas declines. Eighty quads of coal production by 2025; electricity production is mainly minemouth. Nuclear. energy thrives, along with young fusion industry. Solar energy supplies $15 \%$ of U.S. energy.

\section{Foul Weather}

1. lotal energy consumption 130 quads/year by 2025. Energy-consumption growth rate. $1.2 \%$ / year.

2. High demand for energy from industrial sector (economic recovery), residential and commercial sector (heating requirements), and agricultural sector (food production) shows energy/gross-national-product ratio similar to that of 1975 .

3. Coal production reaches 55 quads by 2025 due to relaxing of environmental standards. Solar space heating incorporated into homes. Nuclear energy industry grows.

\section{Disciplined Society}

1. Total energy consumption 110 quads/year by 2025. Annual energy growth rate $2.4 \% /$ year. Energy/gross-national-product ratio half that of 1975 . Efficient energy use is strictly enforced:

2. Fifty quads of coal production by 2025. Thriving nuclear and solar industries. Imported oil no factor by 2010. 0il shale making valuable contribution. 


\section{Transformation}

1. Total energy consumption 100 quads/year by 2025. Annual energy growth rate less than $1 \%$ /year. Energy/gross-national-product ratio half that of 1975 .

2. Forty quads of coal production by 2025. Nuclear energy diminishes. Solar and renewable resources flourish.

Transportation Assumptions

Automobile fleet efficiency assumptions are based on findings of Report by the Federal Task Force on Motor Vehicle Goals Beyond 1980 and are summarized in Table 6. Assumptions regarding nonautomobile transportation efficiency improvements are based on technological and demand forecasts presented elsewhere in study. The assumed improvements are summarized in Table 7 .

Table 6. Auto Fleet Efficiency

\begin{tabular}{lcccc}
\hline & \multicolumn{4}{c}{ Auto } \\
\cline { 2 - 5 } Year & Success & $\begin{array}{c}\text { Foul } \\
\text { Weather }\end{array}$ & $\begin{array}{c}\text { Disciplined } \\
\text { Society }\end{array}$ & Transformation \\
\hline 1995 & 26 & 20 & 20 & 26 \\
2025 & 32 & 25 & 25 & 35 \\
\hline
\end{tabular}

Table 7. Nonautomobile Transportation Efficiency Improvements

\begin{tabular}{|c|c|c|c|c|}
\hline \multirow[b]{2}{*}{$\begin{array}{l}\text { Sector, } \\
\text { Year }\end{array}$} & \multicolumn{4}{|c|}{$\begin{array}{c}\text { \% Nonautomobile Transportation } \\
\text { Efficiency Improvements over } 1975 \text {, by Scenario }\end{array}$} \\
\hline & Success & $\begin{array}{l}\text { Foul } \\
\text { Weather }\end{array}$ & $\begin{array}{l}\text { Disciplined } \\
\text { Society }\end{array}$ & $\begin{array}{l}\text { Trans for- } \\
\text { mation }\end{array}$ \\
\hline Aviation & & & & \\
\hline 1995 & 10 & 10 & 10 & 10 \\
\hline 2025 & 30 & 20 & 20 & 40 \\
\hline \multicolumn{5}{|l|}{ Trucks } \\
\hline 1995 & 20 & 0 & 0 & $20^{\circ}$ \\
\hline 2025 & 50 & 30 & 40 & 60 \\
\hline Railroads & 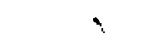 & & & \\
\hline $\begin{array}{l}\text { and urban } \\
\text { transit }\end{array}$ & & & & . \\
\hline 1995 & 10 & 10 & 10 & 10 \\
\hline 2025 & 30 & 30 & 40. & 40 \\
\hline
\end{tabular}


Intracity Passenger Trave1. The Unified Mechanism of Trave1. (UMOT) model of $Y$. Zahavi was used to forecast intracity passenger travel for 10 standard metropolitan statistical areas (SMSAs), later expanded to 80 SMSAs.

Intercity Passenger Travel. A modified version of the Monsod model was used to simultaneously forecast travel by air, bus, auto, and rail. Primary inputs were fuel cost and certain income assumptions. General aviation activity was forecast using a model developed by Ratchford, sensitive to service costs, income growth, and price of commercial aviation services.

Intercity Freight Traffic. Rail and truck traffic were forecast using a modified version of a model developed by Alexander Morton. Forecasts are a result of gross-national-product growth rate and shipment-tariff growth rate as sumptions.

Auto Vehicle Miles Traveled. Forecasts were made using separate aggregate forecasting models (most likely SRI models). Auto ownership model was constructed as well.

CONCLUSIONS

Success Scenario

1. Passenger and freight demand is two to four times 1975 levels. Energy deficiency is $50 \%$ to $200 \%$ greater.

2. Anticipation of population shifts allows for planned towns and cities to integrate mass transit corridors into overall design of residential, commercial, and industrial centers. Regional and local influence in planning and design of transit corridors and vehicle choices.

3. Automobile business booms, creating traffic problems for vacation periods. synthetic fuels allow expansion of autos, buses, and aviation. Vehicles lighter, more efficient, and safer than in 1975.

4. Electrification of railroads and intra-urban auto systems occurs. Advanced cybernetic technology permits higher speeds and traffic density.

5. Forefgn markets tlourish on U.S. transportation technologies.

\section{Foul Weather}

1. Overall transportation demand is below 1975 levels, except for freight and bus travel. Network expansion accompanying population shift to the South.

2. Increasing railroad and urban vehicle electrification. Increases in government control of transportation systems. 
3. Federal control of declining railroads in Northeast. New railroad construction in western coal field regions. In middle and western U.S., government invests in rail transport to aid agriculture and.coal.

4. Long-haul truck use declines.

5. Auto fuel economy increases 100-200\%; however operating costs and fuel rationing restrict use.

6. Southern cities adopt bus transit due to dense developments.

7. Agriculture more energy-intensive than in 1975, resulting in less air travel and fewer liquid-fueled personal vehicles.

\section{Disciplined Society}

1. Passenger travel close to 1975 levels, except for increase in bus and freight ton-miles. Personal travel reduced, being replaced by communication systems.

2. Semimonopolies emerge in railroad, marine, and airline fields. Major reliance on railroads, trucks, buses. Air travel is greatly reduced. Mass transit flourishes. Private vehicle use declines sharply.

3. Electrification and mandatory use of railroads for long haul.

\section{Transformation}

1. Overall demand for transportation is 1.5 to 3 times 1975 levels.

2. More concern with transportation pollution, energy consumption, durability, and cost. Reduced per capita travel. More intraregional travel of people and freight. Autos are shared. People walk, bike more. More intensive use of urban transit and paratransit.

3. Long-distance freight moved by rail and new rail-truck container system.

4. High-level rail electrification and heavy use of urban electric autos.

5. Increased regional and local control of transportation planning. 
TECHNOLOGY ASSESSMENT OF FUTURE INTERCITY PASSENGER TRANSPORTATION SYSTEMS (1976)

Mode: MULTIMODE

Peat, Marwick, Mitche11 and Co. for National Aeronautic's and Space Administration and U.S. Department of Transportaion

EXECUTIVE SUMMARY

Network Coverage:

interurban

passenger with some consideration given to freight and international

System Coverage: road, rail, air, telecommunications

Process Coverage:

system operations terminals and

facilities

Supply/Demand :

focuses on impacts of particular supply but probes interaction between supply and demand as well
This study explores the technical, economic, environmental, and sociopolitical issues associated with future intercity transportation. Emphasized in the study is interurban, domestic passenger transportation including highway, rail, and air linkages up to ald beyuul the year 2000. Some consideracton is given to freight transport, international transportation, transportation interfaces, and telecommunications as well.

While focusing primarily on the impacts created by future transportation modes, the study also seeks to identify the role that different societal settings would have in shaping the future transportation system. What is explored is a dynamic system emerging out of the interaction between the transportation network and the societal conditions shaping that network.

A number of social, economic, environmental, and institutional consequences of technological advances in intercity transportation are identified, although none are documented because of the conceptual nature of the study. Where these consequences are well understood, specific recommendations are made about the characteristics of future intercity transportation modes. Where they are not, future research and analysis activities that should be pursued are outlined. Both kinds of recommendations appear in the study and are presented in the following abstract.

PURPOSE

The study explores impacts of new transportation technologies on society, pointing out potential advantages and disadvantages of individual technologies, and identifies avenues of research for alleviating negative impacts, augmenting positive impacts and fully understanding impacts produced by introduction of new technologies. Described as an experiment in applying technology assessment as a tool for identifying future research and technology tasks, it explores evolving transportation technologies to and beyond the year 2000. Possible consequences of technologies are traced through direct impacts to indirect impacts. The study describes what might occur if certain technological advances take place rather than the likelihood of occurrences. 
APPROACH

The study consisted of a series of tasks and a workshop leading up to a general impact assessment and recommendations for future research and analysis. Initial tasks describe the state of society in year 2000 and identify possible new technological forms of transportation that might emerge by that year.

Four "background scenarios" that would shape the nature of the future transportation network are constructed by systematically varying these four factors:

- National attitude toward public services and economic development.

- Population growth, settlement patterns, life styles, level of prosperity, and capital formation.

- Resource and energy costs.

- Government regulatory controls and levels of R\&D expenditures.

Along with the "background scenarios," three additional transportation-demandrelated settings, each representing different travel markets, are identified for introduction of new technologies. Included are: (1) high-density travel corridors such as the Boston-New York City-Washington, D.C. corridor; (2) large city pairs such as Los Angeles to Washington, D.C.; and (3) smaller and/or shorter city-pair markets. Within the context of "background scenarios" and travel market settings, matching transportation innovations are postulated and analyzed.

Qualitative analysis of transportation scenarios is conducted to measure changes in patronage, cost-revenue relationships, energy consumption, and safety resulting from introduction of postulated innovations. As the basis for estimating impacts, four reference cases are constructed -- one reference case for each background/transportation scenario. A common feature among the reference cases is that each posits the same transportation technology for year 2000; for all modes only nominal improvements are made to the existing system. Reference cases differ in the background scenarios they assume; i.e., national attitudes, population, income, cost of capital, and fuel prices. Impacts are analyzed using reference cases as benchmark for comparison.

Analysis is combined with other analyses conducted throughout study to provide a foundation for broader impact assessment in which possible indirect as well as direct impacts are addressed. For this, transportation options are screened, narrowing the options to the three technologies discussed below. Attention also is given to prospective innovations in vehicle rental, access/ egress features of intercity transportation, intermodal transfer facilities, and information systems.

Aircraft. (1) The evolving fleet of increasingly fuel-efficient and quieter conventional takeoff and landing (CTOL) subsonic aircraft, varying in size from less than 70 to more than 600 seats. (2) Short and vertical takeoff and landing (STOL/VTOL) aircraft. 
Highway. (1) Improved intercity buses. (2) Improved versions of combustion engine automobiles, including alternatives to the gasoline-fueled internal combustion engine. (3) Electric automobiles, with optional power pickup from electrified highways. (4) Dual-mode automobiles, trucks, and buses; that is, vehicles able to operate without direct driver control on specialized automated highways.

Fixed Guideway. (1) Improved passenger trains (IPT). (2) Very-highspeed ground transportation (VHSGT) systems with vehicles operating on dedicated guideways at speeds over $250 \mathrm{mph}$.

\section{METHODOLOGY}

Chains of consequences associated with prospective intercity transportation technologies are unraveled using a multidimensional approach. Reflecting this approach are the following questions, asked repeatedly for each technology option:

- How does the impact affect development and use of economic, natural, and human resources; nature of environment and settlement patterns; life styles, values, and well-being of individuals; and evolution and behavior of political, social; and economic institutions?

- When does the impact occur in the life cycle of the technology? Is it during its invention; promotion, and development; its implementation; its operation; or its revision, replacement, or abandonment?

- How does strength of the impact. change with time?

- Under what political, economic, and social conditions, and physical settings is the impact felt most strongly; and do changes in background conditions affect the nature of the impact? How might the impact change with changes in the setting in which it occurs?

- What are society's likely responses to the impact and how might these responses change the nature of the impact and give rise to additional indirect impacts?

CONCLUSIONS

A comparison of reference cases with the four transportation scenarios is presented in Table 8 (terms such as higher and lower allude to reference case for that scenario). A broader impact assessment is summarized below.

\section{Aircraft}

Low-density routes are inherently more costly than high-density routes, suggesting that small aircraft will not be attractive for some time. If small commercial aircraft become widespread, significant impacts include increased crowding at major hub airports and effects on general aviation growth. Widebody aircraft cannot be expected to compensate for airport airside capacity deficiencies to the extent once hoped. Continuing demand for schedule 
frequency and more convenient ground access, plus relaxed regulatory restraints on charter services, will probably increase the use of satellite airports in major metropolitan areas, although with little relief of congestion at major hub airports.

A major current and future cause of airport congestion is competing airlines' practice of scheduling similar aircraft on the same routes at nearly the same time. Prohibition of this practice is a possible future regulatory response to worsening airside congestion at major hub airports. Another possibility is adoption of the cartel system practiced in Europe and elsewhere.

Since STOL/VTOL aircraft are inherently more costly than CTOL aircraft of the same generation, for the foreseeable future the market for STOL/VTOL service, would be limited to business and well-to-do travelers who place a very high value on their time. Other segments of the population would be expected to strongly resist the environmental intrusion threatened by introduction of this new service into their communities.

While serious environmental and economic (especially fuel consumption) considerations stand squarely in the path of developing an American SST, another less visible but formidable barrier is the lack of a political.constituency for this technology, stemming partially from its image as a technology for the rich. Despite such difficulties, it seems possible that development of an American SST could be pursued later in this century, if backed by private capital, and if prospects for reducing operating costs and environmental impacts appear favorable.

Buses

Buses are the lowest cost and most energy-efficient form of commoncarrier intercity passenger transportation. This mode now has a variety of adverse features, both physical and psychological, that prevent full exploitation of its advantages; but many of these problems seem amenable to technological and institutional action in the future, perhaps with dramatic implications for the role of the bus in future intercity transportation.

The small size of the new bus market, and other factors, seems to inhibit innovation in bus technology. Perhaps, here, government can best stimulate innovation through publicly sponsored research through its role as a consumer by creating new, low-risk markets for innovative bus technology.

$\underline{\text { Automobiles }}$

The many desirable service features of this mode strongly suggest that the personal automobile in one technological form or another will be the dominant form of intercity travel for the foreseeable future. The importance of the automobile in American society and the high visibility of its impacts suggest that technological change in automobiles will occur at a rapid pace during the next several decades, bringing a host of profound environmental, economic, and social consequences. 
Tatle 8. Comparison of Reference Cases and Transfortation Scenarios

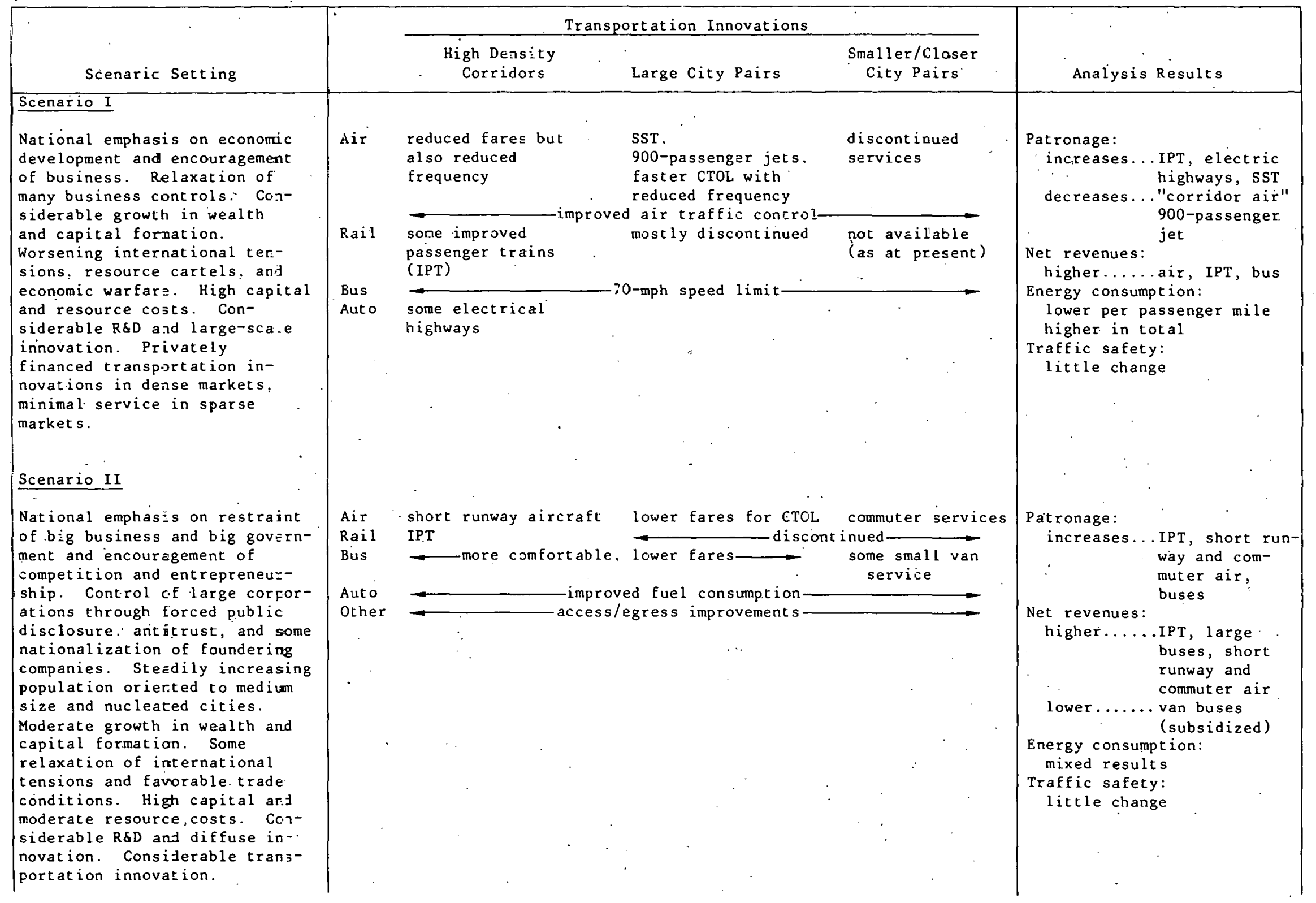


Table 8. (Cont'd)

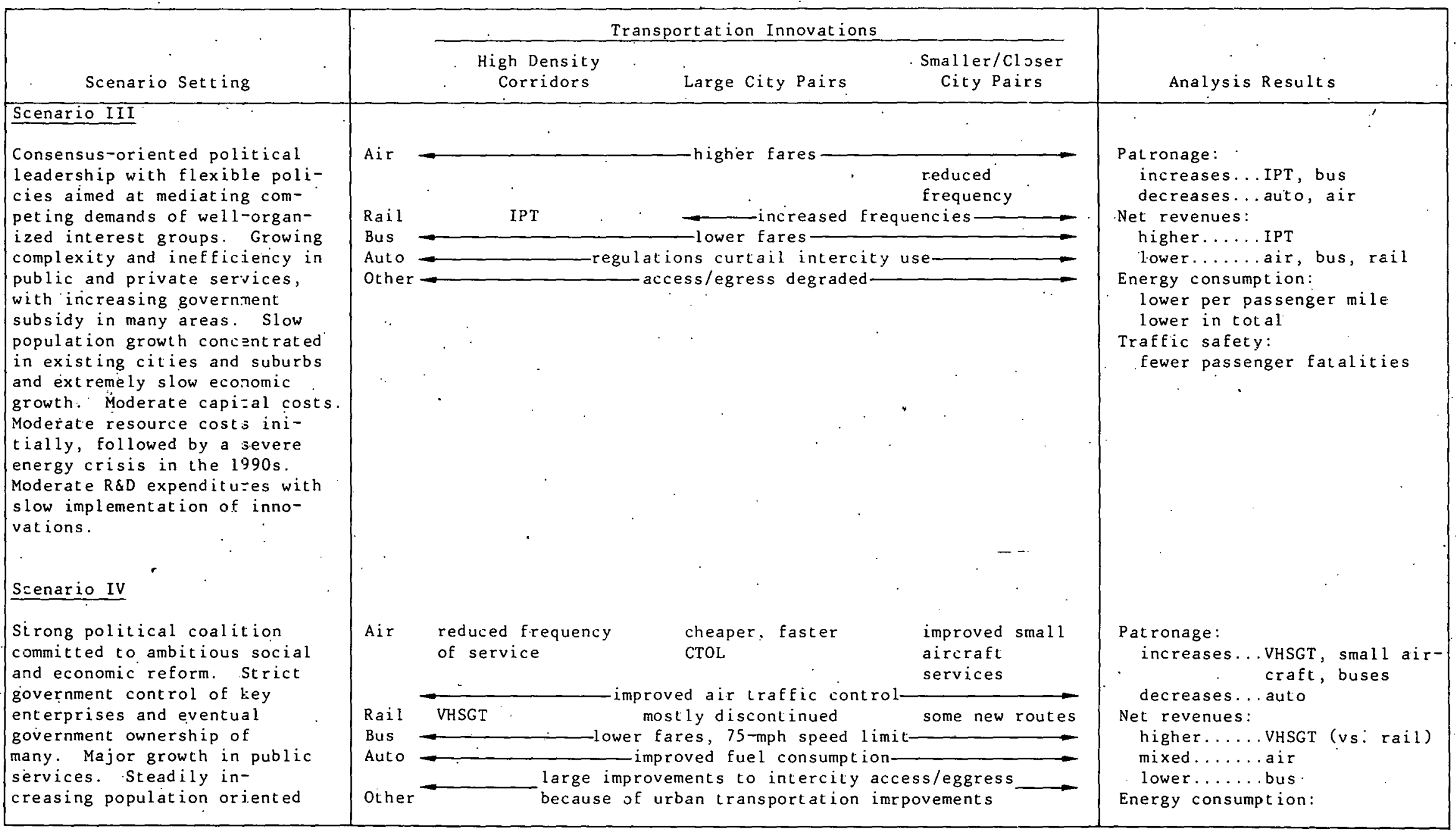


While considerable improvements in the air pollution and fuel consumption characteristics of gasoline-fueled internal combustion engines will occur in the next decade, full achievement of current environmental and energy goals may require transition to another engine technology before the $1990 \mathrm{~s}$. In the very long term, converting automobile transportation to an inexhaustible, nonpolluting energy source may lead to widespread use of electric autos, operating on electrified highways, employing energy generated by nuclear fusion, solar power, and similar sources. Among the impacts of introducing new automobile propulsion technologies are: costs and labor retraining impacts incurred by service stations and automobile maintenance and repair industries, major dislocation in the energy supply industry, possible mobility limitations on owners of obsolete automobiles late in the transition period, increased demand for and possible shortages of scarce materials, the major costs and environmental effects of highway construction and revision, a need for new highway funding mechanisms, difficulties in vehicle recycling due to new materials, and safety problems due to new materials and the increased heterogeneity of the vehicle fleet.

Long-term prospects seem favorable for introduction of automated highways and dual-mode vehicles that can operate under either automated or nonautomated control. Important impacts to be anticipated for this technological development are the large capital costs required for highway construction and revision; need for stringently controlled vehicle repair and maintenance practices to ensure fail-safe operation in the automatic mode, perhaps leading to increased centralization and automation in this industry; possible emergence of a new form of intracommunity private vehicle as a less-expensive, local-service alternative to rented dual-mode vehicles; increased population dispersal in a nucleated settlement pattern, with increased social stratification; and improved transportation service. to nondrivers through central compucer control of driver-less automated vehicles, this possibly leading to computer surveillance of all individual intercity.travel.

\section{High-Speed Ground Transportation}

A possible result of government efforts to promote use of improved passenger trains or very-high-speed ground transportation systems in dense travel corridors could be the restriction of short-haul air service whereever there has been a large public investment in high-speed ground transportation. Such a policy could significantly alleviate congestion at several major airports; however, the mobility of many travelers would certainly decrease, possibly giving rise to significant long-term population and employment relocations within the affected corridors.

Opposition to improved passenger rail transportation may arise from the rail freight industry, due to perceived interference with freight operations, and from the general public, on grounds that the system mainly benefits the suburban rich and business travelers. Also, major public investments in improved rail transportation may discourage private-sector investment in competing bus and short-haul aịr technologies.

Environmental costs of very-high-speed ground transportation (VHSGT) systems, particularly noise and neighborhood disruption, certain safety 
considerations, and probable community resistance to the new system, suggest that any future VHSGT guideway will have to be isolated from its environment, most probably through tunneling. Operating costs of an unisolated system, including high energy consumption, would probably be excessive. With current construction methods, the tunneling costs for such a system would probably be prohibitive.

Conventional VHSGT concepts require large distances between stations in order to achieve high average speeds, seriously reducing traveler access to the system and thus reducing potential patronage. Such considerations suggest that alternative VHSGT concepts should be considered, including network structures that permit skipping intermediate stops, and moving rendezvous techniques. The financial and operational feasibility of such concepts are questionable.

\section{General Considerations}

Financial resources alone probably do not completely eliminate any technology considered in this study from being implemented within the next 25 to 50 years. However, new funding mechanisms, particularly for ground transportation, will be required.

Difficulty of access to and egress from intercity transportation, and of transferring between modes, will probably continue to be the weakest link in intercity public transportation for some time. No solution is in sight. The problem is essentially local and institutional. Nationally designed, sweeping solutions would probably cause more financial and institutional problems than they would solve. One facet of the access/egress and transfer problem is the lack of adequate information available to travelers. Information deficiencies may be resolved partially by means of a federally coordinated traveler information system, but this proposal has serious problems with respect to cost allocation, responsibility for data management, and potential loss of local control over local transport and threats to individual privacy.

Advances in telecommunications may eliminate the need for certain types of transportation. Initially, new communications technology will primarily replace transport of documents and records. Eventually, restructuring of commercial activities may somewhat reduce business travel, inducing considerable population dispersal and increasing the future need for low-density, high-quality transportation, such as automated highways and small commercial aircraft.

Land use patterns that exist 50 years in the future will be affected significantly by the transportation systems that evolve in the interim. In the long run the effects of transportation systems on land use patterns (e.g., accessibility, land values, community impacts) are powerful and should be weighed carefully in decisions regarding major transportation research and investment programs.

Care must be taken to avoid the major economic losses that may occur due to the erratic public funding to which certain intercity transportation modes, such as VHSGT, are particularly vulnerable. Other incremental trans- 
portation technologies, such as electrified and automated highways and improved CTOL, are not as vulnerable to unanticipated fluctuations in public financial support.

In planning future intercity transportation technological development, certain technologies, because of high initial capital costs or perceived unrecoverable social benefits, are treated as "public commodities," and receive government funding for technology development, construction, and in some cases, operation. This state of affairs creates the potential problem that the separate tasks of technology promotion and technology evaluation can become intertwined, with the result that the government-supported technology may gain undue advantage over technologies able to function in the private sector.

Different intercity transportation technologies have varying implications for foreign trade and the U.S. balance of payments. Certain technologies -- such as improved conventional aircraft, an American SST, and improved automobiles -- would probably have worldwide markets. Ot.hers, such ao omall GTOL aircraft, way be particularly attractive to developing countries. Still others, such as VHSGT and automated highways, might have rather limited potential for export as whole systems, but individual components might become valuable export commodities.

\section{RECOMMENDATIONS}

Intercity Automobile Transportation. Pursue an expanded program of propulsion-system and vehicle-design development to improve fuel economy. Undertake a technology assessment of impending technological and institutional changes to the automobile:

Intercity Bus Service. Undertake case studies to identify and test ways to improve services and facilities and to better integrate bus services with those of other modes. Assess regulatory policies affecting bus operations, including ways to increase bus service to. small towns and rural areas.

Aircraft and Air Service. Continue basic research and technology development emphasizing measures to reduce aircraft cost, fuel consumption, and noise. Study mechanisms to hasten implementation of these developments. Continue to conduct systems analyses of changes in aircraft scheduling, routing, and operations, considering a range of future aircraft sizes and technologies. Investigate the possibilities of applying ongoing STOL aircraft technology efforts, to short-runway aircraft systems.

Airport and Air Traffic Control (ATC) Capacity Improvements. Undertake a study to resolve uncertainties regarding features of future generations of the ATC system (beyond the upgraded third-generation ATC system). Undertake a program of airport landside improvement research, coordinated with ongoing airside work. 
Rail (Fixed Guideway) Systems. Analyze the benefits and costs of existing AMTRAK services, on a route-by-route and systemwide basis in relation to other modes. Emphasize technology and systems evaluations of improved (high-speed) passenger train service in specific corridors. Also, conduct technical studies to address currently perceived negative characteristics of very-high-speed (tracked, levitated vehicle) systems, such as safety and noise.

Electric/Automated Highways. Develop technical and economic data on electric/automated highway system options. Undertake a systems study of identified options after technical data have been developed.

Access/Egress and Intermodal Transfer. Establish a continuing program of study of, and experimentation with, multimodal terminals.

Energy and Materials. Pursue a program of research and technology development for all modes to improve the fuel efficiency of intercity transportation vehicles. Continue research on new materials for transportation vehicles, with techniques for disposal and recycling of these materials as an integral concern.

Traveler Values and Preferences. Continue studies to develop improved information on traveler preferences, including the importance of comfort, convenience, and personal security relative to perceived cost and travel time. Determine the feasibility of an expanded and more detailed data base on intercity travel by city pairs.

Transportation Finance. Develop improved estimates of the short and long-term financing requirements of intercity transportation modes. Identify and evaluate funding mechanisms for transportation system maintenance and improvement that accommodate technology substitution and that use public funds to stimulate private investment.

Institutional Impacts. Develop methods to appraise the impacts of institutional forces ontechnology delivery (methods comparable to those used in preparing environmental impact statements).

Regulatory Controls. Develop improved techniques to analyze the effects of alternative economic, environmental, and safety regulations on levels of intercity service, transport industry structure, and technology development and implementation. 
COMMENTS

This study constitutes a first step toward outlining the possible implications of future intercity transportation and defining the direction of future research and technology development efforts. Most of its value lies in the potential impacts it points up, not in its predictions about the longrange character of the transportation network. Despite its long-range orientation, however, many of the study's recommendations focus on existing problems that are likely to persist and specify adapting existing technologies to meet future needs. 
REVITALIZATION OF SMALL COMMUNITIES: TRANSPORTATION

Mode: MULTIMODE OPTIONS (1974)

George Washington University for U.S. Department of Transportation

\section{EXECUTIVE SUMMARY}

The report summarizes the first year of an analytical study designed to assist in formulation of rural transportation policy. Hypotheses were: (1) the U.S. should preserve and revitalize rural towns as a means of future population redistribution and (2) transportation may provide the key to revitalization of rural towns. The study concluded that no policy aimed at reversing present population distribution trends is likely to succeed. Rural development will be a process of rural urbanization. National policy should selectively encourage smal1-town growth while maximizing societal benefits and minimizing societal costs of rural urbanization. Rural towns do and can serve several necessary functions, including future expansion of agriculture, but many will inevitably disappear. Transportation strategy should support existing growth patterns, prevent their disruption by fuel shortages and rising costs, provide access to necessary social and medical services, and assure a degree of personal mobility for those who cannot drive, including those left behind in declining communities.

\section{PURPOSE}

The report summarizes the first year of a policy analysis undertaken to assist in the formulation of rural transportation policy. The proposition to be investigated in this study was: assuming that the U.S. may in the future need to undertake a deliberate policy aimed at redistribution of its growing population, there should now be a national commitment to preserve and revitalize existing small towns (less than 50,000 population) in rural areas (specifically, small towns in counties, that are not part of a standard Metropolitan Statistical Area). A further hypothesis to be examined was that national transportation policies could provide the key to small-town revitalization.

\section{ASSUMPTIONS}

- Continuing concentration of growing population into a few metropolitan areas produces unmanageable diseconomies of scale, congestion, pollution, poverty, and crime.

- The continuing trend toward concentration can be reversed only through deliberate policy decisions and actions designed to attract and hold a large proportion of the U.S. population in nonmetropolitan areas.

- Existing small towns are a valuable resource that should be preserved to maintain this option -- they exist because they serve necessary economic functions, and their infrastructure and facilities are already in place. 
- Small towns in rural America are dying -- they are "places left behind," their youth migrating, their populations aging, their business districts stagnating under the competition of large cities and shopping centers made accessible by the interstate highway system.

- A national commitment should be made now to save small rural towns, especially those in imminent danger of decline and decay.

METHODOLOGY

The report presents an extensive investigation and development of four areas: the future of rural towns, the system of cities, the status of smal1-town transportation, and national options for the revitalization of small communities. The main themes associated with these areas are developed using various quantitative and qualitative analytical tonls. The patterno of growth and decline, population distribution, cultural integration, and residential choice are investigated. Simultaneously, transportation accessibility relative to city size is analyzed. Stratogies for improving small-tuwn transportation also are evaluated. Finally, national options for the revitalization of small communities are reviewed. The effects of factors such as carrier regulations; location incentives for employment activities, growth restrictions, direct transfer payments, and reduced political fragmentation are evaluated vis-a-vis the study objectives.

\section{CONCLUSIONS}

A national commitment to revitalize all small rural towns cannot be juslified on the basis of the necessity of guaranteeing an option for population redistribution. There is no evidence to indicate that there will or should be a major rhange in the current. pattern or U.S. pupularlon redistribution, and no deliherate policy aimed at reversing lie present crends is likely to. succeed. Therefore, the assessment group sought to identify the various economic and social functions that are or can be performed by small. rural towns and to develop policies that would encourage the selective performance of those functions while maximizing societal benefits and minimizing societal costs.

\section{COMMENTS}

This study has some strong analytical material that may become very' relevant as source data conrerning population digtributions wilh respect to transportation. 
A TECHNOLOGY ASSESSMENT OF TRANSPORTATION SYSTEM INVESTMENTS (1978)

Mode: MULTIMODE

Washington University for National Aeronatics and Space Administration

PURPOSE

The objective was to develop and document a technology assessment tool capable of evaluating the suitability of transportation investment sets over a variety of city sizes, land use patterns, and socioeconomic characteristics. Research attempted to develop and test a methodology that (1) presents a framework of analysis of the similarities and differences between metropolitan regions in the U.S. with respect to the characteristics relevant to their transportation needs and (2) identifies the optimal types of transportation technology that meet the needs of metropolitan regions.

\section{ASSUMPTIONS}

1. Technology assessment is a systems analysis approach to providing a conceptual framework, complete both in scope and time, for decisions regarding the appropriate use of transportation technologies.

2. Markovian decision theory (computerized model) can be used to analyze and evaluate the impact, benefits, and costs that will result from implementation of regional transportation technology alternatives.

- A system in state $j$ at time $n+1$ depends only on the previous state $i$, and not all previous states of the system from time zero.

- Final long-run steady-state probabilities are independent of the initial starting state.

- State transition probabilities are probabilities $p_{i j}$ of a system in state $i$ going to state $j$ in the next time interval.

- There is a finite set of states that may be occupied at any one time.

- Time interval spacing is assumed to constant; $p_{i j}$ measures are independent of time.

3. Regional transportation technology alternatives are formulated in relation to their potential for transportation service in the region and locale of available sites.

\section{METHODOLOGY}

San Francisco Bay Area Case Study

County population, labor force, and housing projections were used to define present and future states for the model. Transportation technology alternatives included: 
- Alternative I (status quo): BART, local buses; and express buses.

- Alternative II: BART, local buses, express buses, and car pool program.

- Alternative III: BART, local buses, express buses, car pool program, and demand-responsive transportation service.

- Alternative IV: BART, local buses, express buses, and personal rapid transit.

- Alternative V: Alternative I, plus high-intensity short-takeoff-andlanding (STOL) aircraft system.

- Alternative VI: BART, local buses, express buses, high-intensity STOL, and demand-responsive transportation.

Results of ranking alternatives by associated impacts revealed that Alternatives $V$ and VI supply desired levels of mobility with acceptable environmental and eilelgy. impacts.

St. Louis Metropolitan Area Case Study

Population density, nonresidential core floor space, nonresidential corridor floor space, regional value added, and total personal income were used to define present and future states. Three states of regional development were identified: ' core dominant, corridor dominant, and satellite communities. Core dominance reflects downtown revitalization, corridor dominance reflects controlled nonresidential growth along major corridors, and satellite city reflects balancing of regional dominance through several centers. Transportation technology alternatives included:

- Alternative I: highway-auto and bus transit.

- Alternative II: highway-auto, bus transit, and rail rapid transit.

- Alternative III: Alternative II, plus carpooling.

- Alternative IV: Alternative III, plus demand-responsive transit.

- Alternative V: Alternative III, plus personal rapid transit.

- Alternative VI: highway-auto, demand-responsive transit, bus transit, rail rapid transit, and STOL.

Results of impact ranking procedures show Alternative VI as optimal for growth rate state 1 (core dominant), due primarily to inherent energy savings and less environmental impact. Alternative $V$ was optimal for remaining growth states, due to its operational, pollution, and energy cost attributes.

\section{Louisville Metropolitan Area Case Study}

County projections of population, households, housing units, employment, and 1 and use were used to define growth states for the area. Transportation technology alternatives included: 
- Alternative I

19.1 miles of new freeway construction to four lanes. 5.2 miles of freeway widening from four to six lanes. 15.7 miles of freeway widening from four to eight lanes. 21.3 miles of freeway reconstruction of four lanes. $7.0 \mathrm{miles}$ of new arterial construction of four 1 anes. 20.3 miles of arterial widening from two to four lanes. 10.2 miles of bus transit express service.

- Alternătive II

9.9 miles of freeway widening from four to six lanes.

$3.5 \mathrm{miles}$ of freeway widening from four to eight lanes. 44 miles of bus transit express service.

4.9-mile downtown people-mover.

- Alternative III.

60.7 miles of rapid transit service.

7.5 miles of bus transit express service

4.9-mile downtown people-mover.

Demand-responsive transit service.

- Alternative IV

1.7 miles of freeway. widening from four to six lanes. $5.8 \mathrm{miles}$ of freeway widening from four to eight lanes. 13.5 miles of arterial widening from two to four 1 anes. 4.9-mile downtown people-mover. Demand-responsive transit service.

Results of Markovian analysis showed Alternative IV as optimal in growth states 1 and 3 , while Alternative III was optimal for growth state 2 .

\section{CONCLUSTONS}

A methodology using Markovian decision theory can capture aspects of uncertainty, time-sensitivity, and multidimensional impacts in transportation investments. The methodology can be used at a site-specific level or regional level and can utilize various levels of data. The Markovian approach has allowed both monetary and nonmonetary benefit and cost formulations to be developed in assessing the impact levels.

\section{RESEARCH NEEDS IDENTIFIED}

1. Further efforts to identify the dimensions of differentiation between metropolitan areas, by classifying them into homogeneous groups and identifying the most representative member, most likely using factor or cluster analysis.

2. Development of models using interactive graphics software for Markovian analysis of transportation planning alternatives. 
3. Testing of methodology on a national scale.

4. Further use of the Markovian approach to array and evalute broad urban policy investment decision. 
ENERGY, THE ECONOMY, AND MASS TRANSIT (1975)

Mode: MULTIMODE

U.S. Congress, Office of Technology Assessment

EXECUTIVE SUMMARY

Demand-oriented study, focusing on policies to shift urban travel from automobile to mass transit.

Environmental Implications: energy conservation and economic

System Coverage: road and rail

Network Coverage:

urban network

Process Coverage:

system operations and policy aspects

Environmental Implication: cultural effect of changes in land use and residential densities

This study, prompted by the energy and economic conditions produced by the 1974 oil embargo, seeks to identify national policies that will shift urban travel demand from the private automobile to mass transit, thereby conserving energy. It also explores the role mass transit could play in counteracting economic recessions or depressions. An incremental policy planning aproach is followed, and the study's time horizon is 1980 .

Policy options for promoting transit use and energy conservation are developed and needed institutional changes for implementing these options are recommended. Among the policy options considered are mass transit service improvements; capital investments in new and existing systems; direct economic incentives, such as fare reductions and fare elimination; indirect $t a x$ incentives; and automobile pricing and regulatory restrictions designed to induce shifts from automobile to transit. From the analysis of these alternatives, three transit policy packages are formulated and their impacts on transit. ridership and energy conservation are analyzed. Considerd as well in the study are long-term land use and economic growth policies. These policies, however, are treated summarily, inasmuch as the study focuses on shortterm solutions to energy and urban transportation problems.

PURPOSE

Prompted by energy and economic conditions created by the 1974 oil embargo, this study explores the historic trends in transit ridership, impact of different economic and energy conditions on transit patronage, role transit could play in offsetting economic recession or depression, and effectiveness of variuus transportation strategies in increasing transit use and conserving energy. A policy-oriented document, it is national in scope with some consideration given to experience of local transit operators and their ability to expand transit services in response to changing transit policies. The time horizon for study is 1980 , but the policy nature of the study makes its approach and findings valid so long as shifting travel from automobile to transit remains an effective energy conservation objective. 
APPROACH .

The study follows a five-step approach to determine the relationship of economic and energy conditions to the level of transit ridership and to pinpoint effective transit policies. An analysis of historic trends and government policies influencing transit and automobile use establishes the context for the study. From this emerges the central, guiding premise: energy conservation efforts must focus on the consumer of $98 \%$ of urban passenger transportation -- the automobile. Shifting travel from automobile to transit will conserve energy.

In the first step, a range of future economic and energy conditions are postulated, including:

\section{- Economic Conditions}

Reressinn: Unemployment averaging $0 \%$ fur 1975 and $6 \%$ for the rest of the 5-year period. Duration is 36 months from peak to peak of the business cycle (24-month decline, 12-month recovery).

Depression: Unemployment averaging $9 \%$ for $1975,11 \%$ for $1976,9 \%$ for 1977 , $6 \%$ for 1978 through 1980 . Duration is 48 months from peak to peak of the business cycle (30-month decline, 18-month recovery).

\section{- Energy Conditions}

Decrease-Mild: Decline in total oil consumption of 1 million bbl/day by January 1976. Some cuts in imports (cuts of 10-20\% of 1975 level of imports by January 1976). 1977-80 growth in oil consumption $3 \% /$ year.

Decrease-Moderate: Decline in total oil consumption of 3.million bbl/day by January 1977. Cut in imports equal to $60-70 \%$ of the 1975 level of imports by January 1977. 1978 growth in oil consumption: $1.5 \% /$ year.

Decrease-Severe: Decline in total oil consumption of 6 million bbl/day by January 1980 . Imports cut equal to $100 \%$ of the 1975 level.

The impact of these conditions is analyzed in the second step.

The third major step explores the abilities of the Urban Mass Transit Administration (UMTA) and local metropolitan operators to respond to changes in transit policies and programs. The management of the UMTA program is assessed to determine its capacity to accept new responsibilities. Also evaluated are metropolitan planning and financing and implementation capabilities, drawing on findings of a related study - Assessment of Community Planning for Mass Transit.

Policy options for promoting transit use and energy conservation are developed in the fourth step. Options considered include service improvements; capital investments in new and existing systems; direct economic incentives such as fare reductions and fare elimination; indirect tax incentives; and autowobile pricing and regulatory restrictions designed to encourage shifts from auto to transit. Some consideration also is given to longterm land use and economic growth policies. 
Policy alternatives are evaluated in the fifth phase, drawing on experience of communities that have implemented similar programs. Analysis involves preliminary comparison of effectiveness of alternative actions or combination of actions, with results providing the basis for weighing efficacy of policies.

Three transit policy packages are formulated and analyzed and their impacts on transit ridership and energy consumption are contrasted with the impacts of alternative economic and energy futures. Packages evaluated include:

- Maximum transit incentive policy specifying free-fare transit, a doubling of transit fleet by 1980 , and no significant auto restraints (i.e., the price of gasoline remains constant in real dollar terms).

- Maximum auto restraint policy specifying a $50 \%$ increase in gasoline prices, a $\$ 1.50 /$ day increase in commuter parking costs in employment areas well served by transit, and no significant transit improvements other than additions to transit fleet to accomodate $90 \%$ of ridership increases in peak period.

- Combination policy involving no-fare transit, a doubling of transit fleet by 1980 , a $50 \%$ increase in the real price of gasoline, and a $\$ 1.50 /$ day increase in the cost of commuter parking in employment areas well served by transit.

\section{METHODOLOGY}

The method of analysis varies, ranging from use of simple descriptive statistics and information acquired in interviews to use of more sophisticated tools such as regression analysis for predicting impact on transit ridership of assumed economic and energy futures, input/output analysis for estimating employment impacts of changes in transit policy, and logit modal split models for forecasting transit ridership response to major transit incentive and auto restraint actions. Most data are drawn from primary sources.

Two special studies are carried out as part of the overall research effort, both of which are characterized in the report as yielding rough but reasonable approximations. The first study seeks to determine energy and economic variables most closely correlated with past changes in transit ridership as a basis for predicting the impact on transit patronage of assumed economic and energy conditions. Two sets of national time series data are analyzed using a computer-based, stepwise regression technique.

The second study seeks to estimate the effect of transit incentive and auto restraint actions on transit ridership and automobile energy consumption. Estimates are made by approximating changes in time and cost of auto and transit travel for each action and then applying logit modal split models to gage impact of changes on different modes. 
CONCLUSIONS

Economic Effects of Transit Ridership. Economic changes induce only minor changes in transit ridership. Increase of $2.5 \%$ in unempioyment rate (i.e., from $5 \%$ to $7.5 \%$ ) would be accompanied by decline in transit ridership of $2 \%$ or less.

Capacity of Transit Industry to Respond to Major Changes in National Transit Program and Estimate of Employment Impacts. The transit industry could easily respond to a stepped-up transit program. Metropolitan transit operators indicate that manpower and supplies could be acquired for additional rolling stock. Approximately 80 individuals would be employed if production in transit increased by $\$ 1$ million.

Effect of Alternative Energy Conditions on Transit. Drivers el iminate discretionary trips rather than switching to transit for work and baoic shopping trips. With no growth in total vehicle miles traveled, transit ridership would increase by $3 \%$ annually. Transit ridership forecast to increase $10 \%$ between 1974 and 1976 with mild decrease in energy and $22 \%$ and $40 \%$ between 1974 and 1980 under moderate and severe conditions, respectively.

Increases in Transit Ridership and Decreases in Energy Consumption from Various Transit Incentive and Auto Restraint Actions. Actions that could have a major impact on transit ridership and/or energy consumption include reducing or eliminating fares, increasing transit vehicle fleet, increasing prices or reducing availability of gasoline, and increasing commuter parking charges.

Effect of Alternative Energy Conditions on Transit. A $50 \%$ increase in the price of gasoline would have the greatest impact on consumption, but would have little impact on transit, producing less than a $10 \%$ increase in ridership. A far greater increase in ridership would result from an auto restraint strategy -- a $\$ 1.50 /$ day increase in commuter parking fees in areas well served by transit. A combined strategy of transit incentives and auto restraints would promote energy conservation without lowering the efficiency of the transit fleet. Opportunities exist for funding transit from revenues generated by auto restraints.

POLICY RECOMMENDATIONS

Options within Framework of Current UMTA and Related Programs

- Increase statutory allocation to formula grant funds used for either capital or operating assistance.

- $\operatorname{Re} 1$ ax $12 \%$ ceiling on state participation in national funds since needs of several states exceed the limit. 
- For small urban areas, waive requirement that these areas demonstrate a continuous, comprehensive planning process.

- Waive public participation requirements and environmental impact statement (EIS) process for small-scale improvements.

- Grant UMTA the authority to waive EIS and public participation requirements during emergencies.

- Decentralize structure of UMTA by delegating certain decision making responsibility to Federal Highway Administration field personnel.

- Increase federal funding share on a project-by-project basis when local match is unavailable and project is deemed in the national interest.

- Encourage emergency energy conservation plans at the local level and updated transportation plans, focusing on solutions to current problems.

\section{Possible New Initiatives}

- Reduce or eliminate transit fares.

- Use gasoline taxes to support new transit initiatives.

- Use parking taxes to encourage shifts to transit.

- Significantly increase the level of transit operations.

- Change emphasis of highway program to construction of transit facilities and measures discouraging auto use and encouraging transit use.

Long-Run Considerations

- Make pattern of urban growth more conducive to transit use by encouraging development of clustered single-family dwellings.

\section{COMMENTS}

This study takes an incremental approach to energy problems, focusing on short-term solutions. Reflecting this approach are recommendations that emphasize institutional and program accomodation rather than technological advances. Some of the study's assumptions about energy costs are outdated. But existing conditions actually buttress its findings and recommendations. One shortcoming, perhaps a result of the study's broad policy approach, is its failure to fully probe certain equity issues; namely, who pays the cost of the recommended policies. 
ENERGY FROM THE WEST: POLICY ANALYSIS REPORT (SECTION 11: TRANSPORTATION) (1979)

Mode: MULTIMODE

University of Oklahoma for the U.S. Environmental Protection Agency

\section{EXECUTIVE SUMMARY}

Supply: cost-efficient means of energy materials transportation

Product Coverage:

Tuels

Network Coverage:

regional, impact on

western states

System Coverage:

rail, pipeline, highvoltage transmission lines

Environmental Class: aesthetic, economic, institutiunal
This study identifies and analyzes a broad range of consequences of energy resource development in the western states. It particularly focuses on the transportation of those resources to users, primarily in the East.

;

The study identifies four options to address the need for this increased transportation while minimizing the adverse environmental and socioeconomic effects. The alternatives are: (1) enhance coal-carrying capacity of railroads, (2) mitigate adverse impacts on unit trains, (3) promote coal slurry pipelines, and (4) minimize impacts of high-voltage transmission 1 ines. These policy alternatives are evaluated according to effectiveness, efficiency, equity, flexibility, and implementability. A comparison of the alternatives, particularly as far as effectiveness, was deemed not warranted due to their diversity.

R\&D opportunities are for improving grade crossing safety and rail traffic management, conservation of water in slurry pipelines, and increased effiriency of diroot-current transimissiun line research.

\section{PURPOSE}

This technology assessment identifies and analyzes a broad range of consequences of energy resource development in the western U.S. and evaluates and compares alternative courses of action for dealing with those consequences. The study examines the development of six energy resources (coal, geothermal, natural gas, oil, oil shale, and "ranium) in eight weetern otatcs (Arizona, Colorado, Montana, New Mexico, North Dakota, South Dakota, Utah, and Wyoming) during the period from 1979 to 2000. This abstract describes one chapter of the larger report, the section dealing with the transportation of energy resources from western suppliers to users in other parts of the country.

Since the 1973 OPEC oil embargo, the U.S. has turned to increased domestic energy producticn to reduce dependence on foreign oil. However, the demand for western energy resources largely comes from urban areas outside the West. To satisfy this demand, existing transportation facilities for raw resources (such as coal) and for converted energy forms (such as electri- 
city) will need to be expanded. Many. of the benefits associated with western energy are received outside the West, while the costs of expansion of energy transportation will be largely confined to the western states and other states along the transportation routes. Consequently, expansion of energy transportation networks raises difficult political issues and often involves opposition by land owners, local and state governments, environmental groups, and owners of competing transportation modes.

The final goal of the transportation chapter is to develop viable alternatives by which a policymaker could provide adequate capacity for transmitting energy resources produced in the West while minimizing undesirable environmental and socioeconomic impacts.

\section{APPROACH}

A systems diagram of the general conceptual framework used to structure this research effort is presented in Figure 3. This simplified diagram shows that when a technology is operated, it makes input demands ( $s$ uch as for capital, materials, and labor.) and produces outputs (such as electricity, air pollutants, and water pollutants). When these inputs and outputs interact with the conditions existing at the deployment site (such as ambient air quality, water availability, and the availability of community services and facilities) a range of impacts occurs (such as changes in air and water quality and a need for more housing). Some of these impacts are perceived as causing problems. When policy makers respond to these problems, they operate under a variety of constraints (such as legal, technical, and political) that affect the feasibility and acceptability of alternative policies and implementation strategies.

The tasks to be completed when this general conceptual framework is put into use can be divided into three categories: descriptive, interactive, and integrative. The tasks to be completed for each category are:

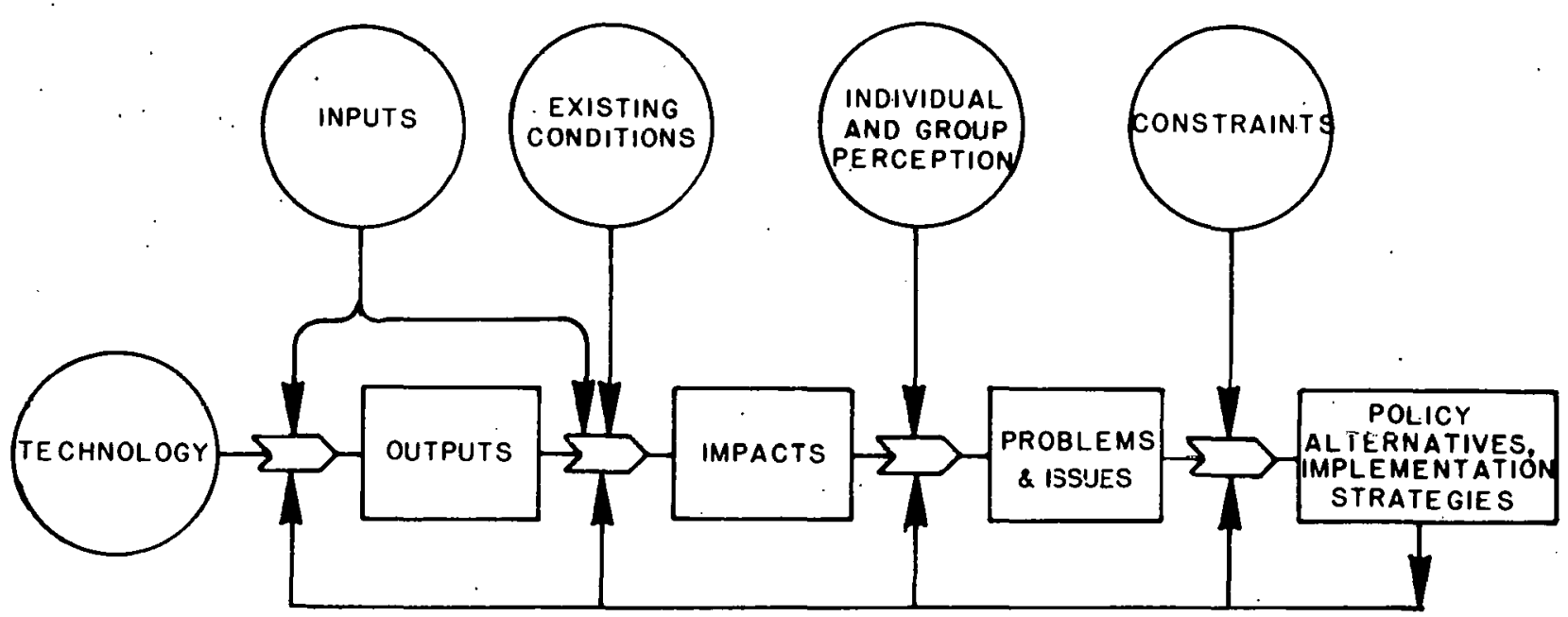

Fig. 3. General Conceptual Framework 
- Descriptive Phase: Identify and describe the technology. Describe the existing conditions

- Interactive Phase: Relate the technology to existing conditions. Identify and describe initial changes. Identify and define higher-order consequences.

- Integrative Phase: Identify and define problems and issues. Describe the policy context. Identify, evaluate, and compare alternative policies and implementation strategies.

\section{ME THODOLOGY}

An interdisciplinary core team approach was employed to implement the framework. All research team products were subject to an intensive critical review by the core team to produce a technically correct, comprehensive, and unbiased product. Each draft was then subjected to an extensive external review by an advisory committee, subcontractors, consultants, and a broad range of interested parties or stakeholders.

This process resulted in a list of viable policy alternatives, which were evaluated according to value, risk, and benefit. They were subsequently ranked according to the following criteria: effectiveness, efficiency, equity, flexibility, and implementability.

The study assumes a national energy production level of 124 quads by 2000 . Increased domestic production will be derived from increased use of coal. The study does not consider substantial increases in oil shale or synfuel production.

\section{FINDINGS}

The study identifies four policy alternativoe with which to address lie need for increased transportation of energy resources out of the West. The alternatives are: (1) enhance coal-carrying capacity of railroads, (2) mitigate adverse impacts on unit trains, (3) promote coal slurry pipelines, and (4) minimize the impacts of high-voltage transmission lines. These policy alternatives are summarized and evaluated in Tables 9 and 10. 
Table 9. Transportation Policy Alternatives

\begin{tabular}{|c|c|c|}
\hline Policy Objective & $\begin{array}{l}\text { Categories of } \\
\text { Alternatives }\end{array}$ & $\begin{array}{l}\text { Specific Policy } \\
\text { Alternative }\end{array}$ \\
\hline $\begin{array}{l}\text { Provide adequate capacity } \\
\text { for transporting energy } \\
\text { resources produced in the } \\
\text { West while minimizing un- } \\
\text { desirable environmental } \\
\text { and socioeconomic impacts }\end{array}$ & $\begin{array}{l}\text { Enhance coal } \\
\text { carrying capacity } \\
\text { of railroads }\end{array}$ & $\begin{array}{l}\text { Expand railroads in energy } \\
\text { areas of the West } \\
\text { Increase rail rates } \\
\text { Assure economic and regula- } \\
\text { tory stability }\end{array}$ \\
\hline & $\begin{array}{l}\text { Mitigate adverse } \\
\text { impacts of unit } \\
\text { trains }\end{array}$ & $\begin{array}{l}\text { Improve safety and mobility } \\
\text { for vehicles crossing rail } \\
\text { routes }\end{array}$ \\
\hline & & $\begin{array}{l}\text { Reduce train noise in com- } \\
\text { munities }\end{array}$ \\
\hline & $\begin{array}{l}\text { Promote coal } \\
\text { slurry pipelines }\end{array}$ & $\begin{array}{l}\text { Grant eminent domain to } \\
\text { coal slurry pipelines }\end{array}$ \\
\hline . & $\begin{array}{l}\text { Minimize impacts } \\
\text { of high-voltage } \\
\text { transmission } \\
\text { lines }\end{array}$ & $\begin{array}{l}\text { Limit voltage } \\
\text { Increase research on tech- } \\
\text { nological alternatives }\end{array}$ \\
\hline . & & $\begin{array}{l}\text { Institute interstate plan- } \\
\text { ning for transmission line } \\
\text { routes }\end{array}$ \\
\hline
\end{tabular}


Table 10. Summary Evaluation of Transportation Policy Alternatives

\begin{tabular}{|c|c|c|c|c|}
\hline Criteria & Enhance Rail Capacity & Mitigate Unit-Train Impacts & Coal Slurry Pipelines & Mitigate HVTL Impacts \\
\hline Effect iveness. & $\begin{array}{l}\text { May be required to finance } \\
\text { needed capacity expansion. } \\
\text { Risk of increased reliance } \\
\text { on railroads due to } \\
\text { strikes. }\end{array}$ & $\begin{array}{l}\text { Grade separations and rerouting } \\
\text { would help access. } \\
\text { Noise impacts will be difficult } \\
\text { to reduce without rerouting. } \\
\end{array}$ & $\begin{array}{l}\text { Sluries represent an } \\
\text { alternative coal } \\
\text { transport mode and } \\
\text { could al low increased } \\
\text { coal production. } \\
\text { Water use concerns } \\
\text { could still block } \\
\text { slurries. }\end{array}$ & $\begin{array}{l}\text { Impacts will be reduced } \\
\text { by all three options, } \\
\text { but no direct effects } \\
\text { on capacity are evi- } \\
\text { dent. } \\
\text { Increased RáD on DC } \\
\text { transmissions is } \\
\text { long-term option. }\end{array}$ \\
\hline $\begin{array}{l}\text { Efficiency } \\
\text { (Economic } \\
\text { costs and } \\
\text { benefits) }\end{array}$ & $\begin{array}{l}\text { Rates may rise or govern- } \\
\text { ment subsidies increase. } \\
\text { Financial stability to } \\
\text { railroads. } \\
\text { Employment benefits: } \\
\text { Capacity improvements } \\
\text { will ue dvailable for } \\
\text { lunethergy shippers. }\end{array}$ & $\begin{array}{l}\text { Cost of } \$ 750,000 \text { to } \$ 1.5 \\
\text { million per grade separation, } \\
\text { and } \$ 500,000 \text { per mile for new } \\
\text { track. } \\
\text { Town planning could improve. }\end{array}$ & $\begin{array}{l}\text { Slurry costs are } \\
\text { lower than rail. } \\
\text { Some state-level tax } \\
\text { benefits would re- } \\
\text { sult. } \\
\text { Railroads' finan- } \\
\text { iial strength will } \\
\text { be léssened. }\end{array}$ & $\begin{array}{l}\text { Voltage limits reduce } \\
\text { impacts, but with con- } \\
\text { siderable increase in } \\
\text { costs and land use. } \\
\text { Risk that increased RoD } \\
\text { on DC transmissinn may } \\
\text { not pay off. } \\
\text { Utilities, consumers, } \\
\text { and residents could } \\
\text { benefit from R\&D. } \\
\text { Dlanning piculutus } \\
\text { will be least expen- } \\
\text { sive. }\end{array}$ \\
\hline Equity & $\begin{array}{l}\text { Coal rates cuuld subsidize } \\
\text { other commodities. } \\
\text { Increased flexibility } \\
\text { could result in loss of } \\
\text { service for some. communi- } \\
\text { ties. }\end{array}$ & $\begin{array}{l}\text { State severance tax funding } \\
\text { would pass costs to energy } \\
\text { consumers. } \\
\text { Railroads would pay only } \\
\text { voluntarily. } \\
\text { Federal funding would be } \\
\text { most abundant for grade } \\
\text { separation construction. }\end{array}$ & $\begin{array}{l}\text { Rail profits may } \\
\text { decline. }\end{array}$ & $\begin{array}{l}\text { Benefits of luwer vol- } \\
\text { tage arcrue to those } \\
\text { in vicinity of HVTLs; } \\
\text { costs will be borne } \\
\text { by consumers. } \\
\text { Utilities may gain } \\
\text { more certainty from } \\
\text { interstate planning. }\end{array}$ \\
\hline Flexibllity & $\begin{array}{l}\text { Would help railroads' com- } \\
\text { petitiveness with other } \\
\text { modes. } \\
\text { Long-term contracts are in- } \\
\text { herently inflexible. } \\
\text { Subsidy programs are often } \\
\text { irreversible. }\end{array}$ & $\begin{array}{l}\text { State-level task force imple- } \\
\text { mentation is very flexible } \\
\text { because of local interests } \\
\text { represented. }\end{array}$ & $\begin{array}{l}\text { Slurties are a less } \\
\text { flexible transport } \\
\text { mode in routing and } \\
\text { commodity types. } \\
\text { federal legislation } \\
\text { would preempt state } \\
\text { decișions over emi- } \\
\text { nenr inmain }\end{array}$ & $\begin{array}{l}\text { Voltage regulation } \\
\text { would not be flexible. } \\
\text { Rod would increase op- } \\
\text { tions available for } \\
\text { HVrls. }\end{array}$ \\
\hline $\begin{array}{l}\text { Implement- } \\
\text { ability }\end{array}$ & $\begin{array}{l}\text { Subsidies are increasingly } \\
\text { unpouldr. and would be } \\
\text { resisted. } \\
\text { Rail abandonment would } \\
\text { be strongly resisted. }\end{array}$ & $\begin{array}{l}\text { State-level activities have } \\
\text { relatively few ubstacles, } \\
\text { but federal funding may be } \\
\text { harder to implement. }\end{array}$ & $\begin{array}{l}\text { Legal precedent exists } \\
\text { tor federal control. } \\
\text { Considerable opposi- } \\
\text { tion to slurries from } \\
\text { states, railroads, and } \\
\text { agriculture threatens } \\
\text { slurries as a widely- } \\
\text { used alternative. }\end{array}$ & $\begin{array}{l}\text { Utilities would opposc } \\
\text { voltage limits, but } \\
\text { would probably favor } \\
\text { increased Rob. } \\
\text { Consumer groups might } \\
\text { be opposed to voltage } \\
\text { limits because of } \\
\text { higher electric bills } \\
\text { that would be likely. }\end{array}$ \\
\hline
\end{tabular}



AND UTILITY CORRIDORS (1975)

U.S. Department of Interior, Bureau of Land Management

EXECUTIVE SUMMARY

Supply: facilitate transport of energy resources through wel1planned rights-of-way.

Systems Operations: various modes of energy transportation examined

System Coverage: road, rail, pipeline, highvoltage transmission lines -- regional, primarily western U.S.

Environmental Classes: aesthetic, economic, and environmental quality

R\&D Issues: develop data base for system of planning corridors
This study examines the necessity for and feasibility and desirability of establishing a national system of transportation and utility corridors: DOI projected a need for increased numbers of these rights-of-way in the near future and sought to determine how to mitigate the environmental and aesthetic impacts of such corridors. The focus of the study is on the western half of the U.S., which is almost $50 \%$ federal lands (the East is only $10 \%$ federal land).

Two types of transportation or utility corridors are studied, each representing the extremes of corridor design. A planning corridor is a broad strip of land connecting two geographic locations within which all future rights-of-way are to be located. A joint-use corridor is a narrow strip of land in which facilities of the same or different systems are. placed adjacent to each other in as close proximity as is technically feasible.

Five major transportation or utility systems requiring rights-of-way are identified and considered: electric power transmission lines, pipelines, communication lines, highways, and railroads.

The study found that establishing a system of joint-use corridors in advance of specific project proposals was not feasible. A national system of planning corridors, however, was found to be feasible, desirable, and needed. At the time of the study, however, there was an insufficient data base on which to determine where to establish such corridors.

PURPOSE

This study sought to determine if there is a need for a national system of transportation and utility corridors across federal lands and, if so, the feasibility of and best timing for developing such a system. The government's overriding policy objective was to- prevent the proliferation of separate rights-of-way across federal lands and to minimize the adverse environmental impacts of those corridors. 


\section{APPROACH}

Two types of transportation and utility corridors were considered, each representing the extremes of corridor design: planning corridors and joint-use corridors.

A planning corridor is a broad strip of land of variable width between two geographic points that has ecological, technical, or economic advantages over other adjacent areas for the location of rights-of-way anywhere within its boundaries. It assures opportunities for the location of future rightsof-way. Such corridors are a result of and dependent upon coordinated land use planning founded upon a data base that identifies existing resources, resource values, environmental values, and future transportation and utility needs.

A joint-use corridor is a narrow strip of 1 and with restricted boundaries in which facilities of the same or different systems are placed adjacent to each other in as close proximity as practical and feasible. Joint-use corridors are generally considered to be 500 feet to 1 mile in width, depending on the number and kinds of systems involved. The maximum width would be no more than that necessary for all systems to function with almost no interference between them. However, this width may not necessarily be the most desirable. The study found that optimum spacing between systems is determined by a complex set of interacting variables that must be quantified and analyzed, and trade-offs must be made before a specific joint-use decision can be reached.

Five major transportation or utility systems requiring rights-of-way were identified and considered in the study: electric power transmission lines, pipelines, communication lines, highways, and railroads. The study examined the ability of both planning and joint-use corridors to meet the right-of-way requirements of these five systems. Factors considered in the evaluation were: (1) environmental, i.e. surface disturbance, air and water quality, and visible and audible effects; (2) technical feasibility; (3) social and cultural considerations, i.e., alternative land use planning, resource development, industrial and utility plant siting, and community expansions; and (4). reliability and safety considerations.

The major emphasis of lle repurt is on the U.S. west of the louth meridian and Alaska. This area, exclusive of Alaska, consists of $47 \%$ federal lands, while the eastern U.S. contains less than $10 \%$ federal lands. Also, to assess the total impact of transportation or utility corridors across federal lands, those nonfederal lands intermingled with and surrounding the federal lands were included in the study.

METHODOLOGY

Findings and recommendations were based on three sources: empirical data gathered from various branches of government, technical reports completed specifically for this study by private consulting firms, and previously published data. Also considered were comments and contributions from federal, state, and local government agencies, industry, and public interest groups. 
SUMMARY OF FINDINGS

General Findings

The study determined that a national system of planning corridors. -developed in accordance with area-wide or regional land use plans that are coordinated among federal, state, and local governmental agencies, private industry, and the public -- is both feasible and desirable. There is a need for such planning corridors. on federal lands to minimize the environmental impacts of transportation and utility systems and to avoid proliferation of separate rights-of-way.

The study further determined that the establishment of a national system of joint-use corridors in advance of specific project proposals is not feasible. However, it may prove feasible to place portions of right-of-way systems in close proximity to each other once project design and site conditions are known. The study also revealed that the potential growth of electric transmission and pipeline systems in the western states will dictate the greatest future demands for rights-of-way across federal lands. Unless planned in a coordinated manner, these new pipelines and electric transmission lines could cause adverse environmental impacts.

Specific Findings

1. Uncoordinated locations of future rights-of-way across federal lands could result in the loss of natural resources within or adjacent to the rightsof-way and excessive or unnecessary environmental degradation.

2. A significant increase is expected in the next ten years only for electric transmission line and pipeline systems. The greatest impacts of these systems on federal lands will be in states west of the 100th meridian.

3. If systematic and coordinated planning is not implemented, significant proliferation of pipeline and electric transmission line rights-of-way could result across federal lands in the western United States because of the development of energy, resources.

4. Except for short connections between energy resource areas and existing systems, there is no substantial increase foreseen through 1985 for primary highway or railroad construction across federal land in states other than Alaska. There is no significant increase foreseen through 1985 for construction of underground communication and electric transmission lines across federal lands.

5. Each right-of-way system has specific minimum requirements for construction and operating space.

6. Joint use of rights-of-way is often both feasible and desirable. However, this determination depends on specific project evaluation -- each project and its requirements must be analyzed individually.

7. Electric transmission lines cause the greatest interference problems between systems in joint use of rights-of-way. 
8. Joint use generally results in a compromise location for rights-of-way, particularly when there is variation in origin and destination of systems. In some instances joint use may not result in the environmentally optimum location.

9. Establishing specific joint-use right-of-way areas across federal 1 ands could determine the location of rights-of-way across nonfederal lands with a resulting influence on individual property values. Planning corridors would provide the flexibility of alternate routes, thereby minimizing such effects.

10. Planning corridors would not negate the need for case-by-case project analyses. Due to 1 and management complexities and system interrelationships, 1 and management agencies must retain the flexibility to assess all alternative locations, both within and outside planning corridors.

11. Land use planning in coordination with future transportation and utility plannfing is' prerequisite to establishing planning corridors. Land use planning at local, state, and regional levels lacks coordination and uniformity as related to right-of-way locations.. Consistent land use planning is necessary to provide uniform considerations for right-of-way siting and management, especially in the preliminary and basic planning stages.

12. The amount of federal land available for future right-of-way needs is diminishing with the continuing designation of special management areas. Future linear right-of-way needs must be fully considered before any federal lands that would constrain right-of-way use are designated as special management areas.

13. Planning corridors can be established when an adequate information base (natural resources and their values) exists, future right-of-way noodo are known; and both are coordinated among federal, state, and local governmental agencies and industry.

\section{RECOMMENDATIONS}

The following recommendations are made based upon a determination of the need for a national ${ }^{-}$system of transportation and utility corridors across federal lands. These recommendations do not address specific corridor locations. The study recommends that:

1. Federal agencies be directed to identify a national system of planning corridors (as defined in this study) across federal lands. These corridors would be suitable for and remain open to future routing of transporcaiton and utility rights-of-way. Specific right-of-way locations (separate or joint-use) within these corridors must be determined for each project. The establishment of such planning corridors must be predicated on the development of an adequate information base containing data on resources, resource values, and environmental values, along with future transportation and utility development needs within the states west of the 100 th meridian. Development of this information base will require the following actions: 
- Federal land managing agencies must be authorized and directed to mutually develop, consistent with their resource planning system programs, an areawide or regional resource and environmental information base in cooperation with state and local governmental agencies in the West.

- Federal land managing agencies must be authorized and directed to mutually develop, consistent with their planning system programs, an areawide or regional evaluation of proposed or projected energy transmittal projects on and across federal lands in the West in cooperation with state agencies, public utilities, and private industry interests concerned with energy generation and transmittal.

This recommendation is based on findings $1,2,3,4,11,12$, and 13 (see preceding pages).

2. During the period in which the information base and evaluation of energy transmittal projects are being developed for lands in the western states, federal land managing agencies should be directed to grant individual. rights-of-way only after determining the feasibility and practicality of combining individual rights-of-way into joint-use corridors on or across federal lands (based on findings $5,6,7$, and 8 ).

3. Federal land managing agencies must retain flexibility to locate rightsof-way -- consistent with federal, state, and local land use and 1 and resource plans -- that will result in the least total impacts after full consideration of environmental, socioeconomic and product-delivery costs (based on findings $5,9,10$, and 12).

\section{COMMENTS}

Report is preliminary in nature. An insufficient data base prevents an analysis of how a federal agency might implement a national corridor network. 
TECHNOLOGY ASSESSMENT OF TELECOMMUNICATIONS/

TRANSPORTATION INTERACTION (1977)

Mode: MULTIMODE

SRI International for National Science Foundation

PURPOSE

The twofold purpose of this report was to (1) comprehensively identify and assess the physical, economic, social, environmental and quality-of-1ife impacts that might result from a shift in the interactions between telecommunications and transportation and (2) outline possible requirements for government policy intervention that might be needed to alleviate the harmful, and accentuate the beneficial, consequences of these interactions.

The final report was published in three volumes. Volume I, the main report, contains background, methodology, major findings, and policy analysis. Volume II for the most part consists of 24 relatively independent "impact papers," which analyze the transportation/telecommunications trade-off from a variety of viewpoints. Also included in Volume II are several appendixes containing background information and a bibilography containing 1090 references. A third volume covers the supply effects of different levels of transportation/telecommunications interactions and received only a small fraction of the total study effort. Only the first two volumes were selected for review.

\section{ASSUMPTIONS}

This study makes every effort to avoid performing sophisticated calculations using purely speculative data. Therefore, the main report and impact papers are supported by empirical data wherever possible. However, the futuristic nature and wide range of effects of the telecommunication field make certain assumptions necessary. Some of the as sumptions are as follows:

- Eight possible scenarios were selected for evaluation. Incorporated into each scenario are additional specific assumptions (see end of this section for scenario descriptions). Scenarios were restricted to areas where telecommunications affects business travel. All scenarios are considered achievable by the year 2000 .

- On the urban level, each scenario assumed a typical city of. roughly two million residents by the year 2000, whose central-business-district (CBD) employment was projected to grow by 50,000 jobs between 1975 and the year 2000 .

- Scenarios $D$ and $E$ assume that half of all office workers in the urban area would be working at home or in neighborhnod office centers by the year 2000. This involves about 250,000 office workers. In the 50 largest urbanized areas, one of five office jobs is located in the CBD:

- In the 50 largest urbanized areas, CBD office employment is expected to increase $80 \%$ by the year 2000 , and non-CBD office employment is expected to grow by $58 \%$. 
- One half of all commercial air and journey-to-work travel is made for the purpose of generating and exchanging information.

- The average American spends $10-15 \%$ of his/her waking hours traveling to and from work.

Three assumptions needed to support the scenarios are: (1) the variety of services and facilities that telecommunication systems can offer is rapidly increasing; (2) while some alternatives to travel, such as audio teleconferencing, are already cost-effective in many situations, others such as video teleconferencing and electronic message systems are at best only marginally competitive with existing practices; and (3) developments in telecommunications are rapidly, cutting the costs of key parts of the electronic communication system.

A selection process produced a set of eight scenarios, five urban and three intercity, with the characteristics described below. See Table 11 for a summary of telecommunications technologies relevant to these scenarios.

- Scenario A, the urban baseline, assumes that office employment in the CBD grows according to the forecasts of urban or regional planning agencies.

- Scenario B, based on a random decentralization theory, postulates that growth in CBD office employment is diverted to surburban office buildings located in a random, unstructured pattern throughout the urban area.

- Scenario C, which calls for the development of satellite centers, also hypothesizes that growth is diverted out of the CBD, but this time to several large office centers spaced in a relatively uniform pattern within the metropolitan area.

- Scenario D, a radical concept, assumes that neighborhood centers would be operated by several employers, each of whom would maintain office space in several such centers. An employee could work at the center closest. to home. Telecommunications would handle intraorganizational communications and replace paper flows.

- Scenario $E$ follows the pattern of authors, artists, consultants, and many musicians, who work at home. This scenario uses telecommunications to make this work pattern suitable for the typical office employee.

- Scenario $F$ is an intercity baseline scenario where the demand for intercity traffic continues to grow, uninfluenced by telecommunications.

- Scenario $G$ hypothesizes that telecommunications substitutes for $20 \%$ of all intercity business trips.

- Scenario $H$ assumes that telecommunications causes a $20 \%$ increase in business, trips above the level in Scenario $F$.

\section{METHODOLOGY}

The general approach to the study was based on concepts of system analyses. The world and its relevant subsystems were perceived as being perturbed by certain changes in the capability and use of telecommunications in a cause/effect fashion. These perturbations were determined by first identifying the affected subsystems (such as urban transportation) and then 
Table 11. Classification of Telecommunications Technologies Relevant to the Scenarios

\begin{tabular}{|c|c|c|c|}
\hline $\begin{array}{l}\text { Communi- } \\
\text { cations }\end{array}$ & $\begin{array}{l}\text { Form of } \\
\text { Signal }\end{array}$ & $\begin{array}{l}\text { Established } \\
\text { Services }\end{array}$ & $\begin{array}{c}\text { New } \\
\text { Services }\end{array}$ \\
\hline . & $\begin{array}{l}\text { Simple } \\
\text { code } \\
\text { signal }\end{array}$ & Radio paging & $\begin{array}{l}\text { Development of paging } \\
\text { devices }\end{array}$ \\
\hline . & Voice & $\begin{array}{l}\text { Standard tele- } \\
\text { phone service, } \\
\text { mobile radio, } \\
\text { and radiotele- } \\
\text { phone services }\end{array}$ & $\begin{array}{l}\text { Audio teleconferencing, } \\
\text { including loudspeaking } \\
\text { telephone (e.g., speaker- } \\
\text { phone) and multipoint. } \\
\text { telephone conferencing }\end{array}$ \\
\hline Person & & & \\
\hline $\begin{array}{c}\text { to } \\
\text { Person }\end{array}$ & $\begin{array}{l}\text { Moving } \\
\text { picture } \\
\text { visual }\end{array}$ & $\cdot \quad--$ & $\begin{array}{l}\text { Videotelephone (e.g., } \\
\text { Picturephone), video } \\
\text { teleconferencing }\end{array}$ \\
\hline ; & $\begin{array}{l}\text { Still- } \\
\text { image } \\
\text { visual }\end{array}$ & Facsimile & $\begin{array}{l}\text { Slow-scan video (e.g:, } \\
\text { for conference graphics), } \\
\text { facsimile }\end{array}$ \\
\hline . & Text & Telex/TWX & $\begin{array}{l}\text { Computer message/key- } \\
\text { board teleconferencing } \\
\text { systems, interconnec- } \\
\text { tion of word proces- } \\
\text { sing typewriters }\end{array}$ \\
\hline $\begin{array}{l}\text { Person } \\
\text { to }\end{array}$ & $\begin{array}{l}\text { Alpha- } \\
\text { numeric } \\
(\text { text })\end{array}$ & $\begin{array}{l}\text { Data links from } \\
\text { teletype or VDU } \\
\text { terminals to } \\
\text { multi-access. } \\
\text { computers }\end{array}$ & $\begin{array}{l}\text { Extensive use of compu- } \\
\text { ters for routine office } \\
\text { automation, including } \\
\text { text editing, informa- } \\
\text { tion storage and } \\
\text { retrieval. etc. }\end{array}$ \\
\hline Machine & $\begin{array}{l}\text { Computer } \\
\text { graphics }\end{array}$ & - & (1) \\
\hline . & Various & -- & $\begin{array}{l}\text { Telemetering and tele- } \\
\text { control or remote con- } \\
\text { trol of machines, } \\
\text { meter reading, etc }\end{array}$ \\
\hline $\begin{array}{l}\text { Machine } \\
\text { to } \\
\text { Machine }\end{array}$ & Digital & Data links & $\begin{array}{l}\text { Development of data } \\
\text { networks }\end{array}$ \\
\hline
\end{tabular}


the particular components affected (such as rail rapid transit). The bulk of the study effort then went into estimating or investigating as rigorously as possible the numerous cause/effect relations that were hypothesized. Within the systems context the procedure followed the major steps listed below:

1. Identify the basic interactions between telecommunications and travel that may result from, or be changed by, improvements in or innovative applications of telecommunications.

2. Describe scenarios that manifest these basic interactions or could result directly from them.

3. Systematically identify and analyze the benefits, costs, and effects of the scenarios, and the direct and indirect social, economic, and environmental changes they imply as accurately as possible with available resources, paying special attention to key areas of uncertainty.

4. Incorporate the results in a series of first-round impact papers.

5. Synthesize the first-round impact papers to highlight major effects and strengthen the analysis of cross-impacts between impact areas.

6. Evaluate the effects in terms of the basic threats and opportunities they imply for society.

7. Outline strategic and tactical policy options open to federal, state and local governments, and other policy activators toward each of the scenarios or their components.

In accomplishing step 2 , the eight scenarios were described in terms of three independent variables: (1) the degree to which telecommunications substitutes for face-to-face business meetings, (2) office location patterns within urban areas, and (3) colocation or dispersion of members of office working groups. In selecting the number and type of scenarios to be chosen, those scenarios that related to the location of workplaces received the highest priority. The indirect effects of telecommunications developments and the first-order effects of the scenarios were evaluated in step 3 by the construction of impact-interaction matrices.

\section{CONCLUSIONS}

\section{Teleconferencing and Business Travel}

- One of the few common themes in telecommunications literature is that business trips are most likely to be replaced by telecommunications. Telecommunications may also have possibilities in the fields of education, health, and regional shopping.

- There are more than 40 teleconferencing systems currently in operation.

- It is commonly thought that two-way video is needed for successful teleconferencing, but research has shown that audio, graphic, and computer systems that can use existing telephone circuits (narrow band) can effectively substitute for about $45 \%$ of all business trips to meetings, whereas video adds only $8 \%$ more substitution possibilities. Widespread narrow-band teleconferencing appears feasible in the near future at prices that usually would be far below the cost of physical travel. 
- The key factors limiting widespread teleconferencing appear to be its novelty, coupled with the inertia of habit, travel policy, and market development.

- If latent demand for travel greatly exceeds available time and budget, the replacement of some trips by teleconferencing will simply. fxee time and budget to satisfy latent demand for more travel.

- Reducing total business air travel 20\% would save about 50,000 barrels of jet fuel per day. Substituting teleconferencing for $20 \%$ of all business travel by auto would save 80,000 barrels of gasoline per day.

- Substituting teleconferencing for trips by a few executives might lead to office relocations that would affect all employees.

\section{Office Relocation}

- Low- or zero-growth CBD scenarios would reduce patronage on rapid rail transit systems and jeopardize center-city fiscal and redevelopment plans.

- Preliminary analyses showed that providing new rapid rail and freeway systems for the 1.9 million additional CBD office workers expected by the year 2000 in cities that do not have rapid rail would cost roughly $\$ 30$ billion, whereas diverting the workers to suburbs and using existing freeways would cost only $\$ 3$ billion. Decentralization to the suburbs would generally reduce the average commute time by one-third to two-thirds.

- From transportation, accessibility, and energy perspectives, satellite centers located in the inner suburbs on major transportation routes appear to be the best location. for future office employment, unless "telework" becomes feasible.

Neighborhood Office Centers and Work at Home (Telework)

- There is little incentive for employers to provide telework equipment, because they do not internalize commuting costs, unless employees trade a reduction in commuting for lower salary.

- Since individual commuting time is valued at roughly $\$ 4.50 /$ hour, the 7.6 billion person-hours spent commuting by office workers in 1975 is conceivably valued at $\$ 34$ billion.

- The neighborhood office center concept could save roughly 238,000 barrels of gasoline per day in 1985; the work-at-home scenariu could anc 320,000 barrels per day. The FEA estimates that a capital investment of $\$ 8.6$ billion in conservation technology would be justified by every 100,000 barrels per day saved.

- Roughly $\$ 30$ billion in otherwise necessary frepway expansions might be saved if all new office workers expected in the 50 largest U.S. cities by the year 2000 (12.million employees) adopted telework rather than commuting to $C B D$ and non-CBD offices by freeway. If rapid rail were used to accommodate $C B D$ growth rather than freeways, the savings potential would be roughly $\$ 47$ billion. 
Changes Resulting from Scenarios

- Shift in communications demand from transportation to telecommunications ... change communications from a batch process to a more continuous process ... more communications will take place.

- Increased locational freedom for organizations and individuals ... greater separation of business and social relationships ... synergy with office automation, on-line documentation, and improved communications within organizations.

\section{Potential Threats Resulting from Scenarios}

- Threat to rapid rail transit ridership ... danger to center-city finances ... loss of office and office-related jobs for center-city residents ... miscellaneous economic dislocations ... increased economic concentration by a few firms.

- Depersonalization of relationships ... loss of travel experiences ... reduced social integration ... reduced identification with employer ... intrusion and loss of privacy.

- Increased pace of affairs ... overspecialization of labor and organization ... increased centralization of power because of better supervision ... proximity to top management and the formation of cliques ... telework inequities since all may not be served equally ... exportation of office employment.

- Abandonment of cities ... déspoilment of rural and resort areas.

- System vulnerability to breakdown ... system evolvability and adaptability.

Potential Opportunities Resulting from Scenarios

- Energy conservation ... allow jobs to be located freely ... reduce commuting ... reduce unwanted business travel ... reduce the need for forced residential relocations associated with changing jobs ... facilitate lifestyles based on the locational and schedule freedom afforded by telework ... provide new flexibility in urban land use planning ... expand uses of CBD land ... support suburban areas during acute fuel shortage ... reduce the need to invest in SST, VSTOL, and new airport development.

- Improve productivity in the office or information sector of the economy through enhancing communications between organizations and between units of physically decentralized organizations ... facilitate new ways of communicating information and structuring organizations ... ease the capital formation lag ... national emergency teleconferencing network.

- Commuting costs are not internalized by organizations, thereby giving them little incentive to reduce commuting ... formal salary scales that would prevent managers from offering lower salaries to teleworkers to offset communications costs could inhibit telework ... telework and teleconferencing are still novel ideas, although researchers see the awareness level rising rapidly ... teleconferencing technology is still in the one-of-akind stage: its cost is high and design improvements are still needed ... 
there is a widespread myth that video is necessary, and the high cost of video discourages further inquiries into narrow-band teleconferencing by potential user organizations ... it is difficult to implement a sufficiently large network to make teleconferencing broadly attractive; user demand for a system with few connections is. low, and suppliers are reluctant to risk creating a large network without proven demand.

- For one employee to work remotely, it may be necessary to provide teleconferencing terminals for all those with whom he or she communicates, as well as to replace a large portion of the organization's paper flow by electronic substitutes (i.e., office automation). This barrier may be avoided. in certain situations, but for wide-scale implementation of telework the entire organization probably must shift to electronically based communication. If telework benefits cannot justify the cost, then telework may become feasible only when office automation technologies replace paper-based information for other reasons, such as productivity.

- Different policies, budgets, and cost-accounting practices within organization for telecommunications versus travel may inhibit substitution ... contracting practices where direct travel costs are recovered but telecommunications contribute to overhead may reduce the incentive to lower travel costs.

Policy Implications

Substitution could be encouraged by three broad types of policy: (1) reduce the attractiveness of travel resulting from the development and subsidy of transportation, (2) encourage the development of telecommunications alternatives through financial assistance or regulatory policy, and/or (3) ensure that businesses are fully informed of the capabilities of telecommunications.

Five possible government policy options are: (1) strongly encourage a particular outcome or scenario, (2) continue present policy of little study in the field of telecommunications, (3) reduce or eliminate government influence on market choice, (4) laissez-faire with protective government constraints, or (5) laissez-faire but the government encourages new options. The assessment states that, since none of the scenarios or strategic options are both clearly preferable and politically realistic, another avenue must be taken. Some process must be started that will eventually lead to consensus on one or a suitable mixture of strategic policies. An appropriate process is a widespread consideration of possible changes in the telecommunications/transportation tradeoff and a continuing debate about their implications, benefits, and disbenefits. Therefore, the study recommends the creation of a "division" within some appropriate agency to serve as a focal point within government for information about new ways that telecommunications could be exploited for the general welfare and for investigating and monitoring the diffuse, long-term threats that may accompany them: The study also suggests starting a broad debate or discussion in planning circles about the possible scenarios, threats, and opportunities outlined in the report. 
COMMENTS

The principal value of the study lies at two levels. At the policy level, it offers tentative conclusions about impacts and makes policy recommendations for action or further study. At the staff or research level, it assembles a great deal of background information and provides several detailed systematic analyses on which technical readers can draw to meet their particular needs. 
CHANGES IN THE FUTURE USE AND CHARACTERISTICS OF THE AUTOMOBILE TRANSPORTATION SYSTEM (1979)

Mode: Ḣ HGHWAY

U.S. Congress, office of Technology Assessment

PURPOSE

This study, authorized in February 1976, assessed factors influencing the automobile system in the near term (1985) and long term (2000 and beyond). Issues were examined in five related areas: energy, environment, safety, mobility, and cost and capital.

\section{AGSUMFTIONS}

The "base case" projects auto system characteristics and use assuming that present federal policies and programs continue. It is not a most probable future, but a no-policy-change baseline. Major assumptions are listed in Tables 12-14. Other assumptions are 1 isted below:

- Trend toward urbanization will continue.. number of households will increase but household size will decline ... productivity of labor force will return to $3 \%$ annual rate of increase for $1985-199.0$.. GNP growth rate of $3.5 \%$.

Table 12. Summary of Base Case Assumptions (constant 1975 dollars)

\begin{tabular}{|c|c|c|c|}
\hline Characteristic & 1975 & 1985 & 2000 \\
\hline $\begin{array}{l}\text { Demographic } \\
\text { Population (millions) } \\
\text { Licensed drivers (millions) }\end{array}$ & $\begin{array}{l}214 \\
130\end{array}$ & $\begin{array}{l}233 \\
151\end{array}$ & $\begin{array}{l}250 \\
177\end{array}$ \\
\hline $\begin{array}{l}\text { Economic } \\
\text { GNP }\left(\$ 10^{12}\right) \\
\text { Disposable personal income per capita }\left(\$ 10^{3}\right) \\
\text { World oil price }(\$ / \mathrm{bb} 1) \\
\text { Gasoline price }(\$ / g a 1)\end{array}$ & $\begin{array}{r}1.52 \\
5.03 \\
13.00 \\
56\end{array}$ & $\begin{array}{r}2.22 \\
6.72 \\
16.50 \\
77\end{array}$ & $\begin{array}{r}3.72 \\
10.07 \\
25.60 \\
121\end{array}$ \\
\hline $\begin{array}{l}\text { Policy } \\
\text { Fue } 1 \text { ecunumy (mpg) } \\
\text { new cars auto. fleet } \\
\text { auto fleet. }\end{array}$ & $\begin{array}{c}-- \\
13.5\end{array}$ & $\begin{array}{l}27.5 \\
19.4\end{array}$ & $\begin{array}{l}27.5 \\
24.6\end{array}$ \\
\hline $\begin{array}{l}\left.\text { New car emission standards ( } \mathrm{CO}, \mathrm{HC}, \mathrm{NO}_{\mathbf{x}}\right) \\
\text { Highway funding - all gov't levels }\left(\$ 10^{9}\right) \\
\text { capital } \\
\text { maintenance } \\
\text { total } \\
\text { Transit funding - all gov't levels }\left(\$ 10^{9}\right)\end{array}$ & $\begin{array}{l}14.3 \\
13.9 \\
28.2 \\
3.22\end{array}$ & $\begin{array}{l}11.2 \\
17.0 \\
28.2 \\
5.34\end{array}$ & $\begin{array}{r}7.0 \\
21.2 \\
28.2 \\
7.54\end{array}$ \\
\hline
\end{tabular}


Table 13. Alternative Assumptions for BaseCase Fuel Economy Standards

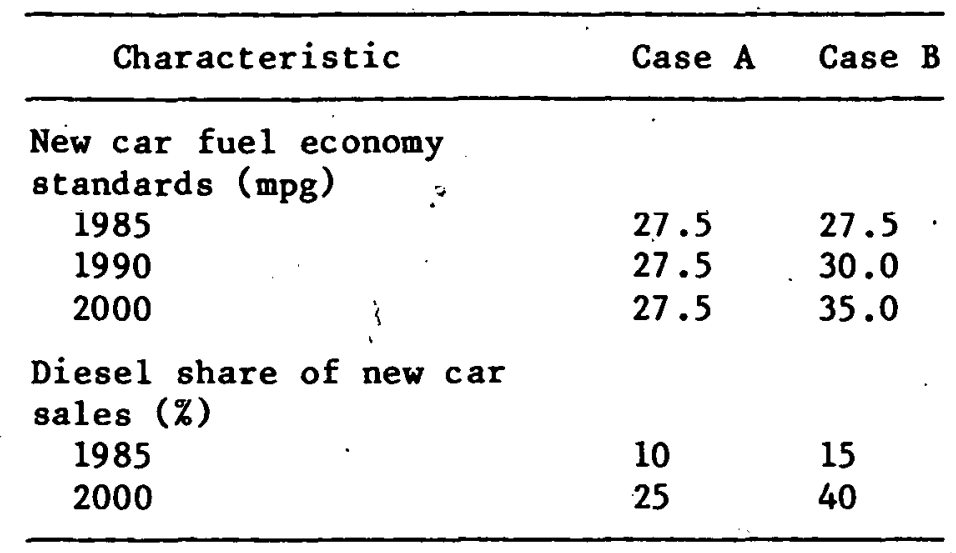

Table 14. Assumed U.S. Petroleum Demand $\left(10^{6} \mathrm{bbl} / \mathrm{day}\right)$

\begin{tabular}{|c|c|c|c|}
\hline Sector & 1975 & 1985 & 2000 \\
\hline Auto & 5.2 & $\cdot 4.8$ & 4.8 \\
\hline Truck & 1.9 & 2.6 & 3.9 \\
\hline Rail, air, water & 2.1 & 2.9 & 3.9 \\
\hline Industrial & 3.2 & 5.6 & 6.1 \\
\hline Residential, commercial & 3.5 & 2.7 & 3.1 \\
\hline Electrical & 2.6 & 2.5 & 0.6 \\
\hline Total & 17.5 & 20.1 & $22.4^{\mathrm{a}}$ \\
\hline
\end{tabular}

- No new engines will achieve extensive commercialization by 2000 although diesels represent $25 \%$ of sales in 2000 . Improvements to occur in sparkignition engines.

- No significant change in highway construction and design ... buses remain backbone of public transportation ... no technology breakthrough assumed for electric vehicles.

- Petroleum assumed to be main source of automotive fuel ... transition to alternate fuels will not occur as result of federal subsidy of production ... federal government will continue to control the price of gasoline ... no gas-guzzler tax ... no oil embargo or abrupt interruption of supply ... no change in enforcement of $55-\mathrm{mph}$ speed limit.

- Smaller cars will represent increasingly greater share of the fleet ... fuel.economy of small trucks will remain unregulated ... no significant improvements in fuel efficiency of large trucks. 
- Petroleum consumption by nonhighway transportation modes will increase due to expansion of the economy ... use of oil by industry will grow with economy due to inability to expand natural gas supplies.

- Auto emissions expected to decline from current levels by 1985 and further still by 2000 (except nitrogen oxides, which rise slightly due to diesels) ... new-car emission standards for 1981 remain in force until 2000 except for nitrogen oxides waiver from $1.0 \mathrm{~g} / \mathrm{mi}$ to $1.5 \mathrm{~g} / \mathrm{mi}$ for $1981-83$ to allow for improvement in diesel emission control technology .... emission control devices deteriorate at rate EPA estimated in January 1978.

- All cars equipped with passive restraints after 1984 ... current highway safety programs continue at present funding.

- Highway Trust Fund and other financing mechanisms continue in their present form ... no new sources of transit funding within the highway program ... taxes on gasoline and diesel fuel will have to incresse in order to maintain reserves at their present level.

- Annual VMT growth over 25-year period is $2.3 \%$ annually (considerably lower than $3.8 \%$ annual growth rate during 1960-75) ... the expected $60 \%$ increase in VMT on rural roads does not reduce average speed since the roads operate below capacity today ... urban congestion will increase with decrease in average daily speeds and increase in duration of peak periods.

- New-car prices expected to increase slightly in real terms but be offset by improved economy of operation ... imports will represent $18 \%$ of domestic auto sales, 1978-2000.

METHODOLOGY

The assessment considered policies to deal with the five groups of issues: - energy, environment, safety, mobility, and cost and capital. SRI, one of the contributors to the study, was directed to use a relevance tree approach to policy selection. Individual policies were identified in each of the issue areas, except safety, for further treatment in the assessment. SYDEC (System Design Concepts), another contributor, was directed to take a more comprehensive approach to the definition of policy packages that address several concerns simultaneously, although each policy has a major thrust. The four policy packages are: petroleum conservation, improved environment, increased mobility, and improved accessibility.

CONCLUSIONS

Energy

Automobiles use about $5 \times 10^{6} \mathrm{bbl} / \mathrm{day}$ of petroleum or $30 \%$ of total. More-efficient designs and smaller cars lead to decline in petroleum consumption under base case. By 2000 autos use $4.2-4.8 \times 10^{6} \mathrm{bbl} / \mathrm{day}$ or $20 \%$ of total. This reduction is more substantial than it appears since auto travel increases by $75 \%$ at the same time. 
Present Policies

- Energy Policy and Conservation Act - mandates new-car fuel-economy standards and promotes carpools, vanpools, right-turn-on-red laws, and transportation system management.

- Nationwide 55-mph speed limit - lack of enforcement remains a major deficiency.

- Emergency Petroleum Allocation Act - provides President with authority to allocate petroleum and set price controls in emergency.

- Electric and Hybrid Vehicle Act - to foster EHVs as alternative and demonstration program of 7,500-10,000 vehicles by 1984 .

- Advanced automotive technology and synthetic fuel development - DOE programs inherited from EPA, development of Stirling engine and gas turbine engine and pilot plants for production of synthetic fuels from oil shale and coal. For perspective it should be noted that a shortfall of only $10 \%$ would limit consumption more severely than all the conservation and curtailment policies normally considered.

Effects of Petroleum Conservation Alternative

- Higher fuel-economy standards - to $35 \mathrm{mpg}$ by year 2000 would save about $600,000 \mathrm{bbl} /$ day compared to base case.

- Higher gas taxes - gradual increments have little effect, $25 \%$ VMT reduction would require real price of gasoline to be four times higher than in base case. A tax could spur production and sale of alternative fuels.

- Free-market pricing - deregulation would allow market forces to allocate limited supplies of petroleum. Could result in substantial decrease in economic growth and hardships on low-income, auto-dependent people, but should increase alternative fuel production.

- Rationing - reasonably equitable short-term policy for substantial and predictable petroleum conservation, but 1 imited long-term value. If burden fell equally on all sectors, total automotive consumption would be 1 imited to $3 \times 106 \mathrm{bbl} / \mathrm{day}$ in 2000; allocation of $6 \mathrm{gal} /$ week per car compared to base case of $9.6 \mathrm{gal} /$ week in 2000 and present usage of $15 \mathrm{gal} /$ week.

- Transition to alternative energy sources - estimates are inherently speculative and include synthetic liquid fuels, alcohol fuels, electricity, and longer-term alternatives such as hydrogen or fuel cells.

Environment

Environmental problems created by widespread use of automobiles include air pollution, noise, disposal of scrap vehicles, and water contamination, but air pollution is considered most important. Much of present federal policy is regulatory and directed toward particular automobile performance characteristics. In the base case, even though auto travel increases $75 \%$, carbon monoxide and hydrocarbon auto emissions are reduced $60 \%$ and nitrogen oxides emissions decline about $30 \%$ from present levels. The frequency of violations of air quality standards will decrease, although in 2000 about $10 \%$ of the 247 Air Quality Control Regions are expected to violate the carbon monoxide standard and $25 \%$ to excede the photochemical oxidant standard. While autos 
are not the only contributors to these problems, they are a significant source. Effects of policy alternatives are listed below.

- Further tightening of new-car nitrogen oxides ( $\mathrm{NO}_{\mathbf{x}}$ ) emission standards - in base case, $\mathrm{NO}_{\mathbf{x}}$ emissions will be the major future air quality problem. Lowering emission standard to $0.4 \mathrm{~g} / \mathrm{mi}$ could reduce national $\mathrm{NO}_{\mathrm{x}}$ emissions from 2.9 to 2.2 million tons/year by 2000 . However, greater potential exists in controlling stationary sources and at a lower cost per ton removed. A lower $\mathrm{NO}_{x}$ standard could preclude diesel cars and increase hydrocarbon emissions by $3 \%$ compared to the base case.

- Mandatory inspection and maintenance appears to have great potential; however, the magnitude of projected benefits depends heavily on estimates of the rapid deterioration rates of emission control devices. Using the latest EPA deterioration rates, an inspection and maintenance program could reduce auto emissions of carbon monoxide by $65 \%$ and hydrocarbons hy $40 \%$ compared to the base case in. 2000.

- Control of auto use in specific locations - policies to reduce auto travel are expected to have small, but beneficial, effects on all types of pollutiants. Auto-use disincentives could reduce urban VMT by $6 \%$ in 2000 .

Safety.

The current annual toll of motor vehicle accidents is almost 48,000 deaths, over 4 million injuries, and an estimated cost of $\$ 44$ billion. (Since $1900 ; 2$ million persons have died in motor vehicle accidents - more than 3 times the combat losses suffered by the U.S. in all wars). Present policy is most affected by the National Traffic and Motor Vehicle Safety Act of 1966 , which involves federal safety standards for new vehicles, safety-defect recall campaigns, and state and local highway safety program assistance.

'The most effective near-term ( $5-10$ years) safety options are increased use of seat belts, strict enforcement of 55 -mph speed limit, and reduction of alcohol use associated with driving. For a higher level of safety, long-range plans should include improved auto crash-worthiness, improved occupantrestraint systems, and improved vehicle designs to mitigate pedestrian injuries. - Highway improvements, primarily elimination of roadside hazards, appear to be cost-effective.

Mobility

Betwecn 1975 and 2000 , the U.3. pupulaliun will Increase by $20 \%$, urbanization will continue, licensed drivers will increase by $36 \%$, there will be $56 \%$ more cars on the road, and VMT will grow by $75 \%$. New highway construction will taper off and travel times, particularly in urban areas, will increase where average speeds will be 10-15\% slower and motorists will encounter congested conditions up to three times more often. Policy alternatives to increase mobility are listed below.

- Enlarge the highway system - This would (1) require $\$ 20$ billion in annual construction expenditures by 2000 instead of $\$ 7$ billion in the base 
case and (2) maintain 1975 travel speeds and increase VMT by $6 \%$ over the base case.

- Expand public transportation through federal capital assistance double the base case levels and operating assistance five times greater. This would increase transit ridership only slightly above base case levels. Improved service to poor, young, elderly, and handicapped.

- Transportation system management - Funding is not yet institutionalized but is scattered for this short-term element of transportation planning. Only 1 imited transportation system management can be carried out in a given area without the management program itself becoming capital intensive.

- Paratransit (ride sharing, special bus systems) and advanced transit technologies (automated guideway, new heavy rail systems) are expected to have limited application or effectiveness in auto diversion.

- Restricted auto travel - Attempts to restrict auto use have been regarded as 1 imiting mobility, but it is now recognized that unrestrained auto travel may conflict with other national goals. Reexamination of effectiveness and impacts of auto-use disincentive policies is necessary.

- Improved accessibility policies, primarily to encourage higher land use densities and high-accessibility corridors, could begin to take effect in 10 years, but effects would not fully emerge for perhaps 50 years.

Costs and Capital

Costs include direct private cost of owning and operating a car, indirect costs of street and highway systems, and social costs borne by user and nonuser alike. Policy options for public funding of highways (proponent view) are 1 isted below.

- Continuation of highway trust fund provides funding for and assurance of . long-term federal commitment to national highway system. Promotes economic efficiency because users pay directly or indirectly.

- Financing from general funds increases flexibility in funding alternative transportation modes. Highway programs would be brought under. normal Congressional budgetary process and would have to compete with other federally aided programs.

- Transportation trust fund - Modal decisions could be based on a comparative cost-benefit analysis.

- Trust fund for each mode - Rationale is the same as for highway trust fund, i.e., other modes have long-term development and construction requirements and need trust fund mechanisms.

Federal funds may be required for highway maintenance since roads are deteriorating twice as fast as they are being repaired. The automobile industry's need for capital investment to meet government standards and changes in consumer demand will increase the sales volume required by each 
firm to realize a profit. Ford and General Motors are conservatively financed and would have many options while others would find it difficult to raise funds in the open market.

Conclusions regarding the private costs of automobile use can be summarized as follows:

Base Case

$20004-5 \%$ increase over 1985 due to gasoline price

Petroleum Conservation Case

$19853 \%$ above 1985 base case due to gasoline price

$20004 \%$ above 2000 base case due to gasoline price

Improved Envirnnment Case

$19855 \%$ above 1985 base case due to gas price and air quality equipment

- $20003 \%$ above 2000 base case due to air quality oquipmont

Increased Mobility Case

$19853 \%$ above 1985 base case due to gasoline price

$20001 \%$ below 2000 base case due to insurance cost decrease

Improved Accessibility Case

$19853 \%$ above 1985 base case due to gasoline price

$20004 \%$ above 2000 base case due to gasoline price

\section{Technology}

Most technology changes in autos are designed to improve performance, handling, comfort, convenienre, versatility, and styling. Guvernment regulations concerning safety, emissions, and fuel economy have forced technology developments in new. directions. Conclusions regarding near-term and longterm prospects. for auto technology include:

- 1985 fuel-economy goal achievable, at expense of large cars ... early investment could commercialize production of liquid fuels from oil shale and coal by 1990s; further examination of environmental and safety hazards of production and use is needed ... alcohol is an attractive fuel with gasohol costs presently slightly. higher than gasoline costs, but pure alcohol is not competitive now; environmental impacts need [urther study ... hydrogen fuels will not be practical until after 2000 .

- Current emission standards can be met without serious penalty in fuel economy ... particulate emissions problem in diesels must be solved before widespread use.

- Nominal weight and cost for crashworthy design of small cars.

- Gas turbine and Stirling engines are attractive, but are not expected to reach the market until after 1990 at the earliest ... electric vehicles for special purposes and limited use may be significant by mid-1980s. 
SHOULD WE HAVE A NEW ENGINE?

AN AUTOMOTIVE POWER

Mode: HIGHWAY SYSTEMS EVALUATION (1975)

Jet Propulsion Laboratory for Ford Motor Company

PURPOSE

This study was designed to provide a balanced, independent assessment of long-term engine options. Work began in December 1973. The objective was to define what "should" be done relative to new engines, requiring a value judgment from the viewpoints of society, the industry, and the consumer (this is distinct from what "could" be done or what is "likely" to happen).

\section{ASSUMPTIONS}

In the course of the study, these fundamental "realizations" -- some of them at variance with widely held opinion -- emerged:

- Automobile will maintain its dominant role in personal transportation. Limited applicability of new and expanded transit facilities will preclude more than a 10-15\% substitution for automobile driving in the next 10-20 years.

- Production of 10 million autos per year is highly specialized and complex. Major changes cannot be made overnight regardless of the amount of money available, technology applied, or legislation enacted. A minimum of three years is needed to mass produce a new design, given a fully developed, producible model.

- World resources of natural and synthetic liquid fuels are sufficient to introduce another generation of combustion engines.

- Given adequate planning, the necessary materials for construction of the recommended heat engines $c$ an be obtained.

- Financial resources for conversion to alternate engines are readily available in our economy.

- Autos powered by alternative engines must at least meet a set of emission standards appropriate to the region in which they are driven.

- The efficiency of catalytically controlled otto engines can be improved without relaxation of the strictest legislated emission standards.

\section{METHODULUGY}

Study objectives

- Understand national needs and problems related to auto use.

- Examine auto industry structure for constraints in implementing vehicle changes. 
- Characterize vehicles, conventional otto engines, and all production and experimental alternative engines.

- Synthesize equivalent vehicles on "equal footing" comparisons of alternative and otto engines.

- Assess national impacts of various introduction scenarios for the most promising alternative engines.

- Develop automotive improvement strategy with funding requirements, time phasing, and options.

\section{Alternative Engines}

- UC Otto - uniform-charge, conventional otto-cycle spark-ignition intermittent-combustion engine.

- SC Otto - stratified-charge otto engine. Direct injected type (Ford PROCO not Honda CVCC) offers best fuel economy and emissions potential and is the only configuration treated in this summary.

- Diesel - includes turbocharger and wastegate. system tọ give equivalent performance.

- Brayton - continuous-combustion engine, a gas turbine. Two configurations evaluated: one with two separate turbines with a conventional transmission (full-turbine) and the other a single turbine with a continuously variable transmission (single-shaft).

- Rankine - continuous-combustion engine, a steam engine.

- Stirling - continuous-combustion engine in which external heat is transferred to a separate closed system containing' a noncondensable working fluid that is alternately heated and cooled.

- Electric - energy storage powerplant using rechargeable batteries..

- Hybrids - powerplants combining a combustion engine with an ancillary electric or other'energy storage system.

\section{Configurations Evaluated}

- Present - engine as it currently exists, whether rudimentary laboratory prototype or production model.

- Mature - near-term improved version of. today's technology.

- Advanced - long-term projections, do not weigh heavily in this evaluation.

CONCLUSIONS

\section{Alternate Powerplant Findings}

- Stirling - lowest fuel consumption of all the mature alternatives, low emissions, and fuel adaptability. Should be developed to point of economic mass production. 
- Brayton - fuel economy second only to Stirling and potentially superior to Stirling in advanced technology. Low emissions, low scheduled maintenance, fuels adaptability, and lowest cost continuous-combustion powerplant. Single-shaft version has greater performance potential than free-turbine, provided an efficient and economically mass-producible continuously variable transmission ( CVT) can be developed.

- Rankine - lower fuel economy than Brayton or Stirling and highest production costs. Low emissions and fuels adaptability alone are insufficient to warrant further development.

- Diese1 - evaluated on an equivalent engine basis and on the basis of energy content of the fuel, the fuel economy advantage is greatly reduced. It can meet current emission standards but there is no margin for further control, and particulate emissions solution is not in sight. These considerations and higher initial costs do not justify its widespread use in personal autos. This does not preclude specialized applications, such as in taxi fleets or heavy-duty vehicles.

- SC Otto - fuel economy is at best only slightly higher than corresponding mature otto engine. Potential for lower nitrogen oxides emissions than UC otto. No major long-term advantages.

- UC Otto - mature vehicles can meet statutory emission standards, with a fleet-average composite fuel consumption that is about $9 \%$ lower than the average of 1975 model cars by using improved carburization and induction systems. Should be accomplished before 1980 .

- Electric - a major breakthrough in battery technology is required to make electric vehicles competitive with heat-engine vehicles. While present performance and range capability limit them to small-scale specialty applications, these vehicles are still an attractive long-term option:

- Hybrids - may achieve $20 \%$ higher fuel economy than an otto engine with comparable acceleration, although an otto engine with CVT.can achieve economy gains almost as large. Emissions are not sufficiently lower to significantly simplify its emission controls. Additional weight and cost of energy. storage system make hybrids unattractive in study time frame.

Recommended Strategy for Research, Development, and Production

- Industry should continue incorporating nonengine-related vehicle improvements with total fleet adoption by 1981 .

- Concurrently, developmental activities"must be stimulated with governmental incentives as necessary. Evolution of Otto engine to mature configuration by 1985 .

- Increase public awareness uf benefits of modest shift. to lighter cars, components of total car ownership costs, and dramatic effects of restraint. systems in reducing auto accident injury.

- Intensified development of Brayton and Stirling engines should begin immediately. Given reasonable success, these engines could be ready by 1985. Heavy-duty applications could serve as an effective test market. 
- Intensify research efforts in key technologies such as high-temperature structural ceramics and high-energy-density storage batteries.

- Petroleum industry should support the automotive program by appropriate planning in fuel production and distribution and should assess the implications of providing broad-cut fuels and further removal of potentially troublesome contaminants, especially sulfur.

- Legislators should provide an integrated national energy, environmental, and safety policy consistent with this automotive strategy.

\section{Additional Conclusions}

- Manufacturability and costs: three-way catalyst UC otto engine is $60 \%$ more costly to manufacture than pre-emissions otto engine. Direct production machinery costs for the stirling, Rankine, and Brayton engines are two to three times higher thán for otto engine due to stainless steel and super alloy content. Vehicles with Brayton or Stirling engines will cost about $10 \%$ more than comparable vehicles with otto engines.

- Industry practices: total conversion to even the most expensive engine lines could be accomplished within 15 years. Potential profits justify expenditures of $\$ 200$ million to $\$ 1$ billion for engine development programs by industry between 1975 and 1981 .

- Vehicle and highway safety: no alternative engine inherently constitutes a safety problem. A vehicle weight decrease of $500 \mathrm{lb}$ with no change in safety design will increase present highway accident rate by $15 \%$. Alcohol is the single largest contributor to highway casualties.

- Automobile ownership costs and economic impact: Brayton and Stirling engines can be economically beneficial to the consumer although initial purchase price would be higher than that of otto engines. The advantagc of these alternate engines is more prominent in larger cars than in smaller cars. Alternate engines can be marketed withnut government support and yet maintain or improve the dollar volume of automobile sales. Imported raw material costs for alternate engines are trivial compared to potential savings in imported petroluem. 
AUTOMOTIVE TECHNOLOGY: STATUS AND PROJECTIONS (1978)

Mode: HIGHWAY

Jet Propulsion Laboratory for U.S. Department of Energy-

\section{PURPOSE}

This report was prepared to help DOE assess and develop a more effective vehicle heat engine program. This is a re-evaluation of alternative power systems (after JPL's 1975 study - Should We Have a New Engine?) in light of the energy crisis, fuel economy legislation, and emission standards.

\section{ASSUMPTIONS}

In assessing the long-term potential advantages of alternative engines, it was necessary to consider changes in conventional automotive technology, that is, to establish a moving baseline for the period 1975-85 that reflected changes in.response to federal emission standards and fuel economy standards. The following trends were assumed to continue:

- Vehicle design trends: downsizing, reduction of exterior dimensions ... weight reduction by material substitution and downsizing ... increased use of front-wheel drive ... reduced performance, lower power-to-weight ratio.

- Engine and transmission trends: development of more-compact, lighter, higher-rpm, 4- and 6-cyclinder gasoline engines ... development of threeway catalyst emission control systems ... turbocharging ... redesign of gasoline engines to passenger-car diesels ... turbocharging of light-duty diesel engines ... refinement of three-valve, stratified-charge gasoline engine ... significant improvement in fuel consumption of rotary engines $\therefore$ increased availability of 4- and 5-speed manual transmissions ... introduction of automatic transmissions with torque convertor lockup.

\section{METHODOLOGY}

The concept of an Otto-engine-equivalent (OEE) vehicle is central to the comparison of alternative engines. The OEE vehicle should be indistinguishable in transportation function, driving behavior, and performance with the baseline vehicle. Once the engine horsepower and vehicle weight for each OEE vehicle have been determined, fuel economy is calculated using a JPL vehicle computer simulation program, with steady-state combustor data and a general knowledge of pollutant formation during combustion.

\section{CONCLUSIONS}

Fue1 Economy

- Stirling vehicles are projected to have $40 \%$ better fuel economy than 1978 baseline $(1.0 \mathrm{~g} / \mathrm{mi} \mathrm{NO})$ and $40 \%$ better than projected 1985 baseline $(0.4 \mathrm{~g} / \mathrm{mi} \mathrm{NO})$. 
- Brayton (gas turbine) engine projected at $30 \%$ better than 1978 baseline $(1.0 \mathrm{~g} / \mathrm{mi} \mathrm{NO})$ and $30 \%$ better than projected 1985 baseline $(0.4 \mathrm{~g} / \mathrm{mi} \mathrm{NO})$ in full-size vehicles, but little advantage for small vehicles. Brayton engine requires ceramic materials to show any significant fuel economy.

- Baseline vehicle fuel economies will continue to improve with new lighterweight engines and turbocharging.

\section{Emissions}

- Stirling engines are expected to have little difficulty in meeting current emission standards and are projected to meet $0.4-\mathrm{g} / \mathrm{mi} \mathrm{NO}_{\mathrm{x}}$ standard based on dynamometer tests and combustor rig tests.

- With additional development, current standards and research standard $(0,4$ g/m1 Nil $I_{x}$ ) can he met by B̈rayton-cngine powered veliciles.

- Conventional UC otto vehicles with three-way catalyst controls should meet legislated standards with no fuel-economy penalty. Research goal $(0.4 \mathrm{~g} / \mathrm{mi}$ $\mathrm{NO}_{x}$ ) should be met in small cars with little fuel-economy penalty.

- Diesels should meet legislated emission standards, probably with advanced control techniques on larger vehicles.

- Unregulated emissions (particulates, odor; and noise) will present problems for diesel vehicles if new emissions regulations are passed.

Multifuel Capability

- Brayton and Stirling engines should perform well using a wide range of fuels.

- Advanced conventional engines under development have dcmonstrated limiled multifuel capability.

Cost

- Brayton engine for ful1-size car is estimated to cost $\$ 500-600$ (1977 dollars) more than conventional engine; a factor of 1.4 , or $10 \%$ of the price of the car.

- Stirling engine in 100-150 hp range is estimated to cost $\$ 800$ (1977 dollars) more than conventional engine, a factor of 1.55 . 
PROSPECTS FOR ELECTRIC CARS (1978, draft)

Mode: HIGHWAY

General Research Corporation for U.S. Department of Energy

PURPOSE

This report presents quantitative estimates of the prospective benefits and costs of large-scale use of electric automobiles in the United States. The study recognizes the many uncertainties regarding the future prospects of electric cars, and therefore investigates a broad spectrum of factors affecting potential production, use, and environmental impacts. Analysis is 1 imited to consideration of battery-powered electric passenger cars.

\section{ASSUMPTIONS}

\section{General Assumptions}

The study assumes no abrupt changes or surprises, such as drastic increases in the price of gasoline, rationing of gasoline, unavailability of sufficient gasoline or electricity to satisfy demand, or sharp limitations on the use of conventional automobiles. The pace of technological progress is assumed to remain high, including the development of significantly improved batteries for electric cars, continued improvements in air pollutant emission controls and in fuel economy for conventional automobiles (in accord with current regulations), and future regulation of noise emissions. With continuing improvement in conventional cars, the potential benefits of electric cars are correspondingly reduced in such areas as petroleum-based fuel consumption, air pollutant emissions, and cost differentials.

\section{Utility Supply/Demand Projections}

Overall demand and supply are assumed to grow in line with utility and Federal Power Commission projections made in 1976, with growth rates that are significantly less than in the past or in earlier projections, but still substantial. Daily and seasonal variations of demand remain as they have been in the past. Generating units are operated to minimize the cost of the electricity produced. Where generating units can burn either oil and coal, or gas and oil, they are assumed to burn the preferred fuel exclusively. A maximum of $85 \%$ of net dependable capacity is assumed to be available for recharging electric cars, usually considerably less than would actually be produced by a utility to meel demands. $\Lambda 11$ generating capacity within this limit, and beyond that required to meet projected demand, could be used for recharging electric cars, regardless of time of day. Major technical innovations will not drastically affect these projections, except as adjuncts to the use of electric cars. 
METHODOLOGY

The wide-ranging subject matter of the report called for a variety of analytical methods. A literature review of state-of-the-art electric battery technology was conducted. Parametric models of weight, cost, and performance of alternative batteries were used to project range, speed, energy requirements, and other characteristics of improved future batteries. Urban travel data from Los Angeles and Washington were analyzed to determine the types of travel that could be accommodated by. limited-range electric automobiles. Supply and demand for 228 electric utilities across the U.S. to the year 2000 were modeled to determine the impact of large-scale electrification of automobiles (up to 100\%). Computer modeling of air pollutant emissions from all sources to the year 2000 was also conducted for the 24 largest U.S. regions, to determine changes in air quality associated with large-scale conversion to electric automobiles. The costs of acquiring and operating electric cars were projected and compared with the costs of competitive conventional automobiles. Parametric and life-cycle cost models were used to develop these comparisons. Other. impacts analyzed via literature review include noise reduction, natural resource consumption from large-scale production of battery materials, visual and economic impacts of abandoned automobiles, thermal pollution at power plants, health and safety effects associated with nuclear power plants as energy sources, and employment and other economic impacts.

\section{CONCLUSIONS}

\section{Characteristics of Future Electric Cars}

- Urban ranges will be as much as two to four times those of present electric cars: up to $150 \mathrm{~km}$ for improved lead-acid batteries, $250 \mathrm{~km}$ for nickelzinc batteries, and $450 \mathrm{~km}$ for lithium-sulfur hatterips.

- Batteries are the key obstacle tn prartiral plectric care; oloctrio motoro and controllers are highly developed and offer exceptionally quiet and reliable propulsion at reasonable weight and cost. Batteries have primarily limited the range and speed of electric cars, and raise their costs above those of automobiles with internal-combustion engines.

- Developers of new batteries expect increases of $50-150 \%$ in operating life and corresponding reductions in the present high costs of battery depreciation. Since a variety of promising approaches to an improved battery are under active development, it seems likely that at least one will succeed. However, even with the most advanced batteries, electric cars will be up to twlce as heavy as their conventional counterparts because of the battery and the extra structure required to support it.

\section{Ability to Meet the Needs of Drivers}

- Electric cars are sufficient for most needs of all three major groups of drivers: secondary and primary drivers in multidriver households and drivers in one-driver households. Even with the longest design ranges, 
however, electric cars would be incapable of occasional long trips now made by conventional cars.

- Only at the shortest design ranges would electric cars be competitive in cost. A range of only $75 \mathrm{~km}$ between recharges would entirely suffice for the urban driving of secondary drivers on $95 \%$ of the days they drive, which is within the range of today's electric cars. For drivers in single-driver households, about twice as much range $(150 \mathrm{~km})$ would be necessary to complete all urban travel on $95 \%$ of driving days. For urban driving by primary drivers in multidriver households (or fór average drivers of new cars nationwide, not just in urban areas) ranges of about $220 \mathrm{~km}$ would be necessary. These are well within the reach of cars with future batteries.

- Though trips too long for future electric cars are infrequent, they are still important: more than $60 \%$ of the households with cars reported one or more such trips in a recent year, mostly for recreation and vacation. The average number of long trips at such households was five per year.

- While their use might necessitate some sacrifice of travel or change of mode for long trips, electric cars could reasonably be applied very widely, especially for urban driving. Roughly $75 \%$ of U.S. cars are in urban areas.

- Although most cars are parked off the street at night, available statistics suggest that a substantial minority is parked on the street, and would consequently be inaccessible for recharging.

\section{Competitive Position in the Auto Marketplace}

- Because future electric cars would be heavier than conventional cars offering similar accommodations, initial costs of electric cars, even without the battery, would generally exceed those of competitive conventional cars. A parametric cost model for future electric cars showed that life-cycle costs would also be generally higher, partly due to this higher initial cost and partly due to added costs of propulsion batteries. Probable longer life (assumed to be $20 \%$ longer than for conventional cars) and very low costs for maintenance and repairs were insufficient to make electric cars generally less expensive. Improvements in battery. life beyond those projected in this study are unlikely by themselves to equalize costs.

- Only at the shortest practical design ranges and with the less-expensive future batteries are electric cars likely to equal conventional cars in life-cycle costs. Depending on the type of battery and design range, gasoline prices 50-150\% higher than in 1977 would be required to equalize life-cycle costs for the longer-range electric cars.

- Though improved electric cars would be widely applicable, they are unlikely to raptiure as much as $10 \%$ of the new-car market in this century, because they will be more expensive and less versatile than conventional cars. They would be most competitive in cost and most capable of meeting travel needs if designed and sold as a household's second car, but only about $10 \%$ of second cars are purchased new. 
Effects on the Use of Fuels and Energy (see Figures 4-7).

- By the year 2000 , almost $60 \%$ of U.S. cars could be electrified with virtually no use of petroleum for recharge. If all U.S. cars were electrified, petroleum use for automobiles would be cut $83 \%$.

- Electric utility facilities that would otherwise be idle, mostly late at night when demand is ordinarily low, would be adequate for recharging tens of millions of electric cars, even on the least favorable day of the entire year. It appears unlikely that the use of electric cars will ever be limited by the capacity of electric utilities, unless historical patterns of supply and demand change drastically. In future years, moreover, the importance of oil-fired facilities for overnight recharging is expected to diminish rapidly. Potential savings of petroleum through wide use of electric cars are thereby immense. Most energy for recharge would come from coal and nuclear power plants.

- The resulting reduction in total national use of petroleum would be under $20 \%$; automobiles now account for only $28 \%$ of national petroleum consumption, and are expected to require even less after average fuel economy rises in line with federal standards.

\section{Effects on Air Pollution}

- Electrification of all cars would reduce regional hydrocarbon and carbon monoxide, emissions by roughly half, but increase sulfur oxide emissions some $20 \%$.

- Emissions from conventional automobiles, which are being reduced over $90 \%$ by federal regulation, will no longer be the major source of urban air pollution in future years. Emissions from power plants are also under relatively tight control. As a result, projected effects of electric cars tend to be dominated by other sources.

\section{Other Environmental Impacts}

- Traffic noise would be significantly reduced by electric cars, even after major quieting of conventional vehicles.

- Identified resources of battery materials suffice for tens of millions of electric cars, but not necessarily for a complete electricification of all U.S. autos. Identified reserves of battery materials for battery production are no more abundant than are identified reserves of petroleum for meeting world demand through 2000. New discoveries, however, seem relatively likely to increase identified reserves and resources of battery materials. Alternative future batteries based on such abundant materials as sodium, sulfur, and chlorine could effectively eliminate problems of inadequate resources.

- Aside from extra costs for motorists, wide use of electric cars would have little economic impact (including employment impact) in the United States. Only about $3 \%$ of U.S. jobs would be affected by a complete switch to electric automobiles, and in a transition over 20 years, a reasonable period, annual changes would be very small. In proportion to the higher 
costs of electric cars, total employment in businesses manufacturing, selling, and servicing automobiles would be increased.

\section{Overall Conclusions}

- A national shift to electric cars to conserve petroleum and enhance the environment would be far more costly than already adopted moves to lowpollution, fuel-efficient conventional automobiles.

- Though future electric cars will be capable of most auto travel, they would nonetheless entail sacrifices in capability and performance far greater than those resulting from existing regulation of automotive safety, fuel economy, and exhaust emissions.

- The ratio of benefits to costs would be most favorable for relatively 1 imited use of electric cars: use as secondary cars and at urban household using other modes for out-of-town travel.

- Overall, the desirability of any deliberate move to electric cars will depend primarily on the importance attached to the problems of importing petroleum. 


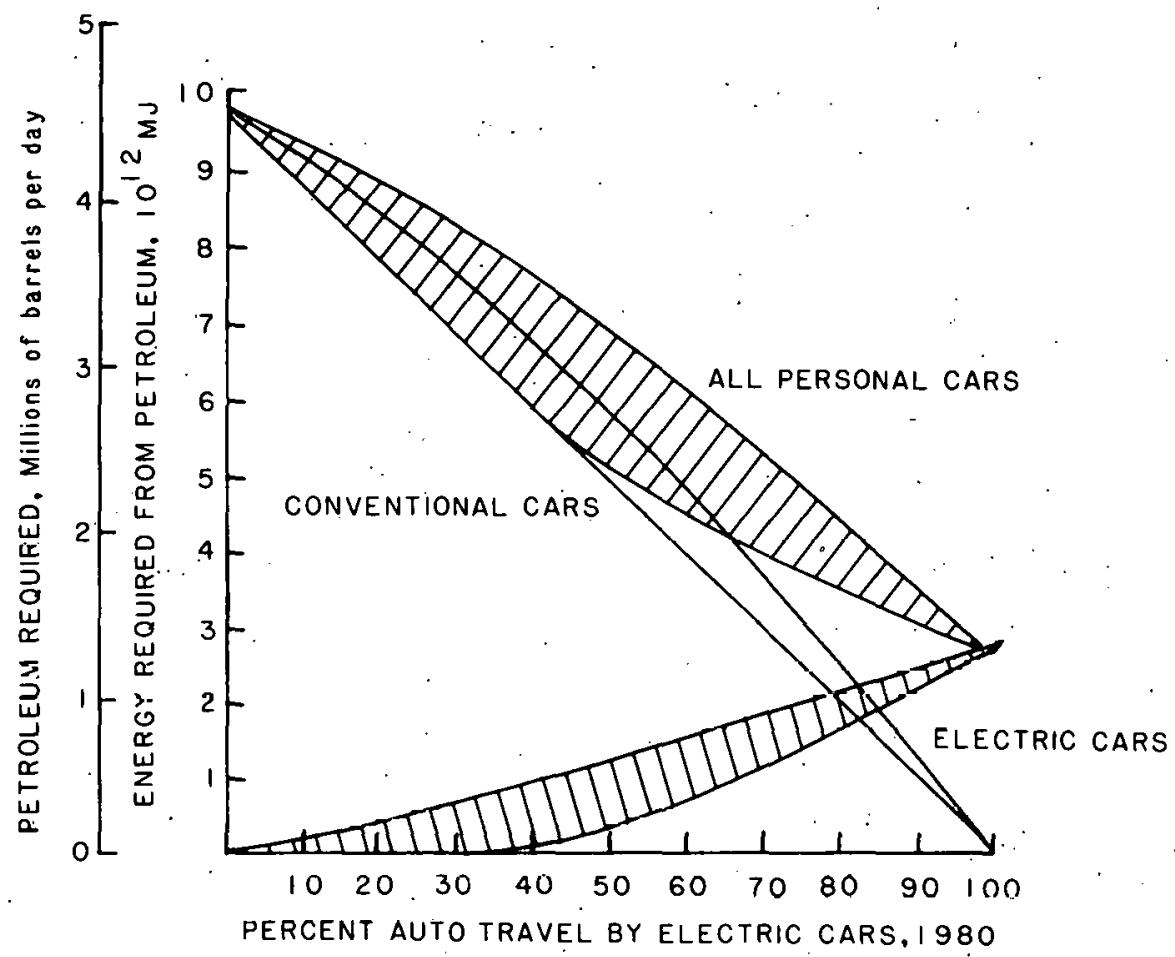

Fig. 4: Petroleum Required for Personal Cars versus Use of Electric Cars, 1980

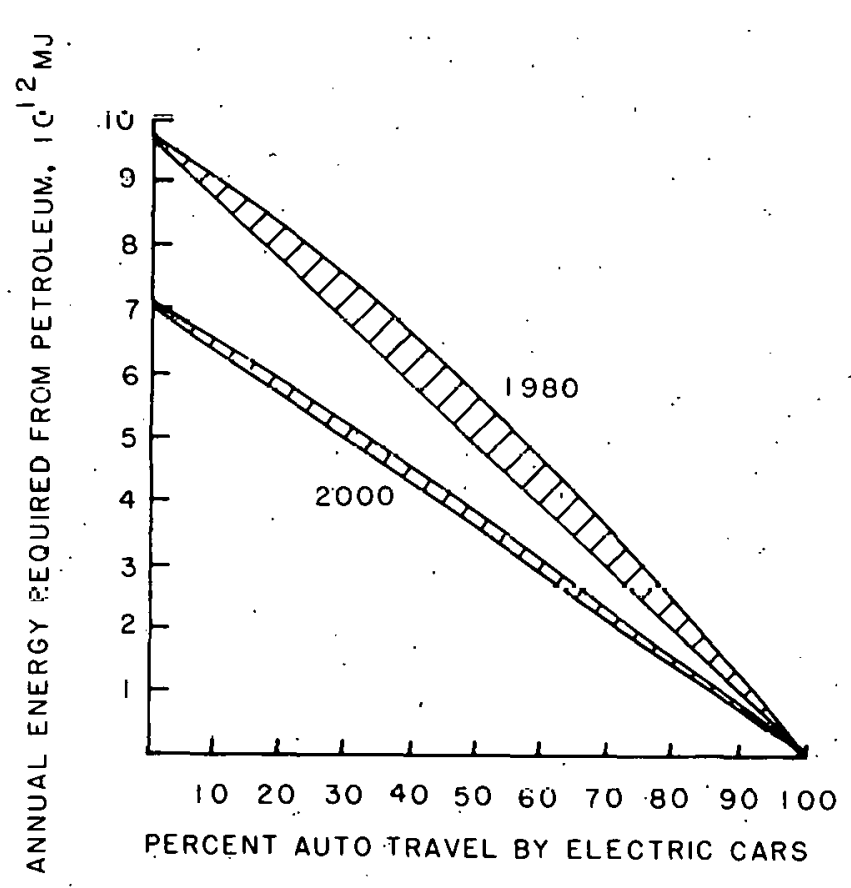

Fig. 5. Pétroleum Required for Conventional Cars versus Use of Electric Cars 


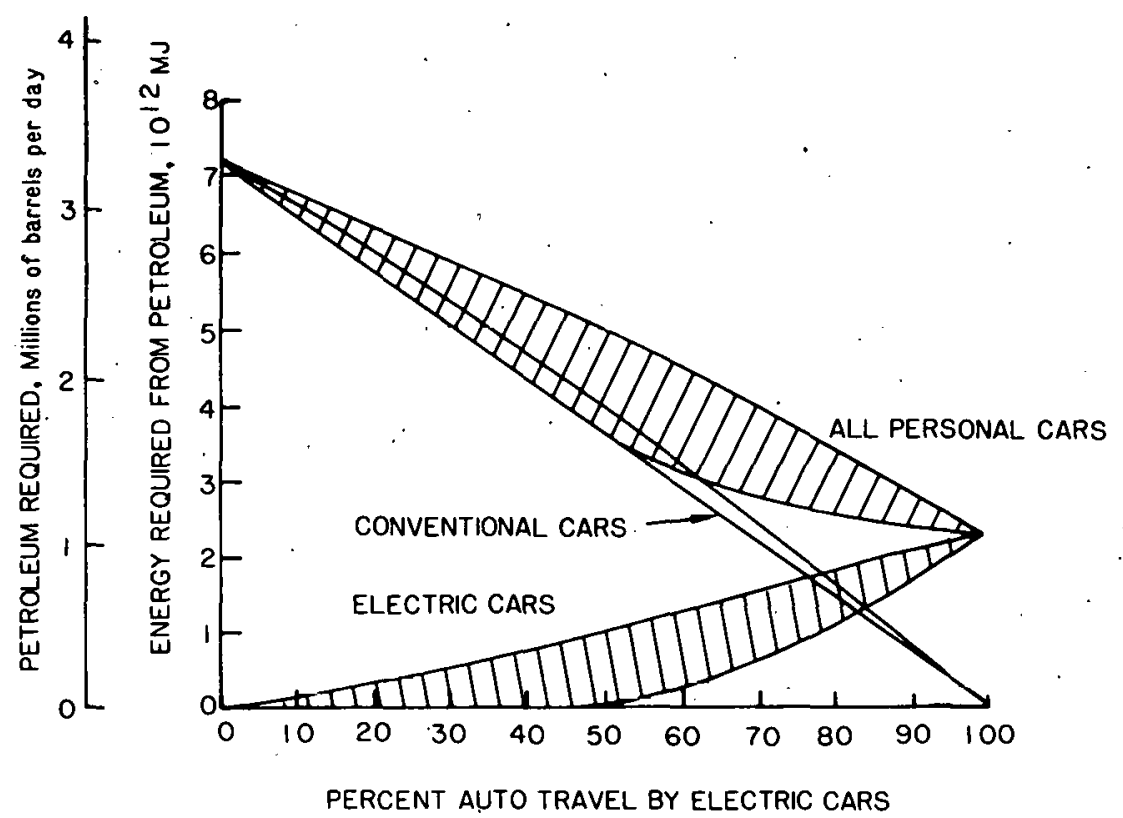

Fig. 6. Petroleum Required for Automobiles versus Use of Electric Cars, 1990
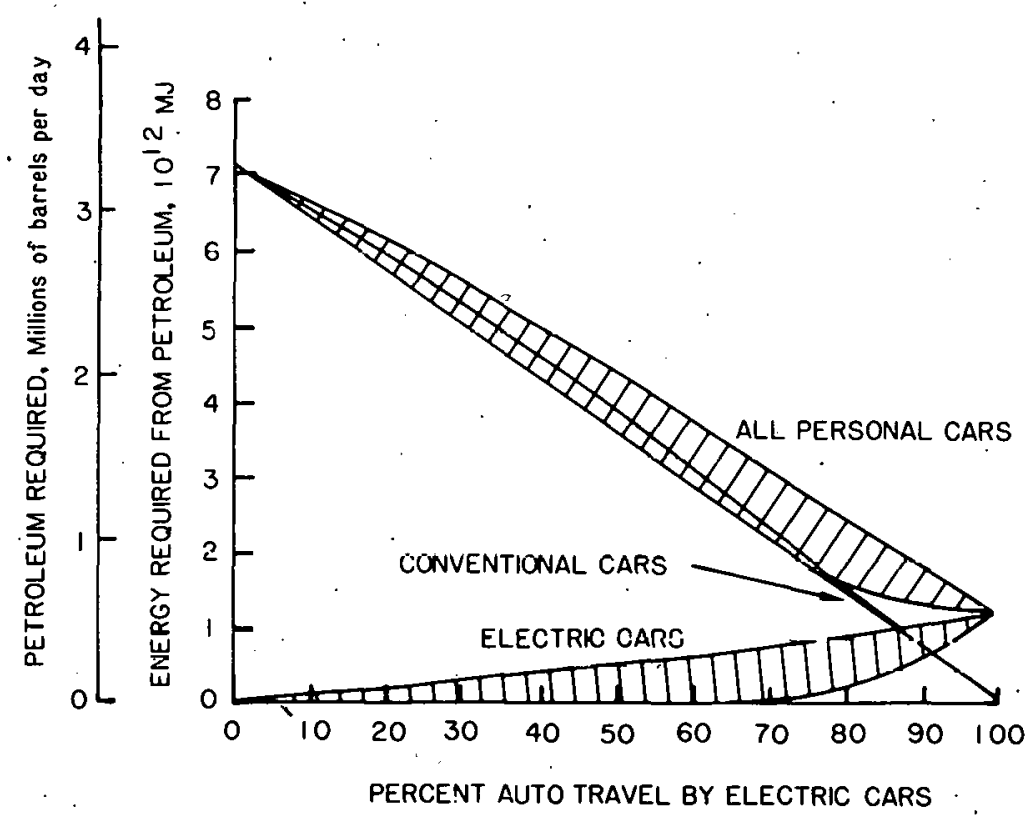

Fig. 7. Petroleum Required for Automobiles versus Use of Electric Cars, : 2000 
STATE-OF-THE-ART ASSESSMENT OF ELECTRIC AND HYBRID VEHICLES (1978)

National Aeronuatics and Space Administration for U.S. Department of Energy

\section{PURPOSE}

This report was prepared in response to Public Law 94-413, the Electric and Hybrid Vehicle Research Development and Demonstration Act of 1976. The report presents baseline data to be used (1) for the comparison of electric and hybrid vehicle technologies and improvements in them and (2) to assist in establishing performance standards and requirements for such vehicles.

\section{ASSUMPTIONS}

Because the report is limited only to the documentation of present testing, user experience, and performance characteristics of electric and hybrid vehicles; no projections of potential future production or utilization are made. Forecast assumptions as used in other technology assessments are consequently not a factor in this study.

\section{ME THODOLOGY}

The report presents data obtained from performance testing of both commercially available and experimental electric and hybrid vehicles (both under this study and from other sources), survey information collected from users of electric vehicles, and data and information on electric and hybrid vehicles obtained on a worldwide basis from manufacturers and available literature. Performance tests for 29 different vehicles were conducted specifically for this study. These data and information were then evaluated and compiled according to the current status of electric vehicles, characteristics of electric vehicle components (tires, differentials, transmissions, traction motors, controllers, batteries, battery chargers), and the performance characteristics and components of hybrid vehicles.

\section{CONCLUSIONS}

Information was collected nn over one-third of the estimated 2,000 American-built electric vehicles of all types currently operating in the United States and Canada. Detailed information also was obtained on the operation of 44 electric and hybrid buses. Additional data were collected from the literature on several hundred other vehicles in operation abroad.

\section{Electric Vehicle Performance}

Electric vehicle performance differed greatly from one manufacturer's vehicle to another. This result was expected because of the great variety of vehicle chassis, propulsion systems, and components that are in use. Three 
of the vehicles tested had automatic transmissions, ten had manual transmissions, and nine others had no transmissions. Even among wel1-engineered piston-engine cars, considerable performance variations exist. For example, according to 1977 EPA figures, the fuel economy of one American small car varies by $50 \%$ depending on the choice of engine and transmission.

Range. Range tests were performed at several constant speeds between 40 and $72 \mathrm{kilometers} \mathrm{per} \mathrm{hour} \mathrm{(} \mathrm{kph})(25$ to $45 \mathrm{mph}$ ) and at the vehicle's maximum speed. For almost all the vehicles tested, the range decreased approximately linearly with increasing speed (see Figure 8). The majority of the personal vehicles had ranges of 42 to $94 \mathrm{~km}$ (26 to 59 miles) at $40 \mathrm{kph}$ (25 $\mathrm{mph}$ ). The range decreased to 40 to $55 \mathrm{~km}$ ( 25 to $34 \mathrm{miles}$ ) at the maximum test speed $(72 \mathrm{kph})$. The best ranges were $163-188 \mathrm{~km}$ (101 to 117 miles) at $40 \mathrm{kph}$ (25 mph) and $87-129 \mathrm{~km}$ (54 to 80 miles) at maximum speed. Four vehicles were tested at maximum speeds of 77-89 $\mathrm{kph}$ (47 to $55 \mathrm{mph}$ ) and demonstrated ranges of $36-87 \mathrm{~km}$ (22 to 54 miles).

The track test results were generally lower than those found in the 1iterature. Where direct comparisons could be made for specific vehicles, the results of the constant-speed range tests were approximately $25 \%$ lower for most cases and $50-60 \%$ lower in a few. Part of the difference can be ascribed to the test procedure used, which requires testing the vehicle at its gross vehicle weight and terminating the test when any test requirement could not be met. This procedure therefore measures minimum range capability. Range values measured for the urban driving schedule tests tend to be greater than those reported by users of electric vehicles.

Energy Consumption. Energy consumption measurements made on the test track were lower than those reported by users of electric vehicles. Figure 9 shows that track data ranged from 0.14 to 0.38 watt-hour per kilometer per kilogram (Wh/ km-kg) (0.10-0.28 Wh/mile-1bm) when measured as a function of vehicle weight. Field experience fell within the range of $0.34-0.68 \mathrm{Wh} / \mathrm{km}-\mathrm{kg}$ (0.25-0.50 Wh/mile-1 bm). In general, the lower boundary of field experience is set by the performance of electric buses, which have the lowest energy consumption of all vehicle types in operation. Tests were conducted on four gasoline-fueled vehicles to compare their energy consumption with that of their electric vehicle counterparts. When measured over the same electric vehicle driving schedule, energy consumption of both types of vehicles was essentially the same when the energy contents of the gasoline used by the conventional vehicles were compared with those of the fuels used to generate the electrical energy for the electric vehicles. Assuming the cost of gasoline is $\$ 0.60 / \mathrm{gal}$ and that of electricity is $\$ 0.05 / \mathrm{kWh}$, fuel costs for both types of vehicles were approximately the same.

\section{User Experience}

Appreciable field operating experience has been accumulated for electric vehicles, although they are a statistically insignificant portion of the nation's transportation system. Within the United States 1,700 automobiles, 450 delivery vans, and 13 buses are in service. To date they have traveled over five million miles. 


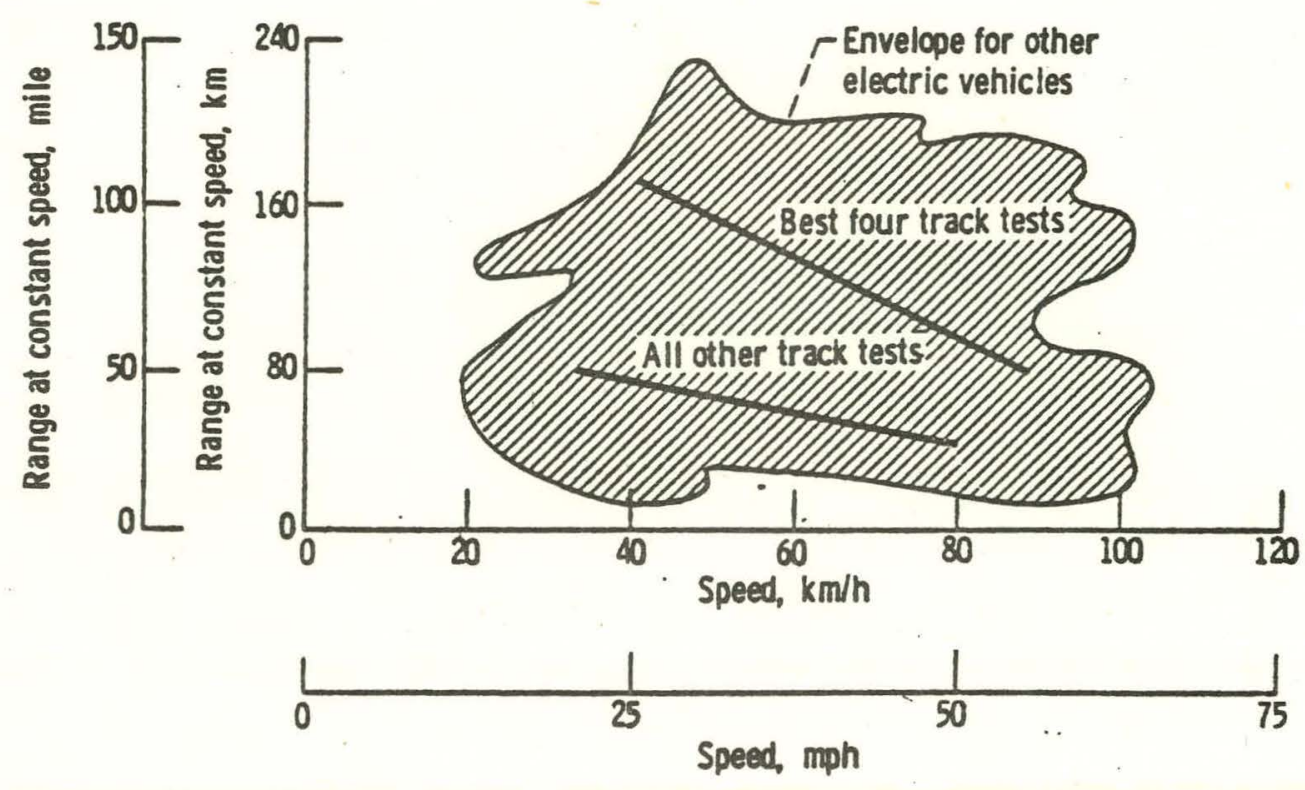

Fig. 8. Electric Vehicle Range as Function of Speed

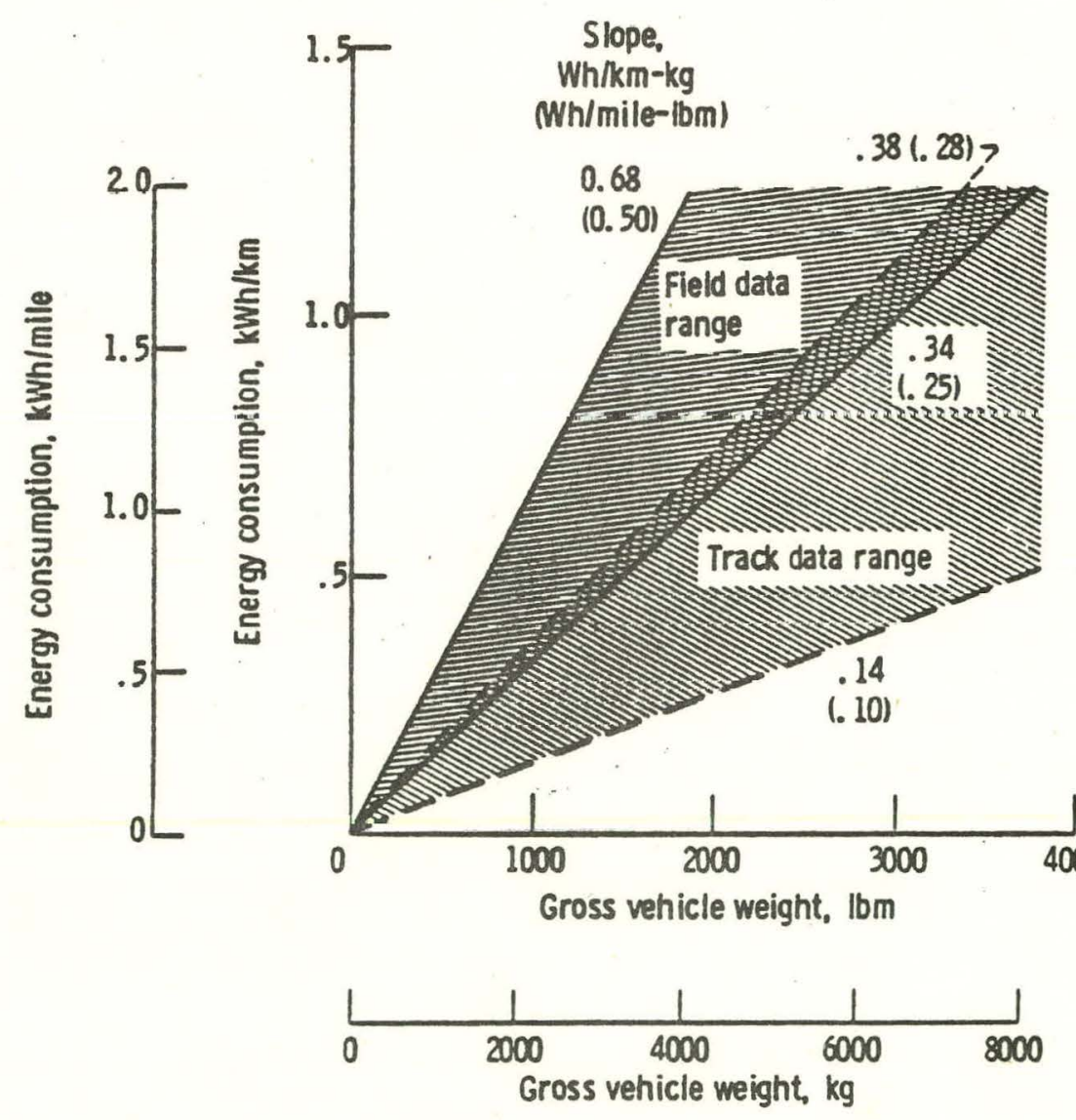

Fig. 9. Energy Consumption - Comparison of Track Tests and Field Experience for Cars and Vans 
Uses. Personal vehicles are used mainly in suburban areas for short trips such as commuting, shopping, and errands -- with daily use ordinarily less than $20 \mathrm{~km}$ ( 12 miles). Commercial vehicle applications include postal delivery, water meter reading, and intrafacility errands at large laboratory or industrial complexes. Electric buses, which are in rather limited use in the United States at present, have been operated mostly on short collection and distribution routes in neighborhoods and auto-free shopping areas where their quiet, nonpolluting characteristics are particularly important.

The annual use of electric vehicles is low, ranging from 4,000 km to $5,000 \mathrm{~km}$ for delivery vans to $13,000 \mathrm{~km}$ for automobiles, and to $53,000 \mathrm{~km}$ for electric buses. This compares with an average annual use of $18,000 \mathrm{~km}$ for conventional automobiles and $50,000 \mathrm{~km}$ for diesel-powered transit buses.

With the exception of a demonstration program being conducted by the U.S. Postal Service (USPS), domestic fleets are small. Automobiles usually are individually owned. Delivery vans and buses are generally in fleets averaging three vehicles. Fleets in the USPS program are larger, ranging from 5 to 99 vehicles at a single location.

Daily routines for the electric vehicles vary from repetitive performance of specific routes on a daily basis to random and even intermittent day-to-day use. Applications are generally characterized by limited range and low speed over relatively level terrain. Users of over $95 \%$ of the vehicles surveyed reported an average daily mileage of less than $32 \mathrm{~km}$ ( 20 miles), although some users regularly operated their vehicles for $48-64 \mathrm{~km}$ per day ( 30 to 40 miles per day).

Estimates of total life-cycle costs of electric vehicles have been based on a limited number of field tests. However, uncertainties related to battery and repair costs lead to a range of results that is too broad to be definitive. Battery costs are the greatest source of difficulty because of the high initial battery cost and uncertain battery 1 ife. Survey results indicate that battery life for most vehicles has been on the order of 250 to 300 cycles. Only one of the vehicles surveyed, a USPS van, has been reported as getting more than 1,000 cycles from a set of batteries. As replacement batteries for the vehicles surveyed cost $\$ 400-3,500$, the battery can significantly influence 1 ife-cycle costs.

The initial cost of electric vehicles is about twice as much as that of their conventionally powered counterparts. Major maintenance costs are associated with the labor involved in battery charging and maintenance. These costs can run as low at $\$ 0.02 / \mathrm{km}$ to as much as $\$ 0.22 / \mathrm{km}$, depending on battery design, duty cycle, fleet size, and efficiency of maintenance procedures. Costs of electrical energy are roughly equivalent to the costs for gasoline or diesel fuel to operate conventional vehicles. The life-cycle costs of electric vehicles appear to be relatively high, but they are determined largely by the lifetime of the electric vehicles and propulsion batteries. Costs are uncertain at this time.

Reliability. Reliability and durability are often cited as factors. offsetting the high initial costs of electric vehicles. User experience to 
date shows lower vehicle reliability for electric vehicles than for conventional vehicles. The nature of the problems reported and the experience with mature electric vehicles suggest that these current problems would not necessarily be representative of vehicles produced by a mature industry.

Electric and Hybrid Vehicle Component Technology

Wide variations in performance of similar electric vehicles reveal the need.for extensive propulsion system optimization. The series arrangement of electric vehicle propulsion system components requires optimization of all components to achieve maximum system efficiency and performance. Few components have been designed specifically for the unique requirements of electric and hybrid vehicles. Designers have adapted whatever components most closely fit their requirements.

The lead-acid battery is the only one available for electric and hybrid vehicles today. Although problems of unsatisfactory 1 ife are now being encountered in the field, they appear solvable based on good experience with the semi-industrial type in one USPS van and elsewhere. Better charge control and improved designs for reduced maintenance are required. Six advanced batteries have reached the point in development where at least one test of each has been conducted in a vehicle. Gains of $50-150 \%$ in vehicle range were reported; this verifies the promise of these systems, if longer life and low cost can be achieved and technical and application problems can be solved. None of these advanced batteries is expected to be available in production quantities for at least several years.

\section{Hybrid Vehicles}

In the hybrid vehicle, electric propulsion is combined with a heat engine. In theory, this approach reduces on-board fuel consumption by substituting battery energy and at the same time extending the range of an all-electric vehicle. The very limited amount of data available in the literature and from this study does not permit an adequate assessment of this potential. While a hundred different electric vehicles have been produced and several thousand are in service, only about 20 hybrid vehicles have been built and operated. Instead of being designed to save on-board petroleum fuel, these few vehicles generally were designed to reduce vehicle emissions.

A hybrid vehicle is heavier and its initial cost is high because it requires a heat engine and an electric propulsion qystem. Buses, because of their size, allow easier packaging of a hybrid system, and their initial cost is less important than the initial cost of a personal vehicle. Hybrid buses have met with some success abroad. 
THE AUTOMOBILE AND THE REGULATION OF ITS IMPACT ON THE ENVIRONMENT (1974)

Mode: HIGHWAY Columbia University for National Science Foundation

\begin{abstract}
EXECUTIVE SUMMARY
Policy oriented document with implications for transportation supply and demand

System: road

Economic Implica-

tions: costs and

efficiency

Network: primarily urban

Product and Process Coverage: vehicles, vehicular controls, and policy

This report examines national and local policies for abating the environmental and economic damages created by automobile travel. Prompted by the clean Air Act Amendments of 1970, it emphasizes the technological and policy accommodations required. to meet the ambient air quality standards and automobile emissions controls mandated in the amendments. Achieving these standards at the lowest cost and with the least economic disruptions is the focus of the evaluation. No attempt is made to attack the broader issue concerning the relevance of the standards, although the report's initial findings support the need for some form of automobile emissions controls to remedy air pollution in urban areas.

Automobile regulation strategies are examined in several separate but related studies: Included in these studies are: a macroanalysis of pollution control strategies; a microanalysis of urban air quality strategies, such as traffic restraint and land use control policies; an examination of evolving emissions control technologies; and an evaluation of legal controls.
\end{abstract}

PURPOSE

This study analyzes policy options for reducing health hazards and economic damages created by the automobile. Emphasized are strategies for combatting air quality problems caused by auto emissions, but policies for solving automobile-related noise, solid waste, and water pollution are touched on as we11.

The major impetus for the study comes from the Clean Air Act Amendments of 1970, which mandated nation-wide air quality standards and established measures to diminish emissions from stationery and automotive sources. The law required a $90 \%$ reduction in the carbon monoxide and hydrocarbons emitted by new cars by the 1975 model year; the same reduction was required for nitrogen oxide emissions but the deadline was the 1976 model year. The study confines its policy evaluation to the question of how these standards can be achieved at the lowest cost and with the least economic disruption. Implicit in this approach is the concept of cost-effectiveness. 


\section{APPROACH}

Starting with an overview of various air pollution abatement strategies and criteria for judging them, the study explores the issues surrounding the relationships between auto emissions and air quality from several angles. The report consists of a set of independent but related studies focused at identifying automobile regulation strategies for achieving national and local ambient air quality standards. Included in these separate tasks are:

- A macroanalysis of pollution control strategies in which future population exposures to nitrogen oxides, hydrocarbons, and carbon monoxides are projected under. two separate auto emissions standards and two separate stationary source standards.

- An examination of the impact of 1970 auto emissions regulations on emissions levels, vehicle performance, and fuel economy.

- A microanalysis of air quality improvement strategies applied within metropolitan areas, examining variations in emissions and pollutant concentrations within a specific Air Quality Control Region.

- An evaluation of two state-run pollution abatement programs, an inspection/ maintenance program to minimize excessive emissions from inadequate or improper maintenance, and a national program to retrofit emissions control systems on automobiles.

- An assessment of future emissions control technology, concentrating on controls for spark-ignition engines.

- An examination of the legal regulation of air pollution, covering the origins of the 1970 amendments, their effectiveness, the problems they have s.pawned, and possible new directions of future policies.

\section{METHODOLOGY}

The method of analysis varies with the task, ranging from use of descriptive statistics to use of sophisticated statistical models, such as an urban dispersion model for predicting aggregate exposure of the U.S. population to air pollution; a marginal cost-effectiveness model for measuring effectiveness of pollution abatement; and a transportation and airshed simulation model for analyzing several policies often proposed to improve the air quality in metropolitan areas.

\section{CONCLUSIONS AND RECOMMENDATIONS}

- A substantial reduction of emissions from new motor vehicles offers the only possibility for rapidly achieving ambient air quality standards for the pollutants produced by moving sources.

- Air quality in local sections of metropolitan areas can be improved through transportation control strategies employed singly or in combination with stationary source controls, but, by themselves, they cannot achieve the air quality improvements mandated by the 1970 clean Air Act Amendments. 
- Severity of pollution levels is very much a function of city size, indicating that the degree of emissions abatement needed is much greater in larger cities.

- Present federal statutory carbon monoxide and hydrocarbon emission standards would ensure that no persons would be exposed to excessive levels of these pollutants after 1985.

- A two-car strategy employing medium- and low-polluting vehicles would reduce aggregate abatement costs to the consumer but would have a variety of transaction costs that would significantly reduce the net benefit of this strategy.

- The ultimate success of a roll-back strategy depends on a durable and maintainable control technology, technology not now available for meeting 1975-76 standards.

- Development of emission control technologies would be better served by delaying these standards until the 1980 model year, an action that would help improve average vehicle fuel economy.

- A conventional spark-ignition engine with engine modifications and an oxidizing catalytic converter is the only technology available before the early 1980 s to meet new-car demand.

- Some alternative spark-ignition engine technologies now being developed offer more durable emission control at equivalent or better fuel economy than conventional engines. These include: lean burning engine, Honda dual-carbureted, divided-chamber CVCC engine; and fuel-injected stratified-charge engines with an oxidation catalyst.

- A strategy of year-by-year delays forces almost $100 \%$ use of catalysts, a technology with little large-scale manufacturing and field experience that demands a performance level attainable only under ideal conditions.

- Interim hydrocarbon and carbon monoxide standards for a five-year period would allow manufacturers to use a more flexible mix of technologies and encourage early mass production of more promising solutions.

- Postponement of 1975-76 standards to 1980 would have minimal adverse consequences on total hydrocarbon and carbon monoxide emissions.

- Legislative postponement must be combined with appropriate inducements to insure that the auto industry uses the delay to develop reliable, stable control technologies.

- Current legislation commits industry to catalyst technology, stifling flexible innovation.

- Legislation should define useful life of vehicle realistically, to encourage development of emission control devices that are effective after engine pronduces more pollutants.

- Legislation should impose graduated emission charges on manufacturers, corresponding to how close vehicles come to meeting standards.

- Mandatory inspection and repair strategies designed to reduce emissions from vehicles in actual use are costly and only marginally effective. Inspection and repair strategies should only be used in a few highly polluted metropolitan areas. 
- A program to retrofit vehicles in air pollution control regions would be unwise and unrealistic, having only marginal effectiveness when compared with its cost.

- Traffic controls and other strategies for modifying vehicle use patterns can be locally effective, although they must be carefully designed to reduce primary pollutants in selected areas.

- Improvements in transit system: (1) simulated $20 \%$ fare reduction resulted in $3 \%$ reduction in vehicle miles traveled, decreasing automotive pollutants by $4-6 \%$ in central areas well served by transit, and (2) simulated extension of subway system commuter lines resulted in no decreases in vehicle miles traveled and only a $1-2 \%$ reduction in pollutants, suggesting this is not a cost-effective approach.

- Traffic flow techniques: speed improvement pintirios, by inducing more vehiclc trips, illisease pollution concentrations $20-60 \%$.

- Vehicle restraint schemes: \$1 parking cost surcharge, a local licensing scheme featuring an entry toll of $35 k$ per vehiele trip in the central business district (CBD), and an entry prohibition on vehicles. Results: (1) parking surcharge is estimated to have the least impact, achieving a $10-35 \%$ reduction in CBD pollutant concentrations, (2) licensing scheme estimated to diminish CBD pollutant concentrations by $50 \%$, but much of the reduction is offset by increases in adjacent areas, and (3) parking prohibition is estimated to have the greatest impact in CBD, but, again, much of the reduction is offset by increases in adjacent areas.

- Altering land use patterns: findings suggest that increasing densities is not an effective policy for improving air quality in central urban areas.

\section{COMMENTS}

Several innovative engine and emissions control technologies are mentioned in the study. Most of them were not in an advanced enough stage of development to be considered as realistic solutions for meeting the thenpressing emission standards deadline, despite offering the potential for moreefficient and more-durable emissions control. That these promising new technologies had to be "shelved" points up a controversial issue about the relationship between government regulations and the way the private sector must respond to them. Some would argue that standards are set without proper consideration of the range of potential technologies available for meeting the goals these standards seek to attain. The result. of this practice is to lock manufacturers into a particular technological solution and set of capital and financial commitments, thereby stifling innovation. 
National Academy of Science

EXECUTIVE SUMMARY

System Coverage:

road

Environmental

Impacts:

air quality, cost and benefits, social impact of automobile emissions
The study examines several issues related to ambient air quality and automotive emission controls. The general objective of the task was to analyze and evaluate (1) the adverse health effects of air pollutants, (2) the relation of emissions to ambient air quality, and (3) the costs and benefits associated with control of automobile emissions.

The general finding of the study was that the evidence accumulated since the promulgation of the federal ambient air quality standards by the EPA in 1971 supports those standards. Yet, as Congress continued to face important decisions about air quality and automotive emissions in the early 1970s, there was an even greater need for strengthening the scientific and informational base used to make decisions and reducing associated uncertainties.

PURPOSE

The objectives of this study were to analyze and evaluate (1) the adverse health effects of air pollutants, (2) trends in air quality and total emissions in the United States since regulations were first imposed on automotive emissions, and (3) the costs and benefits of motor vehicle emission controls using different strategies, estimating the benefits in terms of health, amenities, and damage avoidance that will accrue to the American people from a reduction in air pollution.

\section{APPROACH}

The study was performed. by four study committees. The committee on medical and biological effects of environmental pollutants studied the effect on human health of those pollutants for which federal standards have been promulgated. The committee on the relationship of emissions to ambient air quality analyzed the relation between the amounts of automotive emissions and the resultant concentrations of pollutants in the air. The committee on motor vehicle emissions provided basic data and analyses of the costs associated with alternative control strategies. Further analysis of these data were carried out by the committee on the cost and benefits of automobile emission control. This last committee also appraised the benefits to human health, the avoidance of damage to plants and to property, and other benefits of improved air quality. 
The following questions defined the scope of the study:

- What data base exists for present health-related ambient air quality standards? Is it adequate? What areas should be studied? To what extent are data other than human health data a reasonable basis for extrapolating human health effects?' Are present health standards supported by existing data - does new data support the existing standards? Does the relationship of new data to those standards represent a reasonable measure of protection against scientific unknowns?

- Are the existing standards based on the health of normal, healthy adults or on the health of susceptible groups within the population? Which is a reasonable basis? Can population segments considered susceptible to the referred-to pollutants be identified within the population of any given area? What proportion of the population in major urban areas is within susceptible group categories?

- Are the standards based on "threshold levels" plus a margin of safety or are they established at levels that will protect public health. with a margin of safety? Are there assumed to be threshold levels for health effects of nitrogen oxides, carbon monoxide, and oxidants? What is the best information available as to any threshold levels of the referred-to pollutants? What is a reasonable margin of safety below those "threshold levels?"

- What improvement in air quality has actually occurred as a result of auto emission controls to date? Is there conclusive:monitoring data to indicate that an improvement in ambient air quality will result from meeting present and anticipated emission standards? Can we quantify this improvement in advance of application of controls?

- What groups within the population will still be subjected to health hazards in 1985-86 (assuming statutory standards are met? are changed?). How are these groups characterized (socioeconomic level, unusual. sensitivity to pollutants, old, young, ill, geographical location, seasonal exposure, etc.)? What is the most appropriate means of expressing ambient air quality standards to reflect human health effects (number of exposures, frequency, duration, pollutant concentration)? Can the uncertainties in setting health effect standards be identified for nitrogen oxides, carbon monoxide, and oxidants (confidence limite, standard deviation, errors in analyses, margin of safety concept)?

- What information is available about synergism or antagonism in the set of air pollutants found in cities?

- What proportion of the total health hazard to the city dweller comes from air pollution? From antomobilu emiooions? What pruporlion of the total health hazard from urban air pollution is due to these pollutants in the amounts emitted from automobiles?

- What are the limitations (to predictive judgments on alternative pollution control strategies) dictated by. the probabilistic nature of science, the complexity of environmental health relationships, the variability among persons, and the vagaries of human nature?

Each committee addressed the questions relevant to its particular area, confining the analysis to the air pollutants that were then regulated. 
The investigations did not extend to other problems, such as the known or suspected dangers that may derive from such substances as asbestos, flourides, or heavy metals.

\section{METHODOLOGY}

Each committee adopted a methodology to fit. its particular need for research and data analysis. The committee on medical and biological effects of environmental pollutants formed panels to study photochemical oxidants and ozone, carbon monoxide, airborne particles and sulfur oxide, nitrogen oxide, and synergism and antagonism of pollutants. The panels conducted extensive literature reviews and analyses of available data.

The committee on the relationship of emissions to ambient air quality employed a modified rollback method of analysis. This mathematical model assumed that when the emissions of a substance are reduced by a certain amount, the concentration of that substance in the ambient air will be reduced proportionately. It is used in setting the emission standards for nitrogen oxides $\left(\mathrm{NO}_{\mathrm{x}}\right)$ and hydrocarbons $(\mathrm{HC})$ and it handles interactions between them in producing oxidants by setting the $\mathrm{NO}_{x}$ standard low enough to avoid direct health effects of nitrogen dioxide and then setting the hydrocarbon standard low enough so that the interactions of $\mathrm{NO}_{\mathbf{x}}$ with $\mathrm{HC}$ will not produce oxidants in concentrations exceeding the ambient air quality standard.

The cost-benefit committee carried out three main and several subsidiary analyses. It estimated the costs of achieving currently mandated ambient air quality, under various strategies and time schedules for compliance. The analysis included some strategies that are alternatives or complements to automotive emission controls. The committee also arrived at very rough monetary estimates of what people in the United States appear to be willing to pay for cleaner air, as evidenced not by their responses to opinion polls (which have given rather low estimates), but by their proclivity to pay more for homesites and to accept lower wages in order to live where they can enjoy air they perceive to be purer. Finally, this committee developed rough estimates of the monetary value of maintaining the air qualities specified by the standards, in terms of saving lives, reducing illness, preserving and maintaining materials, and reducing damage to plant 1 ife.

As the cost-benefit committee points out in its report, there may be some overlap between the latter two monetary estimates, since residential preference may be influenced by differences in material maintenance and the desire to protect health. But since the public has, until quite recently, had little information about the actual health effects of air pollutants, it is probably more realistic to assume that the values of improved health were not much reflected in housing prices. Hence, the two sets of benefits should be combined to obtain the best eslimate of the total benefits.

The committee evaluated the health effects from automotive emissions that have been identified by medical and epidemiological studies to date. The committee also estimated from economic data what consumers are willing to pay for better air and estimated the value of reductions in damage to materials and plant life. 
CONCLUS IONS

Health Effects and Ambient Air Quality

None of the panels was satisfied with the data base available for setting the standards. Nevertheless, in general, these panels found that the evidence that has accumulated since the promulgation of the federal ambient air quality standards in 1971 supports those standards. The panels found no substantial basis for changing the standards. However, the panel on nitrogen dioxide suggested that consideration be given to establishing an hourly as well as an annual standard for nitrogen dioxide.

The panels on airborne particles and sulfur oxides considered atmospheric concentrations of sulfur dioxide and total suspended particulate matter to be uselul indices of pollution. However, recent studies indicate that observed health effects correlate better with fine particulate and suspended sulfate concentrations.

Overal1, the evidence concerning the nature and incidence of the health effects is best for sulfur oxides and carbon monoxide and poorcst for oxides of nitrogen and photochemical oxidants. The panels emphasized the need for additional epidemiological studies to improve the estimates of the health effects of air pollutants.

There was consensus among the panels that the present standards do take into account the effects of pollutants on the general population, and on particularly susceptible groups, insofar as existing data permit the risks to such groups to be estimated. The same segments of the population appear to be especially vulnerable to health damage by all of the atmospheric pollutants considered. These vulnerable people are primarily persons suffering from respiratory ailments and persons with cardiovascular disease, as well as the very old and the very young. These groups, taken together, constitute about $20 \%$ of the total population.

Relation of Emissions to Air Quality

Available information suggests that since the implementation of emission control strategies, measured ambient air quality (data available from. 1969) generally reflects the changes that have taken place in aggregate nationwide emissions of several pollutants: decreases for carbon monoxide and particulate matter and increases for nitrogen oxides. However, while total national emissions of sulfur oxides from stationary and mobile sources have continued to increase, urban air concentrations of these oxides have. decreased. Trends in photochemical oxidant concentration are poorly documented except in California. There is a developing body of evidence that oxidant levels. approaching, and sometimes exceeding, the federal standard occur in some nonurban locations. The high rural levels of oxidants may be related to the dispersion on a regional basis of precursor pollutants such as hydrocarbons and nitrogen oxides.

On the basis of analyses using the modified rollback method, it appears that the federal emission standard of $0.4 \mathrm{~g} / \mathrm{mi}$ for $\mathrm{NO}_{\mathrm{x}}$ may be somewhat more 
stringent than is needed to achieve the ambient air quality standard for nitrogen dioxide by itself. However, this finding must be carefully qualified, since the existing analyses relating $\mathrm{NO}_{\mathrm{x}}$ emissions to subsequent oxidant formation are considered inadequate. In addition, there is not a large margin of safety in these estimates, and the analysis assumes that nonautomotive emissions of $\mathrm{NO}_{\mathrm{x}}$ will be reduced in the same proportion as automotive emissions. It is not certain, on the basis of these findings, that the ambient air standards for oxidants would be met in all large cities or locations downwind from cities if the $\mathrm{NO}_{\mathbf{x}}$ emission standards were relaxed, unless auxiliary local measures were taken.

On the basis of analyses applying the modified rollback technique, the emissions-to-air-quality committee concluded that, at least in the Los Angeles area, the federal hydrocarbon emission standard of $0.41 \mathrm{~g} / \mathrm{mi}$ may not be sufficiently stringent to assure compliance with the national ambient air quality standard for oxidants. However, the committee also determined that the impact of motor vehicle emissions on ambient air quality varies greatly among different geographical regions.

With a relatively modest expenditure of funds. (\$1-2 miliion) analyses could be carried out over the next 12-18 months, using existing modeling techniques, that would allow conclusions concerning $\mathrm{NO}_{\mathrm{x}}$ and hydrocarbon standards to be drawn with more certainty than is now possible. This information could be available in time to assist in future evaluation of the emission standards.

Role of Auto Emissions in Total Health Problem

In undertaking to establish what part air quality in general, and automobile emissions in particular, play in the total health hazard to urban residents, this study interpreted "total health hazard". to mean average rates of illness and death among the urban population. The total urban health hazard stemming from air pollution lies somewhere within one percent of the wide range of estimates obtained from the published literature, from consultations with experts, and from analysis.

The proportion of the total air pollution hazard due to pollutants emitted by autos lies in the range of $10-25 \%$ of the health hazard imposed by present air pollution.

The contribution of automotive emissions to the total health hazard produced by air pollution varies considerably from one geographical area to another, depending on the absolute and relative levels of particulate matter and sulfur oxides, which are primarily nonautomotive in origin, and of carbon monoxide, reactive hydrocarbons, oxides of nitrogen and oxidants, on the other.

The hazards from automotive pollution also fall unequally upon different groups of persons. Persons already suffering from respiratory or cardiac ailments bear higher risks than others, and a substantial part of the total adverse health effect probably falls upon this part of the population. Since these same people have higher rates of death and illness from other causes as well, it is not clear whether air pollution poses a larger or smaller portion of the total health hazard on them than on others. 
It is suggested that automobile emissions may account for as much as $0.25 \%$ of the total urban health hazard. For the whole U.S. urban population, effects of this magnitude might represent as many as 4,000 deaths and 4 million illness-restricted days per year.

Costs and Benefits of Auto Emission Controls

The committee evaluated the health effects from automotive emissions that have been identified by the medical and epidemiological studies made so far, judging the monetary value of. those effects to lie in the broad range from $\$ 0.5$ million to $\$ 3$ billion per year. The committee also estimated from economic data what consumers are willing to pay for better air, and estimated the value of reductions in damage to materials and plant life. Taken together, these estimates suggest that annual benefits of perhaps $\$ 2.5-10$ billion could be obtained for the American people by improving air quality from its present levels to the levels of the federal ambient air standards for automobile-derived pollutants. This estimate is useful mainly in scaling the importance of this air quality problem in relation to other problems in our society.

In regard to the costs of attaining the federal ambient air quality standards for automobile-related pollutants, it was found that these costs depend quite sensitively upon the specific policies and technologies used to achieve the standards. On an annual basis, the costs of reaching the standards now mandated at the specified target dates could range as high as $\$ 12$ billion, assuming that catalytic mufflers are essential components of the emission control systems, the average size of vehicles in the automobile fleet does not change, and technological advances do not occur.

However, with the normal and expected development of better technologies, this annual cost could be expected to fall to $\$ 5-8$ billion per year. A number of available policy options, such as altering the $\mathrm{NO}_{\mathrm{x}}$ emission standards or following a "two-car" strategy, could reduce the costs further, perhaps to less than $\$ 1: 5$ billion in the former case, and to the vicinity of $\$ 2$ billion in the latter.

The benefit data are too crude to permit a numerical estimate of the loss in benefits from relaxing the $\mathrm{NO}_{\mathrm{K}}$ emission standard from $0.4 \mathrm{~g} / \mathrm{mi}$ to 2 $\mathrm{g} / \mathrm{mi}$. With the evidence at hand, however, it appears that with the $2-\mathrm{g} / \mathrm{mi}$ standard, or with use of a two-car strategy, a large fraction of the benefits estimated above would still be realized at a relatively low fraction of the cost of attaining the stricter standard.

It is concluded that the benefits, expressed in monetary terms, that could reasonably be expected to accrue. from implementing the federal emission control standards for automobiles are commensurate with the expected costs. Further, several policy options are available for consideration, that, by modifying the control standards, would lower the costs substantially, bringing them below relatively conservative estimates of the benefits. 
Thresholds

All of the health effects panels addressed the question of whether there are thresholds for the adverse health effects of pollutants. The present standards were derived on the assumption that thresholds do exist. Evidence, however, indicates that the amount of health damage varies with the upward and downward variations in the concentration of the pollutant, with no sharp lower concentration limit. Also, at any concentration of pollution, no matter how low, health effects may occur.

Synergism and Chemical Transformation of Pollutants

Each health effects panel addressed the question of physiological synergism. They concluded that no synergisms observed so far are important enough to invalidate the present method of establishing air quality standards. This general conclusion requires at least one qualification: recent evidence about the interactions between fine particulate matter and sulfur dioxide may, if further substantiated and developed, require revision of the present method of regulating particulate matter and sulfur oxides. Physiological synergism of $\mathrm{NO}_{\mathrm{x}}$ with other substances may also require further attention.

The emissions-to-air-quality committee concluded that the present method is inadequate for setting emission standards relating to oxidants, and recommended immediate acceleration of development and testing of more sophisticated modeling methods that take account of meteorological factors, emission distributions, and atmospheric chemistry.

Resources for Evaluation

The costs that will be incurred by society in controlling automotive emissions are on the order of \$5-10 billion per year. In comparison, the annual expenditures by the federal government in recent years for evaluative research have been relatively small: to study the health effects of air pollution, perhaps $\$ 10$ million; to study the costs and benefits of controlling automotive emissions, less than $\$ 1$ million; to study the relation of emissions to air quality, less than $\$ 10$ million. The significant reduction of the uncertainties in decision making for these topics depends on the generation of new knowledge. Much larger commitments of federal funds to these tasks appear to be warranted.

It has been suggested that four areas deserve high priority in the allocation of such funds: (1) epidemiological studies of the human health effects of air pollutants, (2) studies designed to improve the data for measuring ambient air quality, (3) modeling, using known techniques, of the interactions and chemical transformations of pollutants in the atmosphere, and (4) laboratory studies aimed especially at establishing the human health effects of pollutants.

Comments

The report contributes greatly to the understanding of the hazards posed by the introduction of some major pollutants into the environment and 
the options available to minimize these hazards. Yet, it also indicates the need for a more thorough cost-benefit analysis, assessing the financial value of the amenities involved. 
HOW TO SAVE GASOLINE: PUBLIC POLICY ALTERNATIVES

Mode: HIGHWAY

FOR THE AUTOMOBILE (1974)

Rand Corp. for National Science Foundation

PURPOSE

The purpose of this study was. twofold: to develop analytical methods to evaluate national energy policies for the auto and to apply those methods in a systematic analysis and comparison of several alternate policy instruments. Two types of policies were considered: raising the price of driving and improving average auto fuel economy. The study results were reported in a statement of testimony to the U.S. Senate in 1974; the testimony was then commented upon by auto manufacturers.

\section{ASSUMPTIONS}

The base case reflects existing trends and market forces in the absence of new policy intervention. Some base-case assumptions are given in Table 15; other assumptions are listed below.

- All new cars will be equipped with radial tires, air conditioning equipment; rates by market class, same as current rates. An average nationwide temperature of $70^{\circ} \mathrm{F}$ is assumed (to predict savings due to elimination of air conditioning).

- Slight increases will occur in market shares of compacts and subcompacts compared with 1973 (37\% full-size, $18 \%$ intermediate, $17 \%$ compact, $28 \%$

Table 15. Base Case Assumptions (constant 1975 dollars)

\begin{tabular}{|c|c|c|c|}
\hline Characteristic. & 1975 & 1985 & 1995 \\
\hline \multicolumn{4}{|l|}{ Demographic } \\
\hline Households (millions) & 69.0 & 81.8 & 91.6 \\
\hline Economic & \multicolumn{3}{|c|}{. } \\
\hline $\begin{array}{l}\text { Income growth } \\
\text { Car price }\end{array}$ & \multicolumn{3}{|c|}{$\begin{array}{l}1.9 \% \text { avg. annual growth rate } \\
\text { increases at same rate as } \\
\text { overall inflation. }\end{array}$} \\
\hline Gas price/gallon & $\$ 0.67$ & $\$ 0.67$ & $\$ 0.67$ \\
\hline Auto fleet size (thousands) & 90.8 & 134.0 & 186.0 \\
\hline \multicolumn{4}{|l|}{ Policy } \\
\hline Speed limit & $55 \mathrm{mph}$ & $55 \mathrm{mph}$ & $55 \mathrm{mph}$ \\
\hline New-car fuel efficiency & $16 \mathrm{mpg}$ & $16 \mathrm{mpg}$ & $16 \mathrm{mpg}$ \\
\hline
\end{tabular}


subcompact). If full- and intermediate-size cars are, phased out, the relative shares of compacts and subcompacts will be the same in 1976 and beyond as they were in 1975 ( $38 \%$ and $65 \%$, respectively).

- Vehicle miles of travel (VMT) will grow more slowly than auto ownership (opposite of experience in recent past). Gas consumption will grow more slowly than VMT (opposite of experience in recent past).

- No further fuel-economy penalties beyond those associated with compliance with 1973 safety and emissions standards will be, imposed in the base case or any other case.

- In the base case, independent adoption of new technology by industry is not considered.

- The supply of gas for auto travel is assumed to be perfectly elastic so that all increased gas taxes will be reflected in the pump price.

- Predicted fuel savings due to minor vehicle changes are based upon a complete redesign of the car (e.g., use of radial tires results in a lower power-weight ratio; a vehicle designed with this lower ratio will have a better fuel efficiency).

METHODOLOGY

Two policy packages were compared over the 20-year period from 1975 to 1995 on the basis of these impacts: automobile fleet gasoline consumption ... direct and indirect fleetwide energy consumption.... fleetwide user cost ... fleetwide vehicle miles traveled (VMT) ... new car sales ... employment in five sectors (auto manufacturing, tire manufacturing, retail and wholesale trade in auto parts and accessories, auto dealers, and service stations). Four computer models were used to determine these impacts: generalized automobile design model ... automobile-fleet-mix model ... econometric model to project VMT, auto ownership, energy consumption, and new car ownership ... econometric model to project employment.

The following policy measures were evaluated: raise the price of driving. through additional gas taxes, tax on new car purchases, and tax on ownership ... improve average auto fuel economy through mandated maximum weight standard, mandated technology changes, mandated new-car average-fueleconomy standard ... combination of mandated maxium weight and technology changes.

\section{CONCLUSIONS}

$\underline{\text { Pricing Policies }}$

of the three pricing measures tested, only the first, imposing additional gasoline taxes, would save fuel (acc Table 16). A $r$ ax on new-car ownership would increase the average new-car price, which would in turn decrease the volume of new-car sales and decrease the volume of automobile retirements. Gas consumption and VMT would remain unchanged. Even a graduated tax favoring more energy-efficient vehicles would lead to increased overall prices for new cars. This increase would cause the automobile turnover rate to fall, thereby lessening the effectiveness of such a graduated 
tax. Likewise a tax on new- and used-car ownership would not affect VMT or gas consumption. Rather, sales of both new and used cars would drop. The used-car tax, however, would tend to negate the effecl's of the new-car tax: more used cars would be scrapped and replaced with new cars so that new-car sales would not drop as much as with just a new-car tax.

From 1975 to 1990, every additonal one cent. in fuel tax would result in approximately a $1 \%$ fuel savings over the base case. After 1990, the fuel savings will decrease to $0.6 \%$ for every one cent of gas tax. In addition, a gasoline tax would, in the short term, reduce fleetwide emissions, reduce employment in all five sectors, and reduce annual auto user costs. Over the long term, it would reduce auto ownership, reduce VMT, and reduce employment in the sales and services sectors. The reductions are all with respect to the base case and their magnitudes would depend upon the size of the tax. Finally, a gasoline tax would have a greater impact on commuters from low-income families than on those from middle- and high-income families.

\section{Auto Design Measures}

The four policies to improve average auto fuel economy would have similar effects (see Table 17). The weight standard policy would phase out ful1- and intermediate-size cars at a rate of $20 \%$ per year from 1976 to 1980 . Mandated technology changes would require a conversion to the continuously variable transmission (CVT) and the supercharged, stratified, rotary sparkignition engine (SIE) at a rate of $20 \%$ per year beginning in 1980 . The auto design policies would not change new-car sales and auto ownership, would increase VMT roughly in proportion to gas savings, would increase fleetwide emissions, would reduce user costs; and would either decrease or increase employment, depending upon whether reductions in manufacturing employment are caused by changes in auto weight. A mandated weight standard would conserve more fue 1 than mandated technology changes during the first 10 years of analysis. From 1985 to 1995, however; the converse would be true. Of the design policies considered, the combination of these two mandates would save the most fuel throughout the 20-year period. The impacts of mandated fuel efficiency are very close to those of mandated technology changes.

\section{Summary Findings}

In the near term (one to four years), the only way to achieve significant fuel savings is to increase the pump price. In the longer term (seven to eight years), auto design policies offer greater potential for conservation than do price policies. Neither type of policy dominates, however, because of the other impacts (social, environmental, economic). Imposition of a higher tax on new-car sales, even a graduated tax, offers little potential for fuel conservation. Improvements in average new-car fuel economy, which involve the lowest new-car price, will reduce total automotive gas consumption the most. 
Table 16. Impacts of Pricing Measures (\% change from base case)

\begin{tabular}{|c|c|c|c|c|c|c|c|c|c|}
\hline \multirow{2}{*}{ Measure } & \multicolumn{3}{|c|}{ Fuel Consumption } & \multicolumn{3}{|c|}{ VMT } & \multicolumn{3}{|c|}{ New-Car Sales } \\
\hline & $1975^{\circ}$ & 1985 & 1995 & 197.5 & 1985 & 1995 & 1975 & 1985 & 1995 \\
\hline $\begin{array}{l}\text { Additional gas taxes } \\
\text { to increase fuel } \\
\text { price by } 50 \%\end{array}$ & -34.6 & -35.3 & -32.4 & -29.8 & -30.5 & -27.1 & -32.5 & -1.8 & -1.4 \\
\hline $\begin{array}{l}50 \% \text { average new-car } \\
\text { price increase }\end{array}$ & +3.0 & +3.1 & +2.5 & +3.0 & +3.0 & +2.5 & -10.5 & -11.7 & -10.3 \\
\hline
\end{tabular}

Table 17. Impacts of Auto Design Measures (\% change from base case)

\begin{tabular}{|c|c|c|c|c|c|c|c|c|c|}
\hline \multirow{2}{*}{ Measure } & \multicolumn{3}{|c|}{ Fuel Consumption } & \multicolumn{3}{|c|}{ VMT } & \multicolumn{3}{|c|}{ New-Car Sales } \\
\hline & 1975 & 1985 & 1995 & 1975 & 1985 & 1995 & 1975 & 1985 & 1995 \\
\hline $\begin{array}{l}\text { Maximum weight } \\
\text { standard }\end{array}$ & -1.5 & -16.2 & -18.4 & +1 & +15.3 & $+17: L$ & 0 & $\begin{array}{l}0 \\
\cdots\end{array}$ & 0 \\
\hline Mandate technology & -1.1 & -20.2 & -34.1 & +0.7 & +19.7 & $+39 . \Xi$ & 0 & 0 & 0 \\
\hline $\begin{array}{l}\text { Mandate new-car } \\
\text { fleet mpg }\end{array}$ & -1.1 & -20.2 & -34.1 & +0.7 & +19.7 & +39.3 & 0 & 0 & 0 \\
\hline $\begin{array}{l}\text { Mandate weight } \\
\text { standard and } \\
\text { technology }\end{array}$ & -1.5 & -26.2 & -40.3 & +1 & +27.4 & +51.0 & 0 & 0 & 0 \\
\hline
\end{tabular}




\section{Study Implications}

If the government subsidizes automobile research and development for fuel conservation, the program should include support for work on the CVT and the SIE. Average required fuel-economy ranges of $16 \mathrm{mpg}$ to $20 \mathrm{mpg}$ in proposed legislation may be too low, as. the study shows that standard-size cars could achieve over $25 \mathrm{mpg}$ and subcompacts over $40 \mathrm{mpg}$. If national conservation objectives are stated in terms of constant-percentage gas consumption savings over time; it is possible to select combinations of declining taxes and regulatory policies to achieve such objectives.

\section{Automobile Manufacturers' Comments}

The four U.S. auto manufacturers (American Motors, Chrysler, Ford, and General Motors) submitted comments to the Senate concerning this study. They all felt that the study overestimated possible fuel savings. In particular, their criticisms were:

- Fuel savings predicted for elimination of air conditioning were based upon complete redesign of the vehicle, not upon simple removal of the air conditioner. This redesign is infeasible in the short term. Similar criticisms were made regarding reductions based upon vehicle weight reduction and radial tire use.

- Fuel savings due to improved aerodynamics are exaggerated:

- The study considers a new technology (i.e., CVT) to be capable of mass production at the time when its feasibility is being proven.

- The study does not recognize the loss in fuel economy due to 1977-1978 emissions standards.

Rand responded to the comments by stating that it stood by the study's qualitative conclusions, and that the quantitative results were meant only to estimate potential gas savings. Rand further explained that while the technologies cited in the report might not be available until later, the analyses were structured to indicate whether major or minor gains would be achievable. 
Three volume report: THE ROLE OF FEDERAL R\&D ON

Mode: HIGHWAY

ALTERNATIVE AUTOMOTIVE POWER SYSTEMS (1974) ...

FEDERAL SUPPORT FOR THE DEVELOPMENT OF ALTERNATIVE

AUTOMOTIVE POWER SYSTEMS (1976) ...

ISSUES IN FEDERALLY REPORTED RESEARCH ON ADVANCED

AUTOMOTIVE POWER SYSTEMS (1977)

Massachusetts Institute of Technology for National Science Foundation

\section{EXECUTIVE SUMMARY*}

Supply orientod: evaluates alternative power systems versus internal combustion engine

Demand Oriented: examines impact of federal regulation on auto K\&D; federal role in $R \& D$

Economics: evaluates costs of developing alternative power systems.

Institutions ; public versus private critical issues are laid out; putential role of federal $R \& D$ analyzed

Network Coverage: national implications

System Coyerage: roads

Product Coverage: vehicles, motive. power, system operations
MIT pruduced a serles ot threp reports that are interdependent in their presentation and should be considered as one. The study is not a technical evaluation of alternative automotive cngincs; it is a description of the context within which the development of the more attractive of these engincs is occurring, and it seeks to define appropriate objectives for federal $R \& D$, if any, within this context. The relevant time frame coincides with the continued use of, or search for alternatives to, the internal combustion engine.

Federal support with the explicit objective of, advancing the relevant technology is addressed; the technical, economic, and institutional rationales for implementing alternative automotive power systems are analyzed. This study examines four technologies in detail: the Stirling, diesel, electric power, and gao turbinc systens.

The impact of federal regulation on $R \& D$ incentives for the automotive industry (i.e., the Energy Policy and Conservation Act of 1975. and the Clean Air Act of 1977) is examined, as is federally supported $R \& D$ on the automotive gas turbine. Additionally, the study analyzes the issues of federal research strategy.

A revicw of natiunal gudls regarding air pollutant emissions and energy consumption of the automobile -- and the possible policy instruments for achieving these goals -- suggests that although federal R\&D had been used in the past to "lever" the industry, it is unlikely to be effective in the

* Separate abstracts for the three volumes follow this summary. 
future in that role, either politically or technologically. For the purpose of supporting regulation and policy development and advancing the state of the art, federal R\&D might have an important role to play depending on the extent of activities within the industry. To be effective, federal $R \& D$ would be confined to the earlier stages of hardware development where the cost would not be prohibitive, and where manufacturing and consumer acceptance considerations would not be overriding. In spite of the apparently fixed standards and deadlines in the Clean Air Act, the emission standards are in reality coupled to the available technology. The standards have been, and in the future will continue to be, adjusted to levels that the dominant internal combustion engine technology can meet.

The incentives to the manufacturers are probably not sufficient to cause them to perform all the alternative powerplant R\&D that can be justified on the basis of the potential net social benefits from reduced auto emissions. The advantages of a reduced dependence on foreign petroleum supplies result in a similar incentive for $R \& D$, beyond that provided by the marketplace. The benefits to public policy development are even more unlikely to be fully accounted for in industry R\&D budget decisions.

The central issue is the process by which an alternative powerplant would be introduced into the present passenger-car distribution and maintenance system. The experience with the Manhattan and Apollo projects has led to unwarranted expectations for rapid changes in the impacts of the passenger car fleet. Because of the lead times needed to replace the inventory of manufacturing equipment and then of the in-use vehicles, successful alternative powerplant $R \& D$, whether in industry or government, would not substantially affect the average characteristics of the passenger car fleet until at least a decade after its completion.

Comparison shows that there are a number of candidates whose emissions and fuel consumption characteristics are potentially superior to those of the present internal combustion engine, but that each alternative has at least one important attribute in which it is inferior. There is no powerplant that currently stands out as broadly superior to the present internal combustion engine, and the uncertainties regarding the future attractiveness of the more promising alternatives will not be resolved until substantial further development takes.place. The internal combustion engine has considerable remaining potential for development. One cannot now forecast whether the optimum passenger-car powerplant of the medium-term future will be the internal combustion engine, an alternative, or whether it will even be a single engine for all passenger cars. Because the passenger-car powerplant has such a significant influence on the national air pollution and energy problems, it is important that economically justifiable efforts in attaining the options not go unattended. 
THE ROLE OF FEDERAL R\&D ON ALTERNATIVE AUTOMOTIVE POWER SYSTEMS (1974)

Mode: HIGHWAY

Massachusetts Institute of Technology for National Science Foundation

EXECUTIVE SUMMARY -- see page 122

PURPOSE

This study was designed to provide guidance for evaluating proposed federal R\&D programs on alternative automotive power systems. This report was the first in the series of three reports described on page 122. The nhjertive is not to provide a technological evaluation of alternative automotive engines, but rather to describe the context within which the development of the more attractive of these engines is occurring. The report seeks to define appropriate objectives for federal R\&D, if any, within this context. The scope of the study is limited to proposed efforts on alternative powerplants; it does not deal with the areas of alternative fuels, advanced concepts for the internal combustion engine, safety, or any other area, although the methodology developed may be appropriate in these other areas as well.

The report focuses on questions of public policy since the relevant technology has been adequately addressed elsewhere. This report examines the question: Is it appropriate for the federal government to support R\&D on alternative automotive powerplants? Specifically, it addresses the appropriateness of major new expenditures of public funds for advancing alternative automotive powerplant technologies with the explicit goal of significantly increasing the probability of their incorporation into future American passenger cars.

\section{APPROACH}

Past and current industry and government programs were examined, the critical issues laid out, the various possible objectives. for federal R\&D examined, and the potential role of such a program as a policy tool for meeting the relevant national goals was analyzed.

\section{METHODOTIOYY}

For data sources, the researchers relied upon their experience and knowledge in the area, the available literature (technical publications, Congressional hearings, trade journals, etc.), and interviews with personnel in industry, government, and the academic community. From this foundation they developed their analysis of the issues. Data were subject to a number of difficulties, e.g., the automobile manufacturers and government agencies involved in this very controversial area are under pressure to say and do the "right" things. Other complications encountered in information gathering and 
analysis included the difficulty of determining the underlying basis of agency or corporate policies, the proprietary nature of much industry data, and the difficulty in making generalizations about the "Big Three" automobile manufacturers when there are significant differences among them. Because of these problems in gathering data, some findings cannot be stated in an unqualified manner.

\section{CONCLUSIONS}

The study concluded that there is a convincing justification for the federal government to support research and development on alternative automotive powerplants.

The uncertainty regarding the future attractiveness of the more promising alternatives to the internal combustion engine can only be resolved through research and development efforts. Since the passenger-car powerplant has such a large influence on national air pollution and energy problems, it is important that economically justifiable efforts toward attaining the optimum be pursued.

However, only certain objectives and certain levels of effort are appropriate for federally supported $R \& D$ in this area. The most important objectives are providing information to support regulation and policy development and advancing the state of the art. The former is clearly the responsibility of the federal government, and a sounder framework for such R\&D needs to be developed. Depending on industry activities, federal R\&D can play an important role in the latter objective in the earlier stages of the hardware development process, where manufacturing and consumer acceptance considerations are not overriding.

. The incentives to the automobile manufacturers are not sufficient to cause them to perform all the alternative powerplant R\&D that can be justified on the basis of potential social benefits from reduction in emissions. The primary reason for this is that the emission standards in the Clean Air Act are in reality coupled to the available technology -- the internal combustion engine. In the area of fuel economy, the incentives and national goals are less clear, but there may be a divergence here as well.

Industry programs on a number of alternative powerplants are substantial, but they leave significant gaps. They reflect a reasonable allocation of internal funds to this area, given the current potential of alternative engines and the uncertainty regarding future regulations. However, there are projects that industry is not now supporting that appear to be economically justifiable from the standpoint of public policy.

The principal goverment program in this area has been the advanced automotive power systems program. The program has not contributed significantly to advancing the state of the art, but this was never a major program goal. It has been of significant value in providing a focus for alternative powerplant activities and exchange of technical information, and it has contributed to long-range policy planning. Industry R\&D activities could not have served these important functions. 
There is therefore convincing justification for federal support for R\&D on alternative automotive powerplants. Some alternative engine technologies are not receiving adequate attention within the automobile industry for sound reasons that are unlikely to change; a government program can support projects that are justifiable from a public standpoint but not from a private one. Such a program can make substantial contributions to national air pollution abatement and fuel conservation goals by advancing the state of the art of selected engine technologies and by producing the technical data necessary for. developing regulations and other policies. A rough estimate of number of projects and project costs suggests that a two- to five-fold increase above current alternative powerplant funding -- to between $\$ 15$ million and $\$ 35$ million annually -- would be required. The overall goals of such a program would be to reduce the risks inherent in developing and introducing those alternative engines that may have long-term economic and public benefits and that are not now receiving adequate attention, by reducing the current technological and regulatory uncertainty to the point where normal market decision making mechanisms would be in better alignment with social objectives. 
FEDERAL SUPPORT FOR THE DEVELOPMENT OF ALTERNATIVE

Mode: HIGHWAY

AUTOMOTIVE POWER SYSTEMS (1976)

Massuachusetts Institute of Technology for National Science Foundation

EXECUTIVE SUMMARY -- see page 122

PURPOSE

This report was the second in the series of three described on page 122. The first volume (see page 124) concluded that there was convincing justification for federal support for $R \& D$ on alternative automotive powerplants. Subsequently, this report addressed the explicit objective of advancing the relevant technology. The technical, economic, and institutional rationales for implementing alternative automotive power systems are analyzed.

\section{APPROACH}

This report examines three proposed technologies in detail. (the Stirling, diesel, and electric power systems) and broadens the analysis to include technological and structural issues and some stages of the technology introduction process not ordinarily considered "R\&D."

\section{ASSUMPTIONS}

- The general structure of the Clean Air Act is assumed to be retained.

- The schedule of emissions standards for future vehicles and its evolution over time is treated as uncertain.

- Because of the inherent time scales involved in the development and marketing of, and conversion to, an alternative powerplant, the "available technology" has been and will continue to be that of the internal-combustion-engine-powered systems.

Within this framework the selected alternative power plants are compared against the base-case internal combustion engine using the following key attributes:

$$
\begin{aligned}
& \text { emissions } \\
& \text { noise } \\
& \text { fue } 1 \text { economy } \\
& \text { safety } \\
& \text { cost } \\
& \text { starting ease } \\
& \text { drivability } \\
& \text { performance }
\end{aligned}
$$

response to abuse and neglect design horsepower versatility control ease producibility size weight ability to be integrated in vehicle 
METHODOLOGY

The analysis begins with a brief examination of the present market for passenger cars, including the supply side (principally the Big Three General Motors, Ford, and Chrysler), the demand side, and the present government interventions. The study examines past and likely future handing of major technological changes, such as the development and introduction of a new powerplant. A simple descriptive model for this process of "technology development and production" is developed; the model consists of sequential stages of development or productive activity, and intervening decisions to advance, continue, or terminate an evolving system.

\section{CONCLUSIONS}

General Conclusions

There are a number of potentially attractive alternatives to the internal combustion pngine. For exaüple, Lhe Ránkine and Stirling cycle systems stand out with low emission levels resulting from the use of external combustion; the diesel, stirling, and open-chamber stratified charge systems offer potentially substantial fuel-economy improvements with their high thermal efficiencies, and the wankel offers compactness and light weight.

However, each alternative engine now appears to be significantly inferior to the internal combustion engine in at least one important attribute. For example, the Wankel has high fuel consumption and hydrocarbon emissions, the diesel emits odor and particulates, and the Stirling engine is expensive to manufacture. Most of the deficiencies are in areas ultimately related to consumer acceptance. No one powerplant can now be confidently projected as broadly superior to the internal combustion engine.

The internal combustion engine itself is the subject of extensive. development programs to improve its fuel economy and lower its emission levels while preserving its other attractive features. Advances in mixture preparation, ignition, exhaust gas recycling systems, catalytic converts, and basic engine design can be expected.

Whether the optimum powerplant for the last two decades of this century will be the internal combustion engine, an alternative, or whether it will even be a single system for all passenger cars cannot now be confidently forecast. The potential for major gains in ambient air quality and aggregate fuel consumption makes continued development. programs in this area worthwhile.

\section{Policy Conclusions}

A detailed analysis concluded that there was solid ground for government support for $R \& D$ on alternative automotive power systems due, in significant measure, to the unintended effects of government regulations. The regulations result in a disparity between the social. and private benefits of long-range R\&D due to: (1) the disparity between the value of automotive 
fuels and their market price, caused principally by a national goal for security from dependence on foreign supplies not reflected in the market price and government price controls that hold the market price of automotive fuel well below its value to the nation, and (2) the Clean Air Act, which forces the industry to focus its $R \& D$ resources on technology available in the very near term, thus reinforcing its natural predilection toward small and evolutionary changes, and which adds risk to long-term investments due to uncertainties in the standards of the regulated air pollutants, the possibility and unpredictable level of standards for presently unregulated air pollutants, and possible government response to the availability of new technology.

\section{Additional Conclusions}

The barriers to entry in the automotive industry, and the Big Three's demonstrated willingness and ability to respond to technological threats from other automobile manufacturing firms, imply that U.S. auto makers do make major technological product changes when external technological threats must be averted, and also, though less certainly, when significant technological opportunities arise.

Major technological change in this industry is a very risky business. This is due in part to the replacement nature of the demand for automobiles; i.e., most new cars are sold as replacements for old ones and therefore the decision to buy a new $c a r$ is one that usually. can be easily postponed. In part it is also due to the level of performance and cost optimization achieved in the continuous evolution of the automobile, whose principal subsystems are mostly improved versions of those used continuously for nearly half a century. These features result in a demand for automobiles that is highly variable and unpredictable, both over time and in its response to various technological attributes, and a manufacturing process that is highly capital intensive and thus relatively inflexible. Any major technological change must therefore be preceded by a lengthy and expensive R\&D process, and major investments in plant and automated mass production equipment, before being introduced into the marketplace.

There are steps the manufacturers can take to reduce the possible dollar loss associated with the failure of a major technological product innovation, principally associated with designing the innovation for a high degree of "integratability." This and other measures taken to hold down the total initial investment in the innovation, both in the Big Three and in associated support industries (especially fuel supply), provide an "introduction barrier" that an innovation must overcome before its advantages can be fully realized by consumers.

The history of government involvement in the automobile industry has further added to the uncertainties involved in major changes, as perceived by the industry.

The necessarily lengthy stages of technology development and production, plus the subsequent turnover of the in-use fleet, mean that 15-20 years would elapse from commencement of an intensive R\&D program on a major technological innovation until the resulting significant change in the average attributes of the nation's automobile fleet. 
ISSUES IN FEDERALLY REPORTED RESEARCH ON ADVANCED AUTOMOTIVE POWER SYSTEMS (1977)

Mode: HIGHWAY

Massachusetts Institute of Technology for National Science Foundation

EXECUTIVE SUMMARY -- see page 122

PURPOSE

This report builds on and extends the two reports described on pages 124-129. The study examines the impact of two changes in the structure: of federal regulation oin RGD incenclives tor the automotive iudustry. The first change, which occurred in December 1975, was the passage of the Energy Policy and Conservation Act, which mandates fleetwidé fuel-economy standards for the automobile manufacturers. The cocond ehange was in August $19 \%$, when the Clean Air Act was amended and a new schedule of emission standards became law. The Clean Air Act is one of the major determinants of the extent and direction of $R \& D$ on automotive power systems.

The study also examines federally supported $R \& D$ on the automotive gas turbine. Due to project funding limitations, the gas turbine was chosen to represent the general class of advanced heat engines. The analysis focuses on economic, public policy, and organizational issues.

Additionally, the study examines the issues of federal research strategy. Resources were not available for detailed study at a lower hierarchial level of "strategic" decisions -- the number of different types of engines to be supported, the number of different funds to be involved, etc. This set of questions is defined and examined.

\section{METHODOLOGY}

The methodology used to evaluate the impacts of the regulatory changes is basically intellectual evaluation. To assess the "value" of the gas turbine, an analytical framework similar to that used in the second report in this series is employed.

\section{A Simple Vehicle Total Operating Model}

A simple calculation procedure (model) is developed for comparing the "total lifetime operating cost" (initial outlay minus scrap recovery and direct operating costs) of a vehicle equipped with an alternative powerplant to the cost of one having a conventional ("baseline") internal combustion engine (ICE). The model brings out the role of key engine attributes in determining total operating costs, allowing investigation of trade-offs other than just those between initial powerplant cost and efficiency attributes. First, the physical configurations of the altcrnative powerplant and 
ICE vehicle systems are established with the ICE-powered vehicle and what are considered to be appropriate consumer acceptance criteria as a starting point. Second, an equation for determining the total lifetime operating cost associated with these configurations is formulated.

As discussed above, the style of the analysis is one of drastic simplification. The purpose of the model is to crudely estimate the economic benefits available from an alternative powerplant and the key dependencies and uncertainties of those benefits. Detail is retained in the model only as necessary to adequately meet this purpose.

\section{System Configuration}

A consistent basis for comparison of engine technologies was estab1 ished by defining "powerplants" to include the engine and all auxiliaries such as fans, radiator, generator, battery, cooling systems, emission controls (if any), and transmission. Thus all elements of the automobile exogenous to the powerplant are common to all technologies.

Before the total operating costs and benefits associated with altèrnative powerplants were estimated, it was necessary to establish the total powerplant-vehicle system configuration. The description of system configuration was limited to the principal extensive powerplant attributes -- power and weight -- and the major vehicle attribute -- weight.

The Stirling engine work proceeded in the following manner. First, the state of the technology and present R\&D programs were examined. Then a simple social cost-benefit analysis of government investment in Stirling R\&D was performed. This required simple models of the operating economics of Stir1 ing-powered vehicles, the change of the engine's attributes during the R\&D process, and the impact of increased investment on the probability of R\&D success. The principal conclusions of the social and economic analysis were that (1) the uncertainty in the estimate of maximum allowable premium (for positive total social operating benefits) of stirling engine cost over the ICE cost, the engine attribute on which R\&D efforts are focused, is large -- plus or minus half of the maximum premium; (2) the magnitude of the likely total social operating benefits is similarly uncertain, up to several tenths of a cent per mile, thus making cost-benefit calculations extremely tenuous; (3) the status of present $R \& D$ prograns is such that the incremental impact of government funding on the probability of R\&D success is significant; and (4) an investment of several hundred million dollars over five to ten years is likely to be a very good gamble. Next, the process by which the Stirling engine would be introduced into commercial use was examined; an analysis of the disparities between the economics, when examined socially and privately, indicated how a socially beneficial engine might not meet private decision criteria, and the implications of this for the government programs were discussed. Finally, the proposal by the Ford Motor Company for support of its Stirling R\&D effort was considered and it was. concluded that such a sharedcost program was likely to be a good framework for support of Stirling engine R\&D. 
CONCLUSIONS

Federal Regulatory Changes

The industry programs have been developed primarily in response to the air pollution emission standards and the "good faith" requirements of the Clean Air Act. The standards and the uncertainty in their future levels have also made some otherwise potentially attractive projects too risky for industry funding. The study concluded that the industry programs reflect a reasonable approach to the allocation of internal funds to this area, given the potentials of the different engine technologies and the current environment for alternative powerplant development that the government and the public have created. However, there are social benefits not counted by industry that appear to make advanced powerplant R\&D economically justifiable from a public policy standpoint.

The Gas Turbine Engine

The new "upgraded" gas turbine system roughly matches the contemporary ICE in fuel economy and the other important: coneumer attributes and surpasses it in emissions reduction. However, its production costs are too high to make it attractive to consumers. The present engine could probably be put into production in five to eight years; during that period technology changes in the production ICE would allow it to roughly hold its own on efficiency while it met tightened emission standards. Thus, while advances have been made, they have not been sufficient to make the available gas turbine engine technology competitive with the contemporaneous ICE.

Only the most optimistic cost estimates bring the system within the economic range. Substantial uncertainty surrounds these calculations, but the qualitative conclusion seems sound. Further, it is true whether one makes the calculation from the point of view of society as a whole or from that of a private individual.

The economic properties of the gas turbine vehicle have been limited by the available materials technology. The efficiency and power output of a heat engine depend strongly on the maximum temperatures of the thermodynamic cycle. But technical uncertainty, be it in product or process technology, is subject to resolution -- through research and development. The potentially. very large, but simultaneously very uncertain, benefits available from a ceramic-based automotive gas turbine engine make it. an excellent candidate for a major R\&D effort. But this leaves unaddressed the question of who can be expected to pay for this R\&D. The high value of the pulential, benefits does not alone justify the expenditure of taxpayer revenues, since the essential arguments should hold well in corporate board rooms as well.

The major automotive manufacturers claim that their ceramic gas turbine development programs will progress without government assistance, but that the rate of progress would be greatly accelerated if supplemental government support were available. The study concludes that the traditional economic -argument for federal support of the development of advanced technology is a most compelling one in this case. It is difficult for any single private 
entity to be at all certain of capturing more than a small fraction of the benefits that could result from a ceramic gas turbine R\&D program. The principal benefits might not even occur in the automotive sector.

The analysis indicates that the ultimate success of a gas turbine development program will depend on the process by which the engine is integrated into a system optimized for ICE-powered vehicles. The gas turbine can generate more power per unit weight than the ICE and can burn a less-refined fuel. A substantial part of the economic attractiveness of the system is lost if a new vehicle body is not designed for the engine, or if a distillate fuel is not widely available. The automotive industry, in combination with the petroleum industry, has generally moved very gradually into engine innovations, and these practices will likely continue. R\&D. programs are weak tools for dealing with such difficulties. However, the development and introduction of a ceramic-based gas turbine engine are sufficiently distant that such transitional difficulties neer not be a significant concern at the present time.

\section{Choosing a Federal Strategy}

The ambiguity related to advanced engine $R \& D$ arises from two main sources: lack of full information about current and future projects and disagreement among parties about available information.

At this time, there is a high degree of uncertainty about the potential of the competing engine designs that might be introduced successfully in the late 1980s. With such a long time horizon, disagreements within firms and across firms about the best course of action seem very legitimate. The R\&D agency should recognize these disagreements and weigh the firms' opinions according to their allocation of inhouse funds to different projects. Clearly firms give strong signals in their budgets about their estimates of the potential likelihood of an engine introduction. The agency could disagree reasonably with some or all of the firms on certain technical and economic judgments. However, the agency should check before funding a privately "underfunded" project to see whether it truly has positive "social" potential and is not an unatractive project from the perspective of all parties. In particular, the federal R\&D agency should respect the manufacturing and marketing expertise of the Big Three firms, which should certainly exceed that of the government.

There are persistent problems associated wtth contracts between parties. As stated previously in the discussion of company responses to government funding, one can never determine exactly the differences between company plans with and without goverument funding. Currently, government support to advanced engine R\&D still represents a small fraction of the total Big Three allocation to technology development. However, with the availability of long-term government support, the burden of financing research could shift, at least in part, from the Big Three to the public.

There are also difficulties associated with the limited number of potential parties with which the R\&D agency can contract. Frequently the government will be constrained to accept bids from as few as three contractors 
(or not even all of the Big Three). For development of engine systems components and more basic research, the government may face more candidates. Presumably the Big Three are capable of hiring subcontractors so as to complete their tasks more efficiently. With some negative political side effects the R\&D agency could hire foreign automobile manufacturers; however, this would probably create problems in monitoring contracts. Foreign firms also have less concern for the peculiar problems of doing business in the American automobile market.

In all contracts between parties, one can potentially confront a "moral hazard." In examining outcomes after the fact, one cannot always separate chance occurrence from events created by a party's specific decision. In the general case of advanced automobile engine development, no particular problems should arise since the firm and the R\&D agency both presumably desire a favorable outcome for the program. However, if a firm carries out parallel development programs, one supported by its own funds and the other supported by the government (requiring some limitations on the firm's patent and licensing rights), success may "automatically" shift only to the companysponsored work.

The lack of precedent for government R\&D support in the automobile industry creates several potential hazards. In particular, considerations often reputed to be politically important cannot be met clearly by any one R\&D agency's strategies. There are no promises of early commercial payoffs for an advanced engine. Certain engines, such as the metal gas turbine and Ford's Stirling engines, could be demonstrated soon in actual vehicles. Yet neither engine is even nearly ready for commercial introduction. These engines are "research tools," not "commercial" engines. The expected high rate of failure of the advanced engine programs also seems unpalatable for the public. With extensive additional expenditures, the government can force programs to achieve technical success. However, it cannot force commercial acceptance for a risky, new consumer product. Finally, there is considerable political disagreement concerning the appropriateness of duy guvernment intervention in the later stages of product development. Iu pallicular, different parties place more or less emphasis on fairness in the allocation of government support and on the smoothness of the automobile industry"s transition to a major new engine.

Inherent in the concept of a "otrategy" is a cuhterent plan that designates actions contingent on a variety of potential outcome. A true strategy requires consistency in goals and methods for meeting those güals. It also requires flexibility in modifying actions in response to new information and circumstances. Thus, the federal R\&D agency must strike a balance between consistency and flexibility in maintaining a strategy over time. Certainly, without a stable strategy, the R\&D agency merely introduces into the business environment of the U.S. automobile industry one more source of government-induced uncertainty. 
RFGULATING THE AUTOMOBILE (1977)

Mode: HIGHWAY

Massachusetts Institute of Technology for National Science Foundation

EXECUTIVE SUMMARY

Supply: analyzes technological factors that influence automotive supply

Environmental Impacts: ecological, economic, and societal

System Coverage: road

Network Coverage:

urban and interurban

Product/Process:

vehicles and associated equipment, regulatory system

R\&D Issues: more analysis needed to improve system of auto regulation
Five analyses aimed at clarifying the nature of the American system of automotive regulation, that system's impact, and the reasons for its structure are presented in this report. A comparative analysis of safety, fuel economy, and emissions regulation yields insights concerning the effects of the different types of regulatory standards on manufacturers' incentives for equipment durability and for development of innovative technology. The nature and extent of uncertainty in automotive emissions control are examined for four key variables: prediction of vehicle emissions, prediction of ambient air quality, measurement of emissions, and measurement of air quality. The impact of the corporate average fuel economy standards on pricing and structure of the automotive industry are examined in a microeconomic analysis. The study also explores the political choice between standards and taxes for controlling automotive emissions. Finally, the political history of the Clean Air Act Amendments of 1970 is examined to understand the creation of the structure of the American automotive - emissions regulatory system.

PURPOSE

The automobile has become the major source of air pollution, the largest cause of accidental death, and the largest consumer of fuel in the United States. The automobile industry, one of the largest and most highly concentrated in the country, has a significant influence on the nation's economic and labor sectors. As the automobile and its producers continue to affect virtually every aspect of society, the need arises for more-efficient and more-equitable regulation of this sector. The present regulatory process is marred by administrative and political conflicts and inconsistencies. Modifying the regulatory system to address these and other underlying problems is by no means an easy task. Various regulatory alternatives have been suggested, but there is no definitive answer to such a complex problem. What may be possible are marginal improvements that provide better knowledge of consequences, help avoid some of the waste of human and material resources, and yield móre equitable trade-offs among the several competing objectives. 
This study attempts to contribute to the search for these improvements by developing a clearer understanding of the nature of the American system of automotive regulation, the system's impact, and the reasons for the regulatory structure.

\section{METHODOLOGY}

Through five independent studies, this analysis explores selected aspects of three questions about the automotive regulatory system:

- What do we do? Our current system evolved from three independent and largely uncoordinated legislative efforts. How does one develop a coherent framework for analyzing potential changes?

- What effects does the regulatory system have? The regulations are supposed to improve air quality, safety, and fuel ecullumy: How much do we know . about the results of these efforts?

- Why do we do it this way? Analyses of improvements in the regulatory system must take into account the political context out of which these laws and administrative rulings come. What does the legislative and bureaucratic history reveal about the American political system and its influence on auto regulation?

The individual studies incorporate extensive literature research and discussions with many individuals from government and industry. A considerable amount of data was supplied by the U.S. Environmental Protection Agency. The summary of each analysis is presented separately. No overall conclusion from the substudies is available in the original report, beyond the observation that continued policy analysis in emissions regulation regarding phasing of future standards, and the new vehicle rates vs. deterioration over the vehicle's life, could result in lower overall emissions.

The American System of Regulating the Automobile

\section{Purpose}

This study examines safety, air pollution, and fuel economy regulations in a comprehensive analysis of the American automotive regulation system. All three types of regulations are descriptively examined, in contrast to the present administrative structure for regulating the automobile, within which emissions regulation is viewed as a separate issue, from safety and fuel economy.

\section{Approach}

The evolution of the present regulatory system is reviewed and the issues associated with the standards used to force changes in passenger car technology are examined. One such issue is the difference in the structure of the standards among the three areas of regulation. Safety standards are generally set as numerical performance criteria or as design criteria for 
vehicle equipment or subsystems. The three pollutant emissions standards are a vector representing an overall measure of emissions performance and, as for safety, each vehicle in a manufacturer's new car fleet must meet the standards. Fuel economy standards, by contrast, are determined as the average across all vehicles in one manufacturer's fleet in a model year. The result has been to put pressure on the industry to develop technological fixes that could be implemented within the time constraints of each set of standards, resulting in incremental technical changes for air pollution control and more substantial changes under the fuel-economy regulations. With the burden of developing, and proving the feasibility of, new safety technology lying on the regulatory agency, emission and fuel-economy programs have been more aggressive than the safety programs.

With standards serving as a catalyst for changes in motor vehicle technology, research and development activities by both government and industry play an important role in development of, and compliance with, the standards. Thus, the study explores the relationship between governmentand industry-supported $R \& D$ programs that focus on the regulated attributes and the regulatory structure. Emphasis is placed on the emission and safety programs, for which data on government and industry behavior are available.

The study also examines and compares two other issues across the three regulatory areas: the role of consumer and operator behavior in meeting the national automotive goal, and measurement and analysis of data to determine compliance with and effectiveness of standards.

\section{Conclusions}

The greatest similarity among the three regulatory systems is that the principal policy tool is a mandatory technical constraint rather than a monetary incentive. The greatest difference is the type of standard used in each regulatory system. For emission control, the regulation is a set of three quantitative emissions limits (performance standards on the vehicle as a whole) that must be met by every vehicle produced. Safety standards are generally equipment standards, in that they specify in a relatively constrain-

ing fashion the requirements for particular vehicle subsystems. For fuel economy, the standard is an average imposed on each manufacturer's total annual sales of passenger vehicles.

Uncertainty in Automobile Emissions Regulations

\section{Purpose}

This study addresses the technical questions of how we 11 the impact of emission regulations on ambient air quality can be measured. Difficulties of measurement increase the uncertainties associated with predicting the changes in air quality and public health resulting from existing or proposed regulations. 
Method

In an attempt to quantify uncertainties in air quality and air quality trends, an improved trend analysis methodology was devised and applied to data from Kenmore Square, Boston. The other data used are from two sources: air quality data supplied by the U.S. EPA and meteorological data provided by the National Climatic Center. The daily average carbon monoxide concentration was chosen as the summary statistic. It appeared from the results to be feasible to correct ambient air quality data for the effects of meteorology. However, the stochastic components of these data had an internal structure that made it very difficult to measure trends without a very long time series of observation as the baseline.

\section{Conclusions}

There is a need to deal with the uncertainty in emissions regulation. The regulatory structure can respond flexibly to new knowledge. A mechanism $c$ an be developed for gathering information on progress in achieving regulatory goals. Also, research is a useful response to uncertainty. The study focused on a way to reduce this uncertainty by improving air quality monitors.

Corporate Average Fuel-Economy Standards and the Automotive Industry

\section{Purpose}

This study examines the impact of the 1975 Energy Policy and Conservation Act fuel-economy standards on the behavior of the automotive industry, examining the situation where the fleet average fuel-economy standards are constraining when using traditional pricing and marketing strategies. In this situation, auto makers must either break the standards and pay the penalties or take some other short-run action to meet the standards.

Method

It is assumed that an automobile manufacturer behaves as a profitmaximizing firm under some form of competition. Thus the firm will act to bring marginal return and marginal cost in balance in each vehicle line. Two behavioral responses are possible. First, the firm may be willing to violate the standard, pay the legally established penalties, and then add a marginal penalty to the marginal manufacturing cost of each car type. This, in effect, raises the competitive price of vehicles with poor fuel economy and lowers that of vehicles with high fuel economy. Second, a company may decide that it must meet the standard, which would require new pricing schemes and promote the sale of small cars over large ones. The impact on the industry structure would be manifested in each firm attempting to cross-subsidize the sale of low-priced smaller vehicles with high-priced larger cars. Those firms with the most production capacity in large cars would offer the lowest prices on small cars, and firms that produce fewer large cars would not have the advantage of cross-subsidies and would suffer significant losses. 


\section{Conclusions}

A tax rebate scheme, whereby a tax on inefficient cars would subsidize the purchase of efficient cars, could retain much of the regulatory force of the present law while vitiating some of the negative features. (Comment: the gas guzzler tax now in effect meets this description.)

Standards versus Taxes, the Political Choice

\section{Purpose}

The political choice between standards and taxes for controlling automotive emissions is explored in this study. The U.S. has chosen a regulatory system that applies mandatory standards of pollutant emissions and uses penalties to force compliance with these standards. An alternative system is one based on monetary incentives. Given economic competition, effluent charges offer an incentive to attain economically efficient levels of air pollution control, so that the trade-off between pollution costs and costs of control is optimally made. A taxation scheme would offer a continuing incentive to install pollution control devices and modify motor vehicle designs, and, over the long run, to develop new automobile technology.

\section{Method}

The question of why emission charges have been rejected in favor of standards and penalties is addressed by examining five specific areas: (1) the identification of pollution as a health problem, requiring elimination of the health hazard, (2) the predominance of lawyers and not economists in the policy process, (3) the use of tough regulatory standards as symbols in the political arena, (4) the positions of each interest group in the pollution control debate, and (5) the forces influencing the behavior of Congressional legislators.

\section{Conclusions}

The choice between standards and taxes made in the U.S. political arena is not based on "a rational calculation of the costs and benefits of each approach." Instead the choice is based on the emotional appeal that standards have, which is necessary to generate widespread support. This conclusion is drawn from the analysis method outlined, giving the most weight to the economic efficiency issues and to peculiarities of the legislative process, and the least weight to the issues related to public health legislation. 
Another View of the Politics of Auto Emissions Control

\section{Purpose}

This study is directly concerned not with the details of particular decisions, but with the broader social/political context that produced the present way of controlling auto emissions.

\section{Method}

This analysis of the automotive emissions regulations used the Wilson typology of American business regulation. In it, four classes are identified: (1) concentrated costs and benefits, (2) diffused costs and concentrated benefits, (3) concentrated costs and diffused benefits, and (4) diffused costs and benefits. Auto emissions regulation is seen as Case (4), not a well understood situation in the literature. It also is postulated that diffuse effects imply a less politically effective interest group.

\section{Conclusions}

The legislative process is based on the assumption that those who play important roles represent a complete set of the interested parties. The environmental groups represent those who benefit from stricter standards, the auto industry represents the loser, the Congress has attempted to balance them. Political externalities arising from our political system work against a solution representing minimum social cost to attain social benefits, however. There is no special interest group to speak up for the general public, as the environmentalists speak for the environment, and the auto industry speaks for its continued existence and reasonable profito. This implies that the cost passed on to the public in the increased price of automobiles is higher than that of the optimal solution. The problem of how to define a process that moves toward socially optimal solutions is left for future research.

\section{Comments}

No examples of how the situation might have worked better for the public, yet worse for the industry, are provided. This weakens the author's conclusions considerably. 
A TECHNOLOGY ASSESSMENT OF THE TRANSITION TO

Mode: HIGHWAY ADVANCED AUTOMOTIVE PROPULSION SYSTEMS (1974)

Hittman Associates, Inc., for the National Science Foundation.

PURPOSE

It appeared in 1971 that the automotive industry might have difficulty complying with the 1976 vehicle emission standards set up under the National Environmental Policy Act (NEPA) and the $1970 \mathrm{Clean}$ Air Act and Amendments. In reaction to these standards, both government and industry accelerated their work on alternative automotive propulsion systems. In June of 1971 , this study was undertaken to define and examine the interrelationships and secondary impacts resulting from a transition from the current internal combustion engine to alternate propulsion systems. It concentrated specifically on (1) the impacts on U.S. material and energy resources and the environment and (2) the social and economic impacts.

\section{METHODOLOGY}

The technical assessment of impacts involved in a transition from the current internal combusion engine (ICE) passenger car to one or more alternative propulsion systems was conducted according to the following nine-step procedure:

1. Establish the impact areas of principal concern. These were defined as material resources, energy resources, environmental impact, and socioeconomic impact.

2. Develop a baseline against which impacts may be measured. This task required a detailed analysis of the present ICE-powered vehicle in relation to the four impact areas.

3. Define and partially specify all potential advanced systems that might replace the ICE. Alternate low-pollutant propulsion systems were selected from five power-source categories: modified spark-ignition. ICE systems, other heat engine systems, electrochemical systems, mechanical systems, and hybrid systems. From these five categories, 10 advanced systems were initially selected.

4. For an initial comparison, consider $100 \%$ replacement of the ICE with each of the advanced systems studied in Step 3, and select for further study those advanced systems that appear to have potential for reducing emissions without major perturbation in other impact areas. The 10 systems selected initially were narrowed to eight distinct advanced syscems. Most were synthesized in a 4,000-1b curb weight category. As a result of trends in small car production, several systems were also synthesized in the 2,500-1b curb weight category: Finally, two battery systems were synthesized for 1,600-1b vehicles designed only for urban travel. 
5. Fully define the advanced systems that survived the winnowing process of Step 4.

6. Develop a computer program for assessing the impact in each of the four areas of concern. This program must be capable of evaluating these impacts over time as new systems are introduced, but need not be capable of feedback analyses. The program's primary function is to translate selected transitions into relevant output variables within each of five subroutines. Impact evaluation is made by examination and interpretation of the transition results obtained within the mode (see Figure 10).

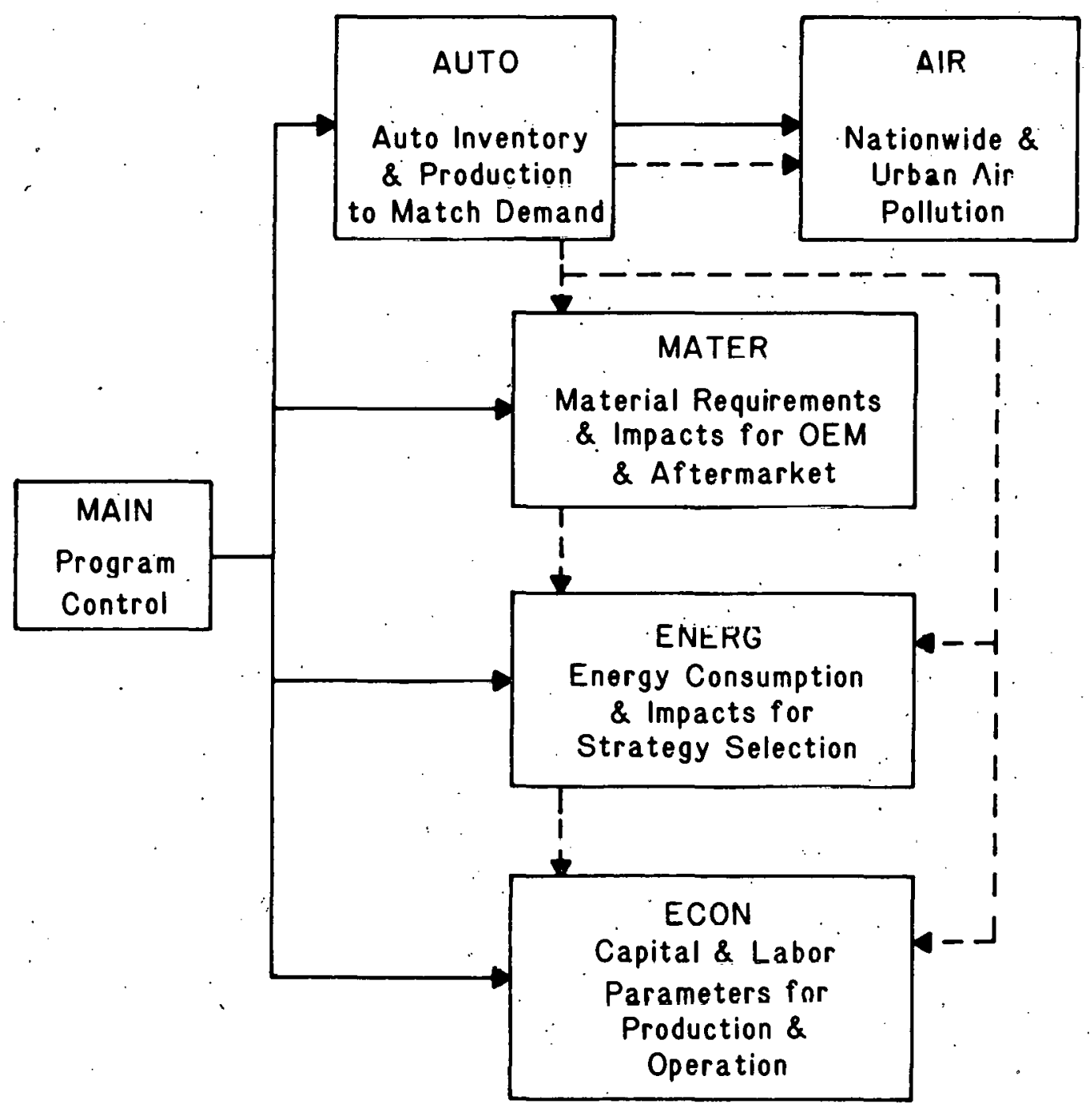

Program Control

- - - Data Flow

Fig. 10. General Program Configuration 
7. Evaluate potential goverment policy options that tend to promote one or more advanced systems. Nearly 100 policy options were considered in assessing the systems that might emerge in the future. These policies were represented by the three basic categories of government subsidies, tax policies, and regulations. Superimposed on these policy options are the technical feasibility of an advanced system and the probability that such a system can effectively replace the ICE.

8. Develop plausible scenarios of transition from the ICE-powered vehicle to the vehicles promoted by such policy options. Seven scenarios with several subthemes were developed that yielded the most interesting and pertinent results regarding the efficiency of policy options. In all cases, the impetus for the transition is conformance with the 1975-1976 emission standards (the dates were later changed to 1976-1977). However, it is also clear that lowering emissions is not necessarily favorable to all impact areas. Therefore, the scenarios are structured to provide information in several impact areas. The following is a summary of the seven scenarios:

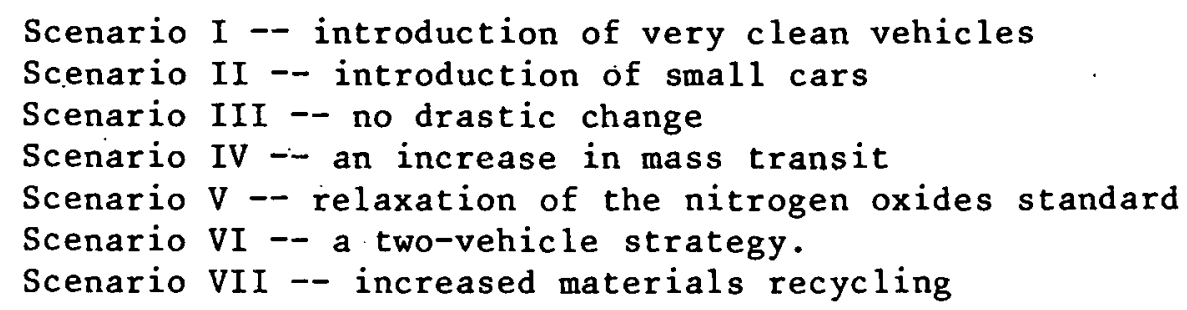

9. Using the computer program developed in Step 6 , determine the magnitude of the impact in each of the four areas and evaluate the consequences of such impacts.

\section{ASSUMPTIONS.}

The demand for new vehicles depends on a variety of factors, such as population growth and distribution, affluence, and fuel availability. The following assumptions were made in assessing demand:

1. Mobility and independence will continue to be basic to the American spirit, and the automobile will be the major means of attaining these goals. Those without access to automobiles, especially in the larger metropolitan areas, will be at an increasing disadvantage in availing themselves of employment, housing, educational, and recreational opportunities.

2. Expected growth in family income will provide substantial demand for second, third, and fourth automobiles, as historically has been the pattern. General Motors, for example, has predicted that $37 \%$ of all car-owning families will own more lialı one ear by 1980.

3. Population growth will be concentrated in the suburbs, where alternative transportation modes are less efficient and less available, and where work, social, and recreational opportunities are more dependent on the automobile. Moreover, this trend will be affected by the movement of 
upper-income and middle-income families from core city areas, especially in the older cities. The strong relationship between increasing incomes and increased automobile ownership and usage will continue.

4. Whether or not Americans come to hate or love their cars in the coming decades, most of them will need their cars. Moreover, as dispersal of the population increases, the ability of public transportation to compete may decrease in many parts of the country. The existing network of roads and service facilities will provide a strong basis for an increased number of automobiles and more usage, except in congested urban areas.

5. In $1970,82.3 \%$ of American families owned at least one car. This trend will continue, except perhaps in the core cities, where there are concentrations of relatively poor socioeconomic groups, and where alternative public transportation is available and sometimes efficient.

6. Existing activities made possible by automobile ownership will continue, althougl, in some cases, traftic volume will necessitate governmental action to control and limit certain activities. For example, some recreational facilities, especially national parks, are already being severely taxed in their ability to handle traffic. Downtown congestion has led to the institution of various schemes that completely close off some areas to automobile traffic. Many new community developments stress concentrated shopping, working, and housing facilities. At the same time, however, these developments are being built where land is cheaper (further from existing downtown areas), thereby creating further dependence on the automobile and more convenient (and cheaper) parking facilities.

7. The existing automobile and ICE, although already subject to both safety and pollution changes in 1975-1976, are viewed positively by most people. While many consumers believe that safety and pollution warrant increased attention, government intervention will be necessary to implement these improvements on a large scale. While not necessarily indicative of most Americans' viewpoints, the unwillingness of most motorists to pay the twn to four cents per galion extra for low-lead gasolines demonstrates the need for this intervention.

8. Leisure time will certainly increase over the coming decades, due to a combination of shorter work-weeks and increased domestic conveniences. With this trend continuing, more people will rely on their automobiles for recreational use and to a greater degree.

To determine the performance of the various advanced alternatives, numerous additional assumptions were necessary. Some of these major assumptions are: . 150 million passenger cars registered in the year $2000 \ldots$ average vehicle lifetime of 9.2 years ... average vehicle conversinn timetable of 20-30 years (ability to replace ICE during the next 20-30 years) ... conversions would be $100 \%$ complete by the year $2000 \ldots$ all systems selected will meet or better 1975-76 EPA emission standards ... six-passenger, 4000-1bcurb weight, V-8 ICE with automatic transmission and 165-brake horsepower selected as a baseline for comparison of the 10 alternatives ... the 10 alternatives involved six passenger, 4000-1b vehicles with 150-brake horsepower (see Tables 18, 19, and 20 for additional characteristics) ... eight transition model vehicle alternatives (see Table 21). 
Table 18. Charactéristics of Alternative Propulsion Systems (values are for engines only, as synthesized in 1971)

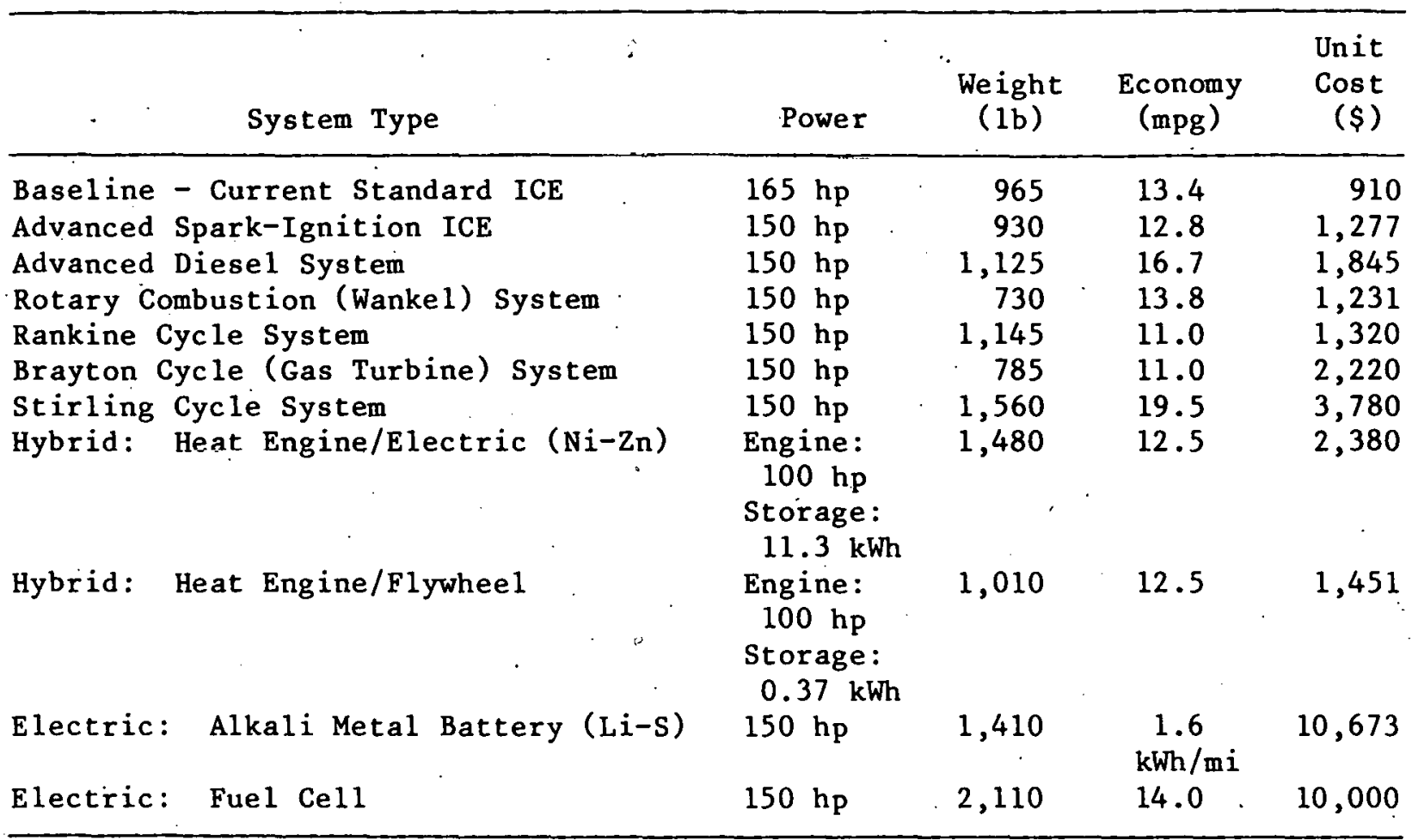

\section{CONCLUSIONS}

The assessment notes that there have been and will continue to be significant changes in technology and government policy. However, such changes do not tend to affect the validity of the methodology or results. Several different conclusions are reached with one over-riding consideration. Since present conditions favor the advanced otto cycle ( $A O C$ ) engine, any policy that directs replacement of that system must be capable of forcing a transition from that which exists to that which is desirable to one or more interest groups.

1. The Small Car Strategy. Of the scenarios studied, the preferred strategy for future vehicles is Scenario II, the small car strategy. This strategy has minimum impact on materials and economy, acceptable emission levels, and minimum energy consumption. Another significant point is that auto manufacturers have the ability to quickly carry out this strategy.

2. Evaluation of Current Policies. A full-sized vehicle propelled by the AOC is an undiliative alternative for two main reasons. Because of the oxidation catalytic converter for carbon monoxide and hydrocarbons, platirum consumption would be nearly four times the projected total U.S. consumption by the year 2000. This would make the U.S. heavily dependent on South Africa, the main supplier of U.S. platinum. Also, the AOC would consume nearly 30\% more energy than the continued production of a 1973 vehicle. 
Table 19. Material Composition of Advanced Propulsion Systems Including Transmission but Excluding Drive Shaft and Differencial (1b)

\begin{tabular}{|c|c|c|c|c|c|c|c|c|c|c|c|}
\hline & $\begin{array}{l}\text { Ref. } \\
\text { ICE }\end{array}$ & $\begin{array}{l}\text { Adv. } \\
\text { ICE } \\
(' 76)\end{array}$ & $\begin{array}{c}\text { Adv. } \\
\text { Diese } 1\end{array}$ & Rotary & Rankine & $\begin{array}{c}\text { Gas } \\
\text { Turbine }\end{array}$ & Stirling & $\begin{array}{l}\text { Hytrid } \\
\text { IC } \equiv, \mathrm{Hi}-\mathrm{Zn}\end{array}$ & $\begin{array}{l}\text { Hybrid } \\
\text { ICE்/ } \\
\text { Flywhee }\end{array}$ & $\begin{array}{c}\text { Alkali } \\
\text { Metal } \\
\text { Battery }\end{array}$ & $\begin{array}{l}\text { Fuel } \\
\text { Cell }\end{array}$ \\
\hline Cast iron & 450 & 348 & 584 & 6 & 336 & 341 & 522 & $2: 6$ & 339 & - & - \\
\hline Low-carbon steel & 206 & 236 & 272 & 264 & 416 & 269 & 523 & 319 & 254 & 156 & 144 \\
\hline Alloy \& stainless stee: & 29 & 105 & 37 & 77 & 100 & 18 & 60 & $: 0$ & 150 & 115 & 225 \\
\hline Superalloys & & 20 & - & - & - & 21 & 70 . & $\cdot-$ & - & - & - \\
\hline Iron & 746 & 668 & $904^{\circ}$ & 427 & 764 & 606 & 1067 & $5<3$ & 716 & 242 & 300 \\
\hline Aluminum & 49 & 57 & 54 & 150 & 100 & 27 & 120 & L:9 & 107 & 129 & 128 \\
\hline Lead & 23.5 & 21.5 & 23 & 21 & 20 & 20 & 20 & 3 & 22 & - & - \\
\hline Copper & 20 & 42 & 19 & 25 & 20 & 5 & 10 & LC 3 & 37 & 93 & 1.12 \\
\hline Zage & 12 & 0.5 & 2.5 & 2 & 1 & - & 1 & $\iota \varepsilon_{0}$ & 9 & 9 & 13 \\
\hline Nickel & 0.3 & 10.2 & 0.5 & 0.4 & 5.2 & 12.3 & 34 & L: 1 & 0.6 & 12 & 502 \\
\hline Chromium & 1.2 & 5.1 & 1.2 & 0.5 & 12.4 & 3.5 & 25.6 & 0.3 & 0.8 & 20 & 38 \\
\hline Molybdenum & 0.2 & 2.1 & 0.2 & 0.2 & 0.2 & 0.6 & 6.3 & 0.2 & 0.4 & $\mathrm{~T}$ & 120 \\
\hline Manganese & 5 & 5 & 6 & 2 & 3 & 4 & 6.5 & 4 & 5 & 0.7 & 0.6 \\
\hline Silicon & 11 & 9 & 14 & 13 & 7 & 8 & 11 & $: 0$ & 7.2 & s & s \\
\hline Tin & 1.8 & 1.8 & 1.8 & 1.5 & $<1$ & $<1$ & $<1$ & 1 & 1 & $\mathrm{~T}$ & $\mathrm{~s}$ \\
\hline Synthetic rubber & 15 & 18 & 17 & 18 & 13 & 13 & 13 & 7. & 18 & - & - \\
\hline Plastics & 3 & 3 & 3 & 3 & 1 & 1 & 1 & 6.3 & 3 & 12 & $203 \ldots$ \\
\hline Ethylene Glycol & 19 & 16 & 16 & 16 & - & - & 64 & $: 6$ & 16 & - & - \\
\hline Electrolyte & $11^{a}$ & $11^{a}$ & $11^{a}$ & $11^{\mathrm{a}}$ & $11^{a}$ & $11^{a}$ & $11^{\mathrm{a}}$ & $43^{b}$ & $11^{\mathrm{a}}$ & $144^{c}$ & $500^{e}$ \\
\hline Petroleum lubricants & 14 & 15 & 15 . & 15 & 13 & 3 & 15 & 2 & 22 & 4 & 4 \\
\hline Magnesium & - & - & - & - & 40 & - & 40 & - & - & - & - \\
\hline Sulfur & $\mathrm{T}$ & $\mathrm{T}$ & $\mathbf{T}$. & $T$ & $\mathrm{~T}$ & - & $\mathrm{T}$ & $\mathrm{T}$ & $\mathrm{T}$ & 541 & - \\
\hline Nonmetallurgical carboa & $\mathrm{T}$ & $\mathbf{T}$ & $\mathbf{T}$ & $\mathbf{T}$ & $\mathrm{T}$ & $\mathbf{T}$ & $\mathrm{T}$ & $\mathrm{T}$ & $\mathbf{T}$ & 72 & 149 \\
\hline Ceramic & $\ll<1$ & 1 & $\mathbf{T}$ & I & - & 40 & - & - & $\mathbf{T}$ & - & - \\
\hline Synthetic lubricant & - & - & - & - & - & 4 & - & $=$ & - & - & - \\
\hline Alumina & - & - & - & - & - & - & 20 & - & - & - & - \\
\hline Lithium & - & - & - & - & - & - & - & - & - & 109 & - \\
\hline Platinum & - & 0.0094 & - & - & - & - & - & - & - & - & 1.1 \\
\hline Other emissions catalyzt & - & - & NA & $\mathrm{NA}$ & - & - & - & - & - & - & - \\
\hline Semiconduc tors & $\mathrm{s}$ & $\mathrm{s}$ & $\mathrm{s}$ & $\mathrm{s}$ & $\mathrm{s}$ & $\mathrm{s}$ & $\mathrm{s}$ & s & 0.5 & 1 & 2 \\
\hline Asbestos & 2 & 4 & $\dot{4}$ & 1 & - & 10 & - & - & 1 . & - & $\therefore$ \\
\hline Tungsten & - & - & - & - & - & 0.4 & 0.4 & - & - & - & - \\
\hline Cobalt & - & 3 & - & - & - & 2.0 & 1.1 & $\therefore$ & - & - & - \\
\hline $\begin{array}{l}\text { Approximate Total } \\
\text { Unfueled Weightd }\end{array}$ & 965 & .930 & 1125 & 730 & 1145 & 783 & 1560 & 1480 & 1010 & 1410 & 2110 \\
\hline
\end{tabular}


Table 20. Measures of Impact of the Alternative Propulsion Systems with $100 \%$ Transition

\begin{tabular}{lcrr}
\hline \multicolumn{1}{c}{$\begin{array}{c}\text { Propulsion } \\
\text { System }\end{array}$} & $\begin{array}{c}\text { Change in Jobs } \\
\text { (relative to present } \\
\text { ICE, in thousands) }\end{array}$ & $\begin{array}{c}\text { \% Change in } \\
\text { Cost of Engine }\end{array}$ & $\begin{array}{c}\text { \% Change in } \\
\text { Ownership Costs }\end{array}$ \\
\hline Advanced ICE & -10 & +40 & +5 \\
Advanced Diesel & +40 & +105 & +5 \\
Rotary Engine & -85 & +35 & 0 \\
Rankine & +50 & +45 & +145 \\
Gas Turbine & -70 & +535 & +10 \\
Stirling & +170 & +160 & +3.0 \\
Heat Engine/Electric & +150 & +60 & +10 \\
Heat Engine/Flywhel & +10 & +1000 & +5 \\
Battery & +130 & +1000 & $?$ \\
Fuel Cell & +270 & & $?$ \\
\hline Water working fluid. & & & \\
borganic working fluid. & & &
\end{tabular}

3. Relaxation of the Nitrogen Oxides Emission Standards. Relaxation of the 1977 nitrogen oxides $\left(\mathrm{NO}_{\mathrm{x}}\right)$ standards from $0.40 \mathrm{~g} / \mathrm{mi}$ to $2.0 \mathrm{~g} / \mathrm{mi}$ would eliminate the need for an $\mathrm{NO}_{x}$ catalytic converter in the AOC. This would reduce the nominal AOC's demand for additional materials (chromium, nickel, ceramics) and energy by about $50 \%$. If it is determined that original $\mathrm{NO}_{x}$ standards were more stringent than necessary, it would be advantageous to relax the standard to $2.0 \mathrm{~g} / \mathrm{mi}$. Changing the $\mathrm{NO}_{\mathrm{x}} \mathrm{standard}$ to $2.0 \mathrm{~g} / \mathrm{mi}$ would also increase the appeal of an advanced diesel engine. Fuel consumption would be greatly reduced, but considerable effort is still needed to produce a light-weight, low-cost, high-performance diesel engine. Therefore, this alternative must be considered a long-term solution, with earliest introduction between 1980 and 1985 .

4. Development of New Internal Combustion Engines. Significant progress has recently been made in the design of a stratified-charge engine. Although it was not included in the transition analysis, it now appears that this engine can be developed with improved fuel economy, low emissions without catalysis, and minor materials and economic impact. This engine, if successful, would be a better option than either the AOC with catalytic controls, the Rankine engine, or the gas turbine.

5. Development of New External Combustion Engines. Introduction of the Rankine-cycle engine would result in the least noxious emissions of all the systems studied. Its main drawback is the fact that passenger vehicles would consume more than $36 \%$ more energy than the baseline ICE by the year 2000. Unless this figure can be reduced, it is doubtful that this engine would be competitive with the ICE. The gas turbine engine is also attractive from an emissions standpoint. Its major drawbacks are a $25 \%$ increase in fuel consumption over the ICE by the year 2000 , and capital and labor requirements that are double those projected for the baseline ICE. It is doubtful that U.S. auto makers will develop this' 
Table 21. Summary of Characteristics of Selected Advanced Systems

\begin{tabular}{|c|c|c|c|c|c|c|c|c|}
\hline \multirow{2}{*}{$\begin{array}{l}\text { Propulsion } \\
\text { System }\end{array}$} & \multirow{2}{*}{$\begin{array}{c}\text { Vehicle } \\
\text { Weight } \\
\text { (1b) }\end{array}$} & \multirow{2}{*}{$\begin{array}{c}\text { Payload } \\
\text { (passengers) }\end{array}$} & \multirow{2}{*}{$\begin{array}{l}\text { Range } \\
\text { (miles) }\end{array}$} & \multirow{2}{*}{$\begin{array}{l}\text { Approximate } \\
\text { Cost (\$) }\end{array}$} & \multirow{2}{*}{$\begin{array}{l}\text { Fuel } \\
\text { Economy } \\
\text { (npg) }\end{array}$} & \multirow{2}{*}{$\frac{\text { Base }}{\mathrm{HC}}$} & \multicolumn{2}{|c|}{ Emissions ${ }^{a}$} \\
\hline & & & & & & & CO & $\mathrm{NO}_{\mathbf{x}}$ \\
\hline $\begin{array}{l}\text { Internal combustion } \\
\text { engine }\end{array}$ & 4075 & 6 & 200 & 3670 & 13.4 & $-\mathrm{b}$ & $-b$ & $--^{b}$ \\
\hline Advanced Otto cycle & 4005 . & 6 & 200. & 3990 & 11.0 & 0.41 & 3.4 & 0.8 \\
\hline $\begin{array}{l}\text { Small advanced Otto } \\
\text { cycle }\end{array}$ & 2500 & 4 & 200 & 2600 & 16.0 & 0.41 & 3.4 & 0.4 \\
\hline $\begin{array}{l}\text { Rotary Otto cycle } \\
\text { (Wankel) }\end{array}$ & 2345 & 4 & 200 & 2500 & 16.0 & 0.41 & 3.4 & 0.4 \\
\hline Rankine (organic) & 4200 & 6 & 200 & 4120 & 10.3 & 0.13 & 0.2 & 0.26 \\
\hline Gas turbine & 3867 & 6 & $200^{\circ}$ & 4815 & 11.0 & 0.12 & 0.7 & 0.4 \\
\hline Flywheel/hybrid & 2500 & 4 & 200 & 3500 & 17.0 & 0.2 & 1.7 & 0.4 \\
\hline Lead-acid battery & 1600 & 2 & 30 & 2560 & $0.53 \mathrm{kWh} / \mathrm{mi}$ & $-c$ & $--c$ & $-c$ \\
\hline $\begin{array}{l}\text { Sodium-sulfur } \\
\text { battery }\end{array}$ & 87.4 & 2 & 150 & 2810 & $0.5 \mathrm{sWh} / \mathrm{mi}$ & $--c$ & $--c$ & $--^{c}$ \\
\hline
\end{tabular}

Emissions are for federal driving cycle.

${ }^{b}$ Emissions for ICE vary according to model year.

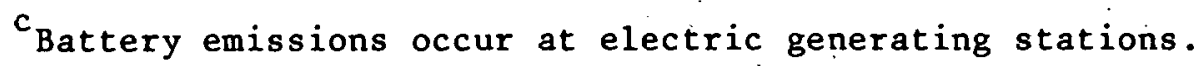


turbine without major government subsidy. The Stirling engine has an extremely high efficiency and emits little pollution. Its drawbacks are its weight, materials impacts, costs, and overall economic impact.

6. Development of a Two-Car Strategy. The two-car strategy, using an urban battery-powered vehicle and a suburban heat-engine vehicle, may be an attractive alternative if the sodium sulfur battery system or its equivalent becomes available. Problems may arise from sulfur oxides and particulate emissions from central power plants and from uncertain sociological impacts. This strategy must be considered a long-term alternative, since current batteries are not suitable for mass introduction.

7. Massive Introduction of Mass Transit. The advisability of the massive introduction of mass transit systems is not at all certain. To decrease the private passenger car population by $14 \%$, mass transit systems would have to increase 17-fold over a 20-year period. Although this strategy. will eventually save energy (possibly by the year 2020), the energy for construction would be required at a time when fossil fuels would be in short supply. Also, beyond the year 2000 the increased use of alternative fuel sources will probably reduce the use of fossil fuels in all sectors. 
IDENTIFICATION OF PROBABLE AUTOMOTIVE FUELS

Mode: HIGHWAY CONSUMPTION: 1985-2000 (1978)

Southwest Research Institute for U.S. Department of Energy

PURPOSE

This. study develops a logical methodology for defining the chemical composition and physical properties of future automotive fuels. It defines those areas of engine design and fuels formulation that could result in a more energy-efficient highway system.

\section{ASSUMPTIONS}

General Assumptions

- U.S. must develop a synthetic fuel industry by 1990-95 to minimize its long-term dependence on imported energy.

- Production of oil and gas in the lower 48 states will, continue to decline ... new coal production and increased nuclear power will provide the major growth in energy supplies ... initial syngas production from coal will be possible in $1985 \ldots$ domestic coal production will grow $4.7 \%$ annually between 1975 and $2000 \ldots$ nuclear energy production will grow $11.5 \%$ annually between 1975 and 2000 .

- From 1975 to 2000 , total domestic energy demand will increase at an annual rate of $2.4-2.7 \%$... demand for liquid hydrocarbons will increase $2.5 \%$ per year trom 1975 to 1985 , and $1.5 \%$ annually trom 1985 to' 2000 ; the largest growth rate in liquid hydrocarbon demand will be for heavy fuels and petrochemical feedstocks ... from 1975 to 1985, gasoline demand will not grow; from 1985 to 2000, gasoline demand will grow at an annual rate of $2.1 \%$... demand for jet $A$ fuel will grow $1.8 \%$ annually from 1975 to 2000 ... diesel No. 2 fuel demand will increase $1.4 \%$ per year from 1975 to 2000 ... demand for residential heating oil will grow $3.7 \%$ annually from 1975 to 1985 , but after 1985, demand will not increase ... petrochemical demand will grow at an annual rate of $3.6 \%$ from 1975 to 2000 .

- Performance levels of gas and middle distillate fuels will remain fixed ... one ton of coal can yield two barrels of syncrude.

Assumptions for Vehicle Fuel Demand Projections

Fuel demand was computed for four subclasses: gasoline-powered auto, diesel-powered auto, gasoline-powered light and heavy trucks, and dieselpowered light and heavy trucks. The projection of fuel demand was based upon extrapolation of 1960-1974 data for vehicle utilization and vehicle economy, using the formula: 
fuel demand $=\frac{[\text { vehicle population] [utilization (mile/yr)] }}{\text { [fuel economy (mile/gal)] }}$

Vehicle population was fitted to a logarithmic function to make linear extrapolations for 1985 to 2000. Fuel-economy projection was based upon 1976 DOE figures and federal fuel-economy legislation.

- Average auto utilization will remain constant at 10,000 miles annually ... diesel automobile fuel economy will be $25 \%$ higher than that of the gasoline automobile ... use of diesel autos will be constant, but will be 6-13\% higher than gasoline auto utilization because of greater fuel economy ... the diesel auto will capture $23-49 \%$ of the total auto market; these upper and lower limits are assumed to be constant for the demand model.

- The overall truck population distribution of $95 \%$ gasoline-powered and $5 \%$ diesel-powered will not change from 1985 to 2000.

- Fuel economy of gasoline-powered light-duty trucks (those with a gross vehicle weight of $10,000 \mathrm{lb}$ or less) will remain at $55 \%$ of the average auto fleet fuel-economy, as it was in $1976 \ldots$ utilization for gasolinepowered light trucks will remain constant at 23,000 miles annually ... fuel economy of heavy-duty gasoline-powered trucks (those with a gross vehicle weight over $10,000 \mathrm{lb}$ ) will remain at $57 \%$ of the average lighttruck fuel economy, as it was in $1976 \ldots$ heavy-duty gas truck utilization will grow at a rate of $9 \%$ every five years, reaching 23,000 miles per year in 2000 .

- The composition of the diesel truck fleet will remain constant at $98 \%$ heavy duty, $2 \%$ light duty ... light-duty diesel truck fuel economy will increase from $21.1 \mathrm{mpg}$ in 1980 to $28.5 \mathrm{mpg}$ in 2000 , based upon federal legislation and market penetration ... utilization of light diesel trucks will remain constant at 10,000 miles annually ... fuel economy for heavyduty diesel trucks will remain constant at $4.4 \mathrm{mpg}$... utilization for heavy-duty diesel trucks will increase at a rate of $9 \%$ every five years, reaching 85,000 miles per year in 2000 .

- There will be no interplay between the increased domestic diesel automobile popularity and a comparative increased popularity in diesel trucks. The complexities, especially of diesel light truck and auto substitutability, preclude such estimations at this time.

Scenario Assumptions

Six scenarios were considered for future fuel demand projection:

1. Baseline -- no diesel auto market penetration.

2. Diesel auto penetration -- $23 \%$ new market; $6 \%$ total fleet increase in diesel auto utilization.

3. Diesel auto penetration -- $23 \%$ new market; $13 \%$ total fleet increase in diesel auto utilization.

4. Diese1 auto penetration -- $49 \%$ new market; $6 \%$ total fleet increase in diesel auto utilization. 
5. Diesel auto penetration - $49 \%$ new market; $13 \%$ total fleet increase in diesel auto utilization.

6. Model presumes the availability in 1985 of a broadcut fuel (with no cetane or octane ratings), for yet-to-be-defined powerplants compatible with such a fuel. Broadcut-fuel/engine systems will achieve $25 \%$ better fuel economies than regular autos, and utilization will be $13 \%$ greater than for gasoline autos. Heavy-duty broadcut trucks will have the same fuel economy and utilization as gasoline-powered heavy-duty trucks and will penetrate the gasoline heavy-duty subcategory by $50 \%$ by 1985 , remaining constant thereafter. The market penetrations 1 isted in Table 22 will be achieved.

\section{METHODOLOGY}

The riport is divided into three distinct sections: synthetic hydrocarbon fuels, alcohol fuels, and trade-offs.

Finished synthetic fuel product slates were projected based on selected reference coal and oil shale resources, conversion of these resources to syncrude, and definition of automotive fuels compositions and physical properties. This definition was accomplished by a linear programming model that economically optimizes any given feed stock composition through refining to produce a product slate based upon several different fuel demand projections. Baseline situations of pure petroleum crude feed stock are compared to syncrude/petroleum fuel blends. Analysis was performed for 1985 to 2000 .

The alcohol fuels section of the report discusses and reviews factors pertinent to the development of alcohol fuels, particularly the production of methanol from coal. In the trade-offs section, hydrocarbon and alcohol fuel compositional and performance data were considered in conjunction with vehicle fuel demand projections. Alternative engine designs were also analyzed with respect to their tolerance of synthetic fuels.
Table 22. Broadcut Fuel Market Penetration (\%)

\begin{tabular}{lccc}
\hline $\begin{array}{l}\text { Year, } \\
\text { Fuel }\end{array}$ & Auto & $\begin{array}{l}\text { Light } \\
\text { Truck }\end{array}$ & $\begin{array}{l}\text { Heavy } \\
\text { Truck }\end{array}$ \\
\hline 1985 & & & \\
\hline Broadcut & 20 & 20 & 35 \\
Gas & 60 & 60 & 35 \\
Diesel & 20 & 20 & 30
\end{tabular}

1990

$\begin{array}{llll}\text { Broadcut } & 50 & 50 & 25 \\ \text { Gas } & 35 & 35 & 25 \\ \text { Diese1 } & 15 & 15 & 50 \\ & & & \end{array}$

1995

$\begin{array}{llll}\text { Broadrut } & 70 & 70 & 20 \\ \text { Gas } & 20 & 20 & 20 \\ \text { Diesel } & 10 & 10 & 60\end{array}$

2000

\begin{tabular}{lrrr} 
Broadcut & 80 & 80 & 15 \\
Gas & 15 & 15 & 15 \\
Diesel & 5 & 5 & 70 \\
\hline
\end{tabular}




\section{CONCLUSIONS}

- Syncrudes can be processed in existing refineries provided that conventional crude oils can be readily substituted for part of the crude slate in order to balance the properties of syncrude ... fifteen to fifty percent by. volume of syncrude can be incorporated into an existing refinery's crude slate without reducing the refinery's normal production ... production of broadcut fuel increases a refinery's flexibility and can significantly decrease processing loss per barrel.

- Impacts of use of straight alcohol as an automotive fuel: modification of engines would be required; fuel economy. would be lower than for gasoline auto; starting below $50^{\circ} \mathrm{F}$ would require special starting aids ... alcohol compatibility with materials currently used in manufacture of fuel system components is poor ... aldehyde emissions are higher and $\mathrm{NO}_{\mathrm{x}}$ emissions are lower. than with gasoline.

- Impacts of use of alcohol-gasoline blends as an automotive fuel (compared to gasoline): no engine modifications required; fuel economy decreases proportionally to amount of alcohol in blend ... unburned-hydrocarbon and carbon dioxide emissions reduced slightly; aldehyde emissions higher than with gasoline ... vaporlock problems may occur ... improved antiknock property ... potential phase separation at low temperatures or in presence of water ... potential corrosion or deterioration of sensitive fuel system parts.

- For hydrocarbon fuel production, the properties with the most potential for trade-off (relaxation of requirements) are ignition quality and distillate range.

- Use of alcohol fuels in diesel engines will require engine modifications ... alcohol fuels will be more expensive than petroleum fuels.

- Alcohol fuels made with higher alcohols have improved solubility and gross heating values over other alcohol fuels ... additional research is required to determine the optimum catalyst. for conversion of synthesis gas to higher alcohols.

- Alternative automotive engines: stratified-charge, rotary, gas turbine, Stirling, and Rankine engines were considered. of these, the Stirling is expected to be the most fuel-tolerant and give the lowest emissions. of all the internal combustion engines, the stratified-charge is the most versatile. 
AUTOMATED GUIDEWAY TRANSIT, AN ASSESSMENT OF

Mode: MASS TRANSIT PRT AND OTHER NEW SYSTEMS (1975)

Office of Technology Assessment, U.S. Congress

EXECUTIVE SUMMARY

Demand: public transportation

Environmental Impacts: social and economic

System Coverage:"

rail

Network Coverage: urban

Product:

vehicles and associated equipment, systems operation

R\&D Issue: should major funding be given to AGT development; what sectors should bear the cost
This assessment was designed to provide information on the social, economic, and technological aspects of automated guideway transit (AGT) development; assess AGT's major problems from the perspective of the potential riders, communities, and transit industry; and identify major policy issues and AGT program alternatives.

Three major categories of AGT systems are investigated: shuttle-loop transit, group rapid transit, and personal rapid transit. The study was conducted by a panel of experts representing contrasting views in the transportation field. Though a statistical analysis is not presented due to a lack of available data, the assessment does illuminate the development of AGT systems in the United States and abroad. It also provides a qualitative analys is of its current status and the issues confronting local and federal governments in determining whether continuing research and development is warranted.

\section{PURPOSE}

Automated guideway transit (AGT) is a class of transportation systems in which unmanned vehicles are operated on fixed guideways along an exclusive right of way. The purpose of this study was to provide information on the status and the social and economic aspects of AGT development. The study sought to assess the major problems associated with AGT as perceived by potential riders, the communities served, and the transit industry. The study also identified major transportation policy issues, and AGT program alternatives, and explored their implications.

\section{METHODOLOGY}

To obtain a broad range of views, the study was conducted by five panels of experts from federal and local public transportation agencies, nonprofit organizations and associations, manufacturers, transit planning organizations, and educational institutions. The analysis centered on the 
economic, social, and technical aspects of the three classes of AGT in the U.S. and foreign countries: shuttle-loop transit (SLT), group rapid transit (GRT), and personal rapid transit (PRT).

In shuttle-loop transit, the simplest type of AGT system, vehicles move along a fixed path with few or no switches: Vehicles in a loop system move around a closed path. The vehicle size varies in both systems, with long headways of 60 seconds or more. Group rapid transit systems serve groups of people with similar origins and destinations. GRT tends to have an intermediate headway of 3-60 seconds. GRT stations may be located on sidings off the main guideway, permitting through traffic to bypass. GRT guideways can merge or divide to provide service on a variety of routes. Vehicles with a capacity of 10 to 50 passengers may be operated singly or in trains. Personal rapid transit is restricted to systems with small vehicles carrying either one person or groups of up to six, usually traveling together by choice. Under computer control, vehicles switch at guideway intersections to follow the shortest uncongested path from origin to destination without intermediate stops. Most proposed PRT systems call for headways of three seconds or less.

The panels examined the following aspects of AGT systems:

1. Current U.S. Developments. Study includes safety records and analysis of causes of major accidents; extent of public acceptance; levels of reliability achieved; and capital, operating, and maintenance costs.

2. Economics. Assessment develops a cost-benefit analysis of AGT relative to other modes of transportation, examining the economic aspects of short headway systems. Short headways range from three seconds to a fraction of a second; the latter headway is required to achieve high capacity with any small vehicles.

3. Social Acceptability. Analysis examines passenger safety and security, safety of the general public, and system security. The environmental impacts, aesthetics, and social implications of AGT are also assessed.

4. Operations and Technology. Study examines the level of service; ride quality and comfort; energy considerations, including comparison with amounts of energy consumed by conventional rail systems, buses, and automobiles; effect of ridership on continuing gasoline price escalation or shortages of supplies; and reliability of AGT systems.

5. International Developments: Assessment appraises public rail transportation developments abroad and extent of international markets for AGT.

The overall study considered the policy implications of AGT by assessing whether the promise of PRT as a cost-effective new mode of transportation warrants a continuing investment of substantial government R\&D funds. 
ISSUES AND CONCLUSIONS

Shutt le-Loop Transit

Issues

- Technical Issues: can inexpensive and aesthetically pleasing guideways and stations be built ... can operational problems due to snow and ice be overcome inexpensively ... how can reliability of components be improved at reasonable cost ... what level of ride quality is required, and what is the trade-off between guideway roughness and vehicle suspension ... how are stalled vehicles best evacuated.

- Economic Issues: what are the ranges of capital and operating costs for ELT ... for what applications, and under what conditions, is SLT a cost-effective mode of urban transit compared to other transit options.

- Social Issues: what is the acceptability of ride and service characteristics .... what are the effects of unmanned operation on passenger security ... what is the impact of the aesthetics of guideway and station design.

\section{Findings}

- SLT systems appear worthy of careful consideration as transportation. alternatives for many specialized urban transportation problems.

- The research and development program of the Urban Mass Transit Administration (UMTA) does not emphasize improvement. of technical operating characteristics and reduction of SLT system costs ... UMTA's technological R\&D is not matched by a corresponding program to develop a better understanding of problems in the areas of economics and public acceptance; SLT systems should receive emphasis in such a program ... there is a lack of criteria for qualifying SLT systems for capital grant funding; there is no apparent mechanism within UMTA for the transfer of R\&D results to implementation under the capital grant program.

- An urban demonstration project for SLT appears justified. Such a project should concentrate on gathering economic and acceptance data and on improving the technical operation of the system.

Group Rapid Transit

Issues

- Technical Issues: basic technical issues cited earlier for SLT apply to GRT as we11; the following additional issues are specific to GRT ... does greater system complexity contribute to a more difficult reliability problem ... are there alternative engineering concepts that can reduce the cost of GRT systems ... can ride quality (particularly freedom from sway 
and jerk) be improved over that of AIRTRANS and Morgantown ... The advanced GRT program being undertaken by. UMTA raises two additional technical concerns -- reduced headways require demonstration of the feasibility of command and control systems, and software must be developed for managing a larger fleet of vehicles.

- Economic Issues: Is there a market for GRT systems or a transit "need" that they would serve ... assuming they fill a need, are GRT systems cost-effective competitors in the urban transit market... is there any justification for hardware R\&D before first gathering economic data such as that described above.

- Social Issues: the GRT systems should be carefully monitored to obtain data relating to public acceptance... human engineering principles must be applied to facilitate the patrons' use of the system.

\section{Findings}

- A number of localities across the country have shown interest in installing GRT systems; however, serious technical problems have arisen in the first two installations and neither is yet operating as planned. These technical problems have been exacerbated by unrealistic deadlines and management problems.

- UMTA's R\&D program does not include market and economic research sufficient to evaluate the need for GRT and its cost-effectiveness as a solution to urban transportation problems.

- Monitoring efforts for AIRTRANS and Morgantown are required to obtain data useful in evaluating GRT. UMTA could perform this service and has initiated such a program for AIRTRANS. Until the Morgantown system has been proven in actual operation, it would be premature to commit funds to expand the system. Additional funding does seem justified to complete the engineering work necessary to develop realistic cost estimates. Federal assistance for this interim operating period may be appropriate if the partial system places a greater financial burden on the University of West Virginia at Morgantown than the full system would have.

- No clear urban transportation need is apparent for the short three-second headway performance specified for the "HPPRT" program. The program should be reviewed to see whether modifications would increase its value.

Personal Rapid Transit

\section{Issues}

- Technical Issues: computer control systems mist be developed to exercise command and surveillance over thousands of vehicles traveling between hundreds of stations at fractional-second headways ... vehicle management (particularly the storage of empty vehicles and their redistribution to satisfy changes in demand) further complicates this problem ... advanced control and braking systems must be perfected to insure that vehicles can be operated safely at very close intervals ... crash survivability should 
be demonstrated for PRT, possibly using techniques similar to those required for automobiles by the National Highway Traffic Safety Administration ... means for emergency evacuation should be provided to insure passenger safety in the event of a failure ... major improvements in reliability -- far beyond levels achieved for any transit equipment in operation -- are required; engineering techniques from other fields may be applicable to this problem ... study of alternative engineering approaches is required to develop cost-effective systems and components.

- Economic Issues: The major economic issue is whether research, without hardware development and urban demonstration, can answer the economic questions, or whether hardware development is necessary to assess the economic characteristics of PRT systems.

- Social Issues: what urban objectives will be served by a PRT system ... what is the overall social acceptability of PRT, and what lessons can be learned from less-sophisticated AGT systems ... can PRT systems offer adequate passenger security, particularly in numerous unattended stations ... what environmental impact. will guideways and stations have on the neighborhood.

- Institutional Issues: should PRT systems be a substantial part of UMTA's R\&D effort ... should other arrangements be considered for PRT development and deployment ... to what extent is international cooperation possible and beneficial.

\section{$\underline{\text { Findings }}$}

- Before major commitments of funds are made for detailed simulations or hardware developments, research is required to resolve the many uncertainties concerning the proper role of PRT systems, their social acceptability and their economic feasibility. These preliminary studies may involve expenditures of $\$ 4-6 \mathrm{mill}$ ion.

- There are possibilities for cooperation with foreign governments or overseas suppliers in PRT research and development. UMTA has recognized these possibilities in starting negotiations with the. West German government. 
AN ASSESSMENT OF COMMUNITY PLANNING FOR MASS TRANSIT (1976)

Mode: MASS TRANSIT

Office of Technology Assessment, U.S. Congress

EXECUTIVE SUMMARY

Policy-oriented study with implications for both supply and demand for urban mass transit

Network Coverage: urban network, emphasizing rail

Process Coverage: policy aspects
This study evaluates the process by which metropolitan areas devise plans to develop and modernize rail transit systems. A policy-oriented analysis whose recommendations have implications for both the supply of and demand for urban mass transit, it identifies problems interfering with sound planning and specifies changes in national programs and administration to remedy them.

Three major factors influencing the planning process are covered: the character of institutional arrangements, the conduct of the technical planning process, and the influence of financing policy. Also examined are the interrelationships between transit and other planning functions, particularly highway and land use planning.

The recommended policy and administrative changes are combined into four alternative national transit policies, each having different implications for urban mass transit and the role it plays in the overall urban development planning process.

\section{PURPOSE}

This report explores the process by which U.S. metropolitan areas make decisions about developing and modernizing rail transit systems. Through a deeper understanding of this process and the impact on it of different financing mechanisms, institutional arrangements, and planning procedures, the study seeks to identify prospective changes in national transit policy programs and administration to improve the way communities plan mass transit. systems.

The emphasis of the study is on rapid rail transit rather than bus or other modes because of technological difficulties of the then-new BART system and emphasis on "heavy rail" fixed guideway systems in urban transit planning. The study focuses on transit planning, but also probes relationships between transit planning and other planning functions, particularly highway and land use planning. 


\section{APPROACH}

The inquiry follows a case study approach, drawing on and comparing transit planning experiences of nine metropolitan areas: Boston, Chicago, San Francisco, Atlanta, Seattle, Denver, Los Angeles, Minneapolis-St. Paul, and Washington, D.C. These cities were chosen because their experiences reflect the full range of issues that arise at different stages in the overall process of planning and developing a mass transit system.

An evaluation of these cities' experiences identified a number of factors that have interfered with sound planning, with special emphasis on problems that might be remedied by changes in federal policy. This led to identification of actions the federal government could take to improve transit planning and to the recommendation of four alternative policies.

METHODOLOGY

A set of evaluation guidelines was employed to structure the investigation of each case and provide a basis for comparative judgments. Guidelines were derived in light of issues pinpointed during preliminary visits to metropolitan areas, from a review of federal requirements for transit planning, and from an investigation of contemporary planning practices. Covered are three major topics: the character of institutional arrangements, the conduct of the technical planning process, and the influence of financing policy on transit decision making.

\section{CONCLUSIONS}

\section{Effects of Institutional Context on Transit Decision Making}

- Fragmentation of authority to plan and implement transit improvements: fragmented authority leads to over-extensive plans without providing for the transit best-suited for specific parts of the region ... division of responsibilities for implementing transit and 角ighway plans frustrates efforts to use traffic management in transit planning ... regional. organizations lack power to control land use, making it difficult to use transit effectively for shaping regional growth.

- Threats to accountability of decision makers: some decision makers (often on the boards of transit authorities) do not represent the views of their constituencies ... decisions are often made out of public view ... major decisions are often turned over to powerful consultants... decision makers representing narrow interests are often unresponsive to broad public concerns.

- Obstacles to citizen involvement: ignorance of potential undesirable effects of transit ... planners' fears of delays and attendent cost increases sometimes motivate them to minimize need for public involvement ... need for public input minimized when a specific plan is favored from beginning. 
Effects of Technical Planning Process on Transit Decision Making

- Goal-Setting: formal planning often starts before public goals are clearly defined, a practice that often hampers planning in later stages... controversy exists over how to develop criteria from goals.

- Factors inhibiting development of alternatives: lack of knowledge about range of options ... tendency to see choice as one between highways and transit ... difficulties of gaining political support cause planners to adhere to one plan ... difficulties of devising joint transit-highway programs or programs curbing auto use.

- Factors threatening effectiveness of alternative evaluations: transit ridership projections do not take into account all important elements ... certain goals, particularly social objectives, are difficult to quantify ... practice of evaluating entire systems, rather than options within subareas ... planning process often does not allot sufficient time, technical staff, etc.

- Little attention given to staging of construction or control of developmental impacts: lack of lead agency for setting implementation priorities ... political pressures to please all parties encourage simultaneous construction rather than construction of needed or easily completed segments.

Impact of Federal Financing Policy on Transit

- Inadequate funding jeopardizes goal of improving transit and narrowly defined purpose prevents funds. from being used for coordinated development of transit and land use goals.

- Achieving the national goal of using highways to provide transit capacity is frustrated by separate financing and administration of highway and transit programs.

- Instability of financing because of short-term federal financing commitment to individual metropolitan areas and lack of secure local financing: lack of federal commitment undermines support ... UMTA funding contingent on planning requirements often imposed late in planning process ... uncer-. tainty about availability of funds causes difficulty in construction staging.

- Some transit financing mechanisms encourage a single-technology response to long-range needs, precluding answers to short-term needs of subareas: UMTA's discretionary grant program encourages cities to submit large plans ... availability of capital improvement funds biases planning in favor of capital intensive solutions ... need to gain voter approval of matching funds has led to overly extensive plans.

- Administrative delays undermine projects: UMTA's centralized structure and small staff slow grant's approval process ... UMTA's project-by-project review procedure is time-consuming ... UMTA applies an equally rigorous evaluation for major and minor decisions, according to local officials. 


\section{RECOMMENDATIONS}

The study outlines four fundamental kinds of policy initiatives that the federal government could take to remedy transit planning problems. Within the context of these policy initiatives, four broad policy options are set forth for improving mass transit programs.

\section{Fundamental Policy Initiatives}

- Develop specific national goals and criteria to measure progress toward these goals.

- Change financing structure to increase spending efficiency and provide incentives for specific transit improvements: merge highway and transit financing mechanisms... allocate more funds by formula and/or tie discretionary grants to specific criteria (e.g., using funds to encourage establishment of strong, lead agency at local level) ... broaden purposes eligible for funding to include goals for coordination of transit and land use planting.

- Increase technical guidance: assist localities in pinpointing procedures and timing of citizen-participation programs ... assist. localities in use of goals and criteria in evaluating options ... assist localities in scheduling and budgeting time and money in alternatives evaluation to allow for resolution of conflicts.

- Changes in federal administrative structure: merge Federal Highway Administration and UMTA ... expand UMTA central office and delegate more responsibility to field offices.

\section{Policy Options}

- Maintain present mass transit policy and program with steps taken to improve transit. planning, such as developing policies calling for new requirements for technical planning and closer relationships between regional planning and operating agencies. This policy would not'significantly improve and expand mass transit and would perpetuate disparity between highway and transit funding levels, although it would clarify policy.goals and regional institutional responsibilities and improve technical assistance.

- Strengthen national mass transit program giving priority to developing urban mass transit, mobilizing financial resources, and streamlining institutional mechanisms and technical planning process to expand mass transit: policy would simplify planning and clarify responsibility ... ridership would increase as a result of fare reduction and service improvements .... savings resulting from drivers switching to transit would tend to offset cost of capital and operating subsidies ... policy would retard evolution of multimodal planning and integrated approaches to transportation and use planning. 
- Strengthen and create balance among all forms of transportation using transit incentives and automobile disincentives as part of program to shift priorities and emphasis away from private automobile to mass transit: policy would require greater investment in mass transit, which would be offset by revenues produced by auto disincentives and lower funding needs for highways ... policy would encourage modal institutions to merge or at least cooperate more closely, promoting greater integration between transportation and land use planning, enhancement of the environment, and energy conservation.

- Strengthen comprehensive community development programs, making multimodal planning and development an integral element of community development. Urban transportation would be subordinated to urban growth management and land use planning objectives and considered a support service. This policy (1) implies considerable federal involvement and assistance in carrying out comprehensive land use development plans and (2) would alter the relationship between transportation agencies and land use planning agencies, putting transportation agencies in a technical support role to overall land use planning.

\section{COMMENTS}

This report seeks to solve institutional problems that inhibit effective urban transportation system planning by proposing changes in national transit policy and administration. Although emphasizing short-term solutions, the study offers several policy recommendations that have significant longterm implications for the character of metropolitan areas and the transit. network serving them. If adopted, the proposal to strengthen comprehensive community development programs and cast transit planning and development in a support role would lead to a new set of transportation priorities -- priorities that would shape both the future transportation network and future transit innovations. 
AUTOMATIC TRAIN CONTROL IN RAIL RAPID TRANSIT

Mode: MASS TRANSIT (1976)

Office of Technology Assessment, U.S. Congress

EXECUTIVE SUMMARY

Study focuses on one aspect of urban transportation supply: automatic train control systems

Network Coverage: urban passenger

System Coverage:

rail

Process Coverage: systems operations and some policy issues
This study examines the automatic train control (ATC) technology employed in urban rail rapid transit systems. Initiated in part because of the misgivings of many engineers about the effectiveness of this technology and the problems encountered with the Bay Area Rapid Transit (BART) ATC system, the study (1) evaluates existing ATC technology and its performance record, (2) analyzes the process by which ATC systems are planned and developed, and ( 3 ) explores the institutional and policy factors influencing this process.

Examined in the study are the experiences of five operating rail rapid transit systems, each representing a different level of automation and control technology. Three other systems in the planning and development stage are examined to evaluate the ATC planning and development process.

Although no formal recommendations are made in the study, a number of recommendations with. policy and R\&D implications are implicit in its findings.

PURPOSE

This report, which assesses automatic train control (ATC) in rail rapid transit systems, (1) examines the design characteristics of ATC systems and evaluates the state of automatic train control technology, (2) evaluates the operating experience and performance of transit systems employing different types of ATC, (3) analyzes the process by which ATC systems are planned, developed, and tested and, (4) explores policy and institutional factors influencing the use of ATC technology in rail rapid transit.

The study was initiated in part because of misgivings of transit engineers about the ability of newer ATC systems to perform as safely and efficiently as manual systems and misgivings about the relative costs and benefits of automation; both misgivings were exemplified at the time by the difficulties encountered by San Francisco's Bay Area Rapid Transit (BART) system. 
APPROACH

Five operating rail rapid transit systems are examined, including BART, Chicago Transit Authority (CTA), Massachusetts. Bay Transportation Authority (MBTA), New York City Transit (NYCTA), and the Port Authority Transit Corporation (PATCO) serving Philadelphia and its New Jersey suburbs. They were selected because they represent a range of system characteristics, differing in extent of service coverage, level of automation, age, and control technology.

Three other systems in the planning and development stage are explored to evaluate the process by which transit systems are conceived, designed, and constructed. These include: Metropolitan Atlanta Rapid Transit Authority (MARTA), Mass Transit Administration (MTA) in Baltimore, and the Washington Metropolitan Area Transit Authority (WMATA).

\section{METHODOLOGY}

The study was conducted and information gathered through interviews with transit system officials, planning organizations, and manufacturers.

\section{CONCLUSIONS}

\section{Operational Experience}

- Performance: transit industry experience indicates automatic train protection provides surer method of train protection ... analysis of passenger injury statistics shows no difference in injury rates between manual and automatic modes, passenger inexperience being more of a causal factor $\therefore$ no evidence that passenger security is affected by reductions in size of train crew permitted by ATC ... automatic train operation provides ride quality equal to that of manual operation; some believe the ride better in that it is more uniform ... ATC systems have experienced difficulties meeting schedules, but many problems stem from complexity and reliability of other new items ... reliability of ATC equipment has been the major problem, but not greater than problems with other components of comparable sophistication.

- Costs: ATC equipment costs constitute rough1y 3-5\% of system costs with $90 \%$ of ATC costs for wayside equipment ... operating costs are slightly lower in systems with automatic train operations because of reduction in operating personnel, but maintenance costs are higher ... automated train operation permits small but significant work-force savings ... automation requires increases in number of maintenance employees, resulting in only minor decreases in total work force.

- Human factors: monotony and light responsibility make it difficult for operators of highly automated trains to maintain vigilance ... ATC designers have made insufficient use of operators in backing up or enhancing system performance, but they are now seeking to more effectively integrate the operator into the system ... ATC system demands new and higher skills and performance requirements. 
Planning, Development, and Testing Process

- Planning: nontechnical factors, such as social and political concerns and attitudes of decision makers toward innovation, influence ATC concept and extent of automation ... alternative ATC concepts rarely evaluated in cost-benefit studies, perhaps because of small costs when compared to entire system.

- Engineering development: trend is toward more quantitative form of specification ... recognized need in transit industry for improved specifications writing and establishment of realistic reliability, maintainability, and availability requirements.

- Testing: testing is done at several points in developmental process for qualification and validation of component and subsystem design, assurance of conformity with specifications, and demonstration of system performance ... pressure to open system may slight performance verification ... quality of testing varies with qualifications and experience of organization managing system development, indicating need for more-detailed and comprehensive test plans, test criteria, and methods of measurement; more test procedures; and more complete documentation.

- Research and development: no test tracks and experimental facilities exist for train control R\&D except at individual transit systems or at a manufacturer's plant ... greatest $R \& D$ need is refining existing technologies to remedy operational difficulties, but little effort is focused on this area.

Policy and Institutional Factors

- Regulations: federal transportation legislation has had little effect on ATC ... most regulation is carried out by individual transit authorities and state public utility commissions, whose principal concern is safety ... UMTA and FRA regulate at federal level but their responsibilities are not clearly defined ... National Transportation Safety Board oversees safety with implementation of its recommendations delegated to UMTA or FRA $\ldots$ little attention given to operational concerns, i.e., reliability, maintainability, level of service, efficiency, and economics ... advantages of federal regulation and standardization might be offset by disadvantage of raising possible obstacle to innovation.

- Institutions: local planning and/or operating authorities and the engineering and technical consultants that advise them have the greatest influence on ATC design and development ... community planners, public interest groups, and general publice play only a small role in ATC design and development, although evidence shows they are assuming more influence in establishing priorities and general service characteristics.

- Policy impacts: federal policy from 1964 to 1975 has encouraged development of technologically advanced transit using highly automated train control ... transit agencies favor advanced technology partly because of their perception of federal policy and their belief that it will help muster public support. 
- State of ATC technology: major difficulties encountered in train protection and operation have arisen from application of new unproven techniques ... automatic train supervision is least-advanced ATC technology ... automatic train protection enhances safety of transit system, safeguarding against collisions and derailments more effectively than manual and procedural methods ... ATC performance and service are probably better than for manual system once lengthy period of debugging is completed ... reliability and maintenance continue to be serious ATC problems.

- Application of ATC technology in new systems: trend in transit industry toward cab signaling in automatic train protection because it is more flexible and facilitates conversion to partially or fully automated train operations ... train operation and supervision is relying more on automatic operation and supervision technologies much like those employed by BART and PATCO systems ... Washington, Atlanta, and Baltimore systems have followed a middle-ground approach, opting for ATC technologies adopted by pATCO rather than the more-innovative ones used in BART ... particular attention is being given to integrating the human operator into the system and to the operator's role in complementing the automated system.

- Testing process: complexity and number of elements that must be tested burden the testing process ... lack of satisfactory method for comprehensive evaluation of transit system is a great shortcoming -- a problem compounded by pressures to open systems for revenue service as soon as possible.

- Selecting level of automation: decision making process often is not deeply analytical, has no explicit criteria of choice, and is not clearly documented ... established transit systems consider engineering characteristics of proposed control system to ensure ATC equipment can be successfully integrated into existing system, but planning and design process does not include studies to determine train control system or to weigh train control design features against service and operating characteristics of other equipment or entire transit system ... process for selecting train control system is not governed by engineering and system trade-off studies; characteristics of ATC system are derived more from general, nontechnical decisions about the nature of the entire system and its desired service features rather than technical considerations of control system design or automation technology ... formal cost-benefit studies of ATC system are usually not conducted, although ATC costs and, to a lesser extent, benefits, are included in studies of entire system ... ATC operational costs are rarely included in system cost-benefit studies and they are not analyzed for their potential influence on life-cycle costs of the transit system.

RECOMMENDATIONS

No specific recommendations are made. 
COMMENTS

A major finding of this study is that the decision to employ ATC systems is often governed by factors other than technical considerations, a practice that has profound implications for the future development and implementation of transit innovations. Among the factors guiding this decision are federal policies that encourage high technology solutions, the desire to garner political support by proposing an attractive and innovative system, and the failure of transit agencies to analyze suboptions within the overall system. Echoing these findings are the findings of another OTA study -- An Assessment of Community Planning for Mass Transit. (see previous abstract) -- which explored the process by which communities formulate plans to develop and modernize rail rapid transit systems. That study found that these same factors often motivate communities to opt for single comprehensive and innovative solutions to their transportation problems rather than to seek out a diversity of alternatives better suited to their needs. 
ASSESSMENT OF FUEL CONSERVATION POTENTIAL OF

Mode: MASS TRANSI'T A GROUND TRANSPORTATION SYSTEM DUE TO FULL UTILIZATION OF ITS MASS TRANSPORTATION CAPABILITIES (1977)

Center for Research, Inc., for National Science Foundation

EXECUTIVE SUMMARY

Supply: fuel

consumption

Environmental

Impacts:

sociological

System Coverage:

rail and road

Network Coverage:

urban

Product: vehicles

and mass transit

R\&D Issue: alternative method for determining capability to divert public traveling and conserve fuel; does not deal'with economic and geographic inequities
During a, fuel shortage, low production/fuelconsumption areas must be identified and their fuelsaving capability must be estimated so that correct and effective emergency relief measures can be proposed. This study presents a model that can be used to assess the overall fuel conservation potential of a ground transportation system due to full utilization of its mass transportation mode.

The approach used in this study is experimental rather than theoretical. For a selected city (Kansas City, Kansas) the study estimates existing excess mass transit capacity, the auto trips that potentially can be diverted to use mass transit, and the fuel savings due to such diversions.

Since only existing data are used in this study and the results are believed to be acceptably accurate, the procedures developed are felt to be useful for assessing the fuel-saving capability of a ground transportation system under an emergency situation. A manual describing the general use of the procedures developed is included.

\section{PURPOSE}

The study develops an approach that can help policy and strategy planners devise relief solutions during a fuel shortage where current fuel consumption and reduced future supply are known. The suggested overall approach is to identify low production/fuel-consumption areas and their fuel savilly capability (quantitative) so that effective emergency relief measures can be proposed. The areas that produce little person travel while consuming fuel in vehicles are considered first in curtailing fuel supplies. The process for finding fuel saving opportunities with little disruption to travel patterns continues until the total fuel savings matches the expected shortage. The study identifies one of the low productivity/fuel-consumption usage areas in ground transportation and develops procedures to assess its fuel-saving potential. 
The study develops implementable procedures and techniques for assessing the mass transportation system's ability to accommodate the person-trips diverted from auto travel for fuel conservation purposes. The study makes two essential assumptions: (1) the capacity of the mass transportation system is constant and (2) people's travel patterns do not change; i.e., if a person usually makes a trip at $8 \mathrm{a} . \mathrm{m}$. by car, he will still make the trip at 8 a.m. if he is diverted to using a bus.

Since the developed process is used in an emergency case, the procedures and technique should involve very little, if any, time-consuming data collection efforts: Ultimately, this process should use only universally available data.

\section{APPROACH}

A case study approach was felt most suitable for the study because it could demonstrate the practicality of a developed process. The study (1) selected a stuity area, (2) developed a logical proccos, (3) collected pertinent data to assess fuel-conservation potential in the study area, and (4) derived a general process for assessing the fuel-conservation potential of a ground transportation system.

The study area selected was Kansas City, Kansas. This city was chosen for a number of reasons. Transit, travel, and other related information for Kansas City is abundant and available. Part of the larger Kansas City metropolitan area, Kansas City has a fairly. independent geographical boundary and an independent bus system with related surrounding areas. This feature tends to indicate that results of this study may have applications to a wide range of cities. The city and its transit system are small enough that the study can examine finer details without large amounts of repetitive data compilation and analysis work.

The Study Process

There are six major activities in the process. Activity 1 estimates the existing transit capacity in terms of hourly person trips. Activity 2 determines the existing transit usage in terms of hourly person trips. These two activities lead directly to the estimation of excess capacity of the existing system, which is the context of Activity 4. These three activities are relatively straightforward and require only careful compilation of collected bus operating records. However, one cannot expect that this excessive capacity would be fully utilized lo accommodate any divertcd automotive trips. The divertable auto person-trips are subject to many restrictive factors, such as walking distance to bus lines, starting time of trips, destination locations, travel time, unusable capacities, etc.' All these considerations are handled in Activity 3, which is the core of this study effort. Once Activity 3 is completed, Activities 5 and 6 become matters of calculation. Activity 5 estimates the number of auto trips diverted to mass transit trips and Activity 6 estimates fuel savings due to the diverted trips. 


\section{Collection of Pertinent Data}

- Tiute frame: the etudy considers 1974 as its time base to take advantage of October 1974 Kansas City transit survey data and to use the then-recent transit patronage records ... the source from which potential divertable auto trips can be estimated is the Kansas City Metropolitan Area OriginDestination Survey conducted in 1970.

- The fundamental trip unit used is the person trip. Clock hours is the unit used for time.

- Data are used for only one direction of travel: trips toward the central business districts of Kansas City.

- Weekday and weekend travel is considered in the study: to determine the existing transit system capacity, seating capacity, by time, of the transit routes is determined from transit schedules and the seating capacity of transit vehicles ... to estimate the existing transit system usage, the maximum number of passengers enroute by time for all Kansas City transit routes was calculated from the average of the collected three weekday drivers' reports ... to develop criteria for trips that can be diverted to bus, (1) seven blocks is adopted as the maximum reasonable walking distance; therefore, trips requiring more than seven blocks walking to transit routes are considered nondivertable trips, (2) seven blocks is also adopted as the maximum walking distance from a bus route to a destination; (3) trips traveled in a car that carries more than three people are not considered divertable; (4) five travel modes were specified and considered: auto driver, truck driver, auto passenger, taxi passenger, and truck passenger; and (5) bus availability, trip length, and usable capacity of transit are also considered.

\section{METHODOLOGY}

A "grand fuel consumption model" of a ground transportation system was developed to quantitively determine the low fuel productivity/fuelconsumption areas. In a ground transportation system, the notations listed in Table 23 are used for parameters related to fuel consumption. From Table 23, it can be seen that the total fuel consumption of the ground transportation system (F) can be expressed as:

$$
\mathrm{F}=\mathrm{N}_{1} \mathrm{U}_{1}+\mathrm{N}_{2} \mathrm{U}_{2}+\mathrm{N}_{3} \cdot \mathrm{O}+\mathrm{N}_{4} \cdot \mathrm{O}
$$

The total trips $(T)$ made in this system are $T=x_{1}+x_{2}+x_{3}+x_{4}$. Since the highest fuel consumption mode of a ground transportation system is auto transport, the fuel conservation potential is determined by assessing how many auto trips can be diverted to other modes of transportation and how much auto occupancy can be increased. Now suppose that the total auto trips $\left(x_{2}\right)$ that can be diverted to various modes is: $x_{2}=x_{1}{ }^{\prime}+x_{2}^{\prime}+x_{3}^{\prime}+x_{4}^{\prime}$, where $x_{1}^{\prime}=$ auto trips diverted to mass transportation, $x_{2}{ }^{\prime}=$ auto trips remaining in the auto mode, $x_{3}{ }^{\prime}=$ auto trips diverted to bicycle trips, and $x_{4}{ }^{\prime}=$ auto trips diverted to walking trips. If such diversions were made, then the total fuel consumption would be:

$$
F^{\prime}=N_{1} U_{1}+N_{2}^{\prime} U_{2}+\left(N_{3}+x_{3}^{\prime}\right) \cdot 0+\left(N_{4}+x_{4}^{\prime}\right) \cdot 0
$$


Table 23. Notations for Fuel-Consumption Parameters

\begin{tabular}{lcccc}
\hline \multicolumn{1}{c}{ Parameter } & $\begin{array}{c}\text { Mass } \\
\text { Transit }\end{array}$ & Auto & Bicycle & Walk \\
\hline Trip (person-mile) & $\mathrm{x}_{1}$ & $\mathrm{x}_{2}$ & $\mathrm{x}_{3}$ & $\mathrm{x}_{4}$ \\
$\begin{array}{l}\text { Average occupancy. (person/ } \\
\text { vehicle) }\end{array}$ & $\phi_{1}$ & $\phi_{2}$ & $\phi_{3}=1$ & $\phi_{4}=1$ \\
$\begin{array}{l}\text { No. of unit (vehicle-mile) } \\
\begin{array}{l}\text { Unit fuel consumption } \\
\text { (gallon/vehicle-mile) }\end{array}\end{array}$ & $\mathrm{N}_{1}=\frac{\mathrm{x}_{1}}{\phi_{1}}$ & $\mathrm{~N}_{2}=\frac{\mathrm{x}_{2}}{\phi_{2}}$ & $\mathrm{~N}_{3}=\mathrm{x}_{3}$ & $\mathrm{~N}_{4}=\mathrm{x}_{4}$ \\
\hline
\end{tabular}

where:

$$
\begin{aligned}
\mathrm{N}_{1} & =\left(\mathrm{x}_{1}+\mathrm{x}_{1}{ }^{\prime}\right) / \phi_{1}{ }^{\prime} \\
\mathrm{N}_{2}{ }^{\prime} & =\mathrm{x}_{2}{ }^{\prime} / \phi_{2}{ }^{\prime} \\
\phi_{1}^{\prime} & =\text { new occupancy of every mass transportation unit } \\
\phi_{2}^{\prime} & =\text { new auto occupancy }\left(=\phi_{2}+\Delta \phi_{2}\right)
\end{aligned}
$$

The fuel conservation potential of the ground transportation system can be obtained by subtracting Eq. 2 from Eq. 1:

$$
\begin{aligned}
F-F^{\prime} & =\left(N_{2}-N_{2}{ }^{\prime}\right): U_{2} \\
& \equiv \frac{x_{1}^{\prime}+x_{3}^{\prime}+x_{4}^{\prime}+N_{2}^{\prime} \Delta \phi_{2}}{\phi_{2}} \cdot \mathrm{U}_{2}{ }^{\prime}
\end{aligned}
$$

\section{CONCLUSIONS}

The case study demonstrated that it is possible to assess the fuel saving potential of a ground transportation system when its mass transportation capacity is fully utilized. Because no data collection effort other than gathering existing information was employed, the procedures developed in this study present an alternative method to be employed in emergency situations. The study also showed that it is possible to estimate the upper limit of potential transit riders for a given area. and a known transit system. This estimated possible transit rider population can be a base for planners to analyze modal split phenomena and to devise transit market studies. This development can enable planners to approach the modal split problem in variance to the existing approach, where the total population is used as an assessing base. 
Since the study showed that it is possible to estimate the fuel savings of increased mass transit use, the fuel savings would be a known quantity in a benefit-cost analysis for promoting transit usage and justifying the financing of a transit-promotion program.

It is also felt that most of the activities conducted in this study are so closely related to transit operations that many of the concepts and techniques engaged in the study are useful to transit agencies in transit route selection, scheduling, expanding or deleting service, etc.

\section{RECOMMENDATIONS}

The procedures and techniques developed can provide fuel savings estimates (due to auto trips diverted to mass transit trips) with acceptable. accuracy, using only existing data. It is recommended that the process developed in this study be adopted by appropriate agencies when a need for such a fuel savings assessment arises.

It has been demonstrated that, by using the comprehensive origindestination information and a given mass transit network of an area, the maximum number of possible mass transit riders can be estimated. This study recommends that research be conducted in the following areas to take advantage of this development: (1) development of a modal split model based on the total possible transit riders and not the total trip makers of an area, (2) development of transit market estimate schemes, and (3) development of emergency contingency plans for using mass transit to transport people in cities.

To improve the accuracy of the assessment process, it is recommended that public transportation and transit agencies improve their data collection techniques. Functional relationships among the pertinent parameters could not be established, so a functional sensitivity analysis for the results was not possible. All the sensitivity analyses are conducted on a parameter basis and some are only descriptive. Therefore, the case study results are undoubtedly subject to errors. 
ASSESSMENT OF BATTERY BUSES (1977)

Mode: MASS TRANSIT

U.S. Department of Transportation, Urban Mass Transportation Administration

EXEECUTIVE SUMMARY

Supply-oriented study focusing on urban bus technology

System Coverage:

road

Process Coverage:

vehicles

Network Coverage:

urban

Environmental

Implications:

air quality and

fuel conservation
This study examines the performance capabilities of battery and hybrid buses operating in the United States, Europe, Japan, and Australia. Through this examination, it seeks to inform American transit operators of the advantages and disadvantages of deploying this technology in urban areas and to guide future UMTA research endeavors.

Employed in the study is a case-hy-case rmparative analysis with most of the information acquired during on-site visits to transit systems using battery buses. The findings of this evaluation show that battery buses, a virtually pollution-free form of transit, offer performance levels comparable to those provided by diesel buses. In light of these findings and anticipated increases in petroleum costs, batteryoperated buses are an attractive transit technology.

\section{PURPOSE}

This study assesses public transport systems using electric battery and hybrid buses, focusing on their performance, reliability, and maintenance needs. It also describes the technical features of these vehicles, such as battery types, charging procedures, power trains, and other vehicle design features affected by the powerplant. The study seeks to provide information needed to guide UMTA research funding decisions and to help American transit operators understand the uses, advantages and disadvantages of available electric battery bus systems. The major impetus for the study came from the Electric and Hybrid Vehicle Research and. Development Act of 1976 (P.L. 94-413).

\section{APPROACH}

A case study and comparative analysis were employed. Information for analysis was acquired through correspondence with various system operators and manufacturers and through on-site surveys of passenger-carrying, electric battery buses operating in the United States, Europe, Japan; and Australia. The survey evaluated 16 different systems, supplied by 15 manufacturers and operated by 18 public transit authorities. All together, these systems contain 57 buses that have logged 2.1 million miles of passenger-carrying 
service. The analysis of advantages and disadvantages of the different systems involved a comparison of performance records and technical features.

\section{CONCLUS IONS}

\section{Capabilities of Existing Battery Bus Systems}

- Capacity and use: buses adapted for electric-battery propulsion ranged from 22-passenger mini-buses to standard 100-passenger transit coaches ... buses used for variety of services from city center circulation to linehaul with routes, schedules, and duty cycle designed to match bus capabilities.

- Performance: buses tested under ideal test conditions showed ranges of 40-180 $\mathrm{km} \mathrm{...} \mathrm{buses} \mathrm{tested} \mathrm{under} \mathrm{actual} \mathrm{conditions} \mathrm{showed} \mathrm{range} \mathrm{of} 24-80 \mathrm{~km}$ ... battery performance and life undermined by permitting discharges of more than $80 \%$... studies in U.S. and England indicate large potential for use of battery buses in cities.

- Speed and acceleration: speeds ranged from 32 to $72 \mathrm{kph}$... acceleration from 0 to $32 \mathrm{kph}$ in 8 to 10 seconds... grades buses ascend at reasonable acceleration rates varied from 5 to $16 \%$... drivers appreciate acceleration capabilities and absence of manual gear shifts to achieve them.

- Noise: electric battery buses are relatively quiet, having typical interior noise levels of 60 to $70 \mathrm{~dB}$ (65 to $80 \mathrm{~dB}$ accelerating) ... highest exterior noise level noted was $80 \mathrm{~dB}$.

- Performance advantages: fuel savings ... better acceleration rates than diesel buses in areas with many stops ... battery buses comparatively quiet and virtually pollution-free ... performance characteristics are well suited for services in city center and automobile-free shopping malls.

- Performance disadvantages: range limitations require planning in scheduling and routing ... drivers must be sensitive to equipment and performance limitations ... extreme temperatures can hurt performance.

\section{Battery Recharging Procedures}

- Ample opportunity to recharge batteries on-board during off-peak periods, when buses not used, overnight, and since sound practices require charging when $50 \%$ of battery discharged, during noon intervals. Adapting duty cycles to charging needs permits daily urban running distances of 42-100 $\mathrm{km}$.

- Devices that automatically exchange hatteries have been developed and tested in Germany and. Japan. The exchange requires less than five minutes and can be made during waiting periods. Buses continue in service during recharge and have achieved daily running distances of $350 \mathrm{~km}$. 
- Advantages of on-board charging: recharging is simple, involving little more than plugging charger into bus ... batteries can be "topped off," extending both the range and battery 1 ife ... cutting bus runs is simpler, since it does not involve scheduling battery exchanges.

- Disadvantages of on-board charging: operation limited to one or two peak periods a day, leaving vehicle unproductive at other times (as is high percentage of conventional fleet) ... flexibility in assigning routes or making substitutions on runs restricted by capability of fixed battery installation.

- Advantages of battery exchange: battery bus can be used throughout the day ... more-flexible scheduling permitted in assigning runs ... batteries can be serviced and recharged on cycles independent of bus operations ... drivers and maintenance personnel can be better utilized.

- Disadvantages of battery exchange: considerable initial investment in spare batteries ... locations must be planned to minimize derd-heading for each exchange and sites must be arranged to accomodate number of scheduled exchanges ... at least three spare batteries must be kept in service for every two buses in operation ... battery exchange mechanisms, automatic charges, and frequent battery replacements contribute to system down time.

Energy Consumption and Life-Cycle Costs of Battery Buses

- Energy consumption for travel ranged from 0.93 to $2.64 \mathrm{kWh} / \mathrm{km}$ for minibuses and 1.64 to $3.1 \mathrm{kWh} / \mathrm{km}$ for regular buses. Energy consumption for heating averages between 0.12 and $0.22 \mathrm{kWh} / \mathrm{km}$.

- Test comparisons between types of traction motors indicate that a separately excited, shunt-wound motor can reduce energy consumption.

- Preliminary analyses indicate electric battery huses are mnre rnsteffective than diesel buses, but definitive comparisons have not been made.

\section{Capabilities of Hybrid Systems}

- Performance of three hybrid systems was examined: duo-bus can travel $40 \mathrm{~km}$ at $15 \mathrm{kph}$ in traffic on batteries alone, but its battery capacity can be replaced by overhead conductors at a rate of one kilometer of battery capacity for each kilometer of trolly operation ... Mercedes-Benz 0E305 operates on $60-65 \%$ diesel electric and $35-40 \%$ battery electric, allowing a daily range of $300 \mathrm{~km}$ on a tank of fuel without a recharge ... Kawasaki hybrid has a range of $180 \mathrm{~km}$, limited by $120-\mathrm{L}$ fuel tank.

- Speed and acceleration: Mercedes has maximum speed of $70 \mathrm{kph}$, while other two can reach $60 \mathrm{kph}$... acceleration varies from 2.5 to $3.8 \mathrm{kph} / \mathrm{sec}$ ... maximum grade that hybrid buses can ascend at a reasonable acceleration is $14 \%$ for Kawasaki and $16 \%$ for the other two. 
- Noise: noise levels inside Duo-Bus while at rest are $60 \mathrm{~dB}$, while accelerating 65-70 dB ... noise levels inside Kawasaki are 67-71 phons while stopped, 76 phons while starting, 81 phons while cruising at $52 \mathrm{kph} \ldots$ exterior noise levels for Kawasaki are 67-70 phons under battery operations and 73-76 phons under hybrid operations ... no data on Mercedes.

- Performance advantages: hybrid buses have almost unlimited range, considerably more than battery buses... Duo-Bus can use existing trolly wire installations, while not being confined to them ... diesel hybrids have almost no restrictions on duty cycles and routes ... performance capabilities exceed transit operation requirements ... hybrids can operate in areas beyond electrified routes, saving the cost of extending catenaries and overhead contact wires.

- Performance disadvantages: diesel hybrids emit some noise and exhausts; but much less than conventional diesel buses ... battery weights and cooling problems limit present performance capabilities of Duo-Bus.

- Energy consumption: Kawasaki buses and Duo-Bus -- $1.8 \mathrm{~km} / \mathrm{L}$ for diesel fuel and $0.24 \mathrm{kWh} / \mathrm{km}$ for battery charging.

- Life-cycle costs: comparisons show greater cost per mile for Duo-Bus than for either trolly or diesel bus, but costs do not reflect increasing energy costs over the life of vehicles.

\section{RÉCOMMENDATIONS}

The study notes that additional information is needed before battery buses can be deployed for regular revenue service in this country. To provide meaningful data that would enable U.S. transit operators to understand advantages and disadvantages of deploying battery buses, study recommends that a demonstration project be undertaken.

The demonstration project should compare service provided by three or more types of buses, to obtain experience and data representative of fleet operations, ensure availability for uninterrupted operations, allow for adequate training of operating and maintenance personnel, and provide economic incentives for system suppliers to make product improvements. The project also should conduct parallel operations with electric battery buses and conventional diesel buses to compare costs and performance, determine realistic life-cycle costs, and assess passenger and driver reactions to the vehicles.

The demonstration project should structure the in-service tests to evaluate the cost and effectiveness of subsystems, including: (1) large, heavy-duty batteries, versus lighter-weight, shorter-life-cycle batteries, (2) on-board charging versus battery exchange techniques, (3) battery chargers, (4) series-wound versus separately excited shunt-wound traction motors, (5) contractor control versus a variety of solid-state motor control devices, (6) regenerative braking, including the trade-offs between energy saving, tire wear, and maintenance costs, and (7) space heaters. Finally, the project should demonstrate a sufficient number of both trolley-battery and dieselbattery hybrid buses, so as to: evaluate the effectiveness of trolley-battery 
hybrid buses in preserving and extending electric trolley service where it presently exists, assess the environmental impact of hybrid buses compared to that of diesel and electric battery buses, and develop data on life-cycle costs for comparison with other public transit systems.

COMMENTS

With the rising cost of petroleum and increased concern over air quality in urban areas, battery buses appear to be an attractive alternative to conventional diesel buses. Both battery and hybrid buses offer performance levels comparable to those provided by diesel buses. Yet to be made, however, is a definitive cost comparison between battery powered buses and diesel buses--a mission the authors of this report indicate should be undertaken. A major obstacle to making a valid cost comparison is that the lack of a large market and sizable production runs tend to make initial capital costs of battery buses artificially high. 

AIRCRAFT (1978)

U.S. Department of Transportation, Federal Aviation Administration

PURPOSE

This study provides a preliminary evaluation of the feasibility of a technology demonstration aircraft for general aviation. It compiles a complete list of advanced technologies suitable for use in general aviation aircraft, evaluates the potential contribution of each technology to the improvement of general aviation aircraft, synthesizes the most promising technologies into a set of representative aircraft configurations and identifies technologies that would improve flight safety, performance, and utility.

\section{ASSUMPTIONS}

General aviation is assumed to consist of all nonmilitary, nonairline aircraft, including fixed-wing aircraft and rotocrafts, home-builts, and executive jets (total U.S. fleet exceeds 180,000 aircraft).

\section{METHODOLOGY}

The study identifies technologies that might have an impact on future general aviation design. It establishes an objective method for choosing the most promising technologies. This method (1) allows each individual technology to be assessed on a consistent basis, (2) provides a means for comparing the relative merits of different technologies, (3) insures that all critical performance, safety, cost, and use categories are considered, (4) provides a method for differentiating between most-important and leastimportant evaluation criteria, and (5) permits sensitivity testing for key parameters and assumptions. Criteria considered are safety, reliability, performance, cost, customer acceptance, efficiency, operational ease and utility, maintenance, weight, and environmental impact. Finally, the study develops various configurations that take advantage of the most promising technologies and are consistent with trends.

\section{CONCLUSIONS}

New Technologies to Improve Safety, Performance, and Utility

- Aerodynamics: spoilers/full span flaps to increase high-speed performance ... improved stall-spin characteristics to increase safety ... leading edge slats to increase lift coefficient and angle of attack at stall ... tailored air foils for drag reduction ... Canard configuration ... winglets to reduce tip vorticity, increase effective wing span, reduce induced drag ... thrust/drag control to improve landing performance ... positive spiral stability. 
- Powerplant: small low-cost turbines ... turbocharging to improve cruise speed, $c l i m b$, and fuel efficiency ... increased time before overhaul (extend operational life) ... Wankel engine (internal combustion) ... auto engine conversions ... diesel engines ... stratified-charge engines ... liquid cooling ... reduced cooling drag ... integrated mixture and spark control (improve fuel economy and lower emissions) ... improved mufflers .... carburetor key detection ... crash-resistant fuel cells ... advanced propeller design ... ducted propulsors.

- Structures, materials and fabrication: crash-resistant cabin structure ... advanced analytic techniques ... high-strength, high-modulus fibers ... matched-die fiber-reinforced plastic ... sandwich panels ... structural foam ... chem milling ... metal bonding.

- Avionics: microminiaturization ... CRT navigation displays ... low-cost programmed navigation ... Navstar (navigation satellite system) ... suppressed antennas ... low-cost weather detectors.

- Instrumentation: coordinated instrument displays ... annunciators (failure-warning check-list) ... on-board performance calculators.

- Airframe and system design: improved fireproofing ... ice-shedding surfaces $\ldots$ oxygen without masks.

- Human factors and operations: controls standardization ... improved passenger restraint ... cockpit delethalization.

Objective Methodology to Evaluate Technologies

Ten factors were identified, defined and ranked in importance by a panel of experts. Weights were assigned to the factors according to panel responses. Technologies judged against criteria on scale from -3 to 3 and then ranked.

Social and Political Issues

Issues: multinationalization of business .... investment tax credit ... statutory speed limits ... simulator flight training.... elimination of G.I. pilot training. ... continuing growth of general aviation sales ... increasing $R \& D$ costs ... improved engine and system reliability ... microminiaturization ... rising cost for lowest-priced aircraft ... growth of amateur-built movement ... deregulation of scheduled airlines ... stringent safety requirements for commuter aircraft ... airport availability ... need for improved fuel efficiency ... products liability litigation ... morestringent noise controls ... legislated safety features ... pesticide legislation ... user charges and taxes ... increasing air traffic command complexity .... increasing U.S. afflience and leisure.

\section{Design Configurations}

Four design configurations that could incorporate a number of the most promising technologies should be performance tested. These designs are: 
- Single-engine, high-speed, four-place airplane. Conventional, but can adapt a variety of powerplant installations and has crashworthy and costreduction features (Design 1, see Table 24).

- Single-engine, five-place, turbofan airplane. Conventional, but wing area is reduced without compromising cabin volume (Design 2, see Table 25).

- Single-engine, four-place, crashworthy airplane. Improved crashworthiness and maximum use of potentially low-cost matched-die molded parts (Design 3, see Table 26).

- Twin-engine, quiet, commuter/cargo airplane. Ducted propulsor engine, Canard configuration (Design 4, see Table 27).

\section{Overall Assessment}

Approximately 40-50 new technologies have the potential for improving general aviation safety and efficiency. A numerical method for ranking candidate technologies appears useful. It is possible to design technology demonstration aircraft so that they can be performance tested. 
Table 24. Specifications and Performance for High-Speed Single-Engine Aircraft (Design 1)

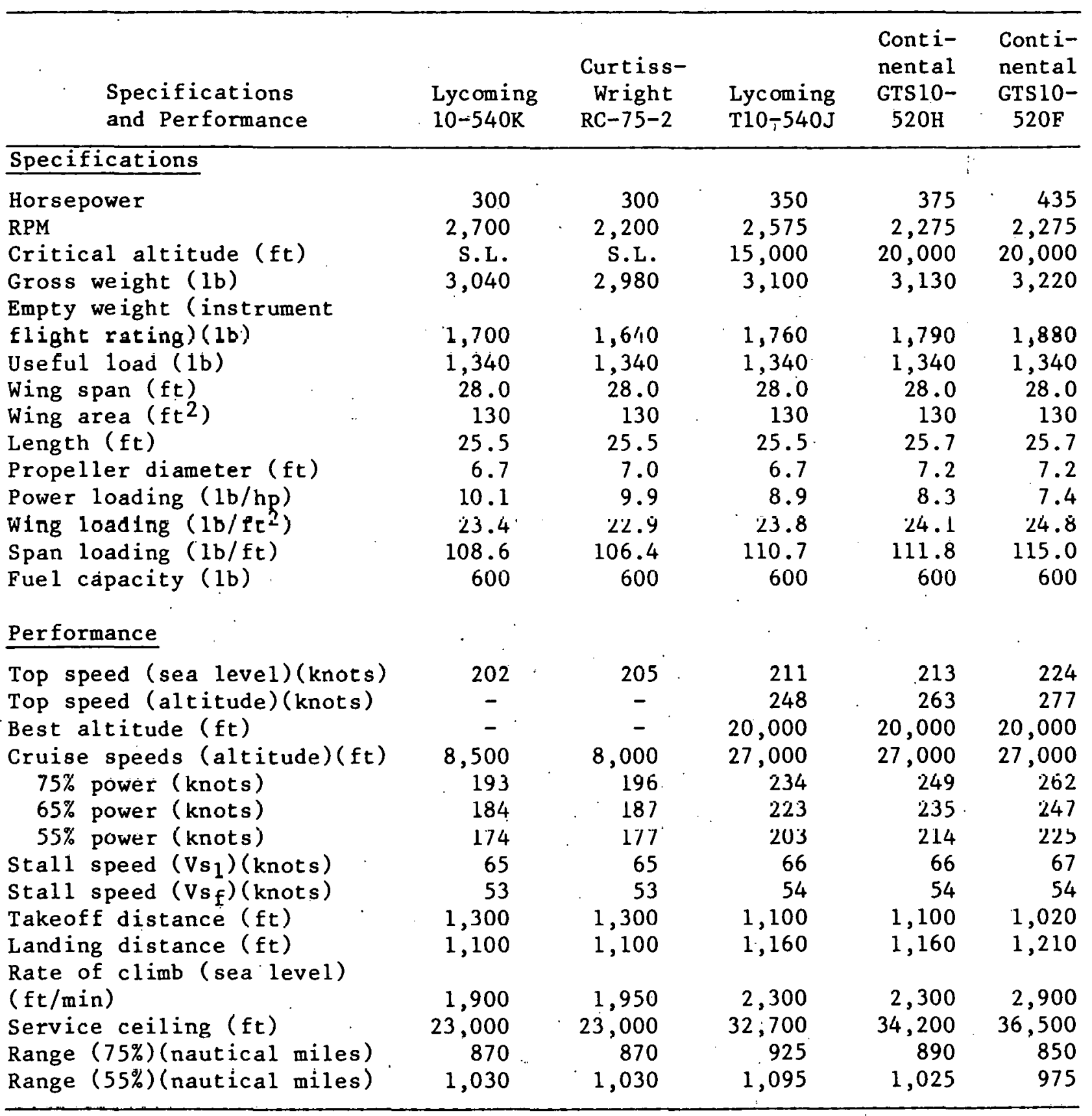


Table 25. Comparison of Modified Turbofan (Design 2) with Current-Technology Turbofan

\begin{tabular}{|c|c|c|}
\hline $\begin{array}{l}\text { Specifications } \\
\text { and Performance }\end{array}$ & $\begin{array}{l}\text { Single- } \\
\text { Engine } \\
\text { Modified } \\
\text { Turbofan }\end{array}$ & $\begin{array}{c}\text { Current- } \\
\text { Technology } \\
\text { Twin } \\
\text { Turbofan }\end{array}$ \\
\hline Specifications & & \\
\hline 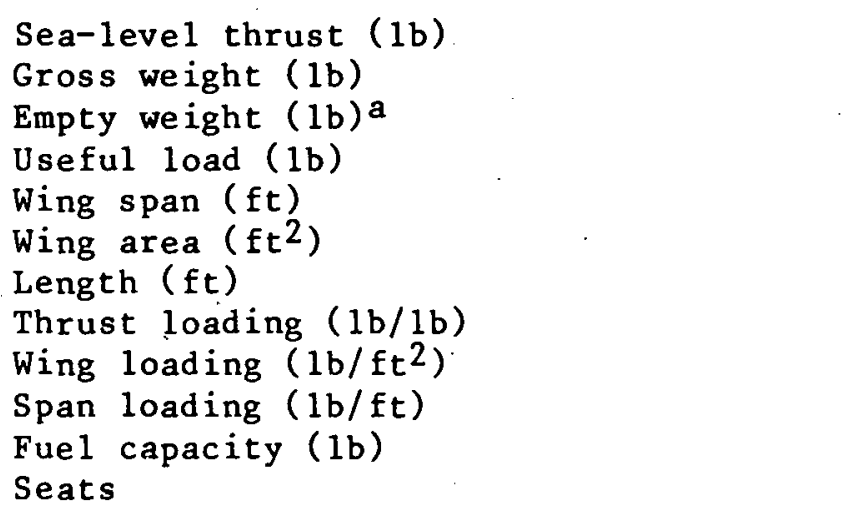 & $\begin{array}{r}2,200 \\
6,200 \\
3,350 \\
2,850 \\
30.0 \\
150 \\
32.2 \\
2.8 \\
41.3 \\
207 \\
1,900 \\
2+3\end{array}$ & $\begin{array}{r}4,400 \\
11,800 \\
6,600 \\
5,200 \\
48 \\
270 \\
44 \\
2.7 \\
43.7 \\
246 \\
3,800 \\
2+5\end{array}$ \\
\hline \multicolumn{3}{|l|}{ Performance } \\
\hline $\begin{array}{l}\text { Max. cruise speed at } 30,000 \mathrm{ft} \text { (knots) } \\
90 \% \text { cruise speed at } 20,000 \mathrm{ft} \text { (knots) } \\
\text { Stall speed, flaps up (knots) } \\
\text { Stall speed, flaps down (knots) } \\
\text { Balanced field léngth ( } \mathrm{ft})\left(\mathrm{int} \mathrm{f}^{\prime} 1 .\right. \\
\text { standard atmosphere) } \\
\text { Rate of climb (sea level)(ft/min) } \\
\text { Service ceiling (gross weight)(ft) } \\
\left.\text { Range ( } 90 \% \mathrm{cr}, 35,000^{\prime}\right) \text { (nautical miles)c } \\
\text { Retail Price }(\$, 1978)\end{array}$ & $\begin{array}{r}402 \\
370 \\
92 \\
74 \\
2,600^{b} \\
3,750 \\
43,000 \\
1,390 \\
575,000\end{array}$ & $\begin{array}{r}2,900 \\
3,300 \\
43,000 \\
1,315 \\
975,000\end{array}$ \\
\hline
\end{tabular}

${ }^{a}$ Equipped for instrument flight rating.

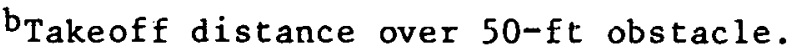

c45-min. reserve. 
Table 26. Specifications and Performance for SingleEngine Crashworthy Aircraft (Design 3)

\begin{tabular}{|c|c|c|c|}
\hline $\begin{array}{l}\text { Specifications } \\
\text { and Performance }\end{array}$ & $\begin{array}{l}\text { Lycoming } \\
10-540 \mathrm{~K}\end{array}$ & $\begin{array}{l}\text { Curtiss- } \\
\text { Wright } \\
\text { RC-75-2 }\end{array}$ & $\begin{array}{c}\text { Conti- } \\
\text { nental } \\
\text { GTS10- } \\
520 \mathrm{H}\end{array}$ \\
\hline \multicolumn{4}{|l|}{ Specifications } \\
\hline 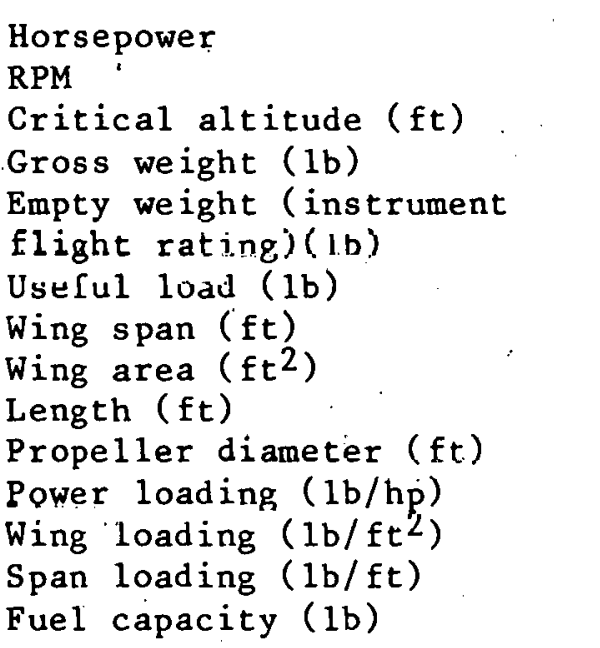 & $\begin{array}{r}300 \\
2,700 \\
\text { S.L. } \\
3,080 \\
1,740 \\
1,340 \\
24.0 \\
195 \\
22.8 \\
6 . .7 \\
10.3 \\
15.8 \\
128.3 \\
600\end{array}$ & $\begin{array}{r}300 \\
2,200 \\
\text { S.L. } \\
3,020 \\
1,680 \\
1,340 \\
24.0 \\
195 \\
22.8 \\
7.0 \\
10.1 \\
15.3 \\
125.8 \\
600\end{array}$ & $\begin{array}{r}375 \\
2,275 \\
20,000 \\
3,170 \\
1,830 \\
1,340 \\
24.0 \\
195 \\
23.4 \\
7.0 \\
8.5 \\
16.3 \\
132.1 \\
600\end{array}$ \\
\hline \multicolumn{4}{|l|}{ Performance } \\
\hline $\begin{array}{l}\text { Top speed (sea level)(knots) } \\
\text { Top speed (allilule)(knots) } \\
\text { Cruise speeds (altitude)(ft) } \\
75 \% \text { power (knots) } \\
65 \% \text { power (knots) } \\
55 \% \text { power (knots) } \\
\text { Stall speed (Vs }) \text { (knots) } \\
\text { Stal1 speed (Vsf) (knots) } \\
\text { Takeoff distance (ft) } \\
\text { Landing distance (ft) } \\
\text { Rate of rlimb (sea level) } \\
\text { (ft/min) } \\
\text { Service ceiling (ft) } \\
\text { Range ( } 75 \% \text { )(nautical miles) } \\
\text { Range ( } 55 \% \text { )(nautical miles) }\end{array}$ & $\begin{array}{r}185 \\
- \\
8,500 \\
168 \\
160 \\
152 \\
64 \\
50 \\
1,300 \\
1,050 \\
1,100 \\
21,000 \\
800 \\
940\end{array}$ & $\begin{array}{r}189 \\
- \\
8,000 \\
172 \\
164 \\
155 \\
63 \\
50 \\
1,300 \\
1,050 \\
\\
1,150 \\
21,000 \\
800 \\
940\end{array}$ & $\begin{array}{r}202 \\
245 \\
20,000 \\
230 \\
219 \\
207 \\
63 \\
51 \\
1,100 \\
1,100 \\
1,600 \\
33,000 \\
790 \\
910\end{array}$ \\
\hline
\end{tabular}


Table 27. Specifications and Performance for Twin-Engine Quiet Commuter/Cargo Aircraft (Design 4)

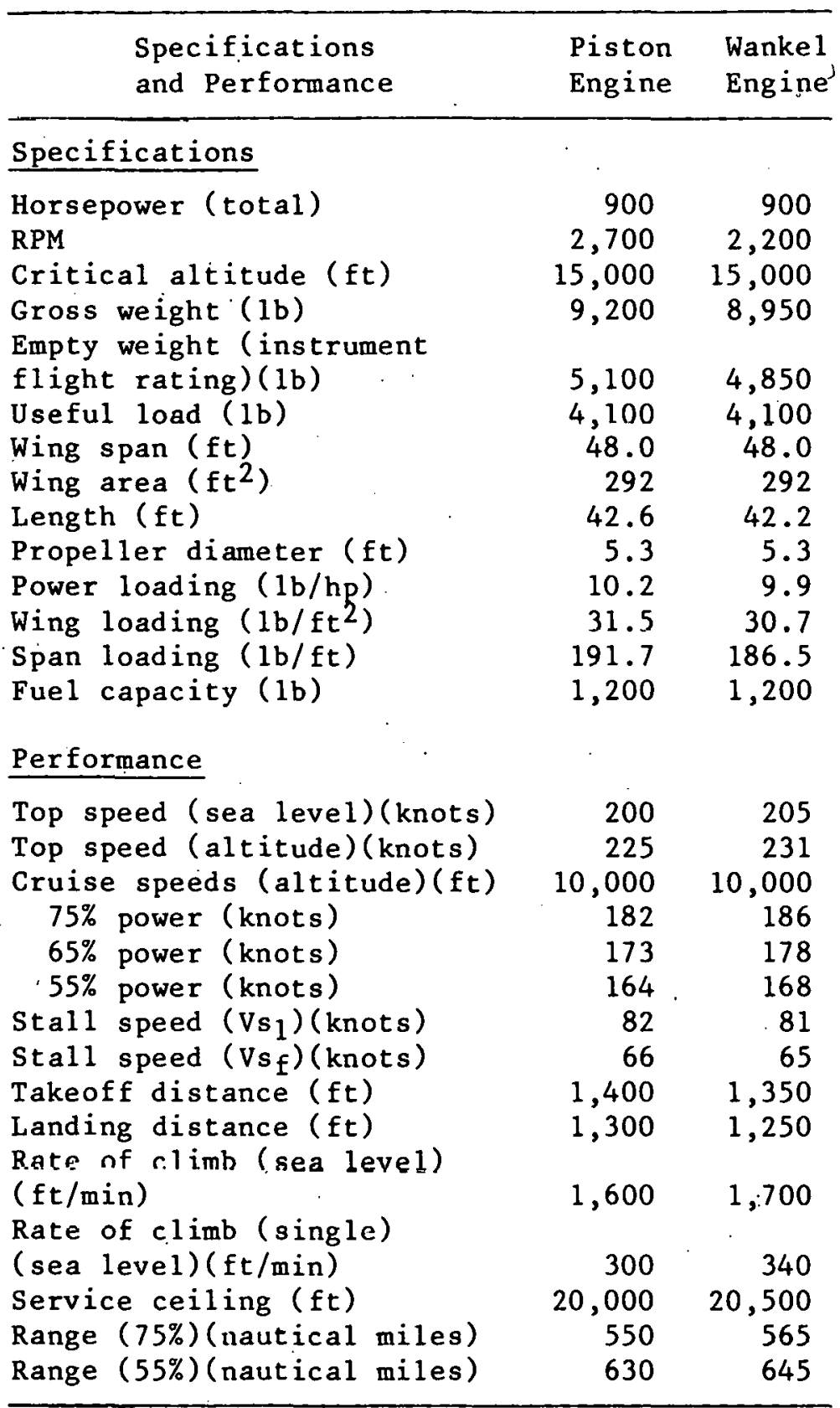


TECHNICAL AND ECONOMIC ASSESSMENT OF SPAN-LOADED CARGO AIRCRAFT CONCEPTS (1976)

Mode: AIR

McDonnell Douglas Corporation for National Aeronautics and Space Administration.

PURPOSE

This study enumerates and quantifies the benefits of span-distributed loading concepts as applied to future commercial air cargo operations. It identifies future technology requirements as well as payoff trends in configuration geometry, performance requirements, cargo-related characteristics, and economics.

\section{ASSUMPTTONS}

Maturing market for air cargo is assumed to be 100 billion ton miles per year by 1990 in this parametric study. The following direct operating cost (DOC) assumptions are made to determine consistent trends.

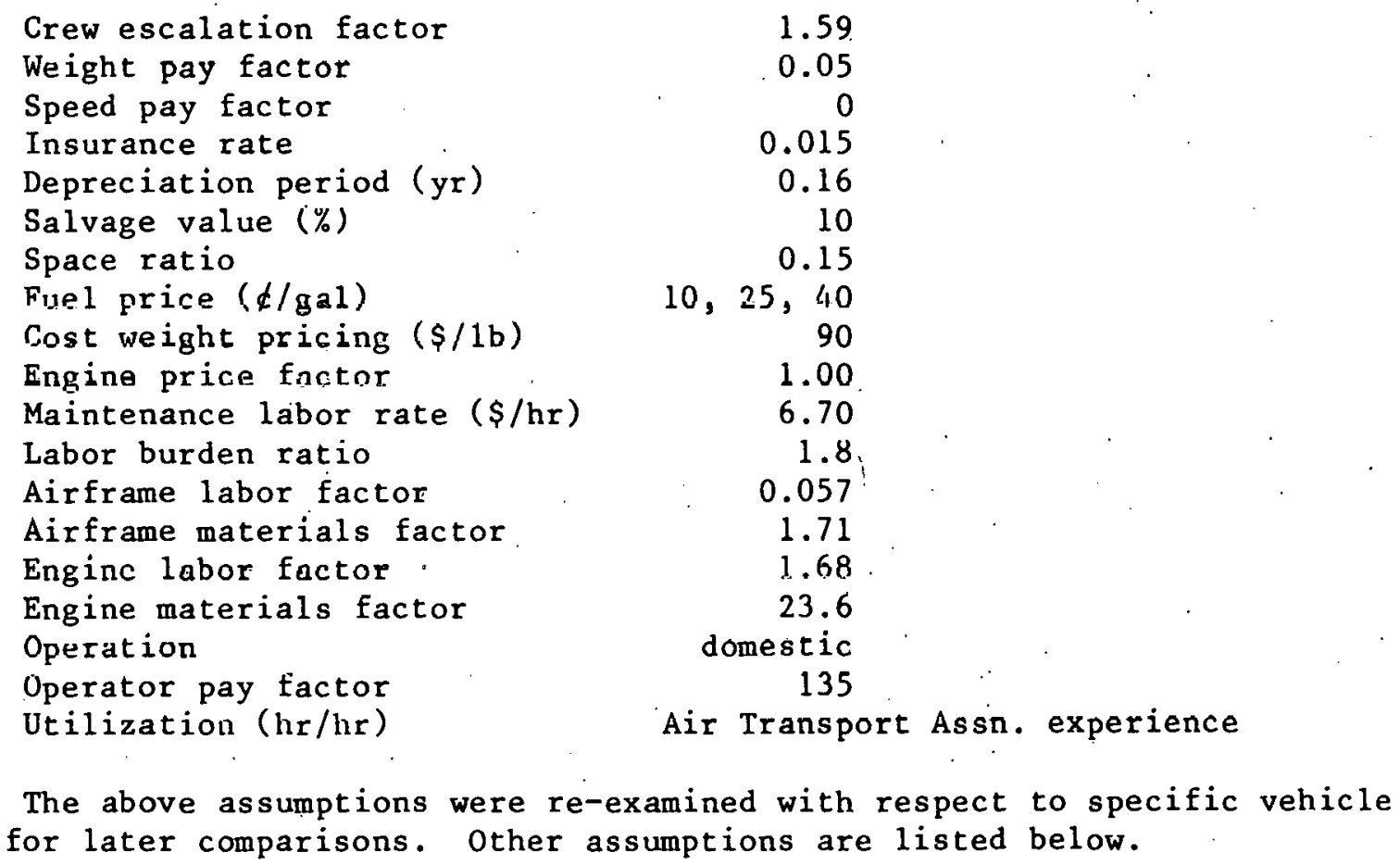
types for later comparisons. Other assumptions are listed below.

- Cargo to be carried in $8^{\prime} \times 8^{\prime} \times 20^{\prime}$ containers ... all containers are unifurmly luaded (cunslant density) ... no pressurtzacton fór cargo is assumed for basic parametric aircraft. 
- Span-loader and conventional aircraft design field lengths should be less than $12,000 \mathrm{ft}$ on standard day at sea-level ... hybrid seaplanes design takeoff distance is $8,000 \mathrm{ft}$ to minimize pounding of structure during takeoff.

- Complete use of graphite epoxy composites assumed for all airframes, including all primary and secondary structures ... reasonable negative static margins permitted ... performance based on high-bypass-ratio fanjet engine (typified by the TF-39 engine) with the specific fuel consumption reduced by $5 \%$ from current levels ... nominal span-loader configuration designated as base line.

- Parametric baseline configuration: aspect ratio $=5$ (nontapered wing) ... gross payload of $600,000 \mathrm{lb}$ at gross cargo density of $15 \mathrm{lb} / \mathrm{ft}^{3} \ldots$ sized skin/stringer, rib, span and cargo floor members to same depth as span-loader point design ... cargo bays unpressurized ... straight wing assumed as prime configuration throughout study ... conventional empennage consisting of a vertical tail and straight taper horizontal tail, sized to accommodate negative static stability margins. Conventional rudder and elevator surfaces assumed.

- Detailed configuration analysis: straight wing configuration ... nominal gross payload size $=600,000 \mathrm{lb} \ldots$ actual gross payload size $=618,000 \mathrm{lb}$ $\therefore$ gross payload density $=11.5 \mathrm{lb} / \mathrm{ft} \ldots$ three-row cargo compartment $\ldots$ capacity $=42$ containers ... nominal wing thickness $20 \% \ldots$ aspect ratio (wing span/wing chord) $=4.45 \ldots$ conventional ailerons and large. fixed winglets ... 12,000-ft maximum field length ... conventional fuselage ... straight, zero-taper horizontal tail ... pressurized cargo compartment at 5 psia.

\section{METHODOLOGY}

The first phase of the methdology was to select parametric studies of three hypothetical configurations to define significant configuration, performance and economic trends. Phase 2, the detailed configuration analysis, entailed analysis and economic evaluations defining technical and economic feasibility. A conventional all-cargo aircraft of comparable technology and size was used as the comparative system. The following parametric study variables are used.

\begin{tabular}{lll}
\multicolumn{1}{c}{ Parameter } & \multicolumn{1}{c}{ Span-Loader } & Hybrid Seaplane \\
\cline { 2 - 3 } Geometric variables & $\begin{array}{l}\text { Aspect ratio } \\
\text { Wing thickness ratio } \\
\text { Wing sweep }\end{array}$ & Aspect ratio \\
Performance variables & Range & Range \\
Payload variables & $\begin{array}{l}\text { Payload quantity } \\
\text { Payload density } \\
\text { Payload pressurization }\end{array}$ & \\
Economic variables & Fuel price & Fuel price
\end{tabular}


There were four steps in the analysis: a parametric baseline analysis of three configurations, a detailed configuration analysis, a conventional aircraft analysis, and a performance comparison. The first three are detailed below; results of the performance comparison are presented in the Conclusions section.

Parametric Baseline Analysis of Three Hypothetical Configurations

This analysis compared characteristics of the straight-wing spanloader, swept-wing span-loader, and hybrid seaplane. Seven critical wing loading conditions were used in the loads determination. Structural and weight analysis were performed, and aerodynamic characteristics were examined. Wing geometry is a function of payload characteristics, including payload size and density and the packaging of cargo containers.

\section{Detailed Configuration Analysis*}

Configuration was determined by cargo characteristics [Note: total system study (i.e., optimum payload.size, density) was not conducted]. Performance and stability and control were analyzed in the economic analysis. Airplane pricing was broken down according to labor and materials; direct operating costs included fuel, insurance, depreciation, and airframe and engine maintenance. The structure and loads analysis examined configurations under a number of design load and ground handling conditions. Critical design load conditions were determined for structural design.

LUNCiLUS IONS

\section{Comparison of Parametric Baseline Configurations}

Direct operating costs, payload/fuel cost, and payload/operatingweight-empty were compared. The swept-wing configuration had the highest potential direct operating costs and payload/fuel costs. The seaplane was generally inferior The straight-wing configuration was selected for detailed analysis because it represents the simplest structural concept with lowest acquisition cost potential, simpler loading, and lower required technology base.

\section{General Conclusions}

- Swept-wing span-loader has highest payoff potential with respect to operating costs and energy use.

- Span-loader has potential operating cost advantage over conventional aircraft of about $15 \%$... spanloader design can have aerodynamic efficiency exceeding that of today's jet aircraft ... span-loader design has superior structural efficiency due to use of distributed inertia loads in wing,

\footnotetext{
*The conventional aircraft analysis was performed according to same criteria.
} 
nearly D-2 aerodynamic wing loading, and minimization of fuselage and empennage structure ... high-payoff technologies for span-loader include winglets, supercritical wing, negative stability margins ... composite structures may not pay off for span-loaders ... because of constraints on wing shape, many optimization payoffs are limited (i.e., weight reduction items).

- Straight-wing span-loader structure results in large percentage of common parts.

- For hybrid seaplane concept to be efficient, small wing with high wing loading is required, but there is practical limit to which design wingloading can be increased. Therefore, hybrid seaplane should not be designed as span-loaded configuration but should be designed with cargo compartment in hull.

Land Plane Span-Loader Parametric Results

This study evaluated the effects of variations in configuration geometry, performance requirements, cargo characteristics and economics to provide a basis for selecting the optimum configuration.

Geometric Variables

- Aspect ratio $=5.0$ for optimum direct operating costs $\ldots$ for optimum direct operating costs, a thinner, larger wing is favored (effects of airfoil thickness on vehicle operating economics is probably small, but favorable to thinner wing) ... wing sweep- $-40^{\circ}$ sweep and zero taper ... range performance--directed operating costs optimized at 3500 nautical miles.

- Payload variables: efficiency increases with payload size ... direct operating costs are lower at higher payload densities ... pressurization of total compartment or selected containers creates dead weight penalties.

\section{Economic Variations (using three fuel costs)}

There is little incentive to select optimum aspect ratio based on operating economics for span-loader concept. The variation of optimum design range with fuel cost is very small. Optimum wing thickness decreases with increasing fuel cost.

Detailed Configuration Analysis

Performance

Operating weight empty (1b)

396,525

Gross payload weight (1b)

618,000

Tare (1b)

Fue1 ( $1 \mathrm{~b})$

80,640

Takeoff weight ( $1 \mathrm{~b})$

Reserve fuel weight ( $1 \mathrm{~b}$ )

335,235

$1,350,000$

63.,048 


$\begin{array}{lr}\text { Net thrust per engine (lb/engine) } & 58,500 \\ \text { Specific fuel consumption (lb/hr/lb) } & 0.582 \\ \text { Wing loading ( } 1 \mathrm{~b} / \mathrm{ft}^{2} \text { ) } & 73.7 \\ \text { Thrust to weight ratio } & 0.259 \\ \text { Ratio operating weight empty to takeoff weight } & 0.894 \\ \text { Ratio gross payload to operating weight empty } & 1.559 \\ \text { Ratio gross payload to fuel weight } & 1.843 \\ \text { Cruise mach number } & 0.655 \\ \text { Cruise lift coefficient } & 0.444 \\ \text { Initial cruise altitude (ft) } & 31,500 \\ \text { Maximum lift to drag ratio } & 18.75 \\ \text { Takeoff field length (ft) } & 10,737 \\ \text { Landing field length (ft) } & 9,960 \\ \text { Approach velocity (knots) } & 169 \\ \text { Second segment climb gradient } & 0.0736\end{array}$

The aconomic analyois found that the cumulative average difplane price would be $\$ 65.1$ million for 350 planes, and $\$ 58.5$ mil.1inn for 525 planes. Direct operating costs are $3.36 \notin /$ ton-mile for fleet size required. Improved aerodynamic efficiency can be achieved by use of active controls; direstinnal stability is considered adequate.

Performance and Economic Comparison: Conventional versus Span-Loader

- The payload of the span-loader exceeds that of the conventional plane by two containers ... spanloader is $5.8 \%$ more efficient on basis of payload carried per pound of invested aircraft weight, but is $15.7 \%$ less efficient from standpoint of energy usage (partially attributable to additional fuel reserve beyond that required by Federal Aviation Regulations) ... takeoff length for span-loader is less than for conventional aircraft; this is primary performance advantage because it increases operational flexibility ... primary performance disadvantage is lower cruise speed and its adverse impact on speed.

- Direct operating costs of span-loader and conventional aircraft are competitive ... price differentials result primarily from individual design attributes and secondarily from differences in fleet size ... span-loader design provides greater parts commonality and simpler construction in wing and tail components $\therefore$ benefits from design and construction of spanloader more than offset increased requirements and costs associated with propulsion, fuel, and winglet subsystems.

\section{RECOMMENDÁTIONS}

- Further detailed analysis is needed of: design of wing-fuselage juncture ... actual extent of landing gear loads on wing ribs (three-dimensional wing analysis)... engine/airframe optimization to determine best engine cycle ... further optimization of location of attachment of all internal and external aircraft components affecting static and dynamic loads on the wings ... impact of parts commonality for straight-wing versus swept-wing span-loader ... impact of use of aluminum versus composite materials ... compromises due to consideration. of military requirements on civilian span-loader. 
- General research needs: airfoil and winglet design ... define structural arrangements for optimum use of composite construction with special attention to high reliability and low cost ... identify developments in manufacturing methods and composite material systems that will be required to fabricate the components ... wing internal arrangement studies ... structural design refinements (optimization of typical wing rib, wing/fuselage juncture, pylon/wing juncture, landing gear/wing attachment, winglet/wing attachment; optimization of fuselage structure) ... payload characteristics ... engine technology requirements (to minimize cost and energy) ... dynamic stability ... operational considerations (realistic fuel reserve requirements, effect of headwinds or reserves, engine shutdown for moreefficient cruise) ... military logistics evaluation. 
ASSESSING THE FUTURE OF AIR FREIGHT (1977)

Mode: AIR

National Aeronautics and Space Administration

PURPOSE

This study describes some current characteristics of air cargo systems and describes a prospective continuous-time recursive model for assessing the future of air freight systems in a given intercity corridor.

\section{ASSUMPTIONS}

- Significant proportion of all air shipments are small (less than 500 1b) ... air freight is the most expensive mode ... lighter. and more-expensive commodities are more likely to be shipped by air; therefore market share of air transportation is influenced by value and density of commodity. Current distribution of freight by mode in U.S.:

\begin{tabular}{|c|c|c|c|}
\hline & $\begin{array}{c}\% \text { of } \\
\text { Ton-miles }\end{array}$ & $\begin{array}{c}\% \text { of } \\
\text { Revenues } \\
\end{array}$ & $\begin{array}{c}\text { Kevenue } \\
(\notin / \text { ton-mile })\end{array}$ \\
\hline Airways & 0.19 & 2.32 & 14.0 \\
\hline Motor carriers & 22.78 & 55.35 & 5.0 \\
\hline Rail & 38.80 & 37.48 & 1.6 \\
\hline Pipelines & 22.87 & 3.59 & 0.2 \\
\hline Waterways & 15.36 & 1.26 & 0.3 \\
\hline
\end{tabular}

- Air cargo growth will continue due to: general econunic growth, expansion of air-eligible markets, cost reductions, service improvements, and new technologies ... under most-favorable economic growth scenar10, by 2000 , air cargo will be 20 to 25 times greater by weight (FAA) ... under worst economic growth scenario, ton-miles transported by air will increase $6 \%$ annualiy, while annual growth of tonnage would be at least $4 \%$ (FAA).

- Air freight carried in bellies of passenger aircraft (compared to dedicated freighters or conversion aircraft) represents $50 \%$ of freight worldwide and $75 \%$ in U.S. Trend expected to persist until 2000 (FAA), excepL U.3. percentage could drop to $50 \%$ under conditions of expansive growth and most-favorable economic conditions ... most of remaining air cargo carried in dedicated freighters ... growth in size and number of dedicated freighters along with increasing land-side and air-side congestion might lead to development of al1-cargo airports ... marginal cost of carrying freight in passenger/freight submode with present aircraft configurations is relatively low, so freight will continue to be carried this way as long as it does not infringe. on passenger operations, which pruduce relatively higher revenues.

- The structure of the air freight system at present favors long-haul operations (function of long-haul and larger aircraft) ... delivery time difference between air and ground transportation diminishes as the stage length decreases, increasing competition between modes. 
METHODOLOGY

The amount of air freight shipped between two points is a function of: (1) total demand for shipping "air eligible" commodities, (2) relative compatibility of these commodities with available modes, (3) level of service provided by each mode, (4) available technology, and (5) decisions made by transportation operators to use available technologies. Alternatively, demand for service is a function of socioeconomic systems. Demand is not homogeneous, but the result of several market segments, each with unique characteristics, expectations, elasticities and size.

The supply of service is a result of the supplier's short-and long-run allocation of resources (i.e., purchase or sale of particular types of equipment, frequency of service, special handling facilities). Decisions are a function of available technological and managerial options, present and future markets, and competition. Service supply decisions plus volume of traffic determine the level of service provided by a given mode, which influences future demand levels and supply decisions (in other words, model must be interactive.)

The theoretical framework used in this study is systems dynamics, which can account for positive and negative feed-back loops and provide continuous time simulation.

System Dynamics Mode1 (Computer Language: DYNAMO)

Three types of variables are used: "level," which measure accumulated value; "rate," which describe how "level" variables change between time periods; and "auxiliary," which clarify intermediate causal relationships. The system is a coupled set of integral equations; each equation gives value of given level variable at given point in time as a function of its value at a previous point and the incremental change during the time interval (which is a function of both other levels and externally determined, exogenous variables). Equations are evaluated in the following order: (1) level equations at given time period evaluated using level, rate, and auxiliary variables of previous period; (2) values of auxiliary equations updated using values of other auxiliary and level variables in the same period, and rate variables applicable to interval between two periods; (3) rate variables evaluated by using level and auxiliary variables in given period, and the rate variable value in the interval between two periods; and (4) process is repeated for following period. Validation should compare the model to other available models used to make similar predictions, test for national behavior, and reproduce historical developments and events. Validations also should evaluate the robustness of the model's policy recommendations, determine sensitivity to various system changes, and examine behavior under extreme conditions.

Demand for Air Freight

The market share captured by mode is a function of the characteristics of different commodities and the relative level of service provided by each mode. These characteristics of market segments are considered: emergency 
freight, captive freight, and choice freight (based on rational analysis, ideally on basis of total distribution costs, including handing, packaging, transportation, loss or damage, capital carrying, storage and stockout costs).

The study proposes establishment of a qualitative "level of service" measure of the effect of a number of factors, including speed and travel time, traffic interruptions, safety, convenience, and operating cost. The proposed measure is based on: (1) cost (total cost, including packaging, inventory cost savings, interest savings, interest savings on goods in transit, reduction in payment delays, and reduction in loss or damage); (2) time in transit, a function of intercity speed of mode, stage distance, handing facilities at terminals, number and duration of intermediate stops, terminal access times, and queuing situations; and (3) commodity/service match, i.e., the general capability of the mode to handle a particular type of commodity--a function of commodity size, need for special handling and storage, and perceived significance of security. and reliability.

Ideally (with more research) a single measure of the level of service from the shipper's perspective can be developed. Modal split model to predict market share could be developed using existing information on relative levels of service and relative amount of goods shipped by different modes. Conversely, it may be possible to enter perceptions of shipper by calibrating modal split model. The decisions of the supplier of freight service address capital investments and operational strategies. In the model, operator decisions are triggered by two factors: load factor (volume/capacity ratio) and market share for a given commodity type. Thus, a mode capturing a large proportion of the market at a profitable load factor needs little change.

If the oyotcm necdo aoocooment, alternative actions by the eupplier are required, including capital investments and operational strategies. Costs and revenues are projected over the planning horizon based on weighted historical costs. Volume-of-traffic projections allow for possible growth or decline of economic activity levels in specific regions and input of changed level of service on tuture trattic volumes.

\section{CONCLUSIONS}

Many gaps exist in present knowledge about air freight systems. For the proposed model to become operational, three activities must be undertaken, Fundamental relationships need to be researched (i.e., between regional economic activity and freight generation and distribution; commodity characteristics and modal splits). Research is needed to assess the sensitivity of different commodity types to basic level-of-service variables. Finally, the model must be developed, checked, and fine-tuned. Ultimately, the model could be used to plot values and parameters over time in light of different technological, economic, and regulatory policies. 


\author{
OIL TRANSPORTATION BY TANKERS: AN ANALYS IS OF MARINE MOde: WATER \\ POLLUTION AND SAFETY (1975) \\ Office of Technology Assessment, U.S. Congress
}

EXECUTIVE SUMMARY

Network Coverage:

tankers

System Coverage: water

Products: vehicle

equipment improvements

Social Impacts: safe working conditions for crew, social cost of oil spills

Economics: cost of changing tanker construction, design and operation; cost of oil spills and casualties

Environmental Quality: oil pollution causes serious ecological

damage

R\&D Issues: advantages and disadvantages of improving tanker cafety and handling of oil spills

PURPOSE

The report discusses issues related to the safety of tanker operations and the potential presented by tankers for introducing polluting oil into the marine environment. Tankers are the single largest contributor to oil pollution of the world's oceans, pollution that seriously damages ocean ecosystems. Also, when viewed in relation to the decreasing supplies of world oil reserves, the one million tons of oil dumped each year in the world's oceans in standard operations--and the 200,000 tons per year spilled by tanker accidents--represent a costly and unnecessary waste of valuable energy resources. 
The study examines various improvements that have been recommended to reduce oil pollution from tankers and to increase the safety of their operations. The study emphasizes the U.S. tanker fleet (seventh largest). In 1975, the fleet had 218 ships with a total capacity of 7.4 million deadweight tons, less than $4 \%$ of world tanker tonnage. The report provides a broad factual base for use in Congressional investigations of the major issues involved in the safety of tankers and in Congressional efforts to develop effective regulatory policies and resolutions to contend with oil pollution.

\section{APPROACH}

This report focuses on technical alternatives concerning the design, construction and operation of tankers in U.S. waters as they relate to safety and pollution prevention. The hazards and impacts associated with an expected acceleration of super tanker operations in the U.S. pose a complex set of issues that necessitate that these alternatives be examined.

The sepurt fisst provides a historical overview of tankers, placing in perspective, water-borne oil transportation, including its present status and projections of petroleum movement. A history of tanker growth, an examination of the status and trends of tankers, and an assessment of super tankers in U.S. waters completes the background.

Second, oil pollution and safety considerations are examined. 0il pollution from tankers is assessed in terms of amounts and sources and the pollution damage threat from the vessels to ocean ecosystems and surrounding environments. The results of significant tanker accidents, including the accompanying oil pollution damage, are illustrated by accounts of several notable spills.

Improvements in the design and construction of tankers are examined to develop approaches to improving safety. Ship improvements include the use of segregated ballast spaces, cargo tank atmosphere control, and any peripheral equipment that furnishes information and/or control to the operator on the ship's hydrodynamic characteristics as modified by the local environment in which the ship is operating.

With over $50 \%$ of the collision or grounding type of tanker casualties attributed to human error, the need for improved personnel training and licensing is evident. lhe study illuminates deficiencies in persunnel training and licensing and suggests methods of improving the system.

The subsystems that furnish information to the tanker operator, information upon which he makes decisions and subsystems that furnish control in the execution of his command, are examined for possible improvements in safety and pollution control. These subsystems are: navigational aid systems, communications systems, information systems, control systems, vessel traffic systems, and collision avoidance systems.

Finally, legal and jurisdictional aspects of tanker.regulation and control are discussed. Both international and national 1 aw is discussed, which provides a basis for understanding the public policy issues raised in the report. 
METHODOLOGY

A systems approach is used in the assessment. It addresses the total tanker transportation system in terms of system safety and environmental protection. The statistical information used in the report is from current data available in 1975. Sources include the Bureau of Mines, U.S. Army Corps of Engineers, Waterborne Commerce of the U.S., the Petroleum Economist, and the Maritime Administration. The study incorporates data analysis, research, and reviews of prior studies.

\section{CONCLUSIONS}

More and more-accurate worldwide data are urgently needed on tanker oil spills and accidents in general. Additional research is needed on the environmental effects of various levels of oil pollution.

Technical Improvements

The oil pollution problem must be treated on a total systems basis to make meaningful improvements in pollution control. Fitting double bottoms or double hulls on tankers offers significant protection from oil pollution in the event of grounding and collisions. Inert gas systems can substantially reduce risks of tank explosions and resulting casualties. Improved maintenance, inspection, and survey procedures can help alleviate tanker structural failure problems.

A substantial portion of tanker accidents is caused by human error, and improvements in the training and licensing of shipboard personnel are greatly needed. Vessel traffic systems and other navigational aids are also in need of continual upgrading and improvement.

$\underline{\text { Regulations }}$

The International Pollution Convention of 1973 provides some major improvements in the regulation of tanker-caused pollution worldwide and deserves U.S. efforts to ratify. The Ports and Waterways Safety Act of 1972 provides authority to the U.S. Coast Guard for certain regulatory action independent of international treaty, if necessary. The National Transportation Safety Board needs to have more autonomous investigative authority than now exists in the case of marine accidents.

Comment

In light of the oil tanker accidents since 1975, several questions can be raised. Which recommendations of this study have been implemented? What are the ecological effects of oil tanker collisions? It is recommended that this study be used in conjunction with U.S. Ocean Shipping Technology Forecast and Assessment (see following abstract). 
U.S. OCEAN SHIPPING TECHNOLOGY FORECAST AND ASSESSMENT (1974)

Mode: WATER

United Aircraft Corporation for U.S. Maritime Administration

EXECUTIVE SUMMARY

Supply:

maritime vessels

Environmental Classes:

impact of techno-

logical and non-

technological changes

in society through

benefits accruing to

maritime industry;

also, indirectly,

through the eco-

logical, economic

and social side

effects

System Coverage:

water

Network Coverage:

maritime network

Produrt: :

vehicles and associated equipment, system operation aspects, power mode

R\&D Issues: cost of research and development will have to be split between industry and government
This technology forecast and assessment was performed to gain insight into the various technological and related nontechnological factors that will influence the future of the U.S. maritime induotry. It also prowirles a hasis for the development of policies to encourage the generation of technologies beneficial to the industry and the national economy.

The technical and related nontechnical (ecological, economic, and sociopolitical) factors of importance were identified, categorized, and interrelated by means of relevance trees. By using weightings for each, tree branch, the relevant parameters, termed "figures of merit," were ranked in terms of their impact on the future of the maritime industry. Historical. data were then. collected for each, and mathematical representations, combiued with judgments, were uced to establish projections to the year 2000. Each such projection represented a "suprise-free" trend. Separate estimates were then made of future events and policies that might change these trends. This technique resulted in a relevant set of future events (acting as a surrogate for past and current policies) that was used to modify the basic trend projections for the selected indicators. The modified trend curves thus developed represent the primary output of the study.

A second approach to technology assessment involved evaluating the benefits of technological advancements in ship design and shipping system operations. By using relevant technological parameters in computerized analytical models, a 1973 baseline ship was defined for two sizes of tanker, a nonbulk ship represented by a timber carrier and a containership: The same parameters, with 1985 values derived from the trend projections, and several perturbations thereof, were used to study the same ships for the 1985 time period. The results of the calculations give insight into the effects of technological improvements on 
required freight rates and economic return on investment under various financing arrangements, with and without subsidies

other indicators (state-of-society index and health-of-the-maritimeindustry index) were derived to assess the atmosphere for technological innovation in the U.S. shipping industry. By combining these indices with the trend analysis and the ship operations study, considerable insight has been gained into: the present state of the U.S. ocean shipping industry, technology areas most likely to enhance the position of the industry, expected economic payoffs, associated sociopolitical ramifications, and policies likely to promote the development of such technologies.

\section{PURPOSE}

This technology forecast and assessment of the U.S. ocean shipping industry was performed to gain insight into the many technological and related nontechnological factors that will influence the future of the maritime industry, and to provide a basis for the generation of technologies beneficial to the industry and the national economy. The specific objectives were to:

- Develop formal technology forecasts of all sectors of the U.S. ocean shipping industry over the next 25 years.

- Conduct a quantitative impact analysis of economic and social factors for the years 1975-1985, develop action options, and analyze the problems and constraints associated with the accelerated application of technology.

\section{APPROACH}

Scope

Specific boundaries were placed on the technological, economic, sociopolitical, and ecological environments considered. Generally, the study was performed within the guidelines outlined below.

U.S. ocean shipping technology is considered as that group of technologies employed in providing U.S. flag shipping services for U.S. foreign trade. U.S. flag shipping services are limited to production and operation of U.S. flag vessels and shore support of U.S. flag vessels from dockside to port warehousing facilities. This represents the U.S. maritime industry for the purposes of this study. Economic, sociopolitical, and ecological factors are 1 imited to those that directly affect, or are affected by, U.S. ocean shipping technology. Great Lakes and coastal shipping are excluded from consideration. Also excluded is the part of the total commodity shipping system that involves transport from commodity source to the land staging area at the port.

The study was performed by a-team consisting of five organizations plus an advisory council. The participating organizations structured and performed the study, while the council monitored the work. The organizations were United Aircraft Research Laboratories, Bath Iron Works, The Futures Group, John J. McMuller Associates, and Hovermarine Corporation. 
The problems analyzed included the likely nature of changes in technology affecting the maritime industry, as a function of time, as well as the impact of these changes on society, not only directly -- through the benefits accruing to the maritime industry -- but also indirectly -- through possibly undesirable ecological, economic and social side effects. The interactions of the two types of effects also were examined. Finally, the analysis considered policies for minimizing adverse effects and maximizing the benefits to society. Of these items, the first (nature of technology changes) is addressed primarily to the "forecast" objective and the other three to the "assessment" objective.

\section{METHODOLOGY}

A relevance tree approach was used to scope, weight, and interrelate the significant technical, economic, ecological, and social factors of the problem, and to identify a set of key parameters (figures of merit) that served as quantitative indicators of these factors. The parameters were extrapolated into the future on the basis of past data on a ceteris paribus basis, and/or on the basis of expert judgment. Events were identified that would tend to change these predictions, and the timing and likely effect of these events were estimated, thus permitting the basic extrapolative approach to furnish answers to what-if questions, i.e., to consider alternative futures.

The benefits of technological advances and related factors to the maritime industry were analyzed by ship-design and ship-operation models. The effect of these benefits and related factors on society was analyzed through cross-impact matrices. Policies favoring various technological advances, potential blockages to these policies, and approaches for circumventing these blockages were identified, based in part on scenarios describing the ramifications of new technology.

Several other techniques were used in support of this mainstream effort, including: judgmental reviews of all steps by the advisory council, an input/output analysis of the economic impact of the U.S. maritime industry on the output of other industries, and a modal-split analysis of express cargo demand.

A11 these efforts were formulated in a set of five tasks: Task I structure the study and develop a candidate list of quantifiable figurès of merit for subsequent analysis; Tasks II and III (carried out simultaneously) establish historical and simply projected trends of candidate figures of merit in both technical and nontechnical areas, and develop a representation of the state of society and health of the maritime industry as indicaluis of potential maritime progress; Task IV - refine the candidate list of technological figures of merit and focus on those expected to most heavily influence technological progress; and Task V - utilize all of the preceding work as inputs to develop technological trend projections as affected by future events and policies and assess technological progress for representative shipping systems : 


\section{CONCLUSIONS}

\section{State of the Maritime Industry}

From a comparison of the U.S. maritime industry with that of other seafaring nations, based on several measures of health, it is concluded that the U.S. maritime industry is in relatively good health, exceeded only by Japan and, in some measure, by the United Kingdom; this health has been stable for the last 20 years and shows indications of improvement for the next 20 years. Based on an examination of 19 appropriate indicators, such as the gross national product (GNP), the share of total U.S. imports and exports shipped in U.S. flagships, etc., it is concluded that the overall sociopolitical climate in the United States for the growth of the maritime industry has been improving over the last 30 years and shows signs of improving over the next 10 years.

A relevance-tree structuring of the U.S, maritime industry, and the associated weighting and ranking, indicates that the technical, economic, and sociopolitical environments tend to be approximately equal in importance (taking into account interactions among them) and the ecological environment somewhat less important now. Within the technical environment, cargo technology, ship design, ship structure, and ship propulsion are the most important factors (in that order). Within the economic environment, loading/ unloading costs and income, production costs and income, and operating costs and income are the most important factors (in that order). Within the sociopolitical environment, policy formulation and administration, legislation, ship owners, financial institutions, and labor unions are the most important elements (in that order). Finally, within the ecological environment, port operations (water and land, including ship operations in port), port construction, and ship construction and operation (outside of ports) are the most important elements (in that order).

On the basis of general considerations and an input/output analysis, it is concluded that although the maritime industry can have a profound beneficial effect on the national welfare through the balance of trade and other factors, its effect on other industries is small.

\section{Individual Trends}

The total U.S. ocean-shipping capacity requirements, based on projected commodity flows, will double between 1972 and 1980 and again by 1990 , but will increase more slowly until 2000; approximately $80 \%$ of this requirement is in the major-bulk area, and this will increase to $90 \%$. The fraction of this demand carried in U.S. flagships will increase from about $5 \%$ in 1970 to $20 \%$ in 1980 and $35 \%$ in 2000 .

The general trend will be for ship operating expenses, fuel costs, charter rates, 1 abor wages and benefits, labor productivity, shipyard capital investment, and shipyard employment to increase steadily for at least the next 20 years. The technical performance parameters -- such as ship size, draft, capacity, speed, power, efficiency (hydrodynamic and fuel consumption), and cargo handling capacity will increase steadily at various, but generally diminishing, rates. Finally, the number of collisions and the fraction of 
cargos with polluting characteristics will remain essentially constant but greater tonnages will be spilled in each collision.

\section{Shipping Systems}

Bulk Cargo Systems. By the year 2000, bulk cargo will constitute over one billion tons in U.S. trade -- over half of all cargo tonnage and $90 \%$ of the deadweight tonnage. Most bulk cargo will continue to be petroleum and grains. Due to economies of scale and the projected magnitude of oil import requirements (as projected in early 1973), future ultralarge crude carriers (ULCC) used for long hauls should be larger than current vessels, but should not exceed a draft of about $85 \mathrm{ft}$ for compatibility with presently planned off-shore terminals and for maximum operating flexibility. Small feeder tankers will meet the continued demand for oil movements over short and intermediate distances. The conclusions derived for tankers generally apply to dry bulk ships of comparable slzes.

Other Cargo Systems. Major nónbulk cargos will remain predominately lumber, followed by iron and steel products, paper and pulp, and automobiles, all of which constitute $75 \%$ of nonbulk imports and exports by tonnage. Approximately $10 \%$ of all tonnage in U.S. waterborne trade in the year 2000 will be general cargo.

\section{Assessment}

\section{Key Technologies}

Based on the weightings generated in conjunction with the relevancetree analysis and on a detailed review of the various technologies, a number of conclusions can be drawn. The efficiency with which ships can load and unload cargo is of prime importance to operational economics and represents an area in which technological advances can be particularly beneficial. The most promising area for future technology of vessel design is reducing the fabrication costs associated with ship construction. Advanced navigation and guidance systems will help avoid ecological problews due to collisions and resulting pollutant release and also will improve ship operational economics directly and indirectly (by reducing crew sizes).

The major issue in propulsion over the next 25 years will be reintroduction of nuclear power plants for high-power applications (containerships, ULCCs). For relatively high-powered (more than 20,000 $\mathrm{h}_{1 \mathrm{y}}$ ) fossil-fucl propulsion systems, the gas turbine is likely to take over much of the market in the mid-1980s; it will represent a merger of aviation-derived and industrial technologies, yielding high efficiencies and reliabilities with small sizes (and weights) and easy replaceability. An improvement in hydrodynamic efficiency could result in significant economic advantages for all ship types considered, but most particularly for high-speed containerships, because of their high-power requirements. 
Technology Payoffs

Based on an integration of the results of pro-forma analyses of ship designs and operations for several shipping services with the results of the technology, demand, and related forecasts and discussions, several conclusions can be drawn regarding technology payoffs. For individual applications, the greatest technology payoffs are likely to be in novel, specialized, marketoriented shipping and ship concepts. Some of the technology payoffs are indirect and difficult to quantify, such as those enhancing safety and resource conservation, decreasing pollution levels or likelihoods, or permitting a ship operator to operate with high load factors; in their totality, these payoffs are likely to be more significant than the traditional direct payoffs.

With the technology improvements forecast between 1973 and 1985 -including cargo handling, design, structures, and propulsion -- economic improvements of $7-17 \%$ in the required freight rate and $5-11 \%$ in the return on investment (before taxes) should be obtainable on a large variety of ships. An additional economic improvement of $5-15 \%$ in the required freight rate can be obtained on these ships by accelerating the application of advanced technology.

Technology, directly and indirectly, can be a significant factor in influencing the shipping market, i.e., the fraction of U.S. imports and exports carried in U.S. bottoms. In terms of impact on the nation, a $\$ 5$ billion difference in income to U.S. ship operators translates directly into a favorable change in the balance of trade by this amount, because that income would otherwise accrue to foreign ship operators.

\section{Costs of Technology}

Economic and Social Costs. The costs of technology are generally difficult, if not impossible, to identify unambiguously, quantify, and express in economic terms. However, some general conclusions can be drawn. The costs of developing ship-system-level technology will, in general, have to be borne largely by the government, although subsystem technology developments will continue to be funded largely by industry. The costs of incorporating advanced ship-system-level technologies that offer clear benefits, reasonable risks, and reasonable total costs -- as well as the cost of incorporating economically viable subsystem-level technologies -- will generally be paid for by ship builders and passed on to ship owners. Although the government can support technology at no direct cost in several ways, such as requiring its adoption, or creating a market by requiring certain cargos to be shipped in U.S. flag ships, these options give rise to indirect costs, which have to be considered when comparing options:

The most significant social cost identified is the decreasing laborintensiveness on board ship and in shipyards, resulting in a slight, gradual decrease in total employment, unless a greater-than-expected market for U.S. ship operations and construction can be developed.

Ecological Costs. Oil-spill prevention and clean-up will require the 
development and installation of spillage prevention and cleanup systems, and the development and use of reliable collision-avoidance systems. Port/harbor sewage control will require the definition of applicable criteria and regulations and the development and installation of appropriate control. equipment. Atmospheric pollution from fossil-fueled powerplants will require modifica$t$ ion of the several types of powerplants to minimize emission of atmospheric pollutants or the use of low-contaminant fuels.

\section{Policy Options}

\section{Priority}

Based on considerations of assessed pay-off and some judgment as to likely cost, it is concluded that the following is an approximate order of priority for support of the development and use of advanced technology (in the conventional sense):

Cargo handling technology

Labor-saving technology for ship yards

High-strength, low-cost steels for maritime application.

Propulsion technology

Ecological technology

Precise guidance, navigation; and collision-avoidance technology

Shipboard-automation technology

Hydrodynamics and advanced suspension concepts

\section{Supporting R\&D Options}

Based on the identification and assessment of technology requirements, the major technology areas identified above can appropriately be supported by individual technolngy developmente, typically. includiug lhe following.

- Cargo handing: development of off-shore cargo feeder systems for liquid bulks; effective, economical oil-spillage-prevention and cleanup systems; management information system for automatic inventory and documentation control of cargo; and total loading and information processing systems from inland points (including complete data handling and processing systems).

- Vessel design, structures, and materials: development of low-cost, easily worked steel and corrosion-resistant materials with a high strength/ weight ratio.

- Propulsion technology: development of gas turbines designed to reduce specific fuel consumption and to operate on low-grade and residual fuels ... research into improved propeller performance, including high loading and thrust-reversing control ... continued development of light-weight, low-cost nuclear powerplants, including appropriate shielding. 
- Navigation and guidance: definition of appropriate maritime environmental and pollution control criteria along with a program of research into the technologies needed for meeting these standards ... development of low-cost, highly accurate and reliable marine collision-avoidance systems for ocean and harbor use ... research into the design of onboard automatic guidance systems with costs not exceeding those for equivalent-performance manned systems ... development of high-accuracy, short-reaction-time navigation and control systems for ocean shipping ... development of supplemental steering devices to enhance ship maneuverability ... exploration of minimum-cost approaches to closed-loop, shore-based total ship guidance systems.

\section{R\&D. Policy Implementation Options}

Based on an identification of the interest/influence groups most significantly affected by the various R\&D options, and therefore most likely to block them, as well as an identification of the various policy alternatives available to the government in support of $R \& D$, there is an appropriate set of implementing policy options representing direct or indirect government support of technology. of these, the most powerful direct stimulants of technology development and use are government support of $R \& D$ and construction subsidies, respectively.

\section{Support Leve1}

To assure the continued growth of the maritime industry, construction subsidies at the current level, or not too much below it, must be maintained for at least the next 10 to 15 years. The potential benefits of advanced technology, as identified, are large enough to justify a considerable expansion, by at least a factor of two, of government-sponsored R\&D programs for maritime technology. 
Office of Technology Assessment, U.S. Congress

EXECUTIVE SUMMARY

Environmental Quality:

transportation of a dangerous material

International: cargo, shipments from international suppliers and Alaska

Syst.em: water

Fuels, Terminals and Handling Facilities: transportation via tanker and termiinals from producer to user.

DOE Research:

harbor navigation and traffic management offshore, LNG terminals, improved safety techniques in handling
During the next two decades, $5-15 \%$ of the U.S. natural gas consumption could be filled with liquified natural gas (LNG) from Alaska or foreign countries. This would be a major increase over present LNG import levels. This gas will reach the United States by means of a complex all expensive oyotem consisting of liquefaction facilities, specialized cargo tankers tankers, and regasification and storage facilities.

LNG is currently imported on a limited scale. Increased imports would require an increase in the scale of LNG tankers and terminals. Limited experience and increased scale make the safecy of LNG transportation an unpredictable and important issue.

This report identifies nine areas that may be of concern to the U.S. Congress in its consideration of possible new legislation, oversight of federal agencies with responsibilities for LNG systems, or appropriations of funds for agency operations and research. Key problems within each issue area are identified, as are posoible policy choices. Analysis of future trends and their effects is also included,

Previous research has been inconclusive or contradictory about LNG safety, inspection, and regulation. Near-term research is unlikely to solve the problem, so public policy decisions concerning LNG will probably be based on nonquantitative approaches. These decisions should result in prudent siting of facilities and strict design, construction, and operation standards.

PURPOSE

Natural gas is a major source of energy for the United States, supplying more than $25 \%$ of the total energy consumed here in 1976. Worldwide, there are significant supplies of natural gas in areas with little or no demand for it. This report examines one alternative for transporting this gas to the United States: carrying liquified natural gas (LNG) in tank ships as opposed to transport via natural gas pipelines. 
Liquified natural.gas could be an important short-term.U.S. energy supply over the next few decades and could help alleviate some near-term fuel shortages in selected sectors of the economy. While the United States is expected to increase its imports of LNG to $5-15 \%$ of the total natural gas consumed in the country, the supply of natural gas that may be sold in the U.S. as LNG is limited, primarily due to the complex and expensive infrastructure required.

This report provides background for, and identifies, areas that may concern Congress in its consideration of possible new legislation, its oversight of federal agencies responsible for LNG systems, or its appropriation of funds for agency operations and research.

\section{APPROACH}

The report is divided into three parts: (1) a factual description of LNG systems and facilities and the federal regulatory process governing the development and operation of such systems, (2) a critical review of key portions of the LNG system where technological or political problems may occur, and (3) an outline of actions desired by interested parties.

Liquified natural gas is now imported from Algeria. New ships and plants will be considerably larger than the existing ones to facilitate this country's increased LNG imports. The problems of scale and limited experience make it difficult to project the safety of the LNG system with any degree of certainty. This study raises nine areas of concern regarding safety and other potential problems.

Five issues are subjects for near-term attention that most directly impact the technology, regulation, decision making, or research that could affect many projects already operating or nearly operational. These five issues are: (1) the design and construction of LNG tankers, (2) the regulation and inspection of LNG tankers and their operation, (3) the regulation and inspection of LNG terminals and their operation, (4) the federal decision making process in the certification of LNG import projects, and (5) the status of current research on LNG and the need for further inquiry. The remaining four longer-term issues require attention following the determination of federal policy regarding LNG. The need for a national LNG policy becomes increasingly important as LNG technology develops. These issues are: (1) regulation of, and criteria for, the siting of LNG facilities, (2) 1iability for LNG accidents, (3) reliability of foreign suppliers of LNG, and (4) policies for pricing LNG.

Key problems within each issue area are identified, as are possible policy choices. Analysis of future trends and their effects is also included.

\section{METHODOLOGY}

The Office of Technology Assessment conducted a public participation program in connection with this assessment of LNG transport. The program consisted of a day-long program in Washington, D.C.; a questionnaire/interview survey of residents of relevant coastal areas; and a review of the draft report by members of the public. 
More than 100 persons from gas utilities and related industries, financial institutions, organized labor, state and local agencies, and public interest groups were directly involved in the program. The public's input is most directly seen in the report's final section, Public Awareness and Concerns about LNG. In addition, public concerns, along with an analysis of both near-term and longer-term effects of deploying LNG technology in various locations around the country, formed the basis for selecting the nine issues analyzed. The public's specific suggestions for action are reflected in this analysis.

The report's primary assumption is that LNG imports will rise significantly over the next two decades, even though the United States is presently a net exporter of LNG and U.S. consumption of natural gas peaked in 1971 . A possible trans-Canada pipeline, deregulation of natural gas, long start-up times, high capital requirements, and limited markets must be weighed against availability and cost of alternative energy sources and the need to reduce dependence on foreign oil.

\section{CONCLUS IONS}

Past research has produced conflicting results and predictions about the safety of LNG, and it is unlikely that, given a short time frame, present research will resolve the differences and offer firm conclusions. Therefore, public policy decisions about LNG systems should be based on nonquantitative. approaches that result in prudent siting criteria, design, construction, and operating procedures.

Current LNG ship construction standards are adequate, but as ship size increases, overall fleet inspection and maintenance and terminal facilities become growing concerns. In transporting $L N G$, the primary concern is a major spill in water. Harbor traffic handling and crew training procedures should be improved to enoure greater. safety and efficiency. Staff is needed to inspect rermillals, and guidelines for inspections and enforcement wüld aloo be beneficial.

The lack of a clearly enunciated federal policy and jurisdiction on import and certification matters, the length of time and cost involved in the approval process; and the numerous (12) and overlapping federal agency jurisdictions prohibit entry into the field and put the United States at a disadvantage compared to orher cuutrico. The federal government needs to establish specific siting criteria for LNG terminals and increase local participation in sleing lecisiono. A fereral policy on liability for LNG accidents is also needed. Pricing of LNG, whether using rolled-in or incremental pricing, should be made part of our overall national energy pulicy. 
A TECHNOLOGY ASSESSMENT OF COAL SLURRY PIPELINES (1978) Mode: PIPELINE

Office of Technology Assessment, U.S. Congress

PURPOSE

This study assesses the environmental, economic, and social implications of coal slurry pipeline development. This issue is surrounded by considerable public controversy over legislative proposals that would grant the power of eminent domain for right-of-way acquisition to coal slurry. pipeline enterprises.

\section{ASSUMPTIONS}

Eight scenarios -- based on energy demands, economic conditions, and environmental regulations -- were executed on a utility simulation model. The selected scenario was represented by a relatively high energy demand with a high proportion of nuclear power beyond 1985 and an environmental policy that illustrates the impact of a nonsignificant deterioration policy (such a policy is characterized by a restrictive utility siting policy and the use of best available control technology).

Underlying assumptions favorable to pipelines include the following: high rate of growth in power consumption after $1985 \ldots$ all coal of a given category is purchased by all power plants in a state from a single source, resulting in artificially concentrated origins ... mining and power generation activity is concentrated in circumscribed locations for cost analysis purposes. .. pipelines are assumed to operate in a stable environment at full capacity ... no additional coal tonnage is required by power plants receiving slurry coal due to water content ... no substantial increase occurs in the present rate of railroad labor productivity.

Underlying assumptions favorable to railroads include the following: relatively high proportion of nuclear power plant construction after $1985 \ldots$ except for Kansas and Missouri, serving more than one state with a single pipeline is not considered ... the possibility of serving industrial customers or coal conversion facilities by slurry pipelines is ignored ... distribution of dewatered coal slurry by barge is not contemplated in cost or market analyses ... cost estimates give no credit for fact that cleaning and grinding coal is more economical in conjunction with slurry operation ... no significant future improvement occurs in pipeline technology.

\section{METHODOLOGY}

Four interrelated studies contributed to the analysis: (1) legal regulatory provisions, relevant to rail and pipeline competition, water rights, environmental protection, and eminent domain; (2) baseline forecasts to year 2000 of volumes of utility steam coal to be transported from nine 
producing regions to each consuming state based on hypothetical demand growth, environmental regulation, and coal-use assumptions; (3) rail and pipeline cost estimates and plausible traffic scenarios; and (4) identification and evaluation of water resource, environmental, and social impacts of the transportation of quantities of coal by pipeline versus rail.

Four hypothetical case studies provide the focus for both the cost and environmental analyses: central western coal transported from Wyoming to Texas, northwestern coal transported from Montana to Minnesota and Wisconsin, central western coal transported from Utah to California, and southern Appalachian coal transported from Tennessee to Florida.

\section{CONCLUS IONS}

- Conditiono that tend to favor pipelines on any particular roufé: high annual volumes of coal shipped.... long distances to be traversed ... high anticipated inflation rates ... low real interest rates ... large closely spaced mines ... secure market of large customers close to a single pipeline ... terrain favorable to pipeline excavation and construction ... availability. of sufficient water at low delivered cost ... low cost ot electric power for pipeline pumping relative to diesel fuel for railroad locomotives ... circuitous rail routes, poor track, or other conditions unfavorable to railroads ... inefficient rail operations, including short or slow trains ... absence of a parallel navigable waterway.

- Regulatory structure - common carrier status for railroads: rail rates contain an element of fixed system costs and losses resulting from requirements to maintain unprofitable services, e.g., low-volume branch lines ... rate regulation that does not allow a "makkt" return on direct rail investment will not permit facility improvements that would reduce total costs ... prohibitions against long-term contracts with shipperis impede railroads from undertaking otherwise economic investments.

- Pipeline eftect on railroad industry and remaining shippers: nut likely to be a substantial effect on the industry, although it could seriously threaten a particular railroad ... rate impacts probably will be felt more strongly by remaining captive rail customers ... the choice between rail or pipeline modes will not be determined by their respective capacity limitations since the capacity of the transportation systems can be expauded faster than coal mining or electric power generation using coal; provided necessary investments are made.

- Other economic factors: total employment roughly equivalent with either rail or pipeline ... agriculture may be affected by future water availability impacts of slurry pipelines, as well as costs of, and services provided by, railroads ... inequities in income distribution and impacts occur with the favoring of either mode over the other.

- Water impacts of slurry pipeline development: in none of the four hypothetical cases is the water needed ( $3 \%$ of available surface flow in the most extreme case of Wyoming to Texas) a large enough percentage of total supply to impact stream water quality ... pipelines would compete directly with other possible future water uses, including alternate forms of energy development involving coal mining, electric power generation, and shale oil ... mitigation procedures with sources of water usable 
for slurry but not for other purposes (irrigation return flows, primary or secondary sewage effluent, saline ground water) ... Constitution gives federal government ample authority over all navigable water and federal water projects ... judicial precedent of preemption doctrine - state law cannot contravene a declared federal interest... federal law has been administered in a way that tends to pressure state control over distribution of water.

- Social and environmental impacts: pipeline water requirements ... transient effects during pipeline construction ... disruption of increased unit train traffic - noise, interruption of highway traffic, additional accidents at grade crossings, interference with cattle movements on range land ... mitigation of rail impacts usually possible through grade separations and land use zoning.

- State implementation plans and relevant federal environmental legislation: National Environmental Policy Act ... Federal Water Pollution Control Act ... Clean Air Act ... Noise Control Act ... Resource Conservation and Recovery Act ... Safe Drinking Water Act ... Occupational Safety and Health Act.

- Federal eminent domain options for coal slurry pipelines: leave the matter to the states; pipeline may have difficulty in meeting public purpose test in a state through which it passes if the coal is not made available to those markets ... full federal authority ... conditional federal authority in cases where states fail to act ... specific federal legislation for each pipeline case.

- Case study results: (1) Wyoming to Texas case illustrates advantages of carrying a large volume over a great distance. Eight power plants serving two regions in Texas would be served by a single pipeline and only four mines near Gillette could produce the required volume ... (2) Montana to Minnesota and Wisconsin case parallels a rail route that is direct and in good physical condition, and rail is flexible enough to serve a larger number of mines and power plants ... (3) Utah to California case represents least annual volume, shortest distance, and smallest mines, with difficult terrain for both pipeline and rail, but with rail having an economic advantage ... (4) Tennessee to Florida case illustrates that even though several mines and power plants would have to be served and a rail route is nearby, pipelines may be advantageous if rail operating conditions are significantly less than ideal ... To oversimplify the results of the four case studies somewhat, the cost of unit train transportation of coal is roughly one-third amortization of investment in facilities and equipment and two-thirds operating expense, including labor. Pipeline costs are nearly two-thirds initial investment and just over one-third continuing operation ... The principal lessons from the case studies are that slurry pipelines are more economical than unit trains for some specific types of movements, and that comparative costs of the two modes do not lend themselves to easy generalization based on simple criteria. 
THE SIGNIFICANCE OF TELECOMMUNICATIONS AS A

Mode: TELECOMMUNICATIONS

PARTIAL SUBSTITUTE FOR TRANSPORTATION (1976)

Carnegie-Mellon University for Urban Mass Transit Administration

PURPOSE

This report was produced as part of a program of research and training in urban transportation sponsored by the Urban Mass Transportation Administration of the U.S. Department of Transportation. The major purpose of this research was to determine the feasibility of using existing communications technology to eliminate the need for many of the central business district (CBD) interoffice busincos trips udde in the puttsburgh area. The use, cost-effectiveness, advantages and $d i$ sadvantagc3, and prujected short-term and long-term development of various communication systems are investigated. The report analyzes contact.record surveys, developed to represent existing trip-making based on a sample of Pittsburgh CBD activity centers. The results of the questionnaire are analyzed and implications for travel substitution are furmulated.

\section{ASSUMPTIONS}

\section{General}

- Two out of five trips within urban areas (world-wide) are home-to-work and work-to-home ... future trend of increased white-collar jobs in the central city ... within the frampwork of home-to wurk and work-to-home trips, three general categories of hypotheses regarding these future trips are espoused by various authors: wnrk at home, neighbulluud work centers, and various substitutional/relocation alternatives.

- Five substitutional/relocational alternatives are available to management: substitute telecommunications for interoffice business trips and maintain present business location ... do not substitute, but change present business location ... substitute and change present business location ... split the organization, some functions remaining at present location and others leaving ... the status quo: do not substitute, remain at present location.

- The following criteria for hypothesis oelection were applied: the hypothesis must affect the need for new urban transportation facilities, particularly mass transit ... it must involve the investment of billions of dollars in transportation facilities ... the impact must have a reasonable chance of occurring within the next 20 years.

- Following the above criteria, the following hypothesis was selected for research: significant advances in telecommunications will substitute for many interoffice CBD business, trips. This will in turn loosen the ties that bind office work to the CBD, thereby making it possible for a greater number of businesses to locate, or relocate, some or all of their functions 
outside the $C B D$. The resulting decentralization will reduce the length of the office work trip and lower the cost to society of providing transportation for office employees and other transportation facility users. In addition, a significant shift in emphasis from radially oriented to circumferentially oriented transportation facilities will take place. This will cause a modal shift from radially-oriented transit lines to automobiles and will reduce, if not eliminate, the "need" for many capital-intensive, CBD-oriented mass transit systems already in existence or presently in the planning stages Several sub-hypotheses are also included in the main hypothesis. In the short-term future, the following items are considered given: land-use characteristics, socioeconomic conditions, transport and telecommunications networks and technologies, and operating and pricing policies. In long-term forecasting, all present and future changes in telecommunications and travel demand and land-use conditions are taken into account. Three existing types of telecommunication are studied: advanced audio communications ( such as conference call lines, loudspeaker audio systems, and the RMT teleconference system), visual communications (such as the Bell Telephone Picturephone and custom-built closed-circuit systems), and the standard handset telephone.

Specific Assumptions for Pittsburgh

Almost $50 \%$ of Pittsburgh's morning peak hour person-trips are those returning home from work, shopping, school, etc. In $1967,60 \%$ of Pittsburgh's CBD employment was office employment. As part of expected CBD growth of 59,000 new employees by the year 2000, 54,000 new employees will be office workers.

METHODOLOGY

Short-and long-term forecasting procedures are outlined in Figures 11 and 12. A major feature of the short-term forecasting procedure is the manner in whicn the cost of personal travel versus telecommunication is evaluated by the potential contact-maker. The individual first decides to make a face-toface contact by some means of physical transport and then must decide whether it is more useful to make the contact by some available telecommunication mode. Finally, the vehicular and communicative flows are adjusted to reflect the potential trip-maker's decision.

To quantify the extent to which existing telecommunications could substitute for $C B D$ interoffice business trips, the contact record survey was developed. This questionnaire was completed by a wide distribution of Pittsburgh CBD office employees. The major purposes of the survey were to determine (1) the number and characteristics of business trips originating in the Pittsburgh CBD, (2) what percentage of these trips could be replaced by telecommunications, and (3) the social acceptability of telecommunications as a substitute for face-to-face contact. Detailed statistical analyses were performed on the results of the survey.

The Type Allocation Technique estimates the percentage of noninspection business meetings that can be replaced by telecommunications contact. It was developed by University College in London and is sensitive to the capabilities 


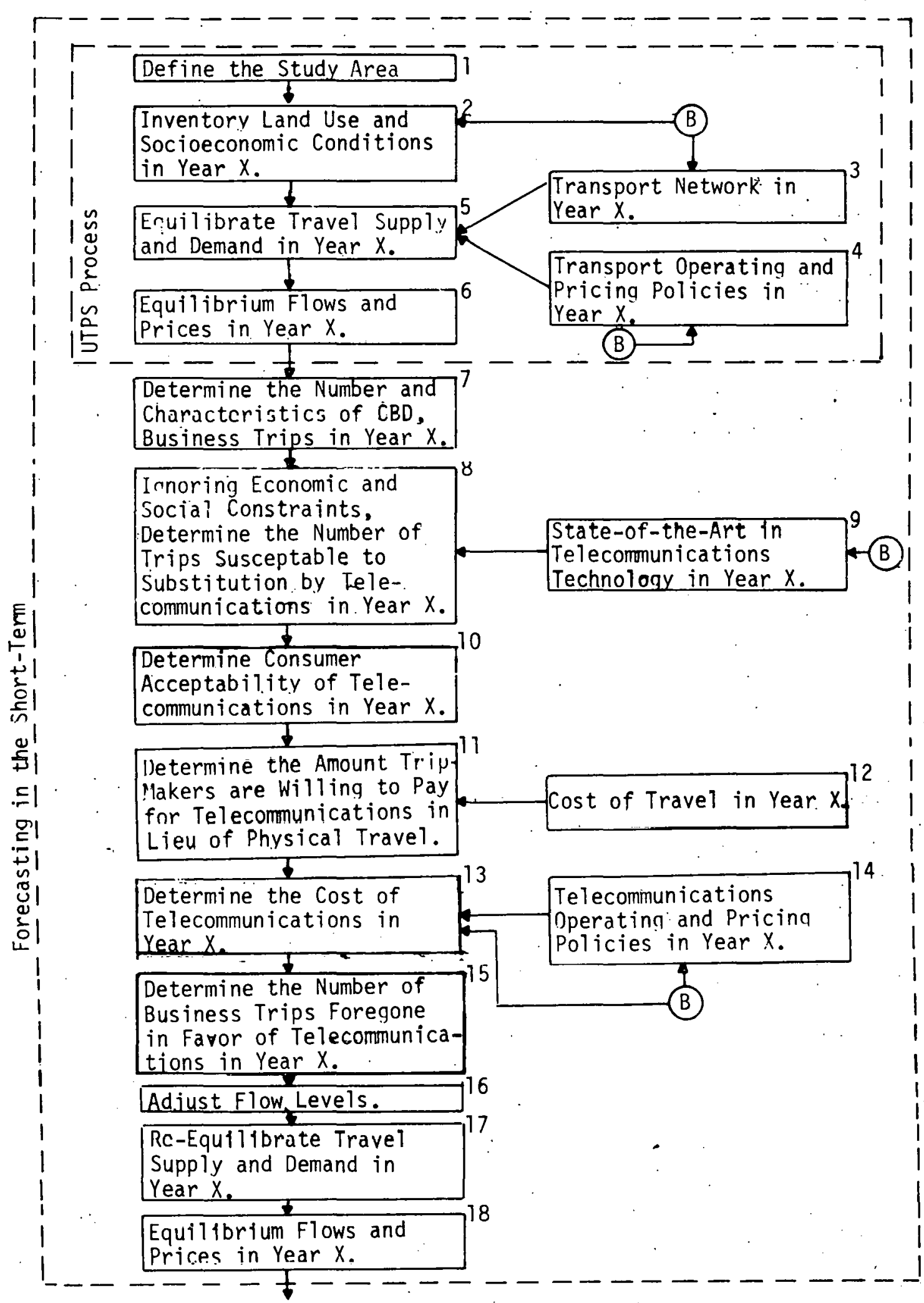

(A)

Fig. 11. The Short-Term Forecasting Procedure 


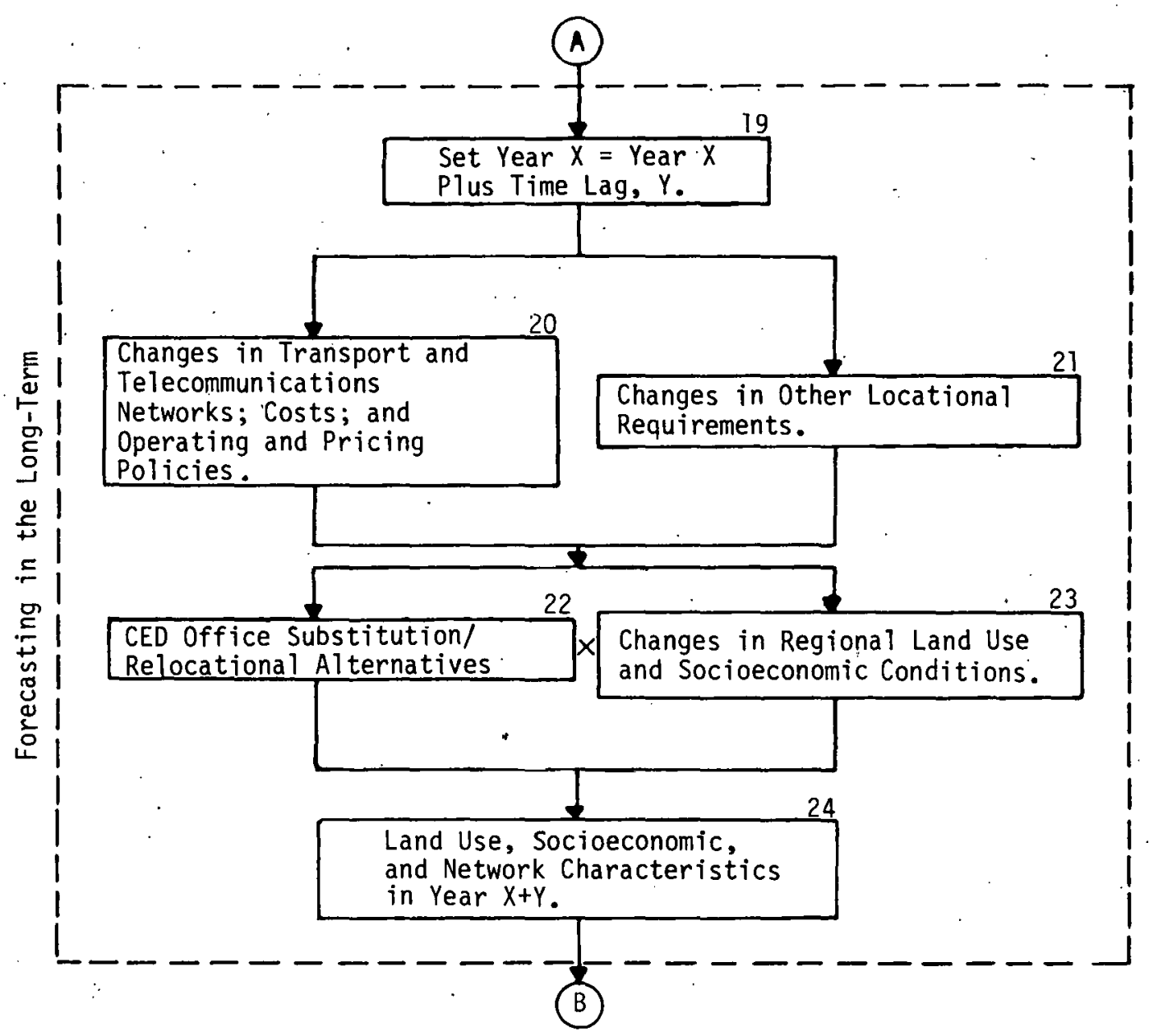

Fig. 12. The Long-Term Forecasting Procedure

of existing telecommunication systems. This technique groups meetings into four modes of contact: visual communications (i.e., brọd-band systems), advanced dudio communications (i.e., narrow-band systems), the standard handset telephone, and face-to-face meetings. Long-term changes in urban land-use patterns, and economic trade-offs between monetary and nonmonetary costs of physical travel and various telecommunication alternatives were beyond the scope of the report.

\section{CONCLUS IONS}

\section{General}

- Transportation and communication are inextricably linked; the more efficient one is, the less need there is for the other... the unit costs of transportation are increasing as the quality and level of service are decreasing ... communication quality is increasing and its unit costs are decreasing. 
- Meetings involving. the verification of facts and the transmission of information are not likely to be affected by the medium of communication. Two areas that are sensitive to the communications medium are: (1) tasks involving interpersonal conflict, where values and opinions are invested, and (2) situations that require forming opinions of strangers or evaluating conversations. Studies indicate that visual communication achieves results similar to face-to-face contact in the above situations. However, present norms and values in common courtesy may affect the use of telecommunications.

- The price of telecommunications must be less than the price of travel before substitution can be achieved ... expected increases in physical travel costs could lead to switching to telecommunications ... decreases in work transportation may result in increases in pleasure transportation:

- Innovations to make teleconferencing possible must reduce costs, but not necessarily improve performance levele. The costs of coumunication can be hroken down into those of alstracting the required information from the original source; transmitting speech and visual patterns and hard-copy graphic material; gains or losses in abstracting or transmitting this information, and maintenance, operations, and capital (associated with equipment acquisition).

- The development of miniature oxidized silicon chips and solid-state images promises to lower the cost of television camera hardware. The unit cost of band-width transmission of video signals could be lowered through (1) free-air optical, using modulated lasers or light-emitting diodes, (2) flexible fiber-optic cables, containing thin glass fibers as opposed to copper strands, and (3) band-width compression through various coding schemes that reduce redundancy of information transmission.

\section{Contact Record Survey Results}

- About $35 \%$ of the respondents said their meetingo involved excluanging information ... the respondents' most frequent meeting lengths were 31-60 minutes and 61-90 minutes ... most respondents $(37.2 \%)$ met with representatives of just one other business ... 26.2\% of the respondents met with no other business ... the meetings most frequently involved three persons ... most respondents had planned the mecting at least two days in advance ... $48.4 \%$ of the respondents discussed several specific subjects.

- Most meetings are infrequent, occurring less than once every two weeks ... $84.6 \%$ of the business trips required less than one hour trave1 time ... over $4 U \%$ of the trips required less than 10 minutes travel time... the vast majority of respundents enjoy traveling to business meetings.

- About 55,700 of Pittsburgh's 89,719 CBD office workers (62\%) take trips for the purpose of engaging in face-to-face business contacts within a week's time ... estimates are that 47,650 walking trips and 39,750 nonwalking trips are made each working day by all office employees in the Pittsburgh CBD ... the mode breakdown of nonwalking trips is: $7 \%$ bus, $5.3 \%$ taxi or 1 imo, $87.7 \%$ auto. Of the auto figure, $66.7 \%$ are by private car, $17.5 \%$ by official car, and $3.5 \%$ by rental car. 
- Substituting telecommunications for physical travel as a principal mode for engaging in business contact would have the greatest impact on daytime auto usage ... the greatest number of face-to-face meetings are early-morning meetings ... replacing business-contact, physical travel with telecommunications would have a negligible effect on morning and evening rush-hour traffic.

- Statistical analysis leads to the conclusion that between $35 \%$ and $93 \%$ of the 188 "normal contacts" surveyed are potentially susceptible to substitution by telecommunications.

Type Allocation Technique Results for Pittsburgh

- The ability to accommodate groups of participants, transmit documents, and exercise persuasion are the most critical factors limiting the use of the telephone as a satisfactory means of business communication ... according to the Type Allocation Technique, $72.9 \%$ of the recorded contacts could be satisfactorily maintained by telecommunications ... the above results cannot be judged as definitive because of certain assumptions that were made; however, a significant proportion of meetings that now take place are potential candidates for substitution by telecommunications.

- Of 100 recorded auto trips, $14 \%$ were internal trips within the CBD study area ... it is conservatively estimated that 7,500 auto trips leaving the CBD between $6 \mathrm{a} \cdot \mathrm{m}$. and $8 \mathrm{p} . \mathrm{m}$. could be foregone in favor of the use of telecommunications; over 5,500 (or $73.4 \%$ ) of these trips occur at the hours of 9 a.m., 10 a.m. and 1 p.m., accounting for $45 \%, 28 \%$, and $18 \%$ of the total auto traffic, respectively.

- Clustering analysis shows that business contacts can be classified into three distinct groups. Orientation contacts, which make up $3 \%$ of the sample, would be difficult to maintain by telecommunications and must be allocated to the face-to-face mode. Programmed contacts -- which are routine, repetitive, standardized, and of short duration -- could be satisfactorily maintained by telecommunications and account for $35 \%$ of the meetings in the sample. The remaining $62 \%$ of the contacts are planning contacts, some of which could be replaced by telecommunications. In all, about $73 \%$ of all business contacts could be replaced by telecommunications, provided effective devices are made available at prices participants are willing to pay.

- The results of the contact record survey tend to indicate that sophisticated telecommunications could substitute for many interoffice business trips originating in CBDs. The results; which are based on limited data and therefore preliminary in nature, point toward a broad market for substitution and underscore the need for further research in this area. 
Stanford Research Institute for U.S. Environmental Protection Agency

\section{PURPOSE}

The basic objective of this study was to assess the feasibility of synthetic liquid fuels (liquid fuels derived from coal and oil shale) development by contrasting the anticipated environmental, economic, social, and institutional impacts of such development with the impacts of conventional petroleum production and recovery techniques. Biomass and tar sands were exrinded trom the study.

\section{ASSUMPTIONS}

\section{General Assumptions}

- Historical growth in U.S. automotive fuel demand cannot be sustained, especialy if U.S. intends to become energy self-sufficient. Several approaches can help satisfy automotive fuel demand: conserve energy, step-up domestic oil production by increasing activity in new geographic areas, import crude oil and refined products, and develop synthetic liquid fuels based on abundant domestic coal and oil shale resources (focus of this study).

- The three automotive energy supply and demand scienarios used were from the Energy Policy Project of the Ford Foundation. They are out 1 ined below and in Table 28 ,

- Historical Growth (HG): consumers ignore fuel prices and return to high consumption rates ... oil prices fall back to the $\$ 4$ to $\$ 6$ per barrel range ... fuels from fossil sources are needed because of rapid growth of demand ... annual growth rate of total energy demand is $3.4 \%$.

- Technical Fix (TF): consumers respond to high fuel prices and conserve ... government orders mandatory conservation ... primary conservation measures are improved building insulation and better auto fuel efficiency (from $14 \mathrm{mpg}$ in 1977 to $25 \mathrm{mpg}$ by 2000) ... annual growth rate of total energy demand is $1 . .9 \%$.

- Zero Energy Growth (ZEG): similar to TF, but with more-stringent governmental controls (e.g., auto fuel efficiency from $14 \mathrm{mpg}$ in 1977 to $33 \mathrm{mpg}$ by 2000 ).

\section{Reference Case Assumptions}

A historic growth supply/demand scenario was chosen in light of USGS estimates of total recoverable U.S. reserves of petroleum. The reference case assumptions are listed in Tables 29-31. 
Table 28. Projected Annual Fuel Consumption by Scenario [quadrillion Btu per year. (million barrels/ day product equivalent) ] ${ }^{a}$

\begin{tabular}{|c|c|c|}
\hline \multirow[t]{2}{*}{ Scenario } & \multicolumn{2}{|c|}{ Years } \\
\hline & 1970 & 1975 \\
\hline $\begin{array}{l}\text { Total all sectors } \\
\text { Transportation } \\
\text { Autos, trucks, buses } \\
\% \text { of transportation }\end{array}$ & $\begin{array}{l}66.0 \\
15.7 \\
11.9(6.2) \\
76 \%\end{array}$ & $\begin{array}{l}78.0 \\
19.1 \\
14.4(7.5) \\
75 \%\end{array}$ \\
\hline & 1985 & 1980 \\
\hline Historical Growth Scenario & & \\
\hline $\begin{array}{l}\text { Total all sectors } \\
\text { Transportation } \\
\text { Autos, trucks, buses } \\
\% \text { of transportation } \\
\text { Technical Fix Scenario }\end{array}$ & $\begin{array}{l}116.1 \\
26.0 \\
18.0(9.3) \\
69 \%\end{array}$ & $\begin{array}{l}186.7 \\
38.4 \\
21.9^{\circ}(11.4) \\
57 \%\end{array}$ \\
\hline $\begin{array}{l}\text { Total all sectors } \\
\text { Transportation } \\
\text { Autos, trucks, buses } \\
\% \text { of transportation }\end{array}$ & $\begin{array}{l}91.3 \\
19.6 \\
12.7(6.6) \\
65 \%\end{array}$ & $\begin{array}{l}124.0 \\
24.7 \\
11.4(5.9) \\
46 \%\end{array}$ \\
\hline Zero Energy Growth Scenario & & \\
\hline $\begin{array}{l}\text { Total all sectors } \\
\text { Transportation } \\
\text { Autos, trucks, buses } \\
\% \text { of transportation }\end{array}$ & $\begin{array}{l}88.1 \\
18.4 \\
12.5(6.5) \\
68 \%\end{array}$ & $\begin{array}{l}100.0 \\
17.2 \\
8.5(4.4) \\
49 \%\end{array}$ \\
\hline
\end{tabular}

$a_{1}$ bbl oil product (typically gasoline) $=5.25$ million Btu, so 1 quad ( $\left.10^{15} \mathrm{Btu}\right)$ per year equals about 0.5 million bbl/day.

Maximum Credible Synthetic Implementation (MCI) Case Assumptions (see Tables 32 and 33 )

To contrast the reference case, a scenario was prepared that attempts to depict the maximum rate at which a synthetic fuels industry could be deployed. It assumes that: (1) all fucl conversiun activicles will occur close to mines; (2) economic incentives exist for the oil industry to develop synthetic fuels; fuels can be produced at a profit and suld at prices competitive with imported natural petroleum; (3) there will be a continuing incentive to develop the synthetic fuels industry; (4) the 10-million-bbl/day (1.6-mil1 ion-m 3 day) of oil equivalent energy of MCI cannot replace the 18-millionbbl/day (2.9-million-m ${ }^{3} /$ day) imports of the HG reference case; and (5) MCI 
Table 29. Domestic Oil Supply, Imports, and Total U.S. Demand

\begin{tabular}{|c|c|c|c|c|c|}
\hline \multirow[b]{3}{*}{ Supply/Demand } & \multirow{2}{*}{\multicolumn{3}{|c|}{$\begin{array}{l}\text { Quantity by Year }\left[10^{6} \mathrm{bbl} / \mathrm{day}\right. \\
(\% \text { of domestic supply })]\end{array}$}} & \multicolumn{2}{|c|}{$\begin{array}{c}\text { Cumulative } \begin{array}{c}1974-2000 \\
\left(10^{9} \text { bbl) }\right.\end{array} \\
\end{array}$} \\
\hline & & & & \multirow[b]{2}{*}{ Total } & \multirow{2}{*}{$\begin{array}{c}\text { From Advanced } \\
\text { Recovery }\end{array}$} \\
\hline & 1974 & 1985 & 2000 & & \\
\hline \multicolumn{6}{|l|}{ Domestic supply } \\
\hline \multicolumn{6}{|l|}{ Lower 48 states } \\
\hline Onshore & $8.9(85)$ & $6.8(52)$ & $5.0(38)$ & 63 & 34 \\
\hline Offshore & $1.4(13)$ & $3.0(21)$ & $4.0(30)$ & 28 & 15 \\
\hline Alaska & 0.2 (2) & $3.6(27)$ & $4.4(32)$ & 30 & 16 \\
\hline Total & 10.5 & 13.4 & 13.4 & 121 & -- \\
\hline Imports & 6.0 & 11.5 & 18.4 & -- & $-\cdots \cdots$ \\
\hline Total & 16.5 & 24.9 & 31.8 & -- & -- \\
\hline
\end{tabular}

is hcavily slepwed toward the Rocky Mountain and Northern Great Piains regions because of abundance of coal and oil shale, and because the pattcrn of gnvernment ownership in these areas will guarantee a plant's lifetime operation.

METHODOLOGY

$\underline{\text { Reference Case }}$

Domestic oil supply projectione by reginn and requirements for imported oil were adapted from the Federal Encrgy Administration Project Independence Task Force Report (1y74) and the Energy Policy Prnject of the Ford Foundation (1974). Estimates of the resources required to increase domestic oil production without synthetic fuels development were also adapted from the Project Independence Task Force Report. Environmental impacts of the reference case were then determined by means of scaling factors for quantifiable characteristics of the oil extraction, transport, and refining processes.

\section{Scenario}

The MCI scenario was derived from a hypothesized growth schedule for a synthetic liquid fuel industry. The growth schedule indicates a slow start until 1985, followed by a rapid growth period until the year 2000. The assumed production schedule and resource inputs are listed above. The environmental impacts of such development (barrels/day of production) were determined by the use of scaling factors. Very involved scaling factors represent constants to be multiplied against the barrels/day of production (e.g., 770 gallons of water used/day/barrel). Scaling factors exist for each aspect of production. For example, for exploration, 24 persons are employed per drilling rig; for pipeline distribution, so many tons of particulates are emitted per 1000 miles of pipeline. 
Table 30. Annual Labor, Drill Rig, and Steel Requirements for Oil Production

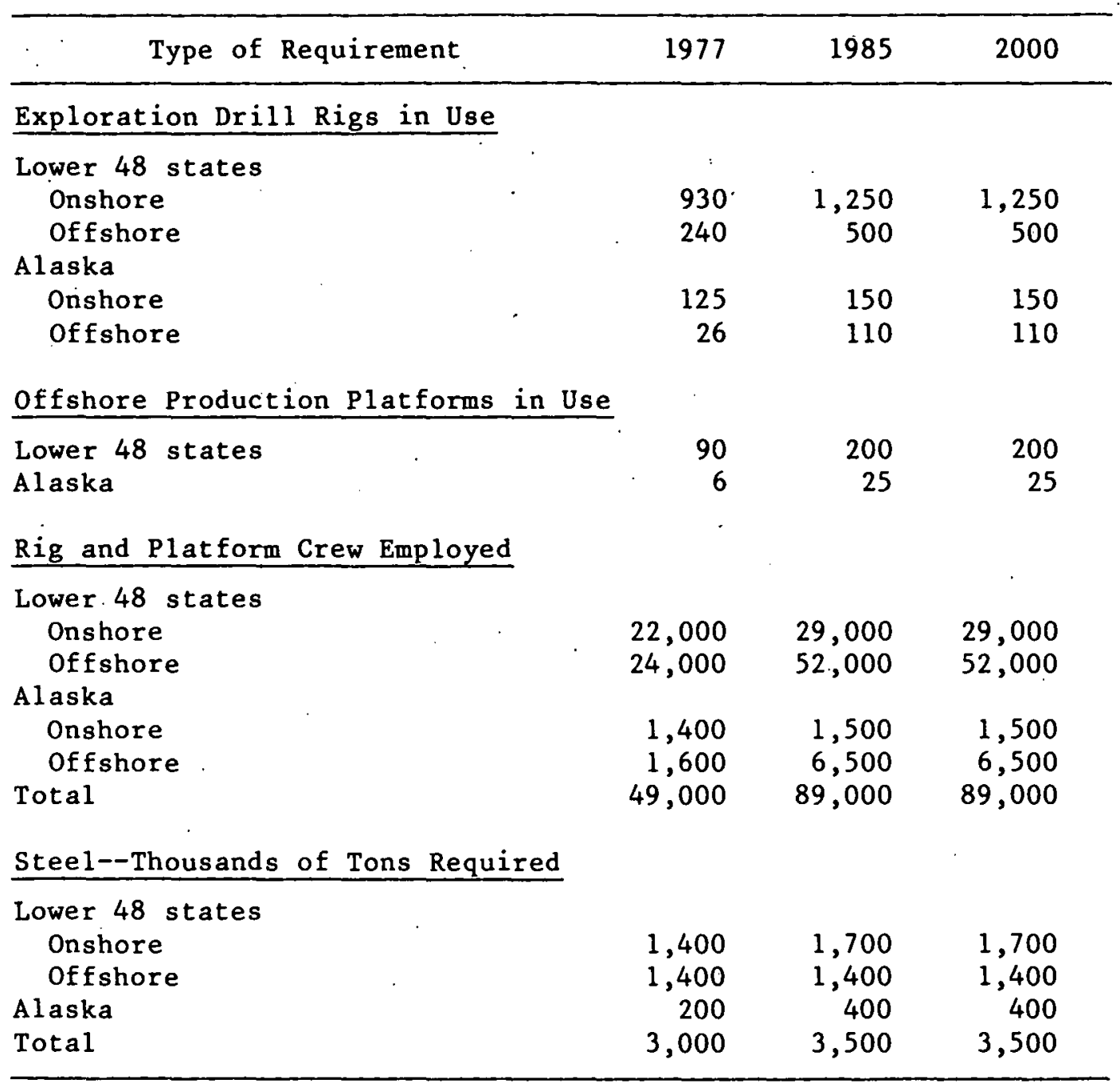

CONCLUSIONS

Major Impacts of the Reference Case

- Alaskan (onshore and offshore): rapid changes in human populations leading to boom towns with low levels of human amenities and environmental protection ... disruption of established cultures, economies, and values ... damage to fragile ecosystems by petroleum spills, the activity of exploration and production, and establishment of transportation corridors ... damage to the marine environment resulting from ocean transport (and landing) of oil to other states ... damage to the marine environment from spills and other accidents (offshore only).

- Lower 48 states (offshore): impingement on other beneficial uses of coastal zones such as commercial fisheries, recreation, wildlife habitats ... induced human population in coastal areas due to increased petroleumrelated activity such as port facilities and refineries. 
Table 31. Annual Capital Investment in Conventional Oil Production $\left(\$ 10^{9}, 1973\right)$

\begin{tabular}{lccccccc}
\hline \multicolumn{1}{c}{ Investment } & 1974 & 1977 & 1980 & 1985 & 1990 & 1995 & 2000 \\
\hline $\begin{array}{llllll}\text { Onshore Recovery } \\
\text { Primary and secondary }\end{array}$ & 1.3 & 1.4 & 3.3 & 3.9 & 3.9 & 3.9 & 3.9 \\
$\begin{array}{l}\text { Advanced } \\
\text { Total }\end{array}$ & 1.0 & 1.0 & 1.0 & 1.0 & 2.6 & 2.6 & 2.6 \\
& 2.3 & 2.4 & 4.3 & 4.9 & 6.5 & 6.5 & 6.5 \\
Offshore Recovery & & & & & & & \\
Primary and secondary & 0.3 & 0.3 & 0.5 & 0.9 & 0.9 & 0.9 & 0.9 \\
Advanred & 0.6 & 0.6 & 0.6 & 0.6 & 1.3 & 1.3 & 1.3 \\
Total & 0.9 & $0 . \dot{9}$ & 1.1 & 1.5 & 2.2 & 2.2 & 2.2 \\
& & & & & & & \\
Alaska & & & & & & & \\
Primary and secondary & 0.7 & 1.2 & 1.2 & 1.3 & 1.3 & 1.3 & 1.3 \\
Advanced & 1.0 & 1.0 & 1.0 & 1.0 & 2.1 & 2.1 & 2.1 \\
Tutal & 1.7 & 2.2 & 2.2 & 2.3 & 3.4 & 3.4 & 3.4 \\
Total & 4.9 & 5.5 & 7.6 & 8.7 & 12.1 & 12.1 & 12.1 \\
\hline
\end{tabular}

Table 32. MCI Cumulative Resource Inputs

\begin{tabular}{|c|c|c|c|c|c|}
\hline Resource & 1980 & 1985 & 1990 & 1995 & 2000 \\
\hline Cunstrucliun & \multicolumn{5}{|c|}{ Cumulative Amount } \\
\hline $\begin{array}{l}\text { Capital }\left(\$ 10^{y}, 1973\right) \\
\text { Labor }\left(10^{3} \text { man-yr) }\right. \\
\text { Steel }\left(10^{6} \text { tons) }\right. \\
\text { Site ( } 10^{3} \text { acres) }\end{array}$ & $\begin{array}{r}1.34 \\
12.9 \\
0.19 \\
1.6\end{array}$ & $\begin{array}{r}7.90 \\
38.1 \\
1.15 \\
9.9\end{array}$ & $\begin{array}{r}26.5 \\
257 \\
3.91 \\
34.1\end{array}$ & $\begin{array}{r}54.5 \\
593 \\
8.5 \\
77\end{array}$ & $\begin{array}{r}89.2 \\
973 \\
14.2 \\
132\end{array}$ \\
\hline Operation & \multicolumn{5}{|c|}{ Annual Amount } \\
\hline $\begin{array}{l}\text { Coal }\left(10^{6} \text { tons/yr) }\right. \\
\text { oil shale }\left(10^{6} \text { tons } / \mathrm{yr}\right) \\
\text { Water }\left(10^{3} \text { acre-ft/yr) }\right. \\
\left.\text { Electric power ( } 10^{3} \mathrm{MW}\right) \\
\text { Labor }\left(10^{3} \text { persons) }\right.\end{array}$ & $\begin{array}{r}13 \\
54 \\
31 \\
0.27 \\
2.6\end{array}$ & $\begin{array}{r}94 \\
270 \\
196 \\
1.58 \\
17.9\end{array}$ & $\begin{array}{r}350 \\
810 \\
685 \\
4.95 \\
50.5\end{array}$ & $\begin{array}{r}920 \\
1080 \\
1505 \\
10.5 \\
100\end{array}$ & $\begin{array}{l}1760 \\
1080 \\
2680 \\
14.0 \\
162\end{array}$ \\
\hline
\end{tabular}


Table 33. MCI Regional Distribution of Synfuel

Production ( $10^{6}-b b l / d a y$ oil equivalent)

\begin{tabular}{llllll}
\hline \multicolumn{1}{c}{ State } & 1980 & 1985 & 1990 & 1995 & 2000 \\
\hline Coal & & & & & \\
Wyoming & 0 & 0.06 & 0.39 & 0.99 & 1.95 \\
Montana & 0 & 0 & 0.08 & 0.58 & 1.6 \\
North Dakota & 0.025 & 0.125 & 0.275 & 0.650 & 1.05 \\
New Mexico & 0 & 0.05 & 0.15 & 0.20 & 0.20 \\
Illinois & 0 & 0.08 & 0.33 & 0.78 & 1.4 \\
Kentucky & 0.025 & 0.075 & 0.205 & 0.48 & 0.90 \\
West Virginia & 0 & 0 & 0.08 & 0.18 & 0.45 \\
Ohio & 0 & 0 & 0 & 0.15 & 0.45 \\
Oil Shale & & & & & \\
Colorado & 0.1 & 0.5 & 1.5 & 2.0 & 2.0 \\
Total & 0.15 & 0.89 & 3.0 & 6.0 & 10.0 \\
\hline
\end{tabular}

ancludes syncrude and methanol from coal and syncrude. from oil shale.

- Advanced recovery: large increase in demand for the chemicals used in tertiary recovery with resulting environmental and health hazards in their manufacture, transport, and use ... increased air pollution from fuel burning for steam generation ... concentration of impacts in heavily populated and polluted Southern California, because past recovery techniques for heavy California crude oil have left much oil that is potentially suitable for advanced recovery.

- Imports: economic and political ramifications of economic disruption in the event of another oil embargo ... increased alteration of the coastal zone through increased ship traffic, spills, and construction of singlepoint offshore moorings and deepwater ports ... increased onshore activity for refining and transport of oil and of induced human population.

The impacts of the reference case are heavily concentrated in coastal areas -- both onshore and offshore and in Alaska. The nation may have to choose between impacts in the Northern Great Plains and Rocky Mountain states or impacts in the Alaskan and coastal zones unless demand for liquid fuels is significantly reduced through conservation.

Major Impacts of the Maximum Credible Implementation (MCI) Case

- Industrial decision making: industrial decisions to deploy commercialscale synthetic liquid fuel plants are necessary unless federal government develops the industry. 
- Capital availability: each profitable synthetic fuels plant would generate retainable earnings to be used to finance more plants.

- Resource depletion: if liquefaction and methanol are the sole uses of strippable coal, then reserves would last 70 years. However, if increases in coal consumption for coal gasification and electricity are considered, then reserves would only last 40 years. A shift to a more dangerous underground reserve would be necessary.

- Water availability: riparian rights in East prevent transfer of water to locations away from water source (stream, lake): appropriation rights in West create claim problems (especially determining Indian claims); in addition, western water reserves are not located near coal reserves ... water distribution problem exists near coal reserves; this will require redistribution of water, within the federal water storage reservoirs, and conflicts with the agricultural interests are assured ... interbasin transfers of water are now illegal for the most part, and coal slurry movements involve interbasin transfers ... problems associated with transporting coal on unit trains include possibilities of labor disputes, disruption to crossing auto trattic, and noise ... problems associaled with slurry pipelines include fixed routes, restriction to single product, and exports of water from water-poor regions.

- Economic spin-off effects: availability of specialty steels, castings, forgings, and special equipment such as mining draglines, compressors, and pumps will be a problem because of inadequate industrial production. Production lead time is major economic concern.

- Environmental effects: reclamation of surface-mined lands in the West is critical in the deployment of any synthetic fuel industry because of the climatic conditions (e.g., limited rainfall).... volume of oil shale needed to produce energy equivalent of coal is much larger ... disposal and reclamation of spent oil shale present problems: returning unused oil shale (which doubles in volume as a result of processing), reclaiming land surface, controlling water pollution problems from runoff ... air quality standards will be violated near oil shale conversion planta ... coal conversion plants will have less of a problem, except when sited in groups ... sewerage, storm runoff, solid waste disposal, etc., will present problems in "boom town" areas.

- Social consequences: rapid population growth will lead to housing shortage, inadequate tax revenues to finance municipal services, and social malaise tendencies ... feelings that the local or regional interests are being subordinated to the national interest may arise, presenting problems for the industry.

\section{Alternatives to MCI Deployment}

Impacts of full-scale MCI deployment can be eliminated by limiting the number of conversion plants in a given area. Impacts still include: (1) need for front-end money for community services, (2) value conflicts, (3) abrupt changes unless plant size and construction timing are closely managed, (4) water demands that strain allocation procedures, and (5) air quality degradation and other environmental impacts. 
3 BRIEF ABSTRACTS OF SELECTED RELATED REPORTS AND DATA SOURCES*

*In order of listing in Table 1. 


\section{THIS PAGE}

\section{WAS INTENTIONALLY LEFT BLANK}


METHODOLOGICAL GUIDELINES FOR SOCIAL ASSESSMENT OF TECHNOLOGY (1975)

Organization of Economic Cooperation and Development

Type of Report: Reference report on technology assessment development.

Scope: Report was the result of concern for the overall impact of technological developments on the basic levels of the individual and society. Conclusion was the promotion of various methodological guidelines for conducting technology assessments.

Highlights Relevant to Technology Assessment: Nine articles are provided in which various authors present innovative methodologies of social assessment of technology. The report addresses several problems associated with developing methodological guidelines for technological assessments. Among them are: (1) selection of topics for social assessment of technology; (2) delineation of the nature and the scope of assessment studies; (3) procedures for organizing the various steps and tasks of an assessment study; (4) practical use of social assessment of technology; (5) requirements and limits of the evaluation process in social assessment of technology; (6) interplay between information and decision making; and (7) importance of participation of interested and affected parties.

Note: Longer abstract available from S. J. LaBelle, Bldg. 12, Argonne National Laboratory, Argonne, IL 60439.

ENERGY IN TRANSPORTATION (1978)

U.S. Department of Transportation

Type of Report: Data

Year of Data: $1973-77$

Scope: Describes present transportation fuel usage and estimate fuel savings for various conservation options. Addresses five modes: highway auto, light truck, commercial truck, air carrier, rail freight.

Highlights Relevant to Terhnolngy Assessment: Projects fuel conservation for the various options, gives an idea of the relative magnitudes of savings, but the quantitative results are probably of little use.

Comments: Methodology for computing savings is quite vague. Much of the report refers to other studies and does not present any new data.

Note: Longer abstract available from S. J. LaBelle, Bldg. 12, Argonne National Laboratory, Argonne, IL 60439. 
NATIONAL TRANSPORTATION: TRENDS AND CHOICES (1977)

U.S. Department of Transportation

Type of Report: Data

Year of Data: Base 1972-75 Forecast 1990-2000

Scope: First multimodal national transportation planning effort by U.S. DOT. Covers all vehicular modes and pipelines, and domestic as well as international transportation. Points out trends in absence of conscious public policy and choices that are available.

Highlights Relevant to Technology Assessment: Presents historical data and projections of highway, railroad, aviation, marine, and pipeline transportation. Breakdowns include domestic and international, and state, metropolitan, small urban, and rural use. Includes some future scenarios (success future, distress future, and transformation future) and technological possibilities.

Comments: Document intended to initiate dialogue of issues; not an end result in itself.

PROCEEDINGS OF THE YEAR 2000 ALTERNATIVE TRANSPORTATION FUTURES CONFERENCE (1976)

Chicago Area Transportation Study

Type of Report: Models/techniques

Scope: The kick-off for the northeastern Illinois year 2000 transportation planning effort was an all-day futures conference in March, 1976, with more than 100 professionals participating. The conference defined three possible alternative futures (scenarios) for the region. The futures were seen as a framework to assist planning and decision making in setting optimal values for variables under regional control.

Highlights Relevant to Technology Assessment: This is an excellent method for obtaining plausible futures and effertively obtaining a broad range of professional input.

Comments: Concept too advanced for regional planning -- had little impact on the year 2000 plan recently produced. 
REGIONAL TRANSPORTATION ENERGY CONSERVATION DATA BOOK (1978) .

Oak Ridge National Laboratory for U.S. Department of Energy

Type of Report: Data

Scope: Highlights regional differences in characteristics affecting transportation energy conservation in the U.S. Basic energy use data are presented for highway, air, rail, marine, and pipeline modes, at three levels of disaggregation: selected metropolitan areas, states, and the ten federal regions. State energy supplies and use and international transportation energy. comparisons are also given.

Highlights Relevant to Technology Assessment: Large regional variations can be found in both the character and quantity of regional transportation demands. This implies that energy conservation programs are likely to vary in effectiveness and impacts from region to region.

Comments: Important data source for any technology assessment.

ANALYSIS OF A STATEWIDE INTEGRATED TRANSPORTATION SYSTEM (1977)

U.S. Department of Transportation

Type of Report: Statewide transportation study

Scope: Report was the result of surveys distributed to determine current and future transportation needs in Mississippi. Conclusion was that there was a need for a central council, which would coordinate planning for all transportation modes in the state.

Highlights Relevant to Technology Assessment: None.

Comments: Good background information and statistics on travel by mode in Mississippi.

Note: Longer abstract available from S. J. Labelle, Bldg. 12, Argonne National Laboratory, Argonne, IL 60439. 
TRANSPORTATION ENERGY CONSUMPTION AND CONSERVATION POLICY OPTIONS IN THE NORTHEAST (1976)

Brookhaven National Laboratory for U.S. Department of Energy

Type of Report: Data

Year of Data: Base - 1972, projections by mode -1985 and 2000

Scope: Estimates baseline energy projections by mode. Review of recent trends in distribution of population and of industrial and commercial activities. Review of conservation actions grouped as "packages," including business as usual, new policy initiatives, new policy directions, and maximum use of alcernative energy sources. Discussion of possible roles of state and local governments in formulation of conservation policies.

Highlights Relevant to Technology Assessment: Over the long term (year 2000), annual savings of over $30 \%$ are possible if fundamental changes in energy conservation policy are made, especially with regard to increased transit usage in suburban areas and land use concrols.

Comments: Estimates annual net energy savings for each policy initiative:

EFFECTS OF ENERGY CONSTRAINTS ON TRANSPORTATION SYSTEMS (annual)

U.S. Department of Energy

Type of Report: Conference proceedings

Scope: Presents an overview of the state of the art in transportation and energy research. Includes long-range planning under energy constraints, energy efficiency of inter- and intra-city movements.

Highlights Relevant to Technology Assessment: Source data and projects should be helpful starting points for any technology assessment. 
ENERGY USE IN TRANSPORTATION: POTENTIAL FOR COMPARATIVE RESEARCH (1975)

Transportation Research Board

Type of Report: Research methods

Scope: Describes findings of a group of researchers sent to selected European countries and multinational organizations to inquire about cooperative research in energy use in transportation.

Highlights Relevant to Technology Assessment: Emphasis on passenger transportation, especially such activities as traffic constraints and efforts to achieve modal shifts; data collection techniques, particularly the possibilities of reasonably monitoring the consequences of new policies; and analytic methodology, particularly for forecasting and policy analysis. Technology was relatively deemphasized.

Comments: It was found that as seemingly simple a matter as information exchange constitutes a very real problem. Language is also a far more severe problem than it might appear to be initially.

ASSESSMENT OF OPERATIONAL AUTOMATED GUIDEWAY SYSTEMS: AIRTRANS (1976)

Transportation Systems Center, U.S. Department of Transportation

Type of Report: Technology performance characteristics

Year of Data: 1975

Scope: Hardware assessment of the Airport Transportation System (Airtrans) at Dallas/Fort Worth Regional Airport to determine its capabilities and limitations for freight/passenger airport and urban applications. Limited data collection.

Highlights Relevant to Technology Assessment: Airtrans is not operating successfully and further technical development is necessary to make it suitable for urban applications. Sufficient data should be collected for analysis.

Comments: An incomplete assessment of the system.

Note: Longer abstract available from S. J. LaBelle, Bldg. 12, Argonne National Laboratory, Argonne, IL 60439. 
THE FINANCIAL VIABILITY OF CONRAIL (1975)

Office of Technology Assessment, U.S. Congress

Type of Report: Financial analysis

Year of Data: 1973

Scope: This report examines the financial outlook for ConRail by analyzing the critical assumptions affecting ConRail's financial viability. Considers revenues and operating costs through a sensitivity analysis. ConRail is a freight-moving railroad (with Amtrak and Commuter Rail) in the Northeast and the eastern portion of the Midwest. It is a consolidation of several bankrupi ur fillamially strapped oactorn iailroads.

High1ights Relevant to lechnology Assessment: Pessimistic relative to the United States Railway Association's projections of ConRail's successes.

Comments: Now dated because actual data on the system exist and better projections can be made.

Note: Longer abstract available from S. J. LaBelle, Bldg. 12, Argonne National Laboratory, Argonne; IL 60439.

A REVIEW OF ALTERNATIVE APPROACHES TO FEDERAL FUNDING OF RAIL REHABILITATION (1975)

Office of Technology Assessment, U.S. Congress

Type of Report: Financial analysis

Scope: Explores proposed federal programs for funding the rehabilitation of the nation's railroad fixed plant. Policy-oriented study concerned with applying an analytical framework to the key issues associated with rehabilitation alternatives. Does nol evaluate alternativco; focus is on the method and an outline of issues.

Highlights Rclevant to Technology Assessment: Deterioration of fixed plant is nationwide problem, but public ownership raises many problems.

Comments: Rehabilitation alternatives are not evaluated. However, the report presents information on many financial issues.

Note: Longer abstract available from S. J. LaBelle, Bldg. 12, Argonne National Laboratory, Argonne, IL 60439. 
A REVIEW OF NATIONAL RAILROAD ISSUES (1975)

Office of Technology Assessment, U.S. Congress

Type of Report: Data

Scope: Explores legislative actions that might be taken by Congress to aid U.S. railroads, focusing on freight movement. Part of overall federal effort that addresses rehabilitation, corporate restructuring of solvent roads, and changes in federal regulation.

Highlights Relevant to Technology Assessment: Financial prospects for the industry are bleak, selective rehabilitation can preserve fixed plants while keeping federal options open, industry-wide restructuring does not appear to be a solution. A selective program of federal assistance to weaker railroads for rehabilitation is recommended along with granting some rate setting flexibility and gradually lifting other regulatory constraints.

Note: Longer abstract available from S. J. LaBelle, B1dg. 12, Argonne National-Laboratory, Argonne, IL 60439.

AN EVALUATION OF RAILROAD SAFETY (1978)

Office of Technology Assessment, U.S. Congress

Type of Report: Safety analysis

Scope: Evaluates the effectiveness of federal efforts to improve railroad safety. Examines current accidents and cost trends; reviews and evaluates railroad safety laws, regulations and inspection programs; and presents overview of current research, development, and voluntary safety programs. Discusses the relationship of safety and economics.

Highlights Relevant to Technology Assessment: Sets out research needs and policy options. Concludes that a combination of deferred maintenance and increased axle loadings appears to relate to the increased property losses due to train accidents, but that the current railroad safety statutory framework is adequate for addressing safety problems. Further sooperation betwecn all particc ic needed.

Note: Longer abstract available from S. J. LaBelle, Bldg. 12, Argonne National Laboratory, Argonne, IL 60439. 
IMPACT OF COAL TRANSPORTATION ON GILLETTE, WYOMING, AND COMMUNITIES SOUTH AND EAST (1978)

Los Alamos Scientific Laboratory for U.S. Department of Energy

Type of Report: Local impact analysis

Scope: Using two coal unit train scenarios, determines impact on Gillette for separation of community services; grade crossing safety; noise, vibration, and visibility disturbance effects on growth patterns; and coal dust pollution. Suggests mitigation techniques: reroute all trains north of town and separate grades.

Highlights Relevant to Technology Assessment: Very little methodology of interest. Little more than secondary source information collected.

Note: Longer abstract available from S. J. LaBelle, Bldg. 12, Argonne National Laboratory, Argonne, IL 60439.

the STATES. AND RURAL RAIL PRESERVATION: ALTERNATIVE STRATEgIES (1975)

Council of State Governments

Type of Report: Railroad branch abandonments

Scope: Analyzes problems of rail abandonment (particularly in the 18 states affected by the Regional Rail Reorganization Act of 1973) and rural development. Presents alternative strategies overall to statea in coping with abandonment problems.

Highlights Relevant to 'Technology Assessment: Only slightly related to a railroad technology assessment.

Comments: Good review of railroad abandonment. 
ENERGY AND ECONOMIC TRADE-OFFS FOR ADVANCED TECHNOLOGY SUBSONIC AIRCRAFT (1976)

National Aeronautics and Space Administration

Type of Report: Models/techniques

Year of Data: 1976

Scope: Studies changes in future aircraft technology that conserve energy. Also analyzes the economic effects of those changes. Uses a computer program to size aircraft for minimum fuel consumption.

Highlights Relevant to Technology Assessment: Gives little information on quantity of fuel savings. Useful for identifying likely future aircraft technologies. Several graphs depicting energy consumption versus aspect ratio and range might be useful.

Comments: The paper is brief and one wonders if all possible new technologies were tested.

Note: Longer abstract available from S. J. LaBelle, Bldg. 12, Argonne National Laboratory, Argonne, IL 60439.

TECHNICAL AND ECONOMIC EVALUATION OF ADVANCED AIR CARGO SYSTEMS (1978)

National Aeronautics and Space Administration

Type of Report: Summary of research to date

Scope: Reviews progress of market studies on the potential response to improved cargo service, reports on studies of advanced freighter concepts, identifies opportunities for application of advanced technology.

Highlights Relevant to Technology Assessment: Presents data on fuel efficiency benefits from new technologies. Also estimates probable year of introduction for new technologies.

Comments: Good concise summary of research to date.

Note: Longer abstract available from S. J. LaBelle, Bldg. 12, Argonne National Laboratory, Argonne, IL 60439. 
AN ASSESSMENT OF LIGHTER THAN AIR TECHNOLOGY (1975)

Massachusetts Institute of Technology for National Science Foundation

Type of Report: Documentation of workshop

Year of data: 1974

Scope: The workshop addressed these issues: should the U.S. government develop lighter-than-air vehicles, and should the U.S. government sponsor lighter-than-air research and technology. Working, groups discussed markets, economics, operations, and technology.

Highlights Relevant tó Technology Assessment: None

Comments: The report mentions that air ships are energy-efficient but never documents this. The recommendations of the workshop are questionable. They appear to be overly optimistic.

Note: Longer abstract available from S. J. LaBelle, Bldg. 12, Argonne National Laboratory, Argonne, IL 60439.

TECHNOLOGIES FOR THE AIR TRANSPORT OF TOMORROW (1976)

National Aeronautics and Space Administration

Type of Report: Discussion of existing research

Scope: Reviews technologies essential to future cost-effective development and implementation of large transport aircraft.

Highlights Relevant to Technology Assessment: Identifies areas for future improvement and development to increase aircraft efficiency.

Note: Longer abstract available from S. J. LaBelle, B1dg. 12, Argonne Nationa1 Laboratory, Argonne, IL $6043 y$. 
POTENTIAL FUEL CONSERVATION MEASURES BY MOTOR CARRIERS IN THE INTERCITY FREIGHT MARKET (1977)

Transportation Research Board

Type of Report: Industry survey

Scope: Qualitatively assesses the extent to which present economics and energy efficiencies of truck transportation are the result of ICC regulation and the extent to. which they reflect fundamental economics of truck transportation. Based on in-depth interviews with a sample of carriers and other data sources in the trucking industry.

Highlights Relevant to Technology Assessment: The degree to which the restrictions affect efficiency depends on the economics of the particular haul, the objectives of the carrier, and the opportunities available to the carrier to avoid the restrictions. In some cases apparent restrictions are not actually considered to be constraints by the carriers.

Comments: Very qualitative.

Note: Longer abstract available from S. J. LaBelle, Bldg. 12, Argonne National Laboratory, Argonne, IL 60439.

NATIONAL ENERGY TRANSPORTATION STUDY (1980)

U.S Departments of Transportation and Energy

Type of Report: Data and uses of models/techniques

Year of data: 1975, forecasts for 1985, 1990, 1995

Scope: Analyzes adequacy of nation's major transportation systems to meet future energy transport needs.

Highlights Relevant to Technology Assessment: Assesses transport requirements and capabilities for coal, oil, and natural gas.. Identifies financial, environmental, and physical (bottleneck) constraints and issues for these systems. Limited analyses of electricity transmission and nuclear fuel transport systems.

Comments: Based on DOE/EIA mid-range energy forecasting system (MEFS) U.S. energy supply-demand forecasts. Includes development and use of major transportation network assignment model. 
IMPACTS OF ENERGY MATERIAL TRANSPORTATION :(1979)

U.S. Department of Transportation for National Energy Transportation Study

Type of Report: Data

Scope: Part of the NETS effort. Includes transport of coal by slurry pipeline, rail, and high voltage transmission; nuclear waste transport; and the transport of LNG and LPG.

Highlights Relevant to Technology Assessment: Extensive data collected, including site-specific information on modes. Social, environmental, and economic impacts identified. Data and analyses useful for a freight transportation technology assessment.

SYSTEMS STUDY OF TWO SYNTHETIC TRANSPORTATION FUEL OPTIONS (1974)

Brookhaven National Laboratory for U.S. Energy Research and Development Administration

Type of Report: Models/techniques

Year of Data: Year 2000 projections

Scope: Analyzes impacts of hydrogen, generated with off-peak electicity or. produced from coal, and methane, produced from coal. Analys is techniques dcocribed in another Brookhaven report on their Reference Energy Eystcm.

Highlights Relevant to Technology Assessment: Maximum amount of available off-peak power in the year 2000. Reference Energy System can satisfy. approximately $50 \%$ of the automotive fuel requirements. Emissions in transportation sector shifted from populated urban centers to central station electric sites.

Comments: Analysis limited, documentation brief, methodology given elsewhere. 
A HANDBOOK OF TECHNOLOGY ASSESSMENT (1978)

U.S. Department of Energy

Type of Report: Techniques

Scope: Discusses definition, development, and use of technology assessments. Contrasts technology assessments with other types of analysis. Describes necessary steps to conduct a technology assessment. Differentiates'technology assessments performed by NSF, OTA, line agencies, and federal government.

Highlights Relevant to Technology Assessment: Should be read before commencing technology assessments in any mode.

STRATEGIES FOR CONDUCTING TECHNOLOGY ASSESSMENTS (1977)

National Science Foundation

Type of Report: Models/techniques

Scope: Defines methods and strategies for conducting a technology assessment. Presents observations on practical difficulties with technology assessments.

Comments: Should be read by anyone attempting to conduct a technology assessment.

Highlights Relevant to Technology Assessment: Five elements are central to definition of a technology assessment.

1. Technology can and should be consciously and rationally managed toward a goal contributing to the long-range benefit of humanity. in general and organized society as we know it in particular. Management should be enhanced by a comprehensive and even-handed evaluation and comparison of the valid alternative choices available.

2. A technology assessment is intended primarily to aid in making policy decisions and as such is expected to compare the broadranging advantages and disadvantages to specified stakeholders of at least the most likely attainable alternatives presently available.

3. A technology assessment is inherently a multidisciplinary effort requiring the active participation of social as well as physical scientists.

4. A technology assessment must include projections into the future and deliberately deal with the uncertainty inherent in such projections. 
5. The general term "technology" includes "management or soft technologies" as well as physical technologies.

These elements in the methodology of a technology assessment were presented by Joseph Coates in 1974: examine problem statements; specify systems alternatives; identify and evaluate possible impacts; identify the decision apparatus, action options for decision apparatus, parties at interest, macro system alternatives (other routes to goal), and exogenous variables or events possibly having an effect on previously. described elements; and prepare conclusions and recommendations.

\section{A Strategy for Conducting Technology Assessments}

- Technology descriptiun and projection

1. Data acquisition: personal Interview, confenence workshop, questionnaires

2. Bounding the assessment domain -- time (projection into future), geographical, institutional, and political jurisdiction

3. Projection of technological alternatives (two or more mutually exclusive alternatives.-- central to concept of technology assessment, may include models or simulations)

4. Example technique for technology descriptions and projection

- Impact assessment: include primary and higher-order social and environmental concerns as well as economics, technical performance, and legal and institutional considerations

1. Impact criteria selection: critical step, can be arranged by scientific discipline, stakeholder groups, functional areas of the rechnology or logical characcerieations (ohuckm lists, relevance trees)

2. Predicting and assessing impacts

- Interdisciplinary and futuristic techniques, including expert opinion, analogy, quantitative models (best used in ancillary role), conceptual models, trend analysis, cross impact analysis, and scenarios (the most popular)

- Social impact assessment is weakest aspect of the process; techniques include quantitative moacures, morphningiral. annlyoio, oxport opinion, and pnlling

- Organizational approaches: expert opinion synthesis depends on large body of experts for existing or emerging technologies; predictive models with tendency to be onesided toward qualitative impacts, and "ad hoc systems andysis" to handle different impacts in different ways.

3. Impact comparisons and presentations

- Subjective impacts presented by public polls, stakeholder representatives, public review synthesis, team as public surrogate, and sampling of alternative viewpoints 
- Quantification: quantify where possible

- Evaluation and summary comparison either by common physical measure or unitless scale

- Policy analysis of complete range of feasible options

1. Lack of methodological consistency in technology assessments because:

- Policy science has generated few analytical processes

- Delays in bounding assessment and analyzing impacts result in reduced time and funds for policy analysis

- Those involved in technology assessments typically are from a systems or environmental background, not a policy analysis discipline

2. Implementation of technological alternatives

- Formulate feasible policy options for implementing each technological alternative

- Conduct a comparative analysis of the options

- Synthesize a single "best" combination of policies

- Present summary comparison of "best" technological alternative-policy implementation combinations

3. Search for permeating issues, concerns, and uncertainties: concentrates on constraints, barriers, and concerns evidenced in impact analysis

- Cross-cutting concerns that normally arise in process of technology assessment: whole societal future contexts, societal values, uncertainty of projections and impacts of effectiveness of proposed policy options, interaction and sensitivity analysis, team interaction, and validation and public participation

Categories of Technology Assessment and Their Effect on Strategy Emphasis

- Primary characteristics of technology assessment categories

1. Problem oriented -- mix of physical and management technologies versus

technology oriented -- single technology along alternative paths

2. Physical technologies -- emphasis on feasibility limits

versus

management technologies -- emphasis on management strategy with physical technology playing minor role

3. Existing technologies -- concentrates on known or strongly anticipated consequences of a given technology versus

futuristic technologies -- broad comparison of impacts and policy analysis 
4. Major technologies -- large social adjustment necessary, government involvement/tolerance essential

versus

minor technologies -- effects may be locally concentrated or pervasively diffuse, government not critical for implementation

- Miscellaneous Aspects of Strategy Emphasis

1. Guided creativity such as group dialog, interactive structural modeling, computer-aided group problem-solving techniques, and policy capturing may bring different perspective to process

2. Adversarial assessment suggested, but no time in practice

3. Retrospective assessment, seeks predictive mechanisms for unexpected societal effects from what is recognized in retrospect as a major technological implementation

Summary Observations on Practical Difficulties with Technology

Assessment

1. Bounding the assessment domain should be agreed upon at a reasonably early point, before $20 \%$ of project timo has elapeed

2. Lack of accepted technology assessment methodology; seems to be essentially the choice of the principal investigator

3. Policy analysis deficiency; ironic that aim of technology assessment is assisting in choosing among policy options but policy analysis is its weakest aspect

4. Team cooperation is vitally important

5. Stakeholder and public inputs are increasingly.important but difficult to obtain

6. Evenhundedncoo and objectivity are olueive but esential

7. Differing views on whether a technology assessment should recommend a preferred option: should it give the client the advantage of staff experience by making recommendations or explain in as complete a context as possible the predicted consequences of various policy. options in that recommendation

8. Mobility and turnover of research personnel, including the principal investigator, should be accepted as a fact of 1 ife and taken into account in planning programs

9. Oversight committees proved largely ineffective in providing substantive review of assessment results, though useful in providing leads to information and lending a prestigious stamp of approval to enhance the perceived validity of the report: 
Summary and Recommendations

1. For sponsors of technology assessments

- Specify category of technology assessment and extent of public or interest-group input desired

- Participate in a preliminary bounding session with contractor

- Assist in identifying and contacting potential data sources

- Be prepared to respond in a timely manner to phased, iterative reports

- Expect proposals to describe methodology to address all functional and cross-cutting elements

- Insure accounting for policy analysis, the weak aspect of past technology assessments

2. For those conducting technology assessments

= Define the technology assessment category and budget major functional elements accordingly

- Plan sufficient funding and time for personalcontact data collection

- Insure key representatives of sponsor are participating in preliminary budget session

- Bring in a wide range of interested parties for selection of criteria by which to assess the impacts

- Select an overall impact measurement philosophy

- Agree with sponsor on extent of public input 
METHODOLOGY FOR IDENTIFYING URBAN TRANSPORTATION TECHNOLOGY ALTERNATIVES (1977)

University of Illinois at Chicago Circle for U.S. Department of Transportation

Type of Report: Technique

Scope: Uses two tables that accept as input characteristics describing a transportation need (such as transporting elderly and handicapped, linking urban neighborhoods to $\mathrm{CBD}$, people movement within an airport complex), to produce a list of transportation technologies that can satisfy that need ( such as PRT, AGT, accelerated moving walkways, shared taxi). Does not address goods movement.

Highlights Relevant to Technology Assessment: None

CONTRIBUTIONS TO THE FOUNDATIONS OF SUPPLY FOR ENERGY AND TRANSPORTATION: CONCEPTS, ECONOMICS AND TECHNOLOGIES (1979)

Resources for the Future, Inc.

Type of Report: Data

Scope: Resource for National Transportation Policy Study Commission. Impressive documentation of energy supply side for transportation. Economics of resources and energy technologies; development schedules.

Highlights Relevant to Technology Assessment: Useful resource, especially for fuels-oriented technology assessments.

PROJECTIONS OF AUTOMOBILE OWNERSHIP AND USE BASED ON HOUSEHOLD LIFESTYLE FACTORS . (1978)

U.S. Department of Energy

'I'ype of Repurt: Models/techuiques

Year of data: 1969 National Personal Transportation Survey (NPTS) by U.S. DOT

Scope: Builds regression models to relate automobile ownership and use to demographic and family cycle variables. Summarizes a dissertation.

Highlights Relevant to Technology Assessment: Conceptual ideas excellent.

Comments: Used NPTS data, which has questionable validity. Aggregation of . data methods may be faulty. 
THE IMPACTS OF URBAN TRANSPORTATION AND LAND USE POLICIES ON TRANSPORTATION ENERGY CONSUMPTION (1977)

Northwestern University for U.S. Department of Transportation

Type of Report: Models/techniques

Scope: Large-scale urban-land-use/transportation interaction simulation model used in 112 experiments to test impact of land use policy options on transportation energy use.

Highlights Relevant to Technology Assessment: Excellent tool to test energy impacts of urban transportation congestion in real and hypothetical small cities. Also to test transit options (system operating options).

TECHNOLOGY ASSESSMENT ACTIVITIES OF THE NATIONAL SCIENCE FOUNDATION (1974)

Office of Technology Assessment, U.S. Congress

Type of Report: Hearings before the Technology Assessment Board of the Office of Technology Assessment, U.S. Congress

Scope: The hearings were held and testimonies presented to permit oTA to learn about and benefit from the National Science Foundation's experiences in technology assessment research. The main areas of interest were NSF's experience, the criteria, the then-present state of the art, the activities instituted for training technology assessment researchers and performers, and national and international activities.

Highlights Relevant to Technology Assessment: Contains a 1973 NSF study that was intended to identify criteria and priorities of candidates for technology assessments.

Cummenls: Provides an excellent background on technology assessment, particularly becaúse of the prominent individuals who testified. 
TRANSPORTATION ENERGY CONSERVATION DATA BOOK (1979)*

Oak Ridge National Laboratory for U.S. Department of Energy

Type of Report: Data

Year of Data: Up to 1977

Scope: Compendium of national data from many sources on transportation system and energy use characteristics. Projects modal activity and energy use to the year 2000, describes government programs and activities, presents energy supply characteristics and demographic information. Data presented in hundreds of tables and figures.

Highlights Relevant to Technology Assessment: Should be the starting point for all data and data sources tor any technology assessment in tranoportation. No city- or urban-area-specific data. Organized by mode for all freight and passenger movement. Data items include energy intensity, passenger miles traveled, vehicle miles traveled, ton-miles traveled, types of fuel consumed, length of passenger trips.

Comments: Published approximately annually since.1977. When combined with the companion Regional Data Book, it is by far the most comprehensive source of transportation energy data.

*Not included in Table. 1 . 